Tesis para optar por el grado de DOCTORA EN ASTRONOMÍA

\title{
Estudio de una Asociación OB distante en la Vía Láctea
}

\author{
Autora: Mariela Alejandra Corti \\ Director: Guillermo L. Bosch \\ Co-Directora: Virpi S. Niemela
}

24 de mayo de 2005

Facultad de Ciencias Astronómicas y Geofísicas

Universidad Nacional de La Plata 


\section{Dedicatoria}

A mis padres 


\section{Agradecimientos}

Cumpliendo mi objetivo de convertirme en Dra. en Astronomía, recorro con mi mente los momentos que he vivido a lo largo del extenso camino que debí recorrer para ello y descubro la cantidad de gente que desde su lugar me ayudó a lograrlo.

No sería una egresada de la Universidad Nacional de La Plata si no fuera por el apoyo incondicional que desde un principio me brindaron mis padres. Gracias papi y mami por acompañarme en esto desde mi adolescencia, con el material de lectura que me compraban y con los viajes que haciamos al Planetario. Gracias a los dos por haberme dado la libertad de elegir mi camino, por siempre confiar en mi creyendo que podía hacerlo. Juntos tuvimos que superar momentos difíciles y mi Doctorado es la prueba de que lo hemos logrado. Quiero agradecerle también a mi hermana, por haberme entendido en todos aquellos momentos en los que me necesitó cerca y debido a los compromisos adquiridos aquí, no pude estarlo. Gracias Fabiana también porque en cada visita que me hacías buscabas la forma de ayudarme y darme ánimo. Quiero agradecerle a mis abuelos, ya fallecidos, por aceptar aunque con dolor mi decisión, sabían que ya no me tendrían con frecuencia a su lado.

La distancia pone a prueba la amistad, pero también nos muestra quienes nos acompañarán toda nuestra vida. Gracias Gabriel, Andrea y Rubén por tanto cariño, por estar cerca aún estando lejos.

Fue muy importante para mi saber que siempre contaba con la flia. De Vito. Gracias Marta y Ricardo por haberme recibido en su casa como a una hija más. Les agradezco también a Alejandra, Cecilia y Florencia por haberlo aceptado brindándome su cariño de hermanas, y a Felisa a quien adopté como mi abuela postiza. Muchas gracias porque saben que sin Uds. en mi vida, en aquellos primeros años, se me hubiera hecho imposible resistir la distancia de mi flia.

A lo largo de mi carrera pude contar con el apoyo y la contención de mis compañeros y amigos, Alejandra, Amina, Alejandro, Lorena, Silvina, Erika, Josefa, Romina, Guillermo, Amalia, Adrián, Rodolfo y Gustavo. A vos Ale particularmente por haberme prestado tu oído tantas veces y haber sabido comprenderme y alentarme. Aprecio también la ayuda que me brindaron, Nidia, al haberme indicado los primeros pasos en investigación, Virpi y Guillermo, que con paciencia y dedicación siguieron guiándome en el desarrollo de todo mi 
posgrado. Les agradezco a Pablo, Gustavo, Edgard, Federico, M. Arnal y C. Cappa por el aporte de conocimientos que me brindaron en el desarrollo de mi Tesis.

A este trabajo lo realicé también con la colaboración de los Dres. Medina Tanco y Teixeira. Quisiera agradecerles lo que he aprendido con ellos y la hospitalidad que junto a los miembros del Observatorio "Abrahao de Moraes" de Valinhos y el IAG de San Pablo, me han brindado en cada oportunidad que tuve de viajar a Brasil.

Mi trabajo de investigación fue financiado por FOMEC, CIC, FCAGLP e IALP (CONICET) a través de las becas que cobré durante el período transcurrido en el desarrollo del mismo y los subsidios que me permitieron participar en Reuniones y Escuelas.

Finalmente, quiero agradecerle a Sixto, aunque siento que las palabas que emplee para hacerlo nunca serán suficientes. Gracias mi amor por haber estado siempre conmigo, desde amigos y alumnos hasta esposos y graduados. Gracias por darme tu tiempo, tu paciencia, tu comprensión, tu apoyo, por estar siempre listo para ayudarme, por alentarme y por creer en mi. Siento que nada de esto me hubiera sido posible hacer sin tenerte a mi lado, vos le diste sentido a cada momento como se lo das a mi ser. 


\section{Índice General}

Índice General

1 RESUMEN 1

2 ASOCIACIONES ESTELARES 3

3 BOCHUM $7 \quad 8$

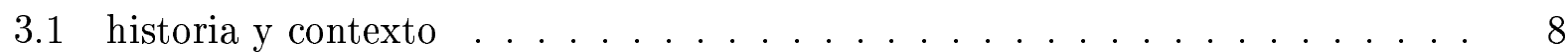

3.2 Objetivo y estructura de este trabajo . . . . . . . . . . . . 14

4 PARÁMETROS ANALIZADOS $\quad 17$

4.1 Proximidad Angular y Radial . . . . . . . . . . . . . . . . . 17

4.2 Enrojecimiento y Parámetro Q . . . . . . . . . . . . . 19

4.3 Clasificación Espectral y Diagrama Color-Color . . . . . . . . . . . . . 22

4.4 Banda Interestelar Difusa . . . . . . . . . . . . . . . . . . . . . 24

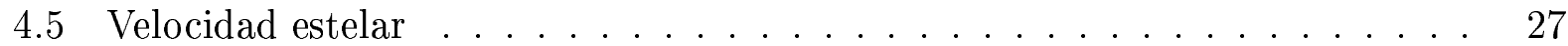

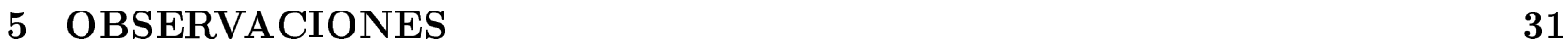

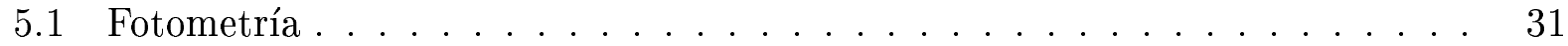

5.1 .1 Distancia a las estrellas OB en la línea de la visual . . . . . . . . 42

5.2 Espectroscopía . . . . . . . . . . . . . . . . . . . 49

5.2.1 Trabajo de Clasificación Espectral . . . . . . . . . . . . 51

5.2.2 Análisis de las Velocidades Radiales . . . . . . . . . . . . . 57

5.2 .3 Banda Interestelar Difusa $4428 \AA \ldots$. . . . . . . . . . . . 85

5.2.4 Extinción interestelar . . . . . . . . . . . . . 88

5.3 Astrometría . . . . . . . . . . . . . . . . . 97

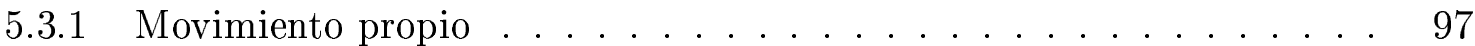

5.4 Datos de literatura y catálogos . . . . . . . . . . . . . . 100

5.4 .1 Infrarrojo: IRAS y $2 \mathrm{MASS} \ldots \ldots \ldots \ldots$

5.4 .2 Longitudes de onda Ópticas y Milimétricas . . . . . . . . . . . 130

5.4 .3 Radio: HI, SNR y otros .................... 138

6 ANÁlisis DE LAS POSIBLES ESTRUCTURAS EN EL CAMPO DE INTERÉS 142

6.1 Agrupación espacial: radial y angular . . . . . . . . . . . . . . 143 
6.2 Movimientos propios y calidad de miembros . . . . . . . . . . . 156

7 RESUMEN Y CONCLUSIONES

173

8 BIBLIOGRAFÍA

178

9 APÉNDICE

185

9.1 Atlas CCD de estándares OB de clasificación espectral . . . . . . . . . 185

9.2 Resultados de estrellas en la visual a Bochum 7 . . . . . . . . . . . . . 190

9.3 Sistema Binario: LS 1135 . . . . . . . . . . . . . . . 202 


\section{RESUMEN}

Las asociaciones OB constituyen un laboratorio ideal, y a veces único, para el estudio de diversos procesos químicos y físicos que caracterizan la interacción entre la componente estelar y las varias fases gaseosas del medio interestelar. Se vuelve así fundamental una caracterización observacional confiable de asociaciones $\mathrm{OB}$, que no se limite a vecinos próximos del sistema solar.

La asociación OB, normalmente conocida como Bochum 7 ubicada entre 4 y $6 \mathrm{kpc}$ de distancia al Sol, puede dar información sobre la estructura espiral de la región más externa de la Vía Láctea. Hasta hoy existe muy escasa información espectroscópica de sus miembros, y tampoco se sabe la cantidad de miembros del tipo espectral OB.

En esta Tesis se analizó fotometría CCD en filtros UBV y $\mathrm{H} \alpha$ cubriendo un campo de 30'x30' centrado en Bo7. Con esta fotometría seleccionamos más de 100 estrellas cuyos colores fueran compatibles con estrellas de tipo espectral temprano. Este grupo de estrellas fue analizado espectroscópicamente. El material observacional consistió en espectros digitales obtenidos en CASLEO.

Con los datos fotométricos y espectroscópicos se efectuó una Clasificación Espectral. Se generó para ello un Atlas CCD de estándares OB de clasificación espectral observadas con Reosc DS en CASLEO. Se encontraron 63 estrellas OB.

Ajustando un perfil Gaussiano a cada línea espectral se analizó la Velocidad Radial de cada estrella. Se encontró un sistema binario con espectro del tipo O6.5 cuya solución orbital se determinó.

En los espectros de las estrellas tempranas se estudió la Banda Interestelar Difusa $4428 \AA$ (DIB).

Se derivaron las distancias espectrofotométricas individuales de cada estrella.

Combinando los datos astrométricos de las estrellas O y B con diferentes catálogos astrométricos, determinamos sus movimientos propios. Realizamos con ellos un análisis en armónicos esféricos que nos permitió evaluar la consistencia estadística de nuestros movimientos propios y la posibilidad de separar nuestra muestra de estrellas O y B en más de una componente en el espacio de las fases. Identificamos 7 grupos con cinemática y distancia común.

Consultando diversas bases de datos disponibles en INTERNET, buscamos imágenes en las cuatro bandas IR del satélite IRAS centradas en la región de Bochum 7, estudiando con ellas las fuentes puntuales posiblemente relacionadas con una región de formación estelar. Analizamos imágenes obtenidas por el satélite MSX en la región espectral de 4.2 a 26 micrones y consultamos las imágenes en $\mathrm{H} \alpha$ del SHASSA. Trabajamos con el relevamiento 
espectroscópico del CS(2-1) para fuentes puntuales IRAS, encontrando una fuente puntual IRAS con una distancia y velocidad que la ubica en la región de Bochum 7.

Combinando todos los datos analizados encontramos una Asociación OB ubicada a una distancia al Sol entre 4 y $5 \mathrm{kpc}$, la cual cinemáticamente se divide en dos grupos. El grupo denominado Bochum 7-A con 17 miembros entre los cuales se encuentran algunas de las estrellas del catálogo LS inicialmente propuestas como miembros de Bochum 7 por Moffat \& Vogt (1975). Bo 7-A se ubica a una distancia de $4.6 \pm 0.4 \mathrm{kpc}$ y tiene un diámetro lineal $\mathrm{D}=36 \pm 3 \mathrm{pc}$. El grupo denominado Bochum 7-B con 10 miembros está ubicado a una distancia $\mathrm{d}=4.3 \pm 0.6 \mathrm{kpc}$ y con un diámetro lineal $\mathrm{D}=37 \pm 5 \mathrm{pc}$. Este último grupo contiene la región HII ultracompacta encontrada con los datos de IRAS. Teniendo en cuenta que Bo 7-A contiene estrellas algo más evolucionadas que Bo 7-B, parece evidenciarse una formación estelar secuencial. 


\section{ASOCIACIONES ESTELARES}

\section{Descripción general}

Una Asociación OB es un grupo de estrellas no ligadas, incluyendo un número de estrellas de tipo espectral temprano (estrellas con tipo espectral O y B). Se cree que las Asociaciones se originan como un grupo que nace en una región del espacio relativamente pequeña, dentro de una nube molecular gigante. Después de la remoción del gas y el polvo, la Asociación se transforma en gravitacionalmente no-ligada y se expande. Este escenario es apoyado por las grandes dimensiones físicas (hasta algunas decenas de parsecs en diámetro) y la baja densidad estelar de las mismas. Tal vez el $90 \%$ de las estrellas en la Galaxia se haya formado en asociaciones OB.

Un aspecto importante del estudio de las Asociaciones OB es la identificación de "sus miembros". La gran extensión en el cielo de las asociaciones OB próximas, ha imposibilitado tradicionalmente la precisa determinación cinemática de pertenencia para la gran mayoría de las estrellas, con excepción de las más brillantes. Los datos obtenidos por el satélite astrométrico Hipparcos permitieron un gran avance en este sentido, incluyendo a las estrellas de mayor masa que el Sol para aproximadamente una docena de asociaciones OB localizadas a distancias menores que 500 pc (Zeeuw et al., 1999). La futura misión satelital GAIA detectará asociaciones a mayores distancias. Para aquellas más próximas que $2 \mathrm{kpc}$, será posible realizar una confiable selección de miembros, hasta las más pequeñas masas estelares, y de ese modo incluirá los objetos que aún estén en su etapa de secuencia principal, incluyendo objetos brillantes en rayos X. (The GAIA Study Report: Executive Summary and Science Section, 2000-04-06). Un mayor progreso en la identificación de miembros de alta masa de las Asociaciones OB ha sido posible a través del uso de datos astrométricos precisos del Catálogo de Hipparcos (ESA, 1997).

Si bien las asociaciones OB son clasificadas como una categoría de objetos separada de los cúmulos abiertos, ambos tipos pueden encontrarse juntos. En estos casos, en general, el cúmulo abierto define la región central de una asociación OB mayor. Con el transcurso del tiempo la asociación OB circundante se dispersa, mezclándose con las estrellas de campo, mientras que el cúmulo abierto, asentado en un pozo de potencial más profundo, permanece observable por períodos mayores conservando su identidad. ¿Qué causa la distinción entre la formación de cúmulos abiertos ligados y asociaciones no ligadas? Varios estudios muestran que el destino de un grupo jóven particular de estrellas depende de la fracción de gas, la 
escala de tiempo en la cual este gas es removido y la dispersión de velocidad estelar (Lada et al., 1984; Verschueren \& David, 1989).

El estudio de cúmulos abiertos y asociaciones $\mathrm{OB}$ en nuestra galaxia está relacionado a varias preguntas importantes en la investigación sobre la estructura y evolución galáctica. El estudio de cúmulos jóvenes inmersos y asociaciones OB, constituye una ayuda imprescindible para alcanzar una clara visión de los procesos de formación estelar, proveyendo pistas para responder a preguntas críticas sobre la función inicial de masa (IMF) y la relevancia estadística de la población de sistemas binarios. Además, las asociaciones más evolucionadas, en fase de disolución, son importantes para probar modelos de evolución química y dinámica de la galaxia.

Históricamente, las asociaciones $\mathrm{OB}$ han sido identificadas como grupos de estrellas $\mathrm{O}$ y B desarticulados en el cielo, tal como en la dirección de las constelaciones de Orión y Escorpio-Centauro. No obstante, como veremos más adelante, las asociaciones OB también contienen estrellas de baja masa y probablemente están formadas con una función inicial de masa normal.

Definitivamente no es trivial definir qué es lo que se entiende por Asociación OB. Se puede concluir que se las define como grupos estelares jóvenes ( $\leqslant 50 \mathrm{Myr}$ ) de baja densidad -tanto que probablemente sean grupos no ligados físicamente- conteniendo una población significante de estrellas O y B. Sus dimensiones proyectadas cubren un rango de $\backsim 10$ a $\backsim$ $100 \mathrm{pc}$.

\section{Estrellas de alta masa en Asociaciones OB}

Los estudios más extensivos del contenido estelar de las asociaciones OB fueron hechos usando datos fotométricos. Esto permite extender la lista de posibles miembros a tipos espectrales más tardíos, para los cuales no se encuentran disponibles aún, los datos exactos de movimiento propio a gran escala para una definición cinemática de miembros.

Las estrellas de tipo espectral temprano tienen un gran efecto sobre el medio interestelar a través de su radiación onizante. Con esto producen regiones HII localizadas y gas ionizado difuso. Basados en la distribución de asociaciones OB en la Galaxia, se mostró que su función de luminosidad puede ser ajustada con una ley de potencia truncada y que 
probablemente hay un límite físico para el tamaño máximo de las regiones HII en la Galaxia (McKee \& Williams, 1997). Una comparación con la distribución de nubes moleculares gigantes (Williams \& McKee, 1997) mostró que una nube de $10^{6} \mathrm{M}_{\odot}$ es de esperar que sobreviva aproximadamente 30 Myr y que en promedio el $10 \%$ de su masa sea convertida en estrellas durante el tiempo que ésta es destruída. La distribución total de las asociaciones OB también es importante para comprender el factor de llenado del gas caliente del medio interestelar (Ferriere, 1995; Ferriere, 1998).

\section{Estrellas de baja masa en Asociaciones OB}

Históricamente el estudio de asociaciones $\mathrm{OB}$ ha estado centrado, principalmente, en el estudio de sus miembros de alta masa (tipo espectral O y B). No obstante, extrapolando la función de masa de estrellas O y B, como la obtenida para Sco OB2 (Geus 1992), se ve que la mayor parte de las estrellas deberían ser de baja masa $\left(<2 \mathrm{M}_{\odot}\right)$. De hecho, desde hace ya tiempo se han encontrado evidencias sobre la presencia de estrellas de baja masa en la vecindad de asociaciones OB (por ejemplo, Haro 1953 en la Nebulosa de Orión).

Desafortunadamente, estudios de movimientos propios a gran escala para definir los miembros más débiles de las asociaciones OB sufren de una mayor contaminación de las estrellas de campo, haciendo difícil su identificación como miembros sin el empleo de información adicional. Por esto, son empleadas otras técnicas en la investigación de miembros de baja masa de asociaciones OB. Los dos tipos de relevamientos más usados son los de espectros de prisma objetivo en $\mathrm{H} \alpha$, sensibles a las estrellas T-Tauri clásicas, y los relevamientos de rayos $\mathrm{X}$, sensibles además a las estrellas T-Tauri de líneas débiles.

En Orión OB1 con el relevamiento en $\mathrm{H} \alpha$ de Kiso (Nakano et al., 1995) y los relevamientos de rayos X, de los satélites Einstein (Walter et al. 1998) y Rosat (Alcala et al., 1996), se han descubierto cientos de fuentes de rayos $\mathrm{X}$ y objetos con líneas de emisión en $\mathrm{H} \alpha$, muchas de las cuales probablemente pertenecen o son estrellas de presecuencia principal (PMS) o TTauri. Las observaciones espectroscópicas ópticas llevadas a cabo confirmaron la naturaleza PMS de muchas de estas estrellas (Alcala et al., 1996). No obstante, Alcala et al. (1998) mostraron que la población de fuentes de rayos $\mathrm{X}$ hacia Orión consiste de una mezcla de verdaderas estrellas PMS de Orión y estrellas tempranas de campo. 


\section{Asociaciones OB cercanas}

Las asociaciones OB son grupos no ligados, en movimiento, que pueden ser detectados cinemáticamente debido a su pequeña dispersión interna de velocidades. Las asociaciones más cercanas tienen una gran extensión angular en el cielo, la cual ha limitado tradicionalmente la determinación de pertenencia astrométrica a las estrellas más brillantes $(\mathrm{V}<6 \mathrm{~m})$, con tipos espectrales más tempranos que aproximadamente B5.

Los datos de movimiento propio aportados por el satélite astrométrico Hipparcos permitieron un mayor progreso en esta situación. De Zeeuw et al. (1999) identificaron en el Cátalogo de Hipparcos grupos con movimientos coherentes, combinando para ello un método de punto convergente renovado (Bruijne 1999) con el método Spaghetti de Hoogerwerf \& Aguilar (1999). Fueron listados miembros astrométricos para 12 grupos estelares jóvenes, más próximos que una distancia de aproximadamente 650 pc.

El procedimiento de selección arriba mencionado, corrigió la lista de miembros astrométricos y fotométricos tipos espectrales B y A previamente conocidos en estos grupos e identificó muchos miembros nuevos, incluyendo un número significativo de estrellas $\mathrm{F}$, como también estrellas evolucionadas, es decir, las estrellas Wolf-Rayet $\gamma^{2}$ Vel (WR11) ${ }^{1}$ en Vela OB2 y EZ C Ma (WR6) en Col 121, y la clásica Cefeida $\delta$ Cep en Cep OB6. En las asociaciones más próximas, como en Scorpio OB2, además de los miembros de tipo más tardío se incluyen objetos T-Tauri y otras estrellas en la fase final de pre-secuencia principal. Esto provee una firme ligazón entre el tradicional contenido estelar de miembros de alta masa y los de baja masa.

La Figura 1 muestra la distribución de las asociaciones OB cercanas, basada en la lista de Ruprecht (1966) e incluyendo asociaciones adicionales discutidas por De Zeeuw et al. (1999), proyectadas sobre el plano Galáctico.

Para las asociaciones OB a distancias mayores que 500 pc, las paralajes de Hipparcos son, de uso muy limitado. Esto dificulta considerablemente la distinción entre el movimiento propio del grupo en el disco y el de las estrellas de campo. Las posiciones con respecto al Sol y los movimientos medios de estos grupos, ahora son determinados mucho más exactamente.

\footnotetext{
${ }^{1}$ número WR del catálogo de van der Hucht (2001) 


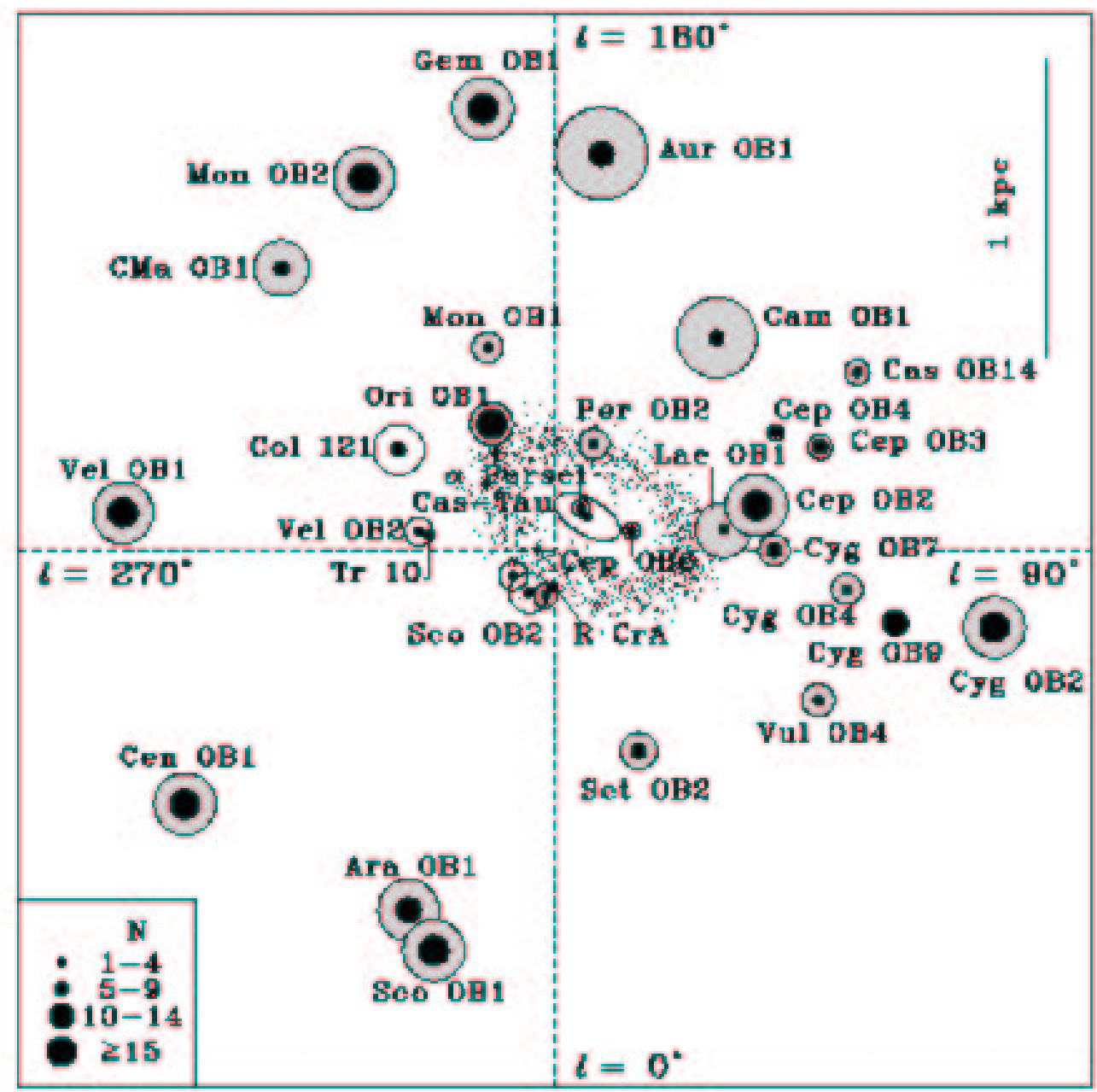

Figura 1: Localización de asociaciones $O B$ dentro de $\backsim 1.5 \mathrm{kpc}$, proyectadas sobre el plano Galáctico, como están enumeradas en Ruprecht (1966). El Sol está en el centro de las líneas a trazos lo cual da la dirección principal en longitud Galáctica, l. Los tamaños de los círculos representan las dimensiones proyectadas de las asociaciones, ampliadas por un factor 2 con respecto a la escala de distancia. Los tamaños de los puntos centrales indican la reciente formación estelar, dada por el número $N$ de estrellas más luminosas que magnitud absoluta $M_{v} \simeq-5$ (Humphreys, 1978). Las asociaciones ausentes en la lista de Ruprecht son las representadas por círculos abiertos. La distribución de pequeños puntos indica el Cinturón de Gould (Olano, 1982). (Figura 1, de Zeeuw et al. 1999) 


\section{$3 \quad$ BOCHUM 7}

\section{1 historia y contexto}

El primer indicio sobre la existencia del agrupamiento de estrellas tempranas ahora conocido como Bochum 7, fue señalado en primer lugar por Moffat \& Vogt (1975). Con la publicación del Catálogo de Estrellas Luminosas en la Vía Láctea Sur (LS)(Stephenson and Sanduleak, 1971) Moffat \& Vogt se motivaron para continuar su relevamiento de fotometría fotoeléctrica del LS de cúmulos abiertos en el cielo austral iniciado en 1970. Buscaron coincidencias entre estrellas luminosas del LS y cúmulos estelares catalogados, incrementando con esto la probabilidad de identificación de cúmulos jóvenes, con el principal propósito de estudiar la estructura galáctica austral.

El propósito de ellos fue:

a) Obtener datos preliminares (edad, distancia, enrojecimiento, miembros gigantes y supergigantes) de cúmulos no estudiados previamente para un posterior y más detallado estudio en casos de interés especial y

b) Encontrar cúmulos abiertos jóvenes y grupos de estrellas (de tipo espectral más temprano que B2 ó B3) los cuales deben servir como trazadores de brazos espirales distantes.

Todas las observaciones fotoeléctricas las obtuvieron con el telescopio de $61 \mathrm{~cm}$ de la Universidad de Bochum en La Silla, Chile, en 1972 y 1973, y los cúmulos nuevos descubiertos fueron nombrados con consecutivos números de Bochum.

A los cúmulos jóvenes los seleccionaron de acuerdo a los siguientes criterios (en orden de importancia):

1) Coincidencias de cúmulos catalogados con Estrellas Luminosas de Stephenson \& Sanduleak (1971),

2) Grupos estelares (no catalogados como cúmulos), conteniendo Estrellas Luminosas,

3) Cúmulos satisfaciendo los criterios de Vogt \& Moffat (1972) (por ej.tamaño, tipo Trumpler, etc.)

4) Cúmulos nuevos no catalogados, posibles cúmulos abiertos, mayormente grupos compactos como los vistos en el POSS o el Atlas del Sur de la Vía Láctea (Wray \& Westerlund, 1971).

Vogt \& Moffat notaron que el catálogo LS muestra una marcada concentración de estrellas OB en la zona $\mathrm{l} \simeq 265^{\circ}, \mathrm{b} \simeq-2^{\circ}$, y sus resultados sugerían que las estrellas LS $1131,32,35$, 
$37,40,44,45 ?, 46,47$ posiblemente formaran una asociación con las siguientes características fotométricas:

$$
\begin{aligned}
\bar{E}(B-V) & =0.86 \pm 0.13 \mathrm{mag} . \\
V_{\circ}-M_{v} & =13.8 \pm 0.6 \mathrm{mag} . \\
d & =5.8 \mathrm{kpc}
\end{aligned}
$$

Con estos parámetros la estrella WR 12 = LS 1145 ubicada centralmente en la concentración estelar, podría tener $\mathrm{M}_{v}=-5.7$.

Con posterioridad, Lundstrom \& Stenholm (1984) propusieron que esta concentración de estrellas jóvenes para la cual Moffat \& Vogt (1975) estimaron una distancia de 5.8 kpc, sería un grupo de $\sim 30$ pc de diámetro, por lo tanto sería más apropiado considerar a este grupo como una asociación OB más que como un cúmulo.

L \& S obtuvieron espectros ópticos para 3 de los 9 posibles miembros enumerados por Moffat \& Vogt (1975). Uno de los resultados que encontraron fue que LS 1132 probablemente sea un objeto de campo, debido a su clasificación MK, B0.5V y del hecho de que esta estrella está menos enrojecida que los otros posibles miembros. Para las otras dos estrellas Lundstrom \& Stenholm (1984) encontraron tipos espectrales O y módulos de distancia media $\simeq 13.5$ magnitudes, lo cual resulta ser similar al módulo de distancia encontrado por Moffat \& Vogt.

WR 12 es una binaria espectroscópica a un espectro con una alta función de masa de acuerdo a Niemela (1982). Lundstrom \& Stenholm (1984) incluyen a WR12 en el grupo de los posibles miembros del cúmulo Bo 7 .

Luego Sung et al. (1999) determinaron magnitudes UBV y H $\alpha$ con fotometría CCD ubicando a Bochum 7 cerca del centro de la asociación Vela OB1, de acuerdo a las coordenadas ecuatoriales celestes de los miembros de ambos grupos estelares, como es posible ver en la Figura 3. Ellos indican que los miembros de Vela OB1 son las estrellas menos enrojecidas, mientras que las estrellas más enrojecidas son las pertenecientes al más distante Bo7. Encontraron para este cúmulo un rango de enrojecimiento muy similar al previamente hallado por Moffat \& Vogt, de valor:

$$
E(B-V)=0.75 \sim 1.05
$$


Para identificar los miembros de Bo 7, Sung et al. (1999) emplearon los criterios de coincidencia dentro de un cierto rango, en los valores de enrojecimiento y distancia. La aplicación de estos criterios en asociaciones distantes presenta algunas limitaciones debido a que las diferencias entre el enrojecimiento y módulo de distancia entre las estrellas de campo y los miembros de la asociación son muy pequeñas. La contaminación por estrellas de campo es inevitable para estrellas de tipo espectral tardío. Para Bo 7 la contaminación de estrellas de campo es menor debido a que los miembros que se buscan en Bochum 7 son estrellas con tipos espectrales B o más tempranos.

Sung et al. encontraron dos estrellas con emisión H $\alpha$ intensa (WR12 \& nro.1066) y dos estrellas con emisión H $\alpha$ débil (nro.867 \& nro.969). Les resulta difícil decidir a qué grupo de los existentes en la visual a Bochum 7 pertenecen estas estrellas. Basándose en el trabajo de Muzzio (1979), quien encuentra que la mayoría de las estrellas con emisión H $\alpha$ pertenecen a grupos distantes, asignan temporariamente a Bo7 (Vela OB3 para Sung et al., 1999), estas estrellas con emisión $\mathrm{H} \alpha$.

La determinación del módulo de distancia de Bo7, se complica debido al pequeño número de miembros de tipo espectral temprano encontrados hasta entonces. No obstante, Sung et al. encuentran que 6 estrellas entre 17 con $(B-V)_{\circ}<0.2$ tienen $\left(V_{o}-M_{v}\right)=13.39 \pm 0.05$ magnitudes. Las otras estrellas tienen valores más pequeños. Ellos adoptaron el módulo de distancia de la asociación como $\left(\mathrm{V}_{o}-\mathrm{M}_{v}\right)=13.4 \pm 0.1 \mathrm{mag}$. $(\mathrm{d}=4.8 \pm 0.2 \mathrm{kpc})$. Este valor es algo menor que el obtenido por Moffat \& Vogt (1975).

Para obtener el diagrama HR, es necesario transformar las cantidades observacionales en parámetros físicos. Sung et al. emplean los modelos de evolución estelar del grupo de Geneva, y el diagrama $\mathrm{M}_{b o l}$ vs. $\log \mathrm{T}_{e f f}$, el cual se desprende del diagrama HR para con ellos derivar la edad de las asociaciones Bochum 7 y Vela OB 1. Para ambas asociaciones encontraron edades similares $(\tau \simeq 6 \mathrm{Myr})$. Ellos encuentran también una Función Inicial de Masa para Bo7 con pendiente igual a $-1 \pm 0.3$, estando definida la FIM por la cantidad de estrellas nacidas en unidad de masa logaritmica por unidad de área en $\mathrm{kpc}^{2}$.

La Figura 2 es una de las imágenes de la región de Bo 7 obtenida en CTIO con el filtro V. En ella están indicadas las estrellas del catálogo LS que Vogt \& Moffat consideraron miembros de Bo 7. 


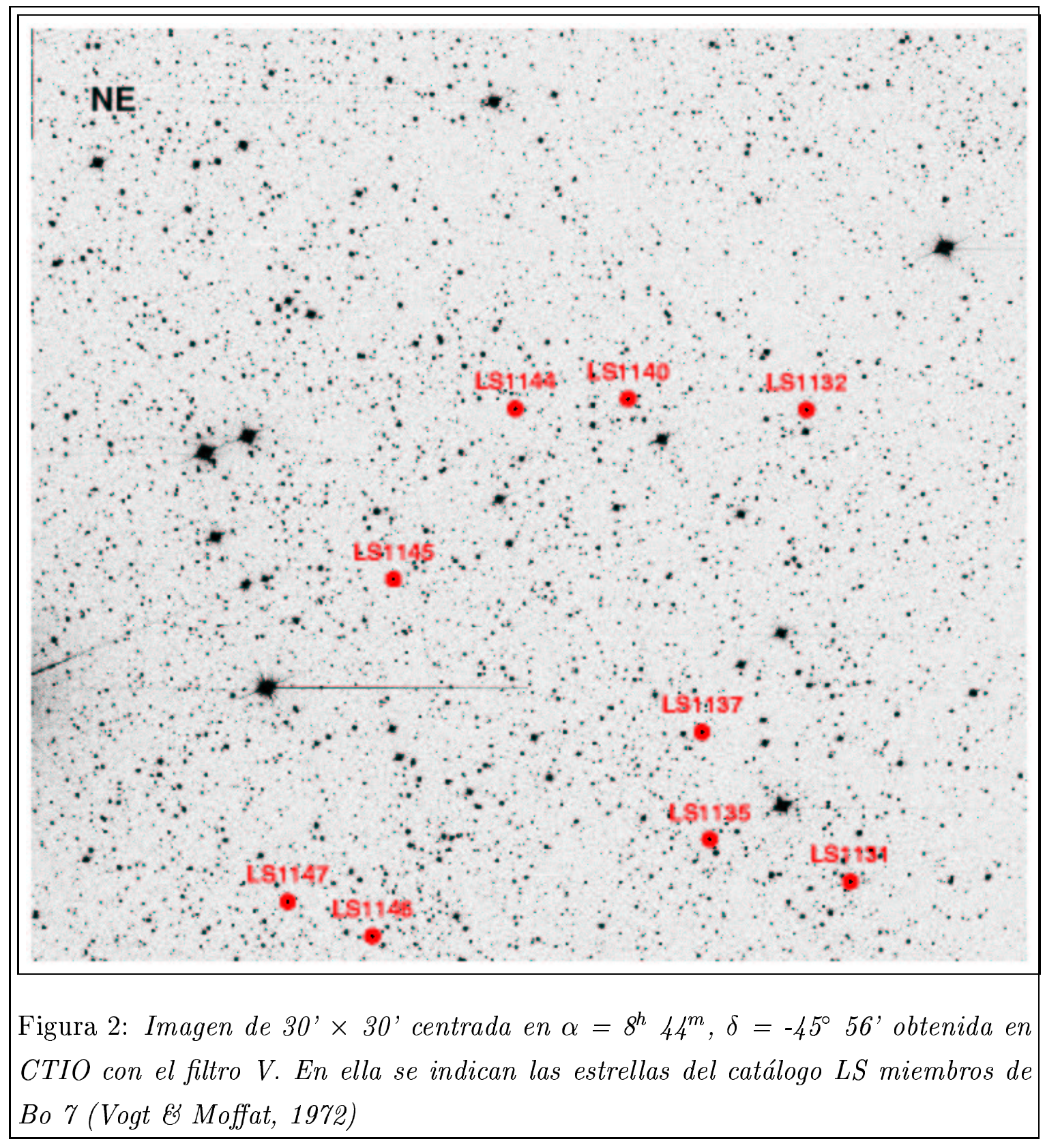

Estudio de una Asociación $O B$ distante en la Vía Láctea 
Siendo Bochum 7 un cúmulo abierto (o asociación OB) distante, puede brindar valiosa información sobre la estructura espiral de la región más externa de la Vía Láctea. Favorece a este propósito que la región en estudio posea relativamente baja extinción, condición del medio fundamental para el estudio de la estructura espiral más externa.

En un trabajo anterior (Corti et al., 2003), se realizó un estudio espectroscópico que permitió confirmar la condición de estrellas tempranas de los posibles miembros del grupo que habían sido observados. Se pudo realizar también un análisis orbital de la binaria espectroscópica LS 1135, mencionada como miembro de la posible asociación por Moffat \& Vogt (1975), determinando el período y la curva de velocidad radial para esta binaria de tipo O. Además, se obtuvieron tipos espectrales y velocidades radiales (a razón de dos o tres determinaciones por estrella) para los restantes candidatos a miembros más brillantes de la asociación (8 estrellas en total), comprendidos en la lista de probables miembros de Moffat \& Vogt (1975). Se estimó también la velocidad radial del conjunto estelar.

La Figura 3 representa la densidad estelar en una imagen de $5^{\circ}$ centrada en la posible Asociación OB conocida como Bochum $7, \alpha=131^{\circ}$ y $\delta=-46^{\circ}$. La misma se obtuvo empleando las estrellas del catálogo LS. En la Figura mencionada, se representan algunas de las Asociaciones o Cúmulos Abiertos conocidos en la región y proyectados en el plano, es decir, ignorando la distancia al Sol a la que se encuentran los mismos. El tamaño y la ubicación de los mismos fueron confirmados consultando el Catálogo Lyngå: Open Cluster Data, $5^{\text {ta }}$ edición, (Lyngå 1987), donde Markarian 18 se presenta como Collinder 205. Esta figura muestra que la imagen de Bochum 7, posiblemente contiene estrellas de otros cúmulos además de las estrellas de campo.

\section{Estructura de la Galaxia en la dirección a $1=265^{\circ}, \mathrm{b}=-2^{\circ}$}

Moffat \& Vogt (1975) fueron los primeros en mencionar la posible existencia del grupo de estrellas tempranas ubicadas a casi $6 \mathrm{kpc}$ del Sol con $\mathrm{l} \simeq 265^{\circ} \mathrm{y} \mathrm{b} \simeq-2^{\circ}$, conocido como Bochum 7. El objetivo de ellos fue encontrar trazadores de brazos espirales distantes como son los cúmulos abiertos y las estrellas muy tempranas. En este trabajo vamos a analizar la región de Bochum 7.

Como es posible ver en la Figura 4, comparado con los modelos de Galaxia de tres y cuatro brazos, el brazo de Perseo está delineado ambigüamente por regiones de formación 


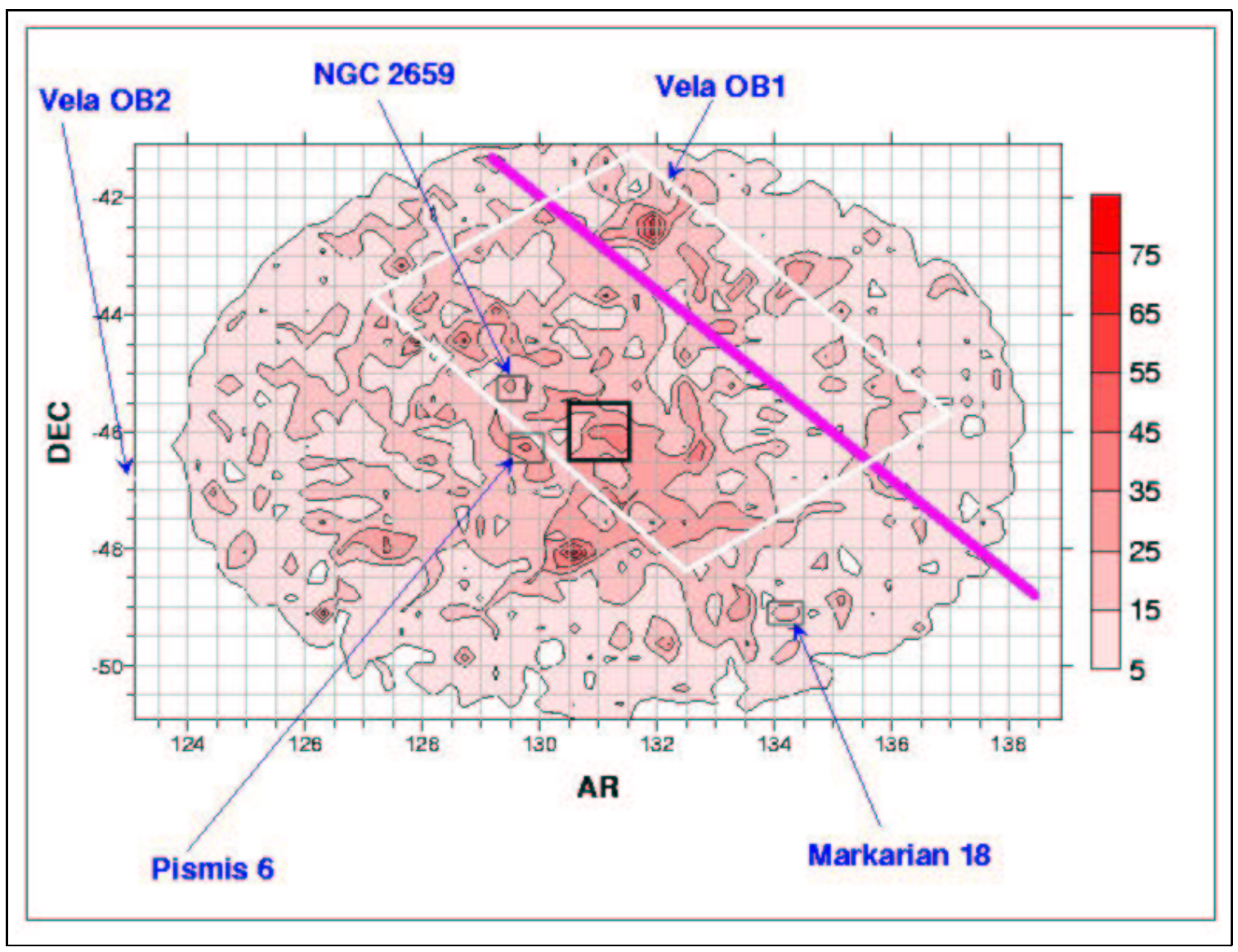

Figura 3: Catálogo LS: $5^{\circ}$ en torno a Bochum 7. Los niveles de contorno representan la densidad estelar en unidades arbitrarias. La línea oblicua corresponde a la posición aproximada del plano galáctico. El cuadrado negro en el centro indica la cobertura de la fotometría CCD presentada en este trabajo y la ubicación de Bochum 7. La Asociación Vela OB1 es el rectángulo blanco, de acuerdo al tamaño y ubicación de la misma (Reed B.C. 2000) 
estelar. Mas allá de este brazo se encuentra la presencia de complejos de formación estelar con una muy escasa distribución donde Heyer \& Terebey (1998) identificaron nubes moleculares pequeñas y compactas. La Asociación OB, Bochum 7, con su ubicación cerca del extremo final observado del brazo de Perseo en la Figura 4, resultaría una trazadora de este brazo espiral de la Vía Láctea.

\subsection{Objetivo y estructura de este trabajo}

Como hemos destacado en la sección anterior, las asociaciones OB constituyen un laboratorio ideal, y a veces único, para el estudio de diversos procesos químicos y físicos que caracterizan la interacción entre la componente estelar y las varias fases gaseosas del medio interestelar. Algunos de estos fenómenos son locales (por ej., colapso de nubes moleculares, fragmentación de gas, formación estelar, segregación de masas, etc.), mientras que otros tienen carácter global, afectando a grandes regiones de la galaxia (por ej., enriquecimiento del medio interestelar por explosiones de supernova, determinación de gradientes galácticos de metalicidad, etc.).

Se vuelve así fundamental una caracterización observacional confiable de asociaciones $\mathrm{OB}$, que no se limite a vecinos próximos del sistema solar. En particular, tanto la necesidad de estadísticas relevantes, como la determinación de estructuras galácticas de gran escala y cuantificación de los gradientes de metalicidad en el disco, requieren el conocimiento de asociaciones OBs a distancias del orden de varios kpc.

Para el caso de asociaciones relativamente próximas, aún considerando el problema obvio de su gran tamaño angular, se cuenta con una cantidad razonablemente confiable de métodos de determinación de pertenencia para ayudar en la definición de estos grupos estelares. En el caso de asociaciones distantes, a distancias superiores al kiloparsec, el problema se vuelve extremadamente complejo y la aplicación de las varias técnicas disponibles se torna necesaria porque el uso de sólo una de ellas proporciona resultados con errores grandes que no permiten obtener conclusiones confiables.

El presente proyecto apunta a continuar y profundizar nuestro conocimiento de la composición estelar de la asociación OB, conocida como Bochum 7 (Moffat \& Vogt, 1975; Lundstrom \& Stenholm, 1984; Sung et al., 1999), localizada a una distancia de entre 4 y 6 kpc. Aplicaremos sucesivamente a Bo 7 las diversas técnicas disponibles y técnicas nuevas de- 


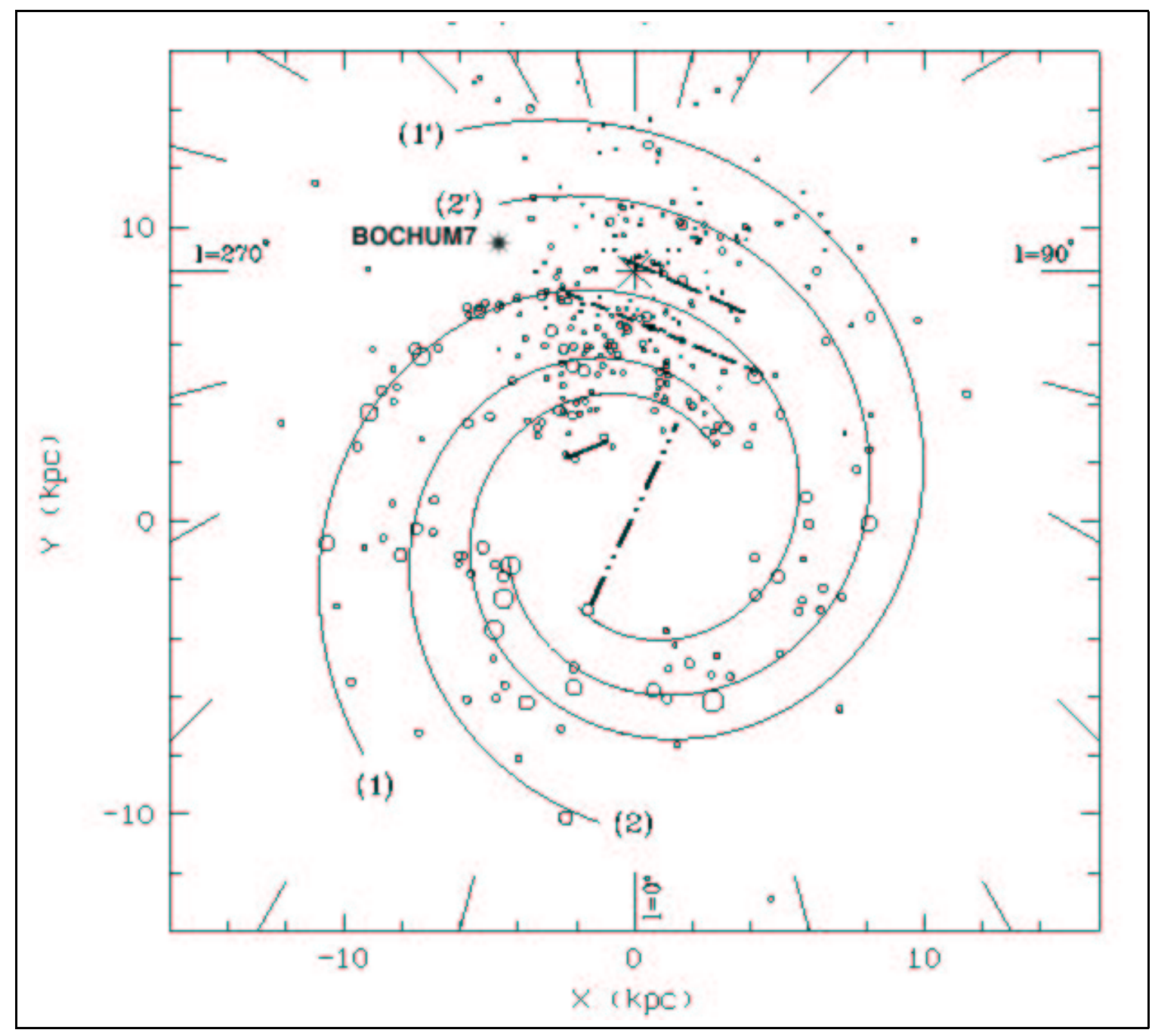

Figura 4: Modelo de Galaxia con cuatro brazos superpuesta a observaciones de regiones de formación estelar. El tamaño de los símbolos es proporcional al parámetro de excitación de la(s) estrella(s). La posición del Sol está indicada por el símbolo como estrella. Los brazos son: 1 Sagitario-Carina, 2 Scutum-Crux, 1'Norma-Cygnus y 2'Perseo. También está bosquejado el perfil del brazo local (línea a trazos largos), la orientación y longitud de la barra (línea trozo-punto-punto), de Englmaier \& Gerhard (1999) y finalmente una característica ligada al brazo a 3 kpc (línea sólida) (Figura 5 de Russeil, 2003). 
sarrolladas en el contexto de este trabajo, para realizar un análisis más detallado de los miembros conocidos y el descubrimiento y estudio de nuevos miembros. Con ello será posible estimar el valor de la distancia al cúmulo y la velocidad radial del conjunto estelar, como así también ampliar el conocimiento de las características que posee la región Galáctica en la cual se encuentra la asociación OB. También es el objetivo de esta Tesis presentar al sistema binario LS 1135, a fin de realizar una determinación más precisa de sus parámetros orbitales. Al tratarse de una estrella de tipo espectral $O$ de secuencia principal, aún la determinación de masas mínimas es de relevancia astrofísica por ser mal conocida la relación masa-luminosidad para las estrellas más calientes y luminosas.

Esta tesis comprende estudios fotométricos, espectroscópicos y astrométricos, de posible interés también en otras áreas, razón por la cual en la sección Apéndice se han incluido conocimientos adicionales. 


\section{PARÁMETROS ANALIZADOS}

El problema de la determinación de pertenencia de objetos estelares a asociaciones distantes, o aún de la propia existencia de una asociación en una determinada región del cielo, es extremadamente complejo, como ya se explicó previamente. Consecuentemente, diversos métodos y criterios fueron analizados y aplicados a los candidatos a miembros y objetos de campo de la región centrada en $l=265^{\circ}, \mathrm{b}=-2^{\circ}$, con un tamaño angular de $30^{\prime} \times 30^{\prime}$, estudiada en esta Tesis. Sus peculiaridades y resultados serán descriptos en detalle a lo largo de esta sección y en las siguientes.

\subsection{Proximidad Angular y Radial}

La publicación del Catálogo LS (Stephenson \& Sanduleak, 1971) impulsó a los astrónomos a estudiar las concentraciones de estrellas luminosas que podían ser observadas, dentro de la cantidad total de este tipo de estrellas que posee dicho catálogo.

Los cúmulos estelares, se observan en las imágenes fotométricas como un grupo estelar de mayor densidad. En el mismo, resulta posible estimar un centro geométrico y luego efectuar el conteo estelar dentro de círculos concéntricos con diferentes radios, que se definen en el lugar. Un ejemplo de lo que aquí se dice es el trabajo de Moffat \& Fitzgerald (1974) donde analizan al cúmulo abierto NGC 2453 en la región de Puppis. Efectuando un conteo estelar en una imagen fotográfica del cúmulo, ellos determinan el centro y la extensión del mismo. El límite del cúmulo yace a aproximadamente 2'.4 de su centro: este es el radio adoptado. Son 67 estrellas las que quedan dentro de ese radio (la región interior) y 26 estrellas de campo quedan fuera de él (la región exterior). Sobre la base de la estadística de Poisson, ellos esperaban $54 \pm 9$ miembros para $\mathrm{V}<15.5$

Sucede que este mismo estudio, no resulta posible efectuarlo en las imágenes fotométricas cuando se buscan asociaciones, ya que la densidad de las mismas es demasiado baja. No se observan grandes concentraciones estelares, las estrellas miembros de la asociación a menudo se confunden con las estrellas de campo, si es que no se tiene información adicional.

Debido a que las asociaciones tienen escalas lineales más o menos restringidas a pocos pc o pocas decenas de pc en algunos casos más extremos, sus tamaños angulares también quedan acotados, quedando los mismos en función de la distancia a la que se encuentra la asociación. Cuando analizamos estructuras a distancias superiores a $2 \mathrm{kpc}$, como en el caso 
de este trabajo, aún las asociaciones de mayor diámetro pasan a ser comparables o menores que el tamaño típico de nuestras imágenes. Una asociación de 5 pc de diámetro, por ejemplo, tiene un diámetro angular que varía entre 9 y 2 minutos de arco a distancias de entre 2 y 7 kpc. Inclusive asociaciones grandes, 20 pc de diámetro lineal, tienen diámetros angulares de sólo 20 minutos de arco a $3.3 \mathrm{kpc}$.

Esto quiere decir que, en la mayor parte de los casos que nos son de interés, nuestro análisis es realizado a distancias tales que estructuras completas pueden estar contenidas en una única imagen, aún con las limitaciones de campo de un CCD. Este es el caso que será tratado en este trabajo.

Si conocemos las distancias individuales de los miembros de un cúmulo, podemos analizar la proximidad radial de los mismos. Con proximidad radial nos referimos a la medida a lo largo de la dirección de observación, no a la proyectada en el cielo. Los objetos más próximos entre sí (dentro de los errores que para estrellas muy distantes son valores considerables), tienen mayor posibilidad de estar asociados físicamente.

Las distancias estelares se derivan a partir de la cantidad V - $\mathrm{M}_{v}$, la cual es una medida de la distancia a una estrella, obtenida comparando su magnitud dentro del filtro visual con su magnitud absoluta en el mismo filtro, y es llamada módulo de distancia de la estrella:

$$
V-M_{v}=5 \cdot \log _{10}(d)-5+A_{v}
$$

La extinción visual, $\mathbf{A}_{v}$ es una consecuencia de los efectos de dispersión y absorción que padece la luz de la estrella debido a la presencia de polvo en su trayectoria.

Es posible obtener la extinción visual como:

$$
A v=R \cdot E(B-V)
$$

siendo el error de la misma:

$$
\delta A v=R \cdot \delta E(B-V)
$$

con un error en el exceso de color $\mathrm{E}(\mathrm{B}-\mathrm{V})$ :

$$
\delta E(B-V)=\delta(B-V)=\sqrt{(\delta B)^{2}+(\delta V)^{2}}
$$


De modo tal que el error en la distancia es:

$$
\delta d=(d / 5) \cdot \ln (10) \cdot \sqrt{(\delta V)^{2}+\left(\delta M_{v}\right)^{2}+(R \cdot \delta(B-V))^{2}}
$$

Un error de mucha influencia en el cálculo de la distancia, surge de la asignación de la $\mathrm{M}_{v}$ correspondiente al tipo espectral encontrado para la estrella. El error $\delta \mathrm{M}_{v}$ se calculó en la subsección 5.1.1. Lo mismo ocurre con la presencia de líneas de emisión en los espectros estelares, la estrella parece ser intrínsecamente más luminosa y por ende más distante.

\subsection{Enrojecimiento y Parámetro $Q$}

Parte de la luz emitida por la estrella, es absorbida cuando atraviesa su propia atmósfera y también en el medio interestelar por el que viaja hasta llegar al observador. La absorción dentro de la atmósfera estelar se incluye en el índice de color intrínseco (B - V)o La cantidad de luz absorbida en el medio interestelar, depende de la longitud de onda en la que la radiación se desplaza en el mismo y de las características que éste tenga.

Al suceder esto, el índice de color observado difiere del valor correspondiente al índice de color intrínseco. Esa diferencia conocida como exceso de color, E(B - V), o enrojecimiento, es una indicadora del material interestelar a través del cual se observa a la estrella. Cuando se observan estrellas miembros de un mismo grupo, se espera que el rango de valores del E(B - V) que ellas tienen no sea demasiado amplio. Esto indicaría que esas estrellas se ubican en un medio interestelar de similares características y podría ser considerado como criterio de pertenencia a un mismo grupo estelar.

Un error en la clasificación espectral o una fotometría no precisa en el sistema estándar, introduce un error en el exceso de color. Esto afectará el cálculo del índice fotométrico no enrojecido y de la magnitud absoluta. También el cálculo de los valores de magnitud visual intrínseca $V_{\circ}$, correspondientes a cada una se verá afectado, ya que este se obtiene como:

$$
V_{\circ}=V-R \cdot E_{B-V}
$$

La razón de la extinción visual al enrojecimiento es $\mathrm{R}=3.23 \pm 0.05$ para estrellas $\mathrm{O}$ y $\mathrm{B}$ tempranas moderadamente enrojecidas. Esto depende de la distribución de energía espectral y el enrojecimiento, siendo:

$$
\begin{aligned}
& R=(A v / E(B-V))= \\
& 3.3+0.2 \cdot(B-V)_{\circ}+0.04 \cdot\left((B-V)-(B-V)_{\circ}\right)
\end{aligned}
$$

Estudio de una Asociación $O B$ distante en la Vía Láctea 
Se puede calcular el parámetro libre de enrojecimiento "Q" para estimar los tipos espectrales en base a fotometría UBV y de allí sus colores intrínsecos y enrojecimientos correspondientes. La clase espectral que se encuentra de este modo, queda determinada unívocamente sólo en ciertos dominios, especialmente para las estrellas más tempranas. La separación de clases de luminosidad no es posible.

Trabajando con la ecuación 12 en la cual empleamos los colores observados, podemos conocer los valores de este parámetro Q observado que le corresponde a cada estrella. Para ello aceptamos que la ley de extinción selectiva es la misma en todas direcciones ya que las estrellas en estudio en este trabajo no poseen altos excesos de color. Por otro lado, con la ecuación 13 podemos calcular el valor de Q a través de los colores intrínsecos que la estrella tiene según sea tu tipo espectral. El desarrollo de las ecuaciones 14, 15 y 16 muestra la razón por la cual es acertado decir que Q es un parámetro libre de enrojecimiento. Las ecuaciones 12, 13, 17 y 18 se obtuvieron del Schmidt-Kaler (1982).

$$
\begin{gathered}
Q=(U-B)-\frac{E_{U-B}}{E_{B-V}}(B-V) \\
Q_{\circ}=(U-B)_{\circ}-\frac{E_{U-B}}{E_{B-V}}(B-V)_{\circ} \\
Q-Q_{\circ}=(U-B)-(U-B)_{\circ}-\frac{E_{U-B}}{E_{B-V}}\left[(B-V)-(B-V)_{\circ}\right] \\
Q-Q_{\circ}=E_{U-B}-\frac{E_{U-B}}{E_{B-V}} E_{B-V}=0 \\
Q=Q_{\circ}
\end{gathered}
$$

La extinción interestelar corre a la estrella en el diagrama color-color a lo largo de la recta de enrojecimiento según la ley de extinción estándar indicada en la ecuación 17

$$
\frac{E_{U-B}}{E_{B-V}}=0.72+0.05 E_{B-V}
$$

El lugar para las estrellas de tipos espectrales O....A0(III-)V de secuencia principal desenrojecidas

$$
(U-B)_{o}=0.08+3.85(B-V)_{o}
$$




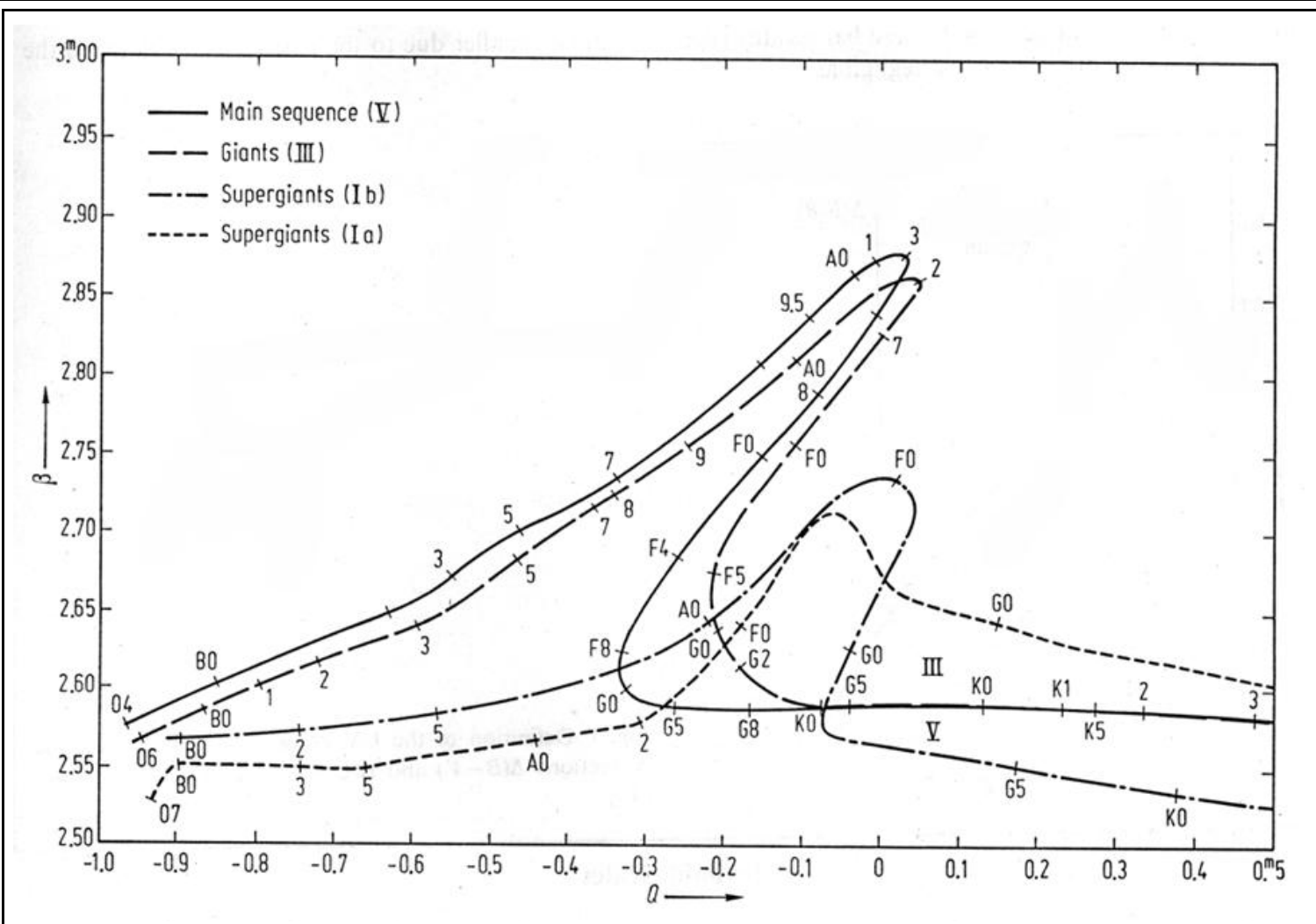

Figura 5: Relación aproximada entre el parámetro $Q$ (de la fotometría $U B V$ ) y $H_{\beta}$ y los tipos espectrales para estrellas de población I normal. (Figura obtenida en SchmidtKaler, 1982)

es válido para $(B-V)_{o}<0,(U-B)_{o}<0$. Estas dos ecuaciones dan el enrojecimiento y tipo espectral en el rango O....A0III-V.

Si a los filtros UBV se les suma el filtro de banda angosta $\mathrm{H} \beta$, resulta posible la separación de estrellas supergigantes y estrellas con líneas de emisión. Este método no obstante no es suficiente para distinguir las estrellas clase de luminosidad III, IV, V y las estrellas Ap, Am., como puede verse en el diagrama $\beta$ vs. Q (Figura 5).

El cálculo del parámetro libre de enrojecimiento Q es uno de los primeros criterios de pertenencia que se aplican al grupo de estrellas en el presente estudio. Se realiza una primera selección reuniendo aquellas cuyo valor de Q sea el esperado para el tipo espectral característico de una Asociación OB. 


\subsection{Clasificación Espectral y Diagrama Color-Color}

Para asignarles a las estrellas su clasificación espectral correspondiente (llamado también tipo espectral, TE), usamos un esquema de clasificación basado en criterios de MorganKeenan (MK)(1943). Este esquema indica una secuencia de temperatura, corriendo desde las estrellas más calientes azules $\mathrm{O}$ hasta las estrellas más frías rojas M. También asigna las clases de luminosidad a los TE (ver Tabla 1). Si bien los conceptos básicos bajo los cuales el mismo fue desarrollado, han perdurado en el tiempo, el esquema tuvo algunos cambios. En este trabajo usamos principalmente los criterios de clasificación espectral para estrellas OB desarrollados por Walborn \& Fitzpatrick (1990).

El diagnóstico de temperatura que se realiza en los espectros de cada estrella para poderlas clasificar, consiste en el cociente de ciertas líneas de HeI y HeII, para las estrellas más calientes. Para las estrellas B tempranas se estudia el cociente de SiIV y SiIII o SiIII y SiII, aunque desde las B2 en adelante se analiza también la razón de los perfiles espectrales correspondientes al MgII y HeI. Este diagnóstico de temperatura es completamente independiente de la metalicidad de la estrella, al menos hasta el tipo espectral B2, ya que se emplea la intensidad relativa de diferentes iones de la misma especie. A partir del TE B2 es posible recurrir a los colores UBV como indicadores de temperatura, debido a que los valores que los mismos tienen cuando se trata de estrellas con $\mathrm{T}<25000^{\circ} \mathrm{K}$ difieren en una cantidad mayor al error fotométrico cometido al obtenerlos. Es así que conociendo los colores (U B) y (B - V) de la estrella, es posible estimar su temperatura y con ella el TE correspondiente.

El esquema de clasificación espectral bidimensional M-K, permite ubicar la posición de la estrella sobre el diagrama Hertzprung-Russell basada completamente en la apariencia de su espectro. Este diagrama conocido también como diagrama $\mathbf{H}-\mathbf{R}$ se construye con las propiedades observadas de las estrellas: magnitud absoluta visual de la estrella, $\mathbf{M}_{v}$, sobre el eje vertical (con la luminosidad incrementándose hacia arriba) y tipo espectral, TE, corriendo horizontalmente (con la temperatura incrementándose hacia la izquierda).

Los colores UBV de las estrellas más tempranas (TE O - B2) no dicen demasiado sobre la temperatura de las mismas. Dos estrellas con la misma $M_{v}$ y con color $(B-V)$ casi idéntico pueden diferir hasta en 2.5 magnitudes en su corrección bolométrica. En el caso de una O3V y una B0I no podríamos distinguir entre ellas que son diferentes en cantidad de masa por un factor 3 . 
Tabla 1: Clases de Luminosidad de Morgan - Keenan

\begin{tabular}{cl}
\hline \hline Clase & Tipo de estrella \\
\hline Ia - O & Extremo, supergigantes luminosas \\
Ia & Supergigantes luminosas \\
Ib & Supergigantes menos luminosas \\
II & Gigantes brillantes \\
III & Gigantes normales \\
IV & Subgigantes \\
V & Estrellas (enanas) de Secuencia Principal \\
VI, sd & Subenanas \\
D & Enanas blancas \\
\hline \hline
\end{tabular}

Cuando de las estrellas tempranas sólo se poseen datos fotométricos, no es mucho lo que se puede decir de las mismas. La mayor parte de la luz de estas estrellas que tienen alta temperatura, resulta observable en el ultravioleta lejano.

La masa y la edad (y quizás en menor proporción la composición), determinan la temperatura efectiva, la luminosidad y de este modo, el radio y la gravedad superficial. En otras palabras, la ubicación física en el diagrama luminosidad vs. temperatura efectiva $\left(\log \mathrm{T}_{\text {eff }}\right.$ vs. $\left.\mathrm{M}_{b o l}\right)$.

Por medio del conocimiento del TE de las estrellas, es posible obtener también los valores tabulados de los índices de color intrínseco $(\mathbf{B}-\mathbf{V}) 。 \mathbf{y}(\mathbf{U}-\mathbf{B})_{\circ}$, sus $\mathrm{M}_{v}$ y sus correcciones bolométricas.

Si lo que estamos investigando es una Asociación OB, determinar los tipos espectrales de las estrellas que se están estudiando, es un criterio esencial de pertenencia a la misma, considerando como posibles miembros aquellas estrellas cuyos tipos espectrales sean O y B.

¿Qué podemos decir acerca de la temperatura efectiva de una estrella OB si sólo conocemos su color? En realidad no mucho, ya que no hay forma de distinguir entre una estrella de $50000^{\circ} \mathrm{K}$ y una de $40000{ }^{\circ} \mathrm{K}$ o una de $40000{ }^{\circ} \mathrm{K}$ y una de $30000^{\circ} \mathrm{K}$, si los únicos datos que disponemos de las mismas son sus colores UBV. Estos valores de temperatura efectiva se 
atribuyen al rango de tipos espectrales de $\mathrm{O} 3$ a B0 y corresponden al amplio rango de masas, yendo de las estrellas de mayor masa $\left(120 \mathrm{M}_{\odot}\right)$ a las de $10 \mathrm{M}_{\odot}$. Esta es una limitación de importancia en los estudios fotométricos de estrellas tempranas porque el no conocer con exactitud la temperatura efectiva de la estrella implica que la luminosidad de la misma tiene gran margen de error (por lo tanto también su masa) si no se tiene información adicional, en general conocimiento de tipos espectrales.

Otro aporte importante que proporciona al trabajo tener la información sobre el tipo espectral, se ve en la comparación del error producido al equivocarse en la clasificación de un subtipo espectral y una clase de luminosidad espectral con el error de la fotometría. En el primer caso, las barras de error en el diagrama H-R quedan inclinadas porque un error en la temperatura efectiva (como consecuencia de tener una clasificación espectral equivocada), también resulta en un error en la corrección bolométrica y como consecuencia en la determinación de masas. Un error en una clase de luminosidad es aproximadamente paralelo al error producido por un subtipo espectral. En el segundo caso, el error resultante en el diagrama H-R debido a pequeños errores fotométricos, como ser 0.02 magnitudes en (B - V)。 y (U B)。, ya es suficiente para impedir conocer lo necesario sobre la masa de la estrella. En la Figura 6 están representados los diagramas H-R con los errores que aquí se comentan.

El diagrama color-color muestra la relación entre los índices de color (U - B) y (B V) para cada clase de luminosidad de las estrellas. Se emplea para realizar la difícil tarea de conectar la posición de la estrella sobre el diagrama color-color con las propiedades físicas de ella.

La Figura 36 en la subsección 5.2.4 es un gráfico color-color donde se evidencia el enrojecimiento sufrido por las estrellas que se estudian en esta Tesis.

\subsection{Banda Interestelar Difusa}

La presencia de líneas o bandas interestelares en los espectros estelares, es una indicadora de la existencia de polvo en el medio interestelar que recorre la radiación emitida por la estrella. Entre las bandas interestelares difusas (Diffuse Interestellar Band (DIB)), la más prominente en la parte azul-violeta de espectros ópticos es la producida en $4428 \AA$ Esta es una banda muy evidente en el espectro de estrellas O y B distantes.

En el trabajo de Snow et al. (2002) se le atribuye a Merrill (1934) haber sido el primero 

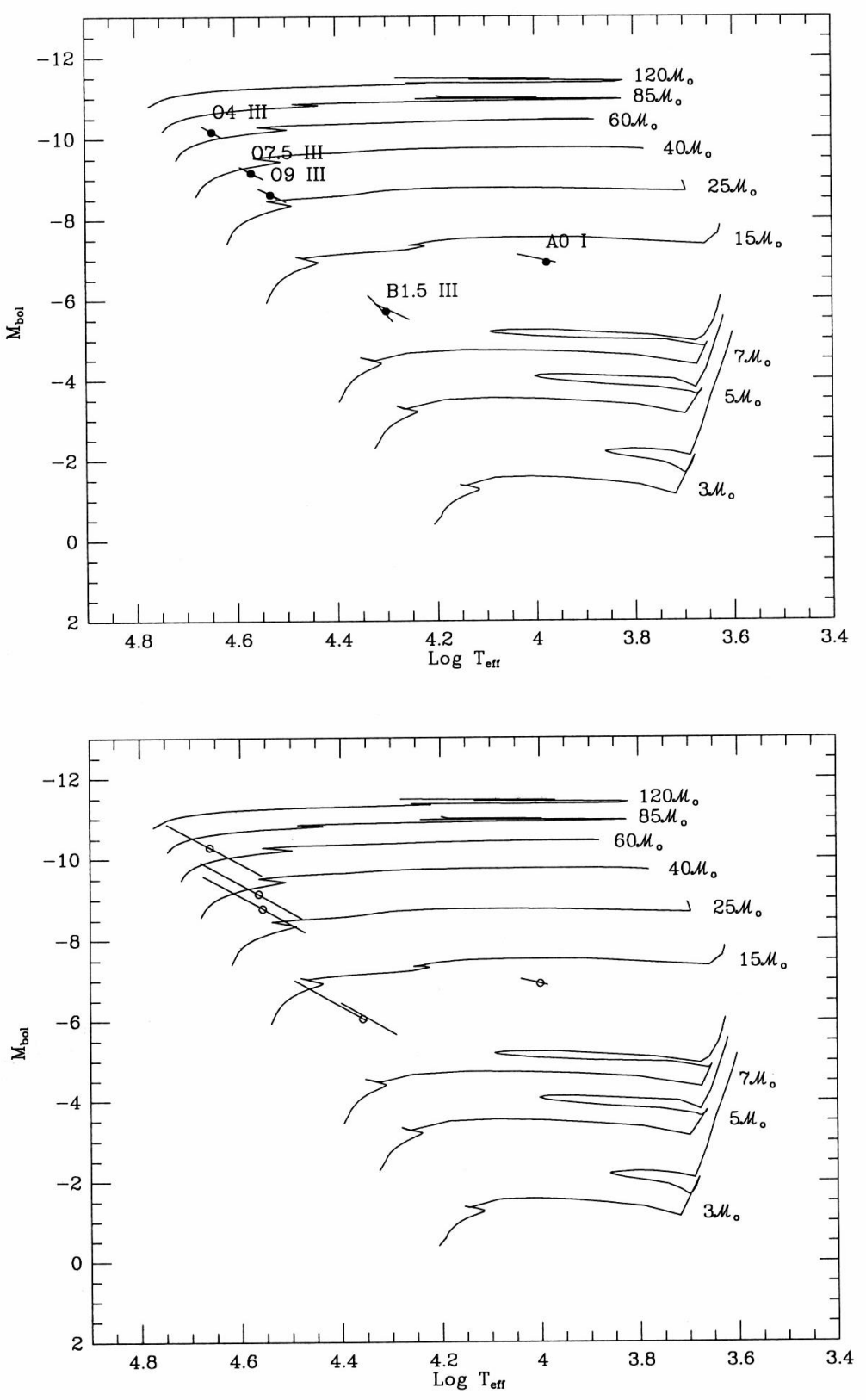

Figura 6: En el diagrama $H-R$ de la figura superior, las barras de error inclinadas se originan debido a un error en la temperatura efectiva (como consecuencia de tener una clasificación espectral equivocada), generando ello un error en la corrección bolométrica y como consecuencia en la determinación de masas. Un error en una clase de luminosidad es aproximadamente paralelo al error producido por un subtipo espectral. En el diagrama $H-R$ de la figura inferior, se indica el error debido a pequeños errores fotométricos, suficiente para impedir conocer lo necesario sobre la masa de la estrella (Stellar Astrophysics for the Local Group, pag. 106) 


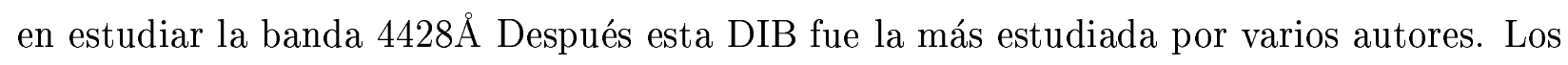
primeros relevamientos de DIBs a gran escala comenzaron a hacerse en la década de $1950 \mathrm{y}$ estuvieron centrados principalmente en el perfil de $\lambda 4428$ (desde Duke 1951 a Gammelgaard 1975 y todas las referencias allí citadas). Los primeros estudios realizados al respecto de las características de $\lambda 4428$ y especialmente de su perfil, han estado basados en espectros fotográficos o mediciones fotométricas de filtro.

No se conoce el mecanismo de producción de la DIB en $4428 \AA$ El trabajo de Snow et al. (2002), que mencionamos previamente, tuvo como objetivo analizar si el origen de la DIB $\lambda 4428$ es molecular o se debe a la presencia del polvo. Hay varios argumentos que para la mayoría de las DIBs indican un origen molecular, pero muchos de esos argumentos no se aplican al perfil de $4428 \AA$ Por ejemplo, se piensa que muchas de las DIBs son muy angostas para corresponder a procesos de absorción del polvo. Esto, claramente, no es el caso para $\lambda 4428$, cuyo ancho a potencia mitad es de varios Angstroms. Sin embargo, una observación de importancia que argumenta en contra del origen de $\lambda 4428$ como consecuencia de los granos en el material interestelar, es la ausencia de estructura de polarización a lo largo de la banda (Martin \& Angell, 1974). Aún así, esto debe ser tomado sólo como un indicativo, y no resulta suficiente para descartar la posible formación del perfil por una población de granos distinta de aquellos responsables de la extinción óptica y la polarización.

Por ahora se acepta que la banda difusa $4428 \AA$ probablemente tiene un origen molecular y que se forma con mayor facilidad en las porciones más externas de nubes densas. De hecho, este perfil parece ser propio de la clase de bandas interestelares difusas representadas por los numerosos perfiles angostos encontrados en longitudes de onda más largas.

Aún no está claro si la buena correlación encontrada entre las DIBs y el material interestelar, indica una asociación específica de los generadores de las DIBs con el polvo que causa la extinción o si estos generadores y el polvo, simplemente están bien mezclados a lo largo de todo el medio interestelar.

La medición del ancho equivalente de la DIB 4428A puede ser un indicador de la cantidad de material interestelar que la radiación estelar ha encontrado en su camino, entonces el ancho equivalente medido en la banda interestelar difusa $4428 \AA$ sería un indicador de distancia. Esperando que los miembros de la Asociación en estudio, se ubiquen en una región que reuna similares características de extinción y se encuentren a una misma distancia, los valores del 
ancho equivalente de la DIB $\lambda 4428$ deberían quedar acotados dentro de un pequeño rango y podrían ser tomados como otro criterio de pertenencia al grupo estelar.

Snow et al. (2002) en su trabajo analizan espectros CCD de estrellas muy enrojecidas y muestran gráficos que relacionan a la longitud de onda central de la DIB $\lambda$ 4428, la intensidad del perfil, FWHM y el ancho equivalente con el exceso de color E(B - V). En el gráfico que relaciona el ancho equivalente de la DIB $\lambda 4428$ con el E(B - V), es posible ver una relación, ya que el primero crece linealmente con el exceso hasta que este último alcanza un valor $\mathrm{E}(\mathrm{B}$ - V) 1.0 magnitud. Después de ese punto la intensidad de la DIB comienza a nivelarse. Lo que se comenta aqui está representado en la Figura32 de la subsección 5.2.3. No se observa ninguna correlación positiva entre la longitud de onda central de esta DIB con el E(B - V), su intensidad con el E(B - V) e incluso el FWHM con el E(B - V).

\subsection{Velocidad estelar}

El vector velocidad de una estrella que se mueve respecto de un observador, puede naturalmente descomponerse en dos componentes mutuamente perpendiculares, una yaciendo a lo largo de la línea de la visual y la otra perpendicular a esta. La componente en la línea de la visual, es la velocidad radial de la estrella, $\mathrm{v}_{r}$. La segunda componente, es la velocidad transversal o tangencial de la estrella, $\mathrm{v}_{\theta}$, sobre el plano tangente de la esfera celeste. Esta velocidad transversal, aparece como un lento cambio angular en sus coordenadas celestes, conocido como movimiento propio (usualmente expresado en fracciones de segundos de arco por año).

\section{Velocidad Radial}

Las velocidades radiales en combinación con los datos astrométricos (movimientos propios) son datos útiles para establecer pertenencia en cúmulos estelares y para determinar las órbitas de los mismos en torno de la Galaxia. Estos datos también proveerán información sobre la población de sistemas estelares binarios en cúmulos.

La velocidad radial de una estrella, puede ser indicada según distintos centros de referencia. La Tabla 2 lista las clases de movimientos que se deben tener en cuenta, la amplitud de los mismos y el centro de referencia respecto del cual queda indicada la velocidad de la estrella.

Se espera que las estrellas que pertenezcan a un mismo cúmulo o asociación, se desplacen 
Tabla 2: Centros de referencia respecto de los cuales puede quedar indicada la velocidad radial medida

\begin{tabular}{|l|l|l|}
\hline Corregido por & $\begin{array}{l}\text { Amplitud } \\
\left(\mathrm{km} \mathrm{s}^{-1}\right)\end{array}$ & Sistema de referencia \\
\hline Rotación de la Tierra & $\leq 0.5$ & \\
\hline $\begin{array}{l}\text { Mvto. de la Tierra en torno al } \\
\text { baricentro Tierra-Luna }\end{array}$ & $\leq 0.013$ & geocéntrico \\
\hline $\begin{array}{l}\text { Mvto. de la Tierra } \\
\text { en torno al Sol }\end{array}$ & $\leq 30$ & heliocéntrico \\
\hline $\begin{array}{l}\text { Mvto. Solar en torno al } \\
\text { baricentro del Sistema Solar }\end{array}$ & $\leq 0.012$ & baricéntrico \\
\hline Mvto. Solar al Ápex & $\sim 20$ & estándar local de reposo(LSR) \\
\hline Rotación Galáctica & $\sim 300$ & galactocéntrico \\
\hline
\end{tabular}

en la galaxia con una misma velocidad radial promedio, cuando esto deja de ser el caso, el grupo estelar dejará de ser tal, ya que quienes en un principio fueron sus miembros, comenzarán a separarse entre sí y pasarán a ser estrellas del campo.

Conociendo el valor estelar de $\mathrm{V}_{L S R}$, con el cual nos independizamos del movimiento del Sol dentro de la galaxia y conociendo las coordenadas galácticas $l$ (longitud galáctica) y $b$ (latitud galáctica) de las estrellas en estudio, puede estimarse la distancia cinemática de las mismas mediante un modelo de la curva de rotación galáctica.

\section{Movimiento Propio}

Es sabido que en un intervalo de tiempo $\Delta t$ la estrella se moverá en dirección perpendicular a la visual del observador y lo hará una distancia

$$
\Delta d=v_{\theta} \Delta t
$$

Si la distancia del observador a la estrella es $r$, entonces el cambio angular en su posición a lo largo de la esfera celeste estará dado por:

$$
\Delta \theta=\frac{\Delta d}{r}=\frac{v_{\theta}}{r} \Delta t
$$


Así el movimiento propio, $\mu$, está relacionado a su velocidad transversal por

$$
\mu \equiv \frac{d \theta}{d t}=\frac{v_{\theta}}{r}
$$

\section{Punto de convergencia}

Considerando los cambios de posición en el tiempo de los miembros de un cúmulo o asociación, debido al movimiento del centro del mismo, es posible determinar sus direcciones de movimiento. Después de remover los efectos del movimiento peculiar del Sol, trazando sus vectores direccionales a través del espacio, da la apariencia de que cada estrella se está moviendo hacia (o viniendo de) un punto común, conocido como el punto de convergencia. En una Asociación estelar, las estrellas pueden no estar ligadas físicamente y poseer movimientos orbitales internos tales que, resultará más probable que la intersección de sus trayectorias genere una mancha antes que un punto. Asi mismo, la existencia de la misma resultaría un buen indicativo para ser empleado como criterio de pertenencia de esas estrellas a la Asociación.

De la geometría ilustrada en la Figura 7, el ángulo entre el cúmulo estelar y el punto de convergencia, visto desde el Sol, debe ser el mismo que el ángulo entre la línea de la visual al cúmulo y su vector velocidad espacial, V (esto es válido solamente porque al punto de

convergencia se lo considera en el infinito).

La distancia angular entre el punto de convergencia y la asociación, depende linealmente de la distancia entre el observador y la asociación y por lo tanto, cuando este método resulta aplicable provee no sólo un criterio de pertenencia sino también un patrón de distancia. Consecuentemente, para asociaciones distantes la distancia angular al punto convergente es grande. Esto implica que, adicionalmente, el tamaño angular de la asociación no debería ser mucho menor que la distancia angular al punto convergente. De lo contrario, las trayectorias proyectadas serían prácticamente paralelas y su punto de intersección estaría mal definido dentro de una región muy elongada, cual una gran mancha extendida y confusa.

Con el incremento de la distancia de las estrellas, el movimiento propio se reduce y los errores crecen. Desafortunadamente, el error actual en la determinación del movimiento propio no es fácil de estimar, ya que éste involucra la combinación de diversos catálogos elaborados, en general, por distintos autores en épocas diferentes y usando distintas técnicas observacionales. Este problema se intensifica cuando se emplean objetos distantes ya que en 


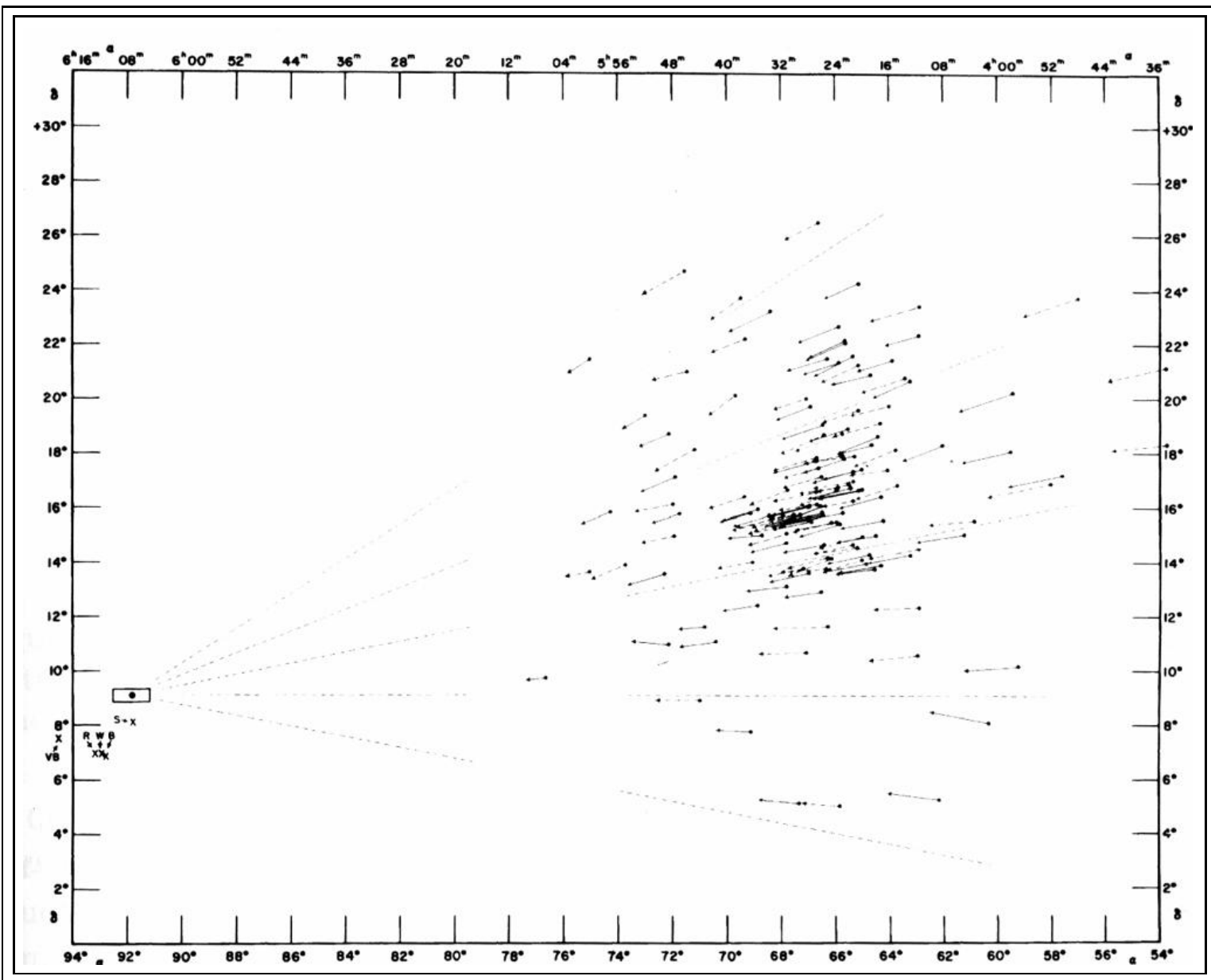

Figura 7: Movimiento aparente de las Hyades a través de la esfera celeste. (Del Elementary Astronomy by Otto Struve, Beverly Lynds, and Helen Pillans. Copyright 1959 by Oxford University Press, Inc. Renewed 1987 by Beverly T. Lynds.)

ese caso se requiere una base de tiempo mayor. 


\section{OBSERVACIONES}

\subsection{Fotometría}

Se realizó fotometría CCD directa de un área de 30' $\times 30^{\prime}$ centrada en aproximadamente $\alpha$ $=8^{h} 44^{m}, \delta=-45^{\circ} 56^{\prime}$ (coordenadas galácticas $\mathrm{l}=265^{\circ} 12, \mathrm{~b}=-2{ }^{\circ}$ ) con el fin de detectar otros probables miembros de la Asociación Bochum 7, además de las detalladas en la subsección 3.1. Las coordenadas fueron elegidas aproximadamente similares a las de la estrella Wolf Rayet, WR12 ( $\left.\alpha=8^{h} 45^{m}, \delta=-45^{\circ} 59^{\prime}\right)$. Las imágenes fueron obtenidas por V. Niemela y P. Ostrov, con el telescopio de 0.6-m de diámetro Curtis-Schmidt del Observatorio Interamericano de Cerro Tololo, en marzo de 1994. Se empleó un detector CCD Thompson 1024 $\times 1024$ con pixeles de $19 \mu \mathrm{m}$ y una escala de 1.834 arcsec/pixel con filtros UBVR y H $\alpha$. Se tomaron dos imágenes con cada uno de los filtros UBVR, obtenidas cada una de ellas con tiempos de exposición largo y corto y se tomaron tres imágenes de tiempo de exposición largo con el filtro $\mathrm{H} \alpha$. El detalle de los tiempos de exposición empleados en las imágenes obtenidas con los distintos filtros se encuentra en la Tabla 4. La longitud de onda central y el ancho de banda de $\mathrm{H} \alpha$ son: $\lambda_{\circ}=6563 \AA \triangle \lambda=78 \AA$

La Figura 8 es la carta astronómica de la región en estudio descripta en el párrafo anterior. En ella están indicadas las 63 estrellas con tipos espectrales O y B que se clasificaron analizando su fotometría y sus respectivos espectros y la estrella WR12. En la carta las estrellas se han indicado con un número de referencia que en la Tabla 3 se relaciona con la identificación CBNcoords. y LS que las mismas tienen.

El campo fotométrico elegido para la época de observación como campo estándar fue sa104 (Landolt, 1992). Ese campo fue el apropiado para esa época debido a su ubicación, próxima a la región en estudio. Del campo sa104 se tomaron una imagen con tiempo de exposición largo y otra con tiempo de exposición corto con los filtros BVR y sólo se tomaron imágenes con tiempo de exposición largo empleando el filtro U.

En estas imágenes se realizó sólo fotometría de abertura y no PSF (Point Spread Function) porque con el gran tamaño del campo en la imagen obtenida con el telescopio CurtisSchmidt, de diámetro menor a 1-m y escala arcsec/mm, se obtuvieron estrellas con valores de FWHM comprendidos entre $1.4 \mathrm{px}$ y $2 \mathrm{px}$.

La fotometría de abertura en las imágenes se realizó empleando el software IRAF y el 


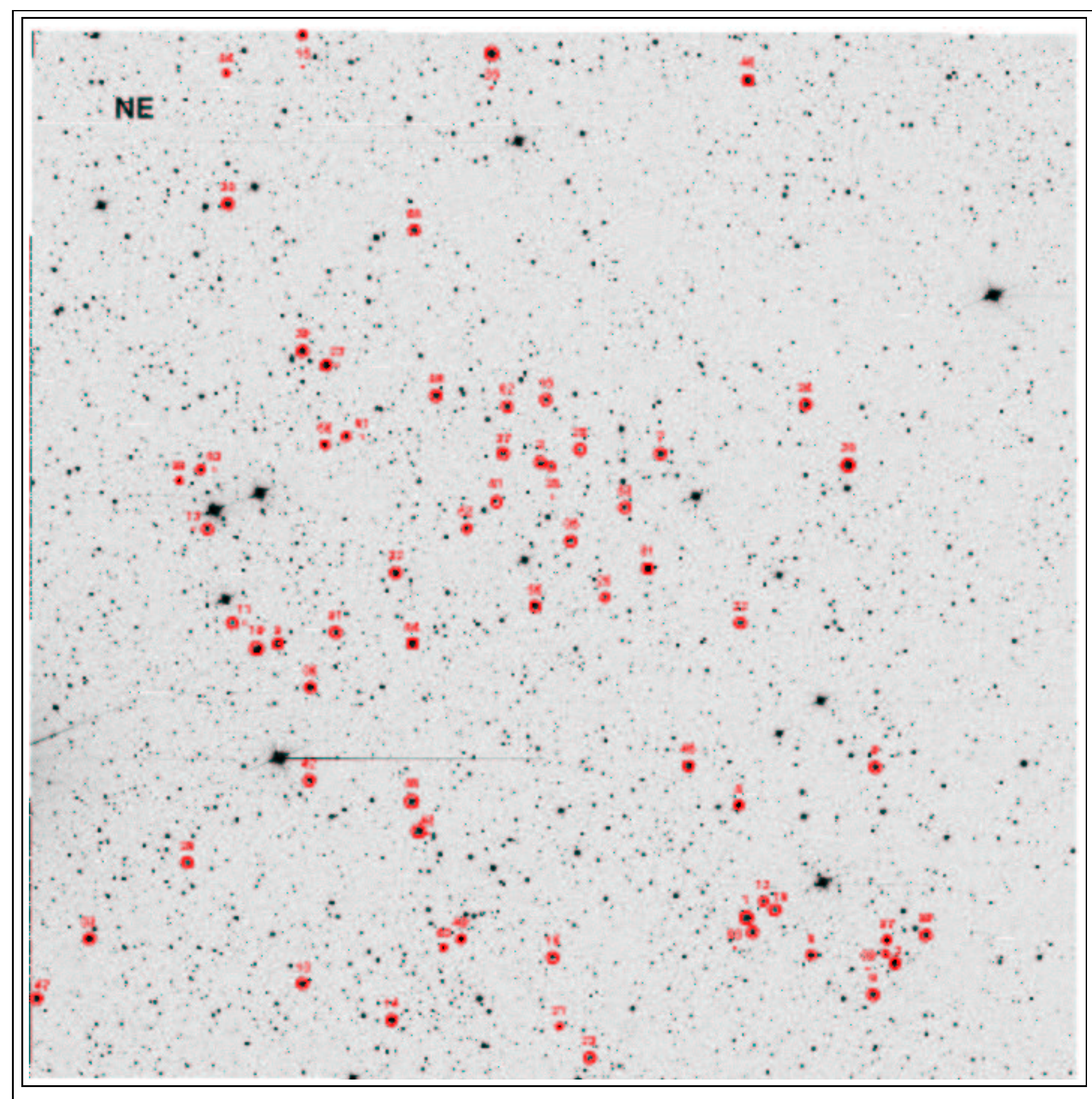

Figura 8: Imagen de 30' $\times 30^{\prime}$ centrada en $\alpha=8^{h} 44^{m}, \delta=-45^{\circ} 56^{\prime}$ obtenida con el filtro $V$. En ella se indican 63 estrellas con TE OB y la estrella WR12 con las que se trabajó en esta Tesis. 
Tabla 3:

\begin{tabular}{|c|c|c|c|c|c|}
\hline Número & $\mathrm{CBN}$ & $\mathrm{LS}$ & Número & $\mathrm{CBN}$ & $\mathrm{LS}$ \\
\hline 1 & 84349.6-460711 & 1135 & 33 & 84543.1-460742 & \\
\hline 2 & $84324.0-460831$ & 1131 & 34 & $84339.5-455148$ & \\
\hline 3 & 84424.9-455334 & 1144 & 35 & $84518.6-454543$ & \\
\hline 4 & 84350.9-460348 & 1137 & 36 & $84526.1-460527$ & \\
\hline 5 & $84510.4-455854$ & & 37 & $84431.5-455314$ & \\
\hline 6 & $84338.5-460817$ & & 38 & 84419.9-455552 & \\
\hline 7 & 84404.4-455316 & 1140 & 39 & $84325.6-460820$ & \\
\hline 8 & $84327.7-460929$ & & 40 & $84442.0-460802$ & \\
\hline 9 & $84327.4-460240$ & & 41 & 84430.9-455442 & \\
\hline 10 & $84423.1-460821$ & & 42 & $84505.0-460300$ & \\
\hline 11 & $84518.2-455816$ & & 43 & $84446.2-460433$ & \\
\hline 12 & $84346.7-460641$ & & 44 & 84447.4-460339 & \\
\hline 13 & 84506.3-460906 & 1147 & 45 & 84349.4-454204 & \\
\hline 14 & 84450.9-461012 & 1146 & 46 & $84446.7-454632$ & \\
\hline 15 & $84505.7-454040$ & & 47 & 84552.3-460929 & \\
\hline 16 & $84344.7-460656$ & & 48 & 84359.6-460237 & \\
\hline 17 & $84522.4-455527$ & & 49 & 84438.9-460746 & \\
\hline 18 & $84421.9-455136$ & & 50 & 84348.6-460736 & \\
\hline 19 & $84510.9-455900$ & & 51 & $84500.4-455834$ & \\
\hline 20 & $84418.2-455307$ & & 52 & $84434.3-455214$ & \\
\hline 21 & 84421.9-461025 & & 53 & $84410.6-455452$ & \\
\hline 22 & $84350.7-455820$ & & 54 & 84518.8-454147 & \\
\hline 23 & $84416.7-461121$ & & 55 & $84527.2-455360$ & \\
\hline 24 & $84423.2-455337$ & & 56 & $84426.0-455749$ & \\
\hline 25 & $84414.0-455733$ & & 57 & $84325.3-460750$ & \\
\hline 26 & $84332.2-455337$ & & 58 & $84443.0-455130$ & \\
\hline 27 & $84501.9-455034$ & & 59 & 84318.7-460742 & \\
\hline 28 & 84433.4-454115 & & 60 & $84502.0-455257$ & \\
\hline 29 & $84506.0-455008$ & & 61 & $84458.5-455242$ & \\
\hline 30 & $84504.8-460013$ & & 62 & $84437.8-455257$ & \\
\hline 31 & $84406.6-455642$ & & 63 & $84523.5-455340$ & \\
\hline 32 & $84450.1-455648$ & & 64 & $84447.2-455856$ & 1145(WR12) \\
\hline
\end{tabular}


Tabla 4: Detalle de las observaciones hechas con los distintos filtros a la región donde investigamos la asociación Bochum 7 y al campo estándar sa104.

\begin{tabular}{|cccc|}
\hline & filtro & \multicolumn{2}{c|}{ tiempo de exposición [seg] } \\
Bochum 7 & & largo & corto \\
\hline & H $\alpha$ & 300 & - \\
& R & 45 & 5 \\
& V & 90 & 10 \\
& B & 90 & 10 \\
& U & 180 & 20 \\
& & & \\
\hline sa104 & & & \\
& R & 20 & 5 \\
V & 60 & 10 \\
B & 90 & 20 \\
U & 60 & - \\
\hline
\end{tabular}

desarrollo fue el siguiente:

i) Completar los headers de todas las imágenes escribiendo en ellos: origen de los datos (OBSERVAT), ascención recta del objeto (RA) expresada en horas, declinación del objeto (DEC) expresada en grados, época de las coordenadas (EPOCH), tiempo sidéreo (ST) y tiempo universal (UT) ambos expresados en horas y el tiempo de exposición a usar en el cálculo de la masa de aire (EXPTIME) o (EXPAIR) expresado en segundos. La masa de aire es un valor único propio de cada imagen debido a que la misma varía con el tiempo de exposición y la hora en la cual se observó. Los valores de ésta estuvieron comprendidos entre 1.15 y 1.18 para las imágenes obtenidas con todos los filtros en los diferentes tiempos de exposición.

En los headers de las imágenes también se agregaron los valores de ganancia, GAIN = 3.3 ADUs y ruido de lectura, RDNOISE $=7$ electrones.

ii) Se determinaron los valores de DATAMIN y DATAMAX para las imágenes de la zona de Bochum 7 obtenidas con cada uno de los filtros. Siendo DATAMIN el dato de la imagen considerado como el mínimo valor aceptable, se obtuvo como la diferencia entre la media del 
cielo y 3 veces la dispersión (sigma) del mismo. Los valores encontrados son los mostrados en la Tabla 5. DATAMAX es el nivel de saturación del CCD y el empleado en este turno de observación tiene un valor de $\simeq 60000$ cuentas. El valor de THRESHOLD (umbral a partir del cual la señal se considera imagen estelar) determinado para las mismas fue 5 veces la dispersión del fondo de la imagen .

Tabla 5: Valores de datamin y sigma del cielo encontrados para las imágenes de la zona de Bochum 7 y del campo estándar sa104 obtenidas con cada uno de los filtros.

\begin{tabular}{|cccc|}
\hline Bochum 7 & filtro & datamin & sigma cielo \\
\hline & $\mathrm{R}$ & 143 & 6 \\
& $\mathrm{~V}$ & 137 & 11 \\
& $\mathrm{~B}$ & 52 & 4 \\
& $\mathrm{U}$ & 34 & 5 \\
\hline SA104 & & & \\
& $\mathrm{R}$ & 61 & 8 \\
& $\mathrm{~V}$ & 130 & 10 \\
& $\mathrm{~B}$ & 75 & 8 \\
$\mathrm{U}$ & 4 & 5 \\
\hline
\end{tabular}

iii) El valor de FWHM que se tomó por igual para todas las estrellas en los cuatro filtros fue de 1.5 px, lo cual se empleó como abertura fotométrica de cada estrella. El radio interior del anillo del cielo fue de 5 px desde el centro de la estrella y 3 px de ancho.

Las imágenes tomadas a la zona de Bochum 7 con los cuatro filtros, presentaban un pequeño corrimiento entre sí, con lo cual se empleó la tarea "imalign" para alinearlas. De ese modo, bastó con encontrar las coordenadas X e Y de las estrellas aplicando la tarea "daofind" a sólo una imagen de la zona de Bochum 7. Con la tarea "phot" se obtuvieron las magnitudes instrumentales de las estrellas en el campo en estudio. Siempre se trabajó con las imágenes de tiempo de exposición largo porque en ellas quedó registrada la integración de la radiación proveniente de las estrellas con magnitudes visuales próximas a 15.

Se decidió el tamaño de la abertura a usar para medir cada una de las estrellas en el campo estándar (abertura que tuvo que ser la misma para las imágenes de dicho campo obtenidas 
con los filtros UBVR). Se eligió un radio de 6 px para cada estrella, lo cual triplicaba el valor del ancho a potencia mitad (FWHM) de la gaussiana ajustada para medir el brillo de las mismas. Esto último se pudo hacer debido a que las estrellas del campo estándar se encuentran muy separadas entre si y sin contaminación causada por alguna vecina de menor brillo. Se tomó un anillo del cielo de 10 px con 6 px de ancho. La identificación de cada estándar se hizo interactivamente en la imagen de cada filtro, con lo cual no fue necesario determinar el valor de THRESHOLD, sólo debieron encontrarse los valores de DATAMIN y DATAMAX para cada filtro, ya mostrados en la Tabla 5. Luego con el paquete PHOT se generó la lista con las magnitudes instrumentales de todas las estrellas del campo estándar.

iv) Con el uso de la tarea MKCONFIG y el catálogo de estándares UBVRI de Landolt se encontraron las ecuaciones de transformación de las magnitudes instrumentales al sistema UBV de Johnson. El paso siguiente fue resolver esas ecuaciones para de ese modo tener ajustados los valores de la constante de punto cero y el coeficiente del término de color, para los cuales se ingresó con valor nulo para los cuatro filtros. El coeficiente de extinción se calculó tomando como valor inicial el proporcionado por el catálogo de estándares UBVRI de Landolt y ajustandolos con el empleo de las ecuaciones de transformación de magnitudes.

El resultado obtenido fue:

$$
\begin{gathered}
m U=(U B+B V+V)+u 1+u 2 \cdot X U+u 3 \cdot U B+u 4 \cdot U B \cdot X U \\
u 1=3.10 \pm 0.03, u 2=3.34 \pm 0, u 3=0.05 \pm 0.11, u 4(\text { cte. })=0 \\
m B=(B V+V)+b 1+b 2 \cdot X B+b 3 \cdot B V+b 4 \cdot B V \cdot X B \\
b 1=2.38 \pm 48.57, b 2=2.46 \pm 42.13, b 3=-0.03 \pm 0.05, b 4(\text { cte. })=0 \\
m V=V+v 1+v 2 \cdot X V+v 3 \cdot B V+v 4 \cdot B V \cdot X V \\
v 1=2.19 \pm 0.02, v 2=2.06 \pm 0, v 3=-0.02 \pm 0.03, v 4(\text { cte. })=0 \\
m R=(V-V R)+r 1+r 2 \cdot X R+r 3 \cdot V R+r 4 \cdot V R \cdot X R \\
r 1=2.14 \pm 6.80, r 2=1.93 \pm 5.88, r 3=-0.02 \pm 0.02, r 4(\text { cte. })=0
\end{gathered}
$$

Donde $m U, m B, m V, m R$ son las magnitudes instrumentales; $U B, B V, V R$ los índices de color; $V$ la magnitud visual, $X U, X B, X V, X R$ las masas de aire, $u 1, b 1, v 1, r 1$ las constantes 
de punto cero; u2, b2, v2, r2 los coeficientes de extinción; u3, b3, v3, r3 los coeficientes del término de color de cada filtro, respectivamente.

v) Finalmente, se empleó la tarea INVERTFIT para aplicar las ecuaciones de transformación al archivo que poseía las magnitudes instrumentales de las estrellas del campo en estudio, que debían ser corregidas.

Los resultados de nuestra fotometría se organizaron en una tabla en cuyas columnas se indican el número de identificación que la fotometría le asignó a cada estrella, sus coordenadas Xcentral e Ycentral, la magnitud V, los colores (B - V) y (U - B) y en la última columna el valor del parámetro fotométrico libre de extinción, Q (ecuación 40). El rango de valores de $\mathrm{Q}$ que las estrellas de la tabla poseen es $-1.5<\mathrm{Q}<2$. En esta tabla se muestran únicamente las estrellas con magnitud visual, $\mathrm{V}<17$, las mismas suman un total de 765 estrellas. Las estrellas con $\mathrm{V} \geq 17$ no fueron consideradas porque sus colores (U - B) se obtuvieron con errores demasiado grandes. Debido a que la tabla a la que aquí se hace referencia es muy extensa, no será puesta en la versión en papel de esta Tesis, sólo estará en la versión digital que quedará en la Biblioteca de esta Facultad.

En la Tabla 6 se comparan los tipos espectrales, magnitud visual, colores y módulo de distancia que fueron obtenidos para las estrellas del catálogo LS, probables miembros de Bo 7, empleando Vogt \& Moffat (1972) fotometría fotoeléctrica y nosotros fotometría digital.

\section{Comparación de los resultados fotométricos con la fotometría de Sung et al.} (1999)

Comparamos nuestros resultados fotométricos con los obtenidos por Sung et al. (1999). Ellos obtuvieron imágenes fotométricas CCD UBVI para la región centrada en $\alpha=8^{h} 44^{m} 47.2^{s}$, $\delta=-45^{\circ} 58.9$ (J2000.0), en parte coincidente con la presente fotometría, usando el telescopio de 1-m (f/8) del Obervatorio Siding Spring (New South Wales, Australia). Sung et al. analizaron sus imágenes empleando fotometría PSF por lo cual la comparación de nuestra fotometría con la realizada por ellos, fue considerada como un procedimiento para evaluar la confiabilidad de nuestros resultados. Para hacer la comparación, primero obtuvimos la calibración astrométrica para todas nuestras estrellas, identificando estrellas en nuestra imagen con astrometría del USNO y derivando la solución astrométrica, empleando para ello la tarea ASTROM dentro del software STARLINK. Luego tuvimos que referir sus coordenadas 
Tabla 6: Resultados obtenidos para las estrellas del catálogo LS, probables miembros de Bo 7, de la fotometría fotoeléctrica realizada por Vogt \& Moffat (1972) y la fotometría digital realizada por nosotros.

\begin{tabular}{|c|c|c|c|c|c|c|c|c|c|c|}
\hline & \multicolumn{5}{|c|}{ Vogt \& Moffat } & \multicolumn{5}{|c|}{ Nuestros datos } \\
\hline $\mathrm{LS}$ & $\mathrm{TE}$ & $\mathrm{V}$ & B-V & U-B & $\mathrm{V}_{o}-\mathrm{M}_{v}$ & $\mathrm{TE}$ & $\mathrm{V}$ & B-V & U-B & $\mathrm{V}_{o}-\mathrm{M}_{v}$ \\
\hline 1131 & $\mathrm{OB}^{+}$ & 10.80 & 0.51 & -0.55 & 14.0 & $\mathrm{O} 7.5 \mathrm{~V}$ & 10.80 & 0.46 & -0.50 & 13.30 \\
\hline 1132 & OB & 10.05 & 0.37 & -0.46 & 12.9 & B2IV & 10.10 & 0.30 & -0.41 & 11.43 \\
\hline 1135 & $\mathrm{OB}^{+}$ & 10.88 & 0.40 & -0.68 & 14.5 & $\mathrm{O} 6.5 \mathrm{~V}((\mathrm{f}))$ & 10.90 & 0.34 & -0.61 & 14.13 \\
\hline 1137 & $\mathrm{OB}^{-}$ & 11.38 & 0.49 & -0.56 & 13.7 & O9-9.5V & 11.40 & 0.45 & -0.49 & 13.37 \\
\hline 1140 & $\mathrm{OB}^{+}$ & 11.65 & 0.76 & -0.35 & 14.1 & B0III & 11.70 & 0.68 & -0.33 & 13.66 \\
\hline 1144 & OB & 11.27 & 0.64 & -0.46 & 13.1 & $\mathrm{O} 7.5 \mathrm{~V}$ & 11.33 & 0.61 & -0.44 & 13.29 \\
\hline 1145 & WN8 & 10.78 & 0.56 & -0.39 & - & - & 10.82 & 0.51 & -0.36 & - \\
\hline 1146 & OB & 11.57 & 0.50 & -0.52 & 13.9 & B1III & 11.59 & 0.47 & -0.48 & 13.62 \\
\hline 1147 & $\mathrm{OB}^{+}$ & 11.53 & 0.58 & -0.54 & 14.6 & B0IIIe & 11.47 & 0.55 & -0.47 & 12.92 \\
\hline
\end{tabular}

ecuatoriales celestes a las correspondientes a la Wolf Rayet WR12 que Sung et al. (1999) usaron como referencia para centrar la imagen fotométrica. Para ello empleamos la ecuación 30 en la cual ambos valores de ascensión recta se introducen en horas y la declinación en grados. El resultado final es la diferencia en ascensión recta entre la estrella en estudio y WR12, dado en minutos de arco.

$$
\Delta \alpha_{s t a r}=\left(\alpha_{W R}-\alpha_{s t a r}\right) 15 \cos \left(\delta \frac{\pi}{180^{\circ}}\right) 60
$$

A la declinación de la estrella también la indicamos respecto de la declinación de WR12, obteniendo con ello un valor $\Delta \delta$ en minutos de arco, ecuación 31.

$$
\Delta \delta_{s t a r}=\left(\delta_{W R}-\delta s t a r\right) 60
$$

Luego correlacionamos la tabla de nuestra salida fotométrica con la tabla de Sung et al., relacionando a las estrellas por sus coordenadas celestes. Restringimos la diferencia en ascensión recta y en declinación a que fuera menor a dos segundos de $\operatorname{arco}, \Delta \alpha<2$ " $\mathrm{y}$ $\Delta \delta<2$ " (menor que ese valor no se puede pedir porque el RMS de la astrometría no lo es). De este modo encontramos aprox. 1100 estrellas en común, de las 2000 estrellas identificadas en nuestra fotometría. Entre las estrellas coincidentes entre ambas fotometrías, habia más de 300 con magnitudes más brillantes que 15 en la banda V. La comparación entre ambas 
fotometrías puede verse en la Figura 9, en ella se ven las diferencias en magnitud visual y colores $(\mathrm{B}-\mathrm{V})$ y $(\mathrm{U}-\mathrm{B})$ que se presentan para las estrellas con un valor de $10<\mathrm{V}<16$. Es posible detectar en estas estrellas una diferencia sistemática en la magnitud visual entre ambas fotometrías de $\Delta V=0.04$ magnitudes.

En los histogramas de la Figura 10, es posible ver la cantidad de estrellas con diferencias en $|\Delta V|<0.4$ magnitudes, $|\Delta B|<0.4$ magnitudes y $|\Delta U|<0.8$ magnitudes, resultantes de la comparación realizada entre ambas fotometrías. Para este caso empleamos un grupo de estrellas más amplio, ya que obtuvimos los histogramas con las estrellas que cumplen tener $8<\mathrm{V} \leq 17$. La desviación estándar, $\sigma$, resultante del cálculo del promedio en las diferencias entre las magnitudes de ambas fotometrías fue, $\sigma_{V}=0.08, \sigma_{B}=0.10 \mathrm{y} \sigma_{U}=0.18$. Estos valores se han tomado como referencia para estimar un límite superior para las incertezas resultantes en la determinación de nuestras magnitudes estelares.

Después de realizar esta comparación entre ambas fotometrías seleccionamos más de 100 estrellas más brillantes que $\mathrm{V}=15$ cuyos colores fueran compatibles con estrellas de tipo espectral temprano. La selección se realizó con el objetivo de acudir a turnos de observación y obtener las imágenes espectrales de cada una que nos permitieran confirmar su tipo espectral. Se descartaron las estrellas con $\mathrm{V}>15$ porque los espectros que se obtuvieran de ellas, empleando la configuración instrumental que se detalla en la sección 5.2, tendrían una relación señal ruido demasiado baja para ser analizados correctamente.

La selección de la cual hablamos en el párrafo anterior fue hecha usando el parámetro libre de enrojecimiento "Q" (subsección 5.2.4), siendo las estrellas con $Q<-0.3$ las candidatas a tener tipos espectrales $\mathrm{O}$ y $\mathrm{B}$. Optar por valores de $\mathrm{Q}<-0.5$ hubiera asegurado que, considerando incluso los errores fotométricos, estuvieramos tomando el valor $\mathrm{Q}$ de una estrella temprana OB. Debido a lo reducida que quedaba la muestra si sólo nos quedabamos con estrellas que cumplieran tener un $\mathrm{Q}<-0.5$ y una $\mathrm{V}<15$ nos arriesgamos a considerar también los valores de $-0.5<\mathrm{Q}<-0.3$, sabiendo que con ello corriamos el riesgo de incluir en la muestra de estrellas aquellas cuyos tipos espectrales no fueran los buscados. El conocimiento del parámetro Q se convirtió, junto al criterio tomado respecto de la magnitud visual $\mathrm{V}$, en los métodos empleados para seleccionar al grupo de estrellas cuyos correspondientes espectros se obtuvieron en los turnos de observación en el CASLEO, descriptos en la sección 5.2 . 


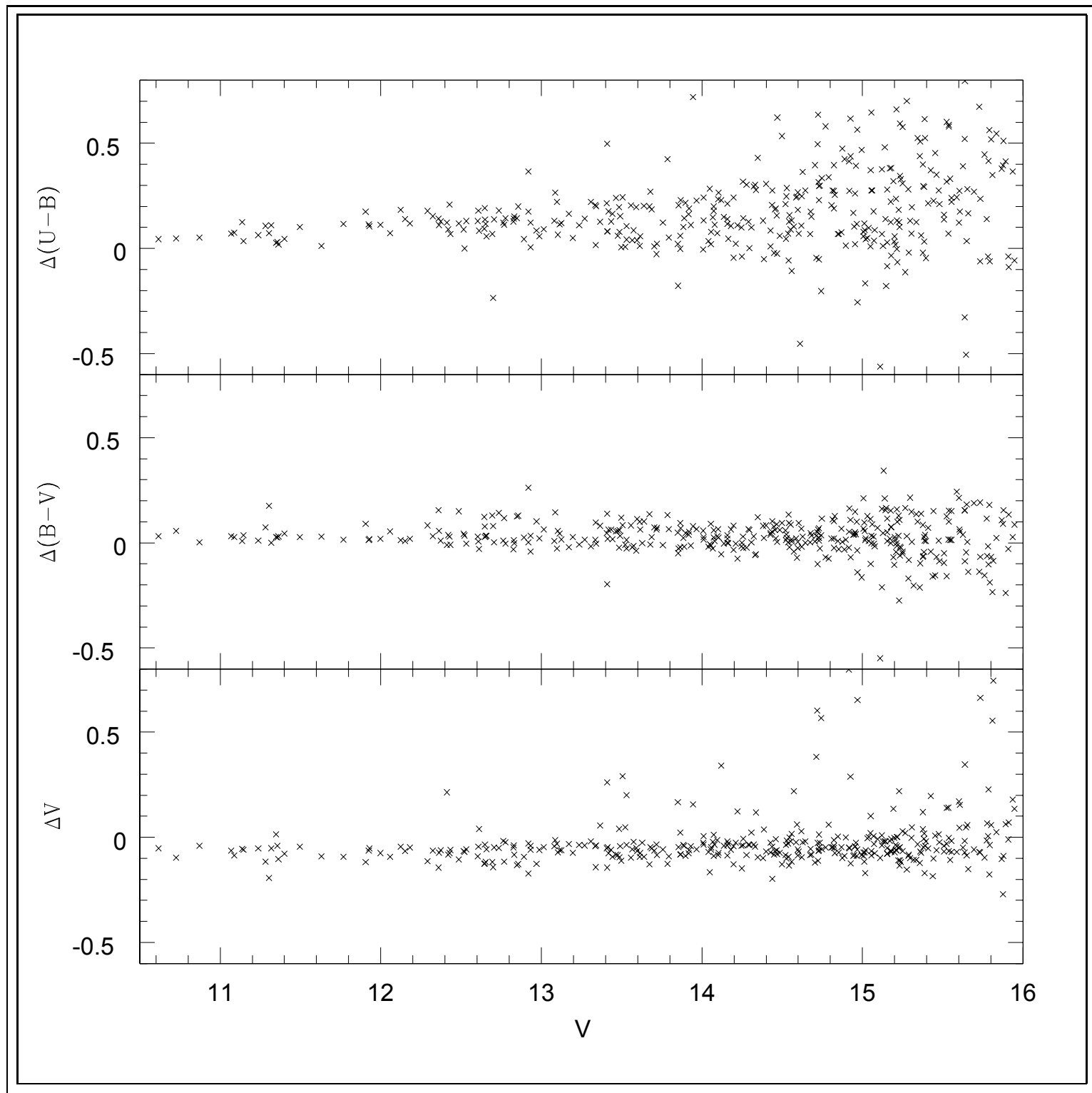

Figura 9: Diferencias entre nuestra fotometría y la de Sung et al. (1999), empleando una muestra de 556 estrellas con magnitud visual $10<V<16$ mag. 


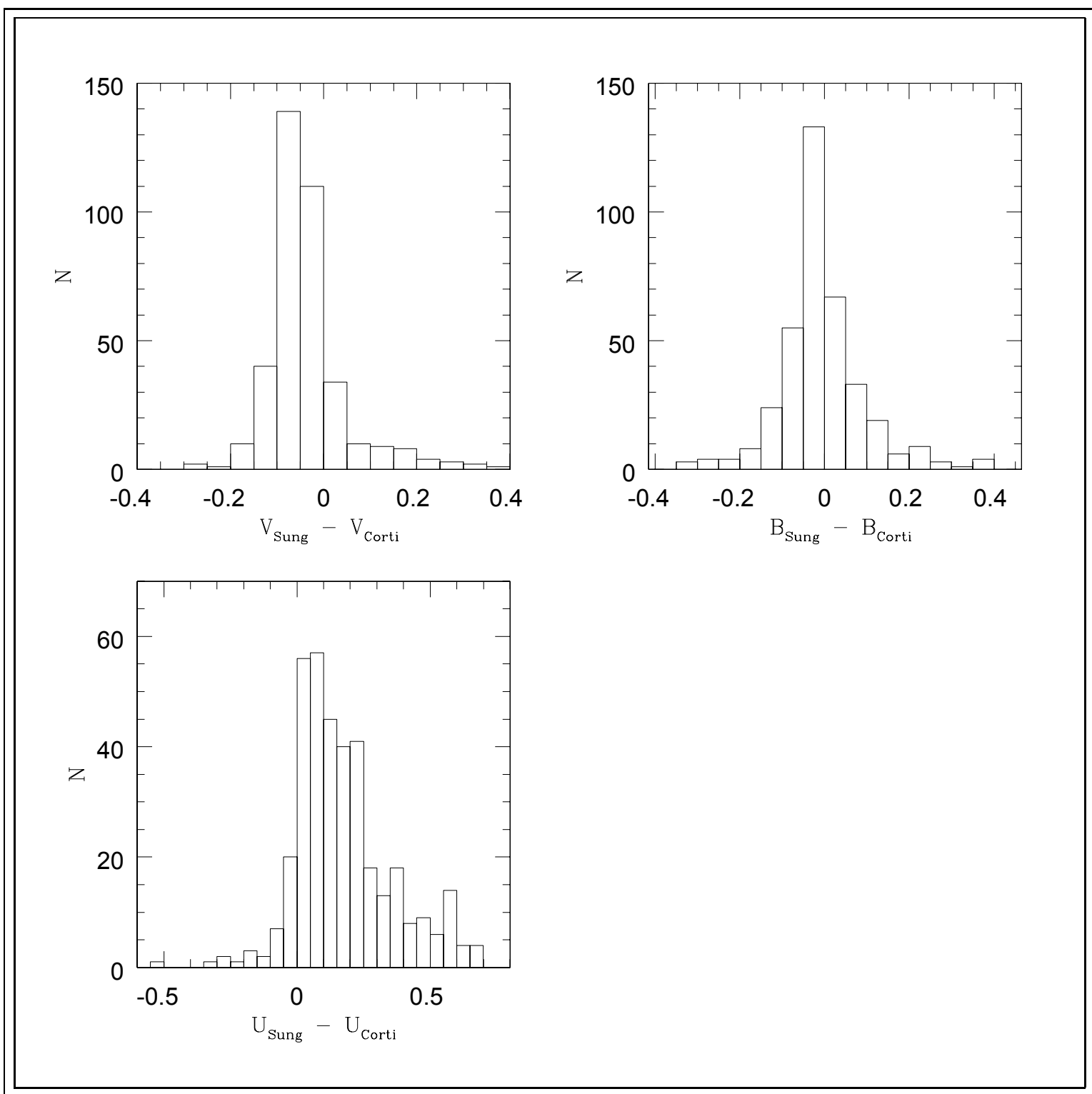

Figura 10: Número de estrellas en una muestra de 848 con diferencia en las magnitudes $V, B$ y $U$ resultantes de la comparación de nuestra fotometría con la de Sung et al. (1999) 


\subsubsection{Distancia a las estrellas OB en la línea de la visual}

Una vez que los tipos espectrales han sido estimados, se calculan las distancias en el modo usual, empleando la ecuación 5 de la subsección 4.1. El valor de $\mathrm{M}_{v}$ fue estimado del tipo espectral de las estrellas y la absorción en el visual, $\mathrm{A}_{v}$, se calculó directamente de sus colores intrínsecos de dos maneras diferentes.

Una de ellas usando solamente nuestros datos de los filtros B y V:

$$
A_{v}=3.26 \cdot E(B-V)
$$

Calculando el valor de R para cada estrella con el empleo de la segunda parte de la ecuación 11, es posible encontrar un R para el grupo de estrellas en estudio obteniendo el promedio de ellos con la desviación estándard, $\sigma$, del promedio como su error. Con el empleo de las 63 estrellas con tipos espectrales $\mathrm{O}$ y B que analizamos en este trabajo calculamos un valor promedio de $\mathrm{R}=3.26$ con $\sigma=0.01$, el cual sólo resulta ser un valor representativo, correspondiente al color promedio de la muestra. El valor del parámetro $\mathrm{R}$ generalmente usado en la literatura es $\mathrm{R}=3.23$ con $0.1<\sigma<0.2$

El otro modo de calcular $\mathrm{A}_{v}$ fue combinando nuestra fotometría con la fotometría infrarroja del 2MASS y refiriendo todos los resultados al sistema fotométrico de Koornneef (1983), de ahora en más K83:

$$
A_{v}=1.107 \cdot E(V-K)
$$

La muestra que combina información óptica e IR es algo reducida debido a que en K83 no hay información sobre los colores intrínsecos para las estrellas OB gigantes. Pudimos entonces estimar el valor del $\mathrm{E}(\mathrm{V}$ - K) sólo en 47 estrellas. Las distancias calculadas usando las extinciones de las ecuaciones 32 y 33 muestran una diferencia incrementada con el crecimiento de la distancia, como puede verse en la Figura 11, donde las distancias y las diferencias entre ellas están en kpc. Las distancias tienen inherentemente errores grandes. Nuestros errores son del orden de $\simeq 1 \mathrm{kpc}$ y $0.5 \mathrm{kpc}$ a d $\simeq 6 \mathrm{kpc}$, calculada con $\mathrm{E}(\mathrm{B}-\mathrm{V})$ y $\mathrm{E}(\mathrm{V}-\mathrm{K})$, respectivamente. Viendo que algunas de las estrellas de la Figura 11 presentan una diferencia muy grande entre sus distancias calculadas con los $\mathrm{E}(\mathrm{B}-\mathrm{V})$ y $\mathrm{E}(\mathrm{V}-\mathrm{K})$, recurrimos a los resultados de la fotometría de Sung et al. En ella encontramos que sólo hay dos estrellas en común con nuestro grupo de estrellas con grandes valores de $\operatorname{Dist}_{(B-V)}{ }^{-}$ $\operatorname{Dist}_{(V-K)}$. Para ambas sus colores $(\mathrm{B}-\mathrm{V})$ sólo son levemente diferentes a los nuestros, con 
Tabla 7: Estrellas en las que no se cumple la ley de extinción interestelar

\begin{tabular}{|clrl|}
\hline \hline$I D$ & $T E$ & $\begin{array}{r}D_{(B-V)} \\
\mathrm{kpc}\end{array}$ & $E(V-K) / E(B-V)$ \\
\hline $8 N .$. & & 2.5 & 2.5 \\
$84437.8-455257$ & $\mathrm{~B} 8-\mathrm{A} 0 \mathrm{~V}$ & 2.4 & 2.6 \\
$84418.2-455307$ & $\mathrm{~B} 1 \mathrm{~V}$ & 10.5 & 3.3 \\
$84346.7-460641$ & $\mathrm{~B} 1-5 \mathrm{~V}$ & 8.0 & 3.5 \\
$84442.0-460802$ & $\mathrm{~B} 2 \mathrm{~V}$ & 6.6 & 3.6 \\
$84325.6-460820$ & $\mathrm{~B} 2 \mathrm{Ve}$ & 9.6 & 3.6 \\
$84421.9-461025$ & $\mathrm{~B} 1 \mathrm{~V}$ & 12.7 & 4.0 \\
\hline \hline
\end{tabular}

lo cual la diferencia mencionada sigue siendo grande. Nos preguntamos si en las estrellas empleadas en la Figura 11 se cumplia la ley de extinción interestelar. Buscando una respuesta a nuestra pregunta realizamos el gráfico de la Figura 12, en el cual se presenta el cociente $\mathrm{E}(\mathrm{V}-\mathrm{K}) / \mathrm{E}(\mathrm{B}-\mathrm{V})$ cuyo resultado debería ser 2.94 (indicado en el gráfico con una línea horizontal), en caso de cumplirse la ley de extinción interestelar y el mismo no debería variar con la distancia al observador a la que se encuentra la estrella. El resultado obtenido fue que dicha ley de extinción no se cumple para las mismas estrellas cuya diferencia $\operatorname{Dist}_{(B-V)}$ - $\operatorname{Dist}_{(V-K)}$ es inusual. Las estrellas con excesos discrepantes son las que se presentan en la Tabla 7 .

Con las 47 estrellas con $\mathrm{E}(\mathrm{V}$ - K) (donde están incluidas las 4 estrellas del catálogo LS, 1135, 1131, 1144, 1137) el valor de distancia media es 4.4 kpc y 4.2 kpc con E(B - V) y $\mathrm{E}(\mathrm{V}-\mathrm{K})$, respectivamente. Las distancias derivadas para las 63 estrellas están en la Tabla 28

Con el fin de verificar que los tipos espectrales obtenidos con el empleo del diagrama color-color coinciden con aquellos que pueden conocerse del estudio de sus espectros, en la Figura 13 se muestra una comparación entre las distancias estimadas empleando las ecuaciones 5 y 32, a las estrellas OB identificadas espectroscópicamente y las mismas estrellas OB identificadas con el diagrama color-color. El eje horizontal muestra las distancias usando $\mathrm{M}_{v}$ y $(\mathrm{B}-\mathrm{V})$ 。 obtenidos de los tipos espectrales espectroscópicos. El eje vertical muestra las distancias usando $\mathrm{M}_{v}$ y $(\mathrm{B}-\mathrm{V})$ 。 obtenidos del diagrama color-color de la Figura 36 y ecuación 44. En la Figura 13 puede verse que hasta una distancia de $\sim 10 \mathrm{kpc}$ el uso del diagra- 


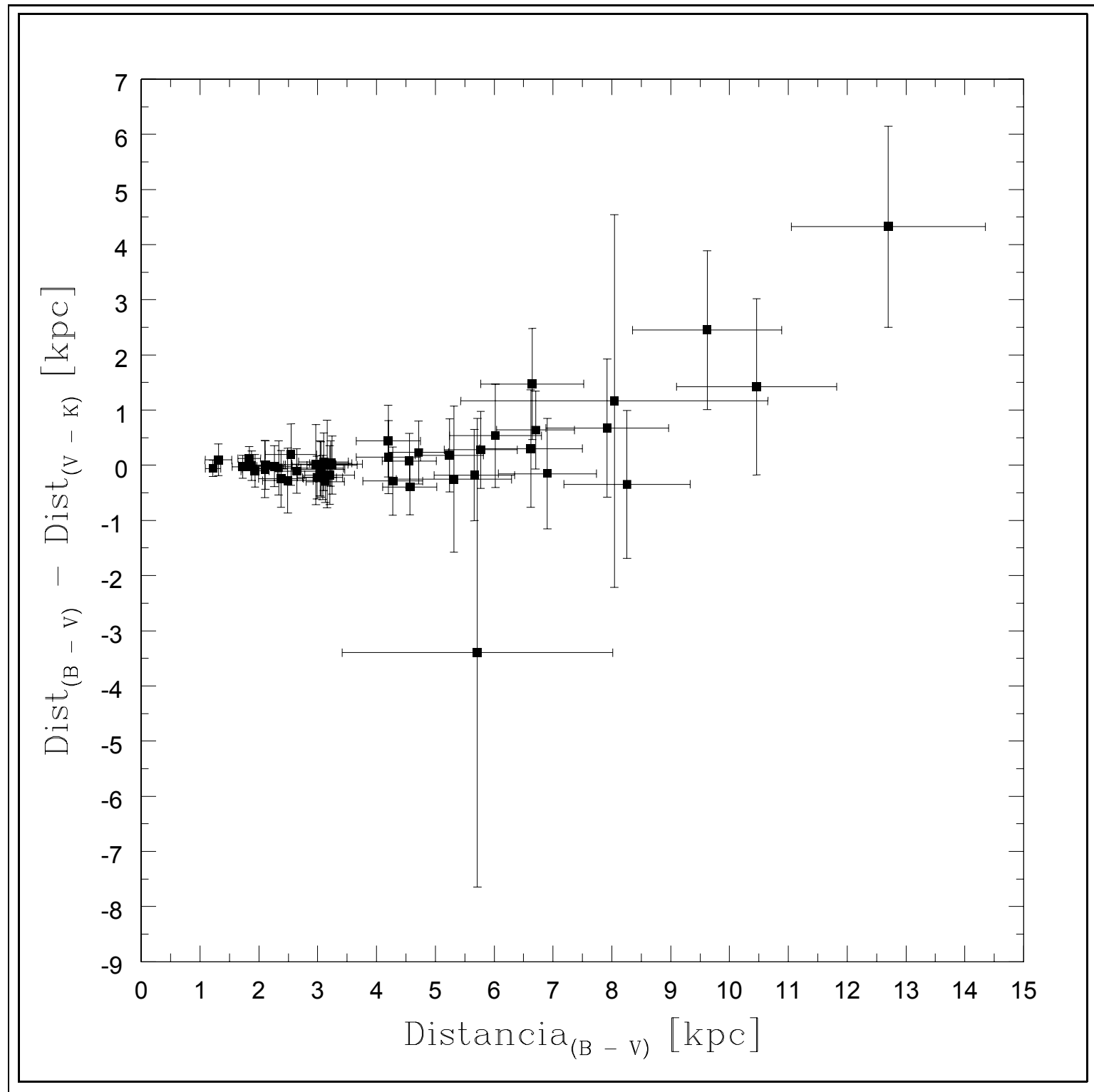

Figura 11: Diferencias entre distancias calculadas con los excesos $E(B-V)$ y $E(V$ $K)$, a las estrellas $O B$ con tipos espectrales determinados espectroscópicamente. 


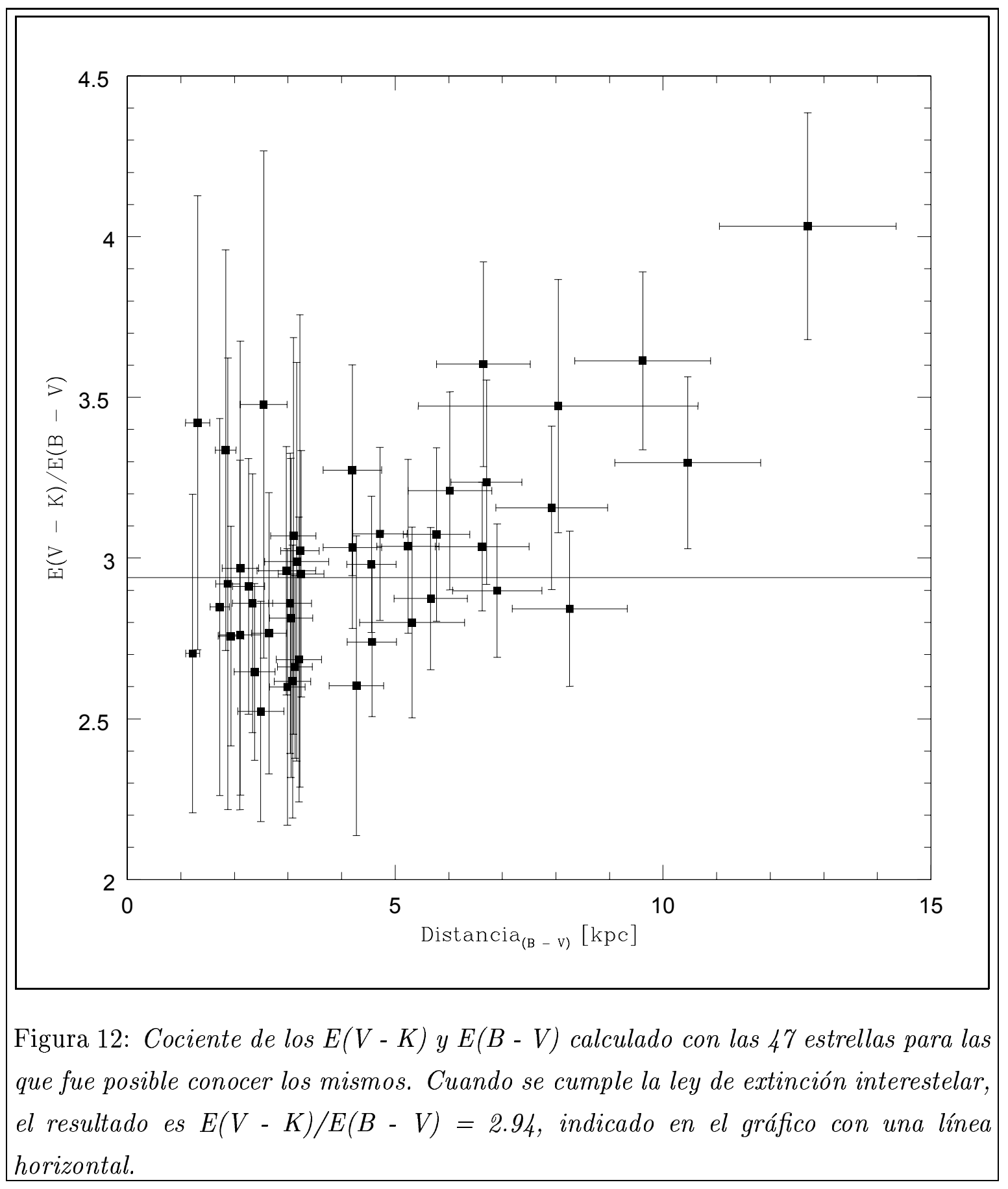

Estudio de una Asociación $O B$ distante en la Vía Láctea 
ma color-color para determinar tipos espectrales es bastante bueno, indicando que la calidad de los colores observados no se ve afectada por la distancia a la que se encuentran las mismas.

El problema de usar el diagrama color-color para estrellas de tipo espectral B tardío enrojecidas es la posibilidad de confundirlas con estrellas de tipo $\sim$ F0 a $\sim$ G2 sin enrojecer. Esto puede deberse principalmente a dos factores: uno de ellos es partir de la ley de extinción supuesta (ecuación 44), en la cual se puede estar empleando una pendiente que no resulte apropiada para la estrella en estudio. El otro factor pueden ser los errores relativamente grandes que posiblemente se cometan en los colores (U - B) y (B - V). No hay nada que nosotros podamos hacer sobre este problema aunque esperamos que esté restringido a no más del $30 \%$ de las estrellas. El efecto de los errores en los colores, en torno a los tipos espectrales F y G puede ser minimizado descartando las estrellas que yacen demasiado cerca de la curva no enrojecida, quedando así un límite inferior de estrellas OB. Fue así que descartamos las estrellas que quedaban dentro de la franja con $0.3<(\mathrm{B}-\mathrm{V})<0.7$ y $(\mathrm{U}-\mathrm{B}) \simeq 0 \pm 5 \sigma$, siendo $\sigma$ el error fotométrico estadístico $=\left(2 \times(0.01)^{2}\right)^{(1 / 2)} \simeq 0.014$ magnitudes, encontrado realizando la fotometría de abertura en el modo estándar. Trabajando como describimos, descartamos del orden de 50 estrellas del total de $\sim 300$ O y B encontradas inicialmente.

De este modo en un campo de 30 x 30 minutos de arco centrado en la región en estudio, identificamos espectroscópicamente 63 estrellas $\mathrm{O}$ y B y fotométricamente empleando el diagrama color-color 255 estrellas $\mathrm{O}$ y B, las cuales serán usadas en el siguiente análisis. Se debe recordar que la muestra espectroscópica es mucho más confiable que aquella puramente fotométrica. Aún así para fines estadísticos, la muestra puramente fotométrica es significativa, compensando ampliamente las incertezas relativas introducidas.

Para conocer cómo afecta al resultado de la distancia el error que posee cada parámetro, reemplazamos en las ecuaciones 7,8 y 9 por los valores correspondientes obtenidos de la fotometría, explicados en detalle en la subsección 5.1. Siendo $\delta \mathrm{B}=0.1$ y $\delta \mathrm{V}=0.08$, resulta $\delta(B-V)=0.13$, el cual es el error en el exceso de color, $\mathrm{E}(\mathrm{B}-\mathrm{V})$. De este modo, el error en $\mathrm{Av}$ es $\delta \mathrm{Av}=3.26 \cdot 0.13=0.42$. De modo tal que finalmente el error en la distancia es:

$$
\delta d=(d / 5) \cdot \ln (10) \cdot \sqrt{(0.08)^{2}+\left(\delta M_{v}\right)^{2}+(0.42)^{2}}
$$

Cuando el tipo espectral asignado a la estrella no es el correcto, la equivocación queda manifiesta en el valor de magnitud absoluta visual escogida para la misma. En este caso esta magnitud se obtiene como: 


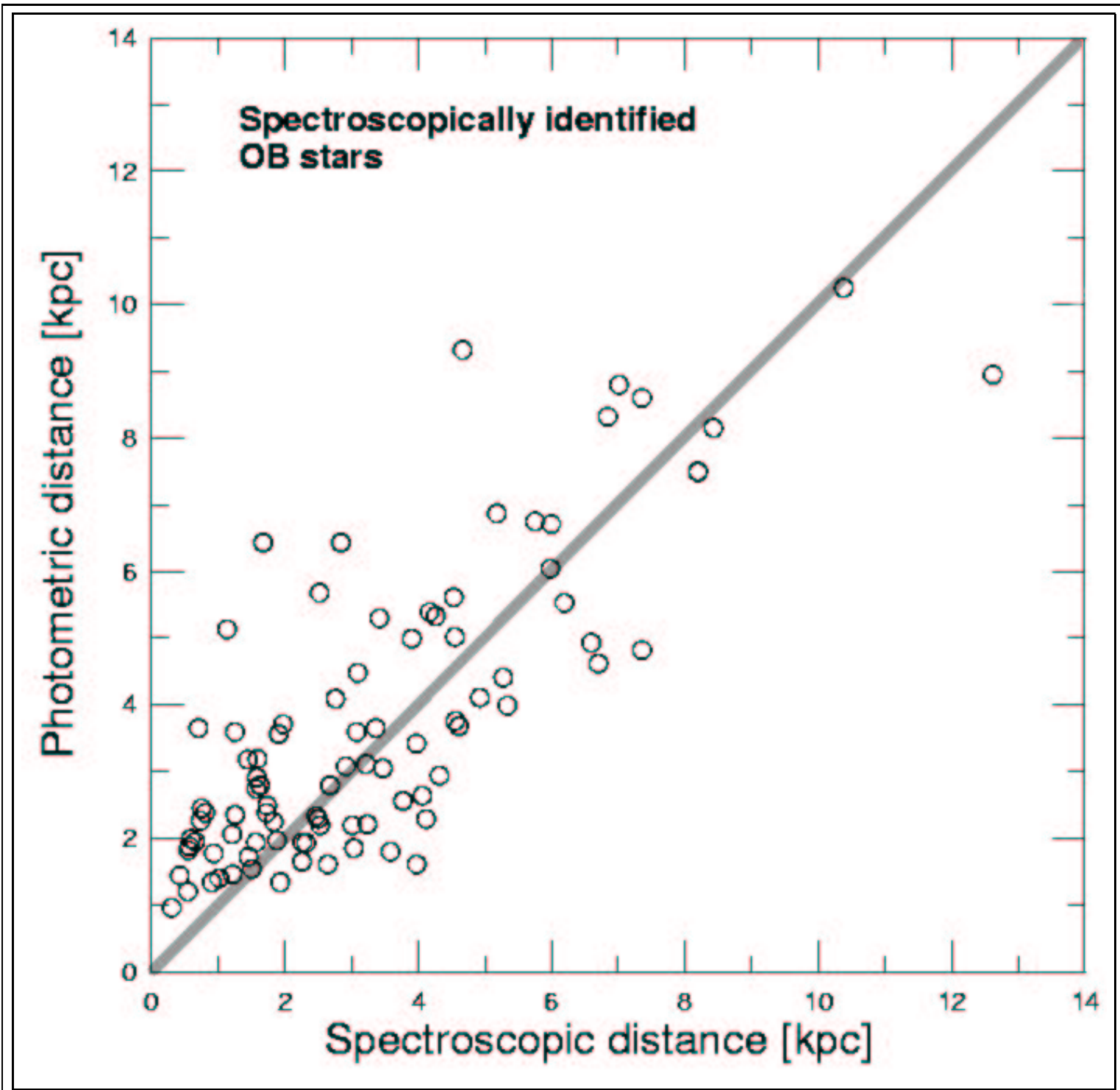

Figura 13: Estrellas OB identificadas espectroscópicamente. Comparación entre distancias calculadas conociendo los tipos espectrales del análisis de los espectros y con los tipos espectrales estimados con el empleo del diagrama color-color. 


$$
\bar{M}=\frac{M_{(a)}+M_{(b)}}{2}
$$

siendo $\mathrm{M}_{(a)}$ y $\mathrm{M}_{(b)}$ la magnitud absoluta visual correspondiente a cada tipo espectral entre los que se supone está el verdadero de la estrella. El error cometido en este caso es $\delta M_{v}$ y se obtiene empleando la ecuación 36 :

$$
\delta M_{v}=\frac{\left|\frac{\left(M_{(a-1)}+M_{(a)}\right)}{2}-\frac{\left(M_{(b)}+M_{(b+1)}\right)}{2}\right|}{2}
$$

En la ecuación 34 resulta evidente que el mayor error fotométrico que incrementa la magnitud del error en la distancia es el correspondiente al color (B - V). La espectroscopía influye en el error de la distancia cuando se asigna a la estrella un tipo espectral equivocado $\left(\delta M_{v}\right)$, la magnitud de este error variará según sea el tipo espectral con el que se clasifique equivocadamente a la estrella.

Lo mencionado previamente vincula al error de la distancia directamente con el valor de la misma.

Como se muestra en esta sección, el exceso de color, E(B - V), participa en el cálculo de la distancia a la que se encuentra la estrella y lo hace a través de la ecuación 32. En principio otro camino para estimar la magnitud de este enrojecimiento, se presenta mediante el análisis de la DIB $4428 \AA$ en las imágenes espectrales de cada estrella. Este tema está ampliado en la subsección 5.2.3. 


\subsection{Espectroscopía}

Los espectrógrafos astronómicos son instrumentos con los que se puede analizar la luz que nos llega de los cuerpos celestes, descomponiéndola mediante elementos dispersores (prismas o redes) y obteniendo su espectro, donde queda registrada la intensidad de la radiación en función de la longitud de onda.

El material observacional espectroscópico empleado en este trabajo consistió en espectros fotográficos y digitales.

Las imágenes espectrales digitales fueron obtenidas en el Complejo Astronómico El Leoncito (CASLEO), San Juan, empleando las Configuraciones Instrumentales (CI) que se detallan en los párrafos siguientes.

CI I: Espectrógrafo B \& C anexado al telescopio de 2.15m "Jorge Sahade". Detector CCD PM $512 \times 512$ px, cada uno de ellos de $20 \mu$ Se usó la red nro. 260 de $600 \mathrm{l} \mathrm{mm}^{-1}$ resultando en una dispersión recíproca de $115 \AA \mathrm{mm}^{-1}$ y un ancho de ranura que osciló entre $200 \mu$ y $300 \mu$. La misma se ubicó con un ángulo aproximado de $7^{\circ} 20^{\prime}$. Se empleó el decker nro. 8, con el cual se restringe la entrada de luz de cielo en la ranura consiguiendo de ese modo que la imagen obtenida sea principalmente estelar. El rango espectral de los espectros obtenidos en los diferentes turnos de observación fué $\lambda \lambda 3800-5000 \AA$ y la relación señal a ruido $120<\mathrm{S} / \mathrm{N}<200$.

CI II: Espectrógrafo Reosc Cassegrain en modo dispersión simple (DS) anexado al telescopio de 2.15m "Jorge Sahade". Detector CCD TK 1K de 1024×1024 px, cada uno de ellos de $24 \mu$. Se usó la red nro. 260 de $6001 \mathrm{~mm}^{-1}$ resultando en una dispersión recíproca de $1.64 \AA \mathrm{px}^{-1}$ y un ancho de ranura que osciló entre $200 \mu$ y $300 \mu$. La misma se ubicó con un ángulo cuyo valor osciló entre $7^{\circ} 50^{\prime}$ y $8^{\circ} 15^{\prime}$. Se emplearon los deckers nro.1 y nro.11, con el decker 11 la ranura queda totalmente descubierta y permite que en ella se observen más de una estrella aunque éstas esten algo separadas, con el decker 1 se puede limitar el alto de la ranura. Con este espectrógrafo en los diferentes turnos en que fue empleado se obtuvieron espectros de ranura larga, con un rango espectral de $\lambda \lambda$ 3700-5200 A y una relación señal ruido $150<\mathrm{S} / \mathrm{N}<200$

CI III: Espectrógrafo Reosc Cassegrain en modo dispersión cruzada (DC) anexado al telescopio de 2.15m "Jorge Sahade". Detector CCD TK 1K de 1024×1024 px, cada uno de 
ellos de $24 \mu$. Se usó la red nro. 580 de $4001 \mathrm{~mm}^{-1}$ resultando en una dispersión recíproca de $7 \AA \mathrm{mm}^{-1}$ y un ancho de ranura que osciló entre $250 \mu$ y $400 \mu$. La misma se ubicó con un ángulo cuyo valor osciló entre $6^{\circ} 2^{\prime}$ y $7^{\circ} 15^{\prime}$. Se empleó el decker nro.8. el cual al restringir la entrada de luz de cielo posibilita que los ordenes del espectro se separen completamente, evitando superposición de los mismos en sus bordes. El rango espectral de los espectros echelle obtenidos en los diferentes turnos de observación fué $\lambda \lambda$ 3700-6000 y la relación señal a ruido $20<\mathrm{S} / \mathrm{N}<50$

$\mathrm{Al}$ procesamiento de los datos lo llevamos a cabo utilizando el software IRAF, disponible en la Facultad de Ciencias Astronómicas y Geofísicas de la UNLP. Dicho proceso tiene como objetivo obtener un espectro estelar con una calibración en longitud de onda muy confiable y con el menor ruido posible, (esto es con la mayor relación señal ruido posible), para determinar buenas posiciones de líneas espectrales.

Los espectros fotográficos fueron obtenidos por la Dra. Virpi Niemela en varios turnos de observación que ocuparon el período 1982 - 1985. Son espectros de las estrellas 1131,

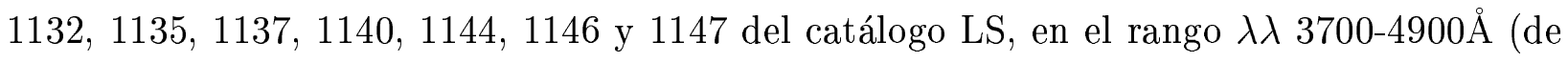
aquí en más espectros de placas azules) y una relación señal a ruido $30<(\mathrm{S} / \mathrm{N})<60$.

Estos espectros tienen 1mm de ancho y se registraron sobre placas Kodak IIIa-J horneadas y sensibilizadas. Las observaciones fueron realizadas en el Observatorio Interamericano de Cerro Tololo (Chile)(CTIO), con el telescopio Yale de 1m y el espectrógrafo Carnegie con tubo intensificador de imágenes. Se utilizó una red de difracción que produce una dispersión recíproca de $45 \AA \mathrm{mm}^{-1}$ en el azul. Hay que tener en cuenta que la distorsión producida por el tubo de imágenes y la caída de sensibilidad de la placa se acentúa hacia los bordes de la misma, resultando poco confiables los valores de velocidad radial para líneas que se encuentran por debajo de $3850 \AA$ y por encima de $4850 \AA$ en las placas azules. Cada espectro estelar está acompañado de espectros de comparación de He-Ar.

Todos los espectrogramas fueron digitalizados con el microdensitómetro Grant en el Observatorio de La Plata, conectado a una PC286 utilizando un soft que permite la obtención del archivo digital en formato FITS, donde se guardan además los datos del momento de observación y las coordenadas de las estrellas. Los espectros fueron calibrados en densidad de placa. 
Para registrar los espectros usamos una velocidad de desplazamiento de carro del microdensitómetro de $4 \mathrm{~mm} / \mathrm{min}$. y un muestreo de un punto cada 8 micrones en la placa. Se digitalizaron separadamente los espectros estelares y de comparación correspondientes.

Empleando las rutinas contenidas en el paquete Onedspec, dentro de IRAF, realizamos la calibración en longitud de onda de los espectros digitalizados.

\subsubsection{Trabajo de Clasificación Espectral}

Las imágenes espectrales obtenidas en los turnos de observación descriptos en la sección 5.2 , han sido clasificadas según los criterios empleados en el "Contemporary optical spectral classification of the OB stars - A digital atlas" (Walborn N. \& Fitzpatrick E., 1990). Por medio de esto descubrimos 63 estrellas de $\mathrm{TE}=\mathrm{O}$ y B entre las 102 estrellas que fueron posibles observar, de las 137 seleccionadas en un principio, por cumplir la condición de tener un valor del parámetro $Q$ propio al correspondiente a las estrellas tempranas y una magnitud visual $\mathrm{V} \leq 15$. Las 39 estrellas restantes que no son del tipo espectral OB de las 102 observadas, fueron clasificadas espectralmente de acuerdo a los criterios empleados para tal fin por Jaschek C. \& Jaschek M. (1990), usados para encontrar la clasificación espectral de estrellas con TE de A a G y distintas clases de luminosidad. El trabajo de clasificación espectral realizado a estas 39 estrellas se comenta en el Apéndice, subsección 9.2.

Teniendo en cuenta que el Atlas de estándares de Clasificación espectral OB de Walborn \& Fitzpatrick (1990) contiene espectros estelares obtenidos con una configuración isntrumental algo diferente a la que se empleó para obtener los espectros de esta Tesis, la cual podría afectar la determinación de los TE, obtuvimos los espectros de todas las estándares de clasificación espectral OB del Atlas que se menciona, con la misma configuración isntrumental que la utilizada para clasificar los espectros de las estrellas en este estudio. Por esta razón, elaboramos un Atlas CCD de estándares de clasificación espectral OB observadas con Reosc DS en el CASLEO. El mismo se detalla en el Apéndice de esta Tesis, subsección 9.1.

El criterio de clasificación para las estrellas de tipo espectral $\mathrm{O}$ dado en términos de las intensidades de las líneas, como así también por la presencia o no de las mismas es: HeII $\lambda 4541 / \mathrm{HeI} \lambda 4471$ y HeII $\lambda 4200 / \mathrm{HeI}(+\mathrm{II}) \lambda 4026$. El tipo espectral O7 está definido por HeII $\lambda 4541=\mathrm{HeI} \lambda 4471$. Cuando este cociente tiene un valor mayor que uno se trata de un tipo espectral O temprano, O3-O6 y tardío O7-O9 cuando el mismo resulta ser menor que uno. La Figura 17 muestra los espectros de todas las estrellas con TE O del grupo en estudio, 
todas ellas son de clase de luminosidad V.

La Figura 14 muestra la comparación del espectro estelar de CBN84338.5-460817 de tipo espectral 09.5V con el espectro de la estándar de clasificación espectral HD93027 del mismo TE, obtenido en el CASLEO. En ella se muestran los perfiles identificados y los criterios usados para obtener la clasificación espectral correspondiente.

Las estrellas de tipo espectral B no presentan las líneas de HeII. En el tipo espectral B más temprano, el principal criterio de clasificación son las razones SiIII $\lambda 4552 / \operatorname{SiIV} \lambda 4089$ y SiII $\lambda \lambda 4128-30 / \operatorname{SiIII} \lambda 4552$, como es posible ver en los espectros de las Figuras 18 y 19. La estrella CBN84506.3-460906 (LS 1147) es una B0IIIe por la presencia del perfil H $\beta$ de la serie de Balmer en emisión.

En las supergigantes luminosas de los tipos espectrales dentro del grupo de las estrellas con $\mathrm{TE}=\mathrm{B}$, los criterios de luminosidad son la presencia de SiIV $\lambda \lambda 4089,4116$ en absorción y la no presencia de la línea HeII $\lambda 4686$ en absorción.

Las Figuras 15 y 16 muestran el espectro estelar de CBN84509-455530 de TE = B2II con el espectro de la estándar de clasificación espectral HD141318 del mismo TE y la comparación del espectro estelar de CBN84446.2-460433 de TE = B3V con el espectro de la estándar de clasificación espectral $\eta$-Hya del mismo TE, obtenidas todas en el CASLEO. En ellas se muestran los perfiles identificados y los criterios usados para las clasificaciones espectrales correspondientes.

En "An atlas of galactic OB spectra observed with the Far Spectroscopic Explorer" de Pellerin et al. (2002), están las 45 estrellas galácticas OB observadas con el Far Ultra Violet Spectroscopic Explorer. Este Atlas cubre la región en longitud de onda comprendida entre $912 \AA$ y $1185 \AA$ con una resolución espectral efectiva de $0.12 \AA$ La única estrella de la zona de Bochum 7 que se encuentra en este Atlas es HD74920 (LS1148) con A.R. = 8:45:10.5, Decl. = -46:02:19, L.G. = 265.29, Lat.G. $=-1.95, \mathrm{TE}=$ O7IIIn, V = 7.53, E(B $-\mathrm{V})=0.35$. Esta estrella en las imágenes fotométricas conque hemos trabajo tiene coordenadas $\mathrm{X}=314.224, \mathrm{Y}=244.081$ y la identificamos como CBN84510.5-460219 con $\mathrm{TE}=$ O8III((f)) por presentar en su espectro una emisión de NIII en 4640A En ella su fotometría se presenta saturada, razón por la cual no se puede conocer su distancia. En el trabajo de Reed Cameron (2000) en el que se buscan probables nuevos miembros de la Asociación Vela 


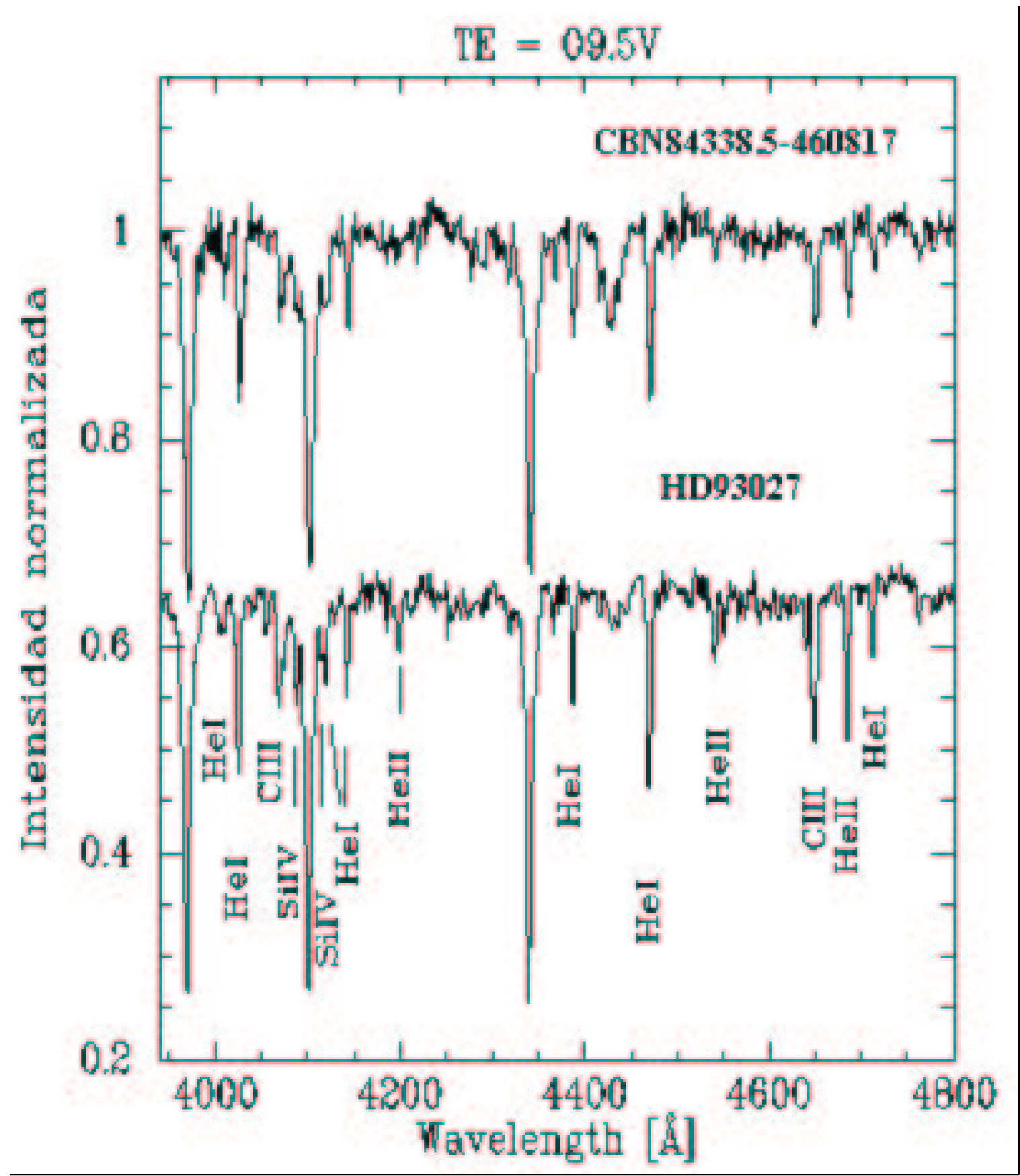

Figura 14: Líneas de absorción identificados para TE = O9.5V: HeI $\lambda \lambda$ 4009, 4026, 4121, 4144, 4387, 4471, 4713; CIII $\lambda \lambda$ 4070, 4650 blends; SiIV $\lambda \lambda 4089$, 4116; HeII $\lambda \lambda$ 4200, 4541, 4686. El principal criterio de luminosidad yendo de $09.7 \mathrm{Ib}$ a $09.5 \mathrm{~V}$ es la razón entre las líneas SiIV $\lambda 4089 / \mathrm{HeI} \lambda \lambda 4026$, 4121, 4144 y SiIV $\lambda 4116 / \mathrm{HeI} \lambda 4121$ y el efecto negativo en intensidad de absorción de HeII $\lambda 4686$. 


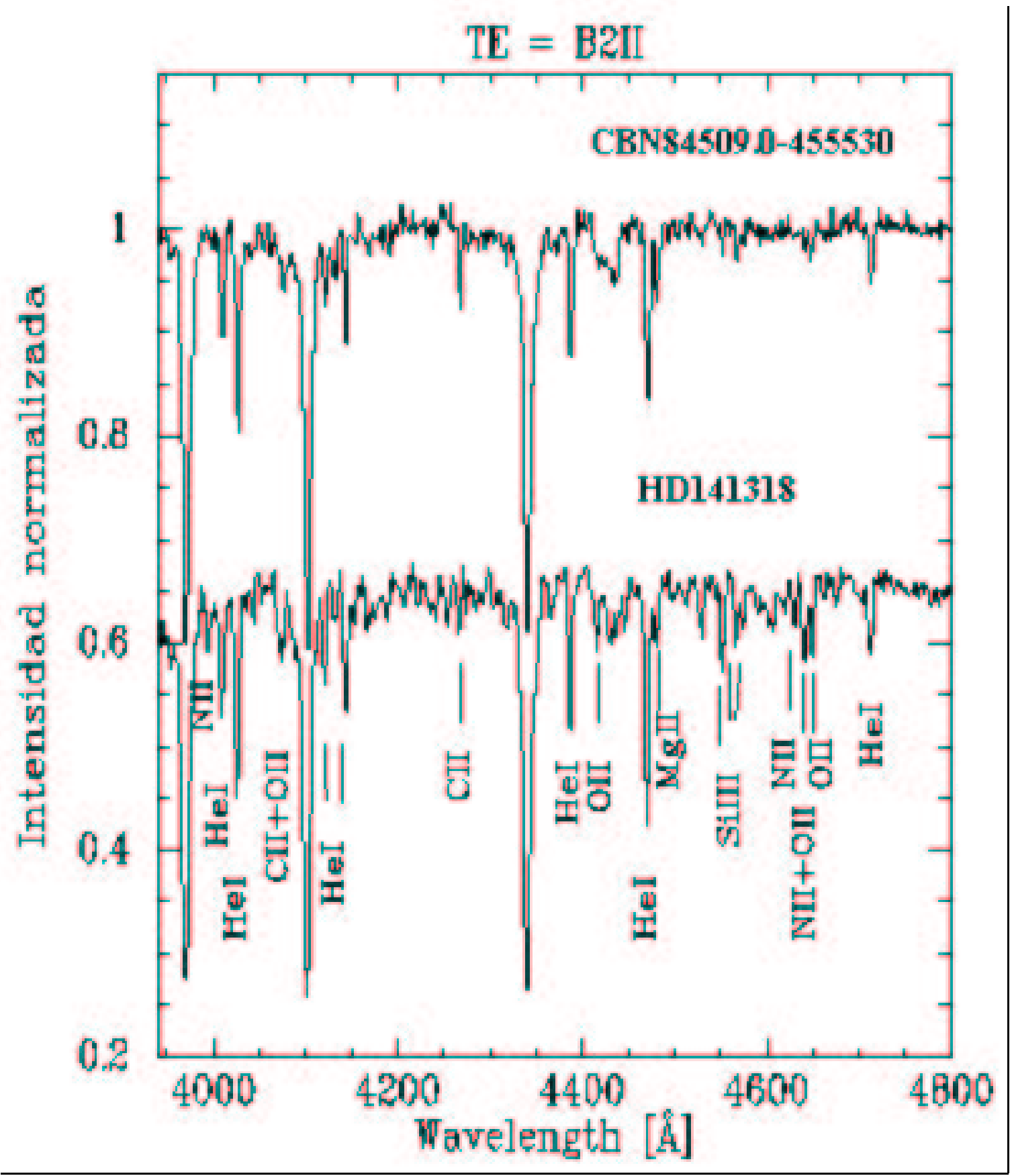

Figura 15: Líneas de absorción identificados para TE = B2II: NII $\lambda \lambda$ 3995, 4631; HeI $\lambda \lambda 4009$, 4026, 4121, 4144, 4387, 4471, 4713; CII+OII $\lambda 4070$ blend; CII $\lambda$ 4267; OII $\lambda \lambda 4415-17$, 4650; MgII $\lambda$ 4481; SiIII $\lambda \lambda$ 4552-68-75; NII+OII $\lambda 4640$ blend. El principal criterio de luminosidad empleado desde B2II a B2V es la razón SiIII $\lambda 4552 / \mathrm{HeI} \lambda 4387$ 


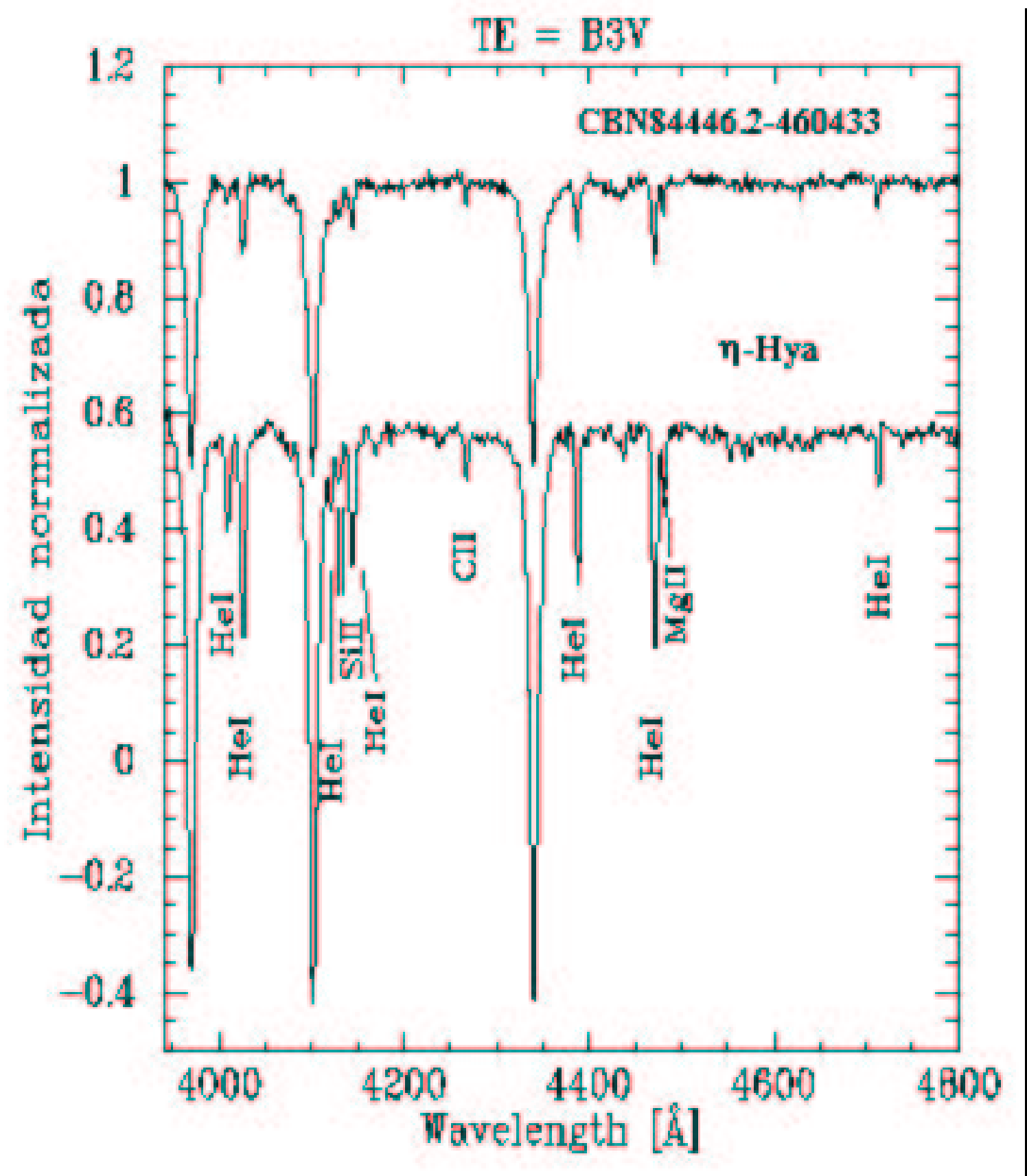

Figura 16: Líneas de absorción identificadas para $T E=B 3 V: H E I \lambda \lambda 4009$, 4026, 4121,

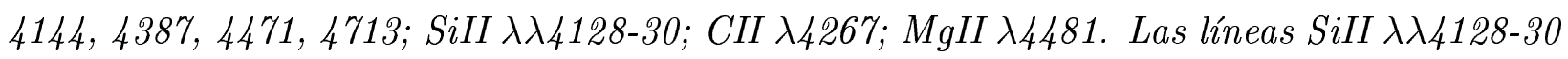
y MgII $\lambda 4481$ incrementan su intensidad yendo del TE B2V al B3V. 
Tabla 8: Clasificación espectral cuantitativa para estrellas con tipo espectral O, según Conti y colaboradores desde 1971 a 1977 (reproducida de K.A. van der Hucht, 1996)

\begin{tabular}{|c|c|c|c|}
\hline subtipo & $\log W^{*}$ & subtipo & $\log W^{*}$ \\
\hline $\mathrm{O} 3$ & $<-0.90$ & $\mathrm{O} 7$ & $-0.10 \mathrm{a}-0.01$ \\
\hline $\mathrm{O} 4$ & $-0.90 \mathrm{a}-0.61$ & O7.5 & $+0.00 \mathrm{a}+0.09$ \\
\hline O5 & $-0.60 \mathrm{a}-0.46$ & $\mathrm{O} 8$ & $+0.10 \mathrm{a}+0.19$ \\
\hline O5.5 & -0.45 a -0.31 & O8.5 & $+0.20 \mathrm{a}+0.29$ \\
\hline O6 & -0.30 a -0.21 & O9 & $+0.30 \mathrm{a}+0.44$ \\
\hline \multirow[t]{2}{*}{ O6.5 } & $-0.20 \mathrm{a}-0.11$ & O9.5 & $+0.45 \mathrm{a}+0.65$ \\
\hline & & O9.7 & $+0.65 \mathrm{a}+1.00$ \\
\hline
\end{tabular}

OB1, esta estrella está identificada como miembro de la misma, con lo cual su distancia se estimaría de aproximadamente $2 \mathrm{kpc}$.

Paralelo al trabajo de clasificación de Walborn \& Fitzpatrick (1990), Conti y colaboradores han desarrollado desde 1971 (desde Conti \& Alschuler, 1971 a Conti \& Frost, 1977) un sistema de clasificación espectral cuantitativo para estrellas de tipo espectral O. Usando una resolución espectral $16 \AA \mathrm{mm}^{-1}$ midieron los anchos equivalentes W de las líneas utilizadas en la clasificación y definieron para cada subtipo espectral $\mathrm{O}$ un rango de $\log W^{*}=$ $\log W(4471)$ - $\log W(4541)$, como se muestra en la Tabla 8, reproducida de K.A. van der Hucht (1996).

En el presente trabajo medimos los anchos equivalentes de las líneas de HeI $\lambda 4471$ y HeII $\lambda 4541$ en los espectros clasificados con TE O según el criterio de Walborn \& Fitzpatrick (1990), y comparamos los valores obtenidos con los valores dados por el sistema de clasificación de Conti (Tabla 8). Con la coincidencia de los resultados verificamos la validez del tipo espectral $\mathrm{O}$ encontrado para 6 de las estrellas en el presente estudio.

Realizando el trabajo de clasificación espectral que se describe en esta sección, descubrimos seis estrellas con tipo espectral $\mathrm{O}$, cinco de las cuales son de secuencia principal y una es gigante luminosa, siendo la más temprana el sistema binario con TE $=\mathrm{O} 6.5 \mathrm{~V}(\mathrm{f}))$. Dentro 


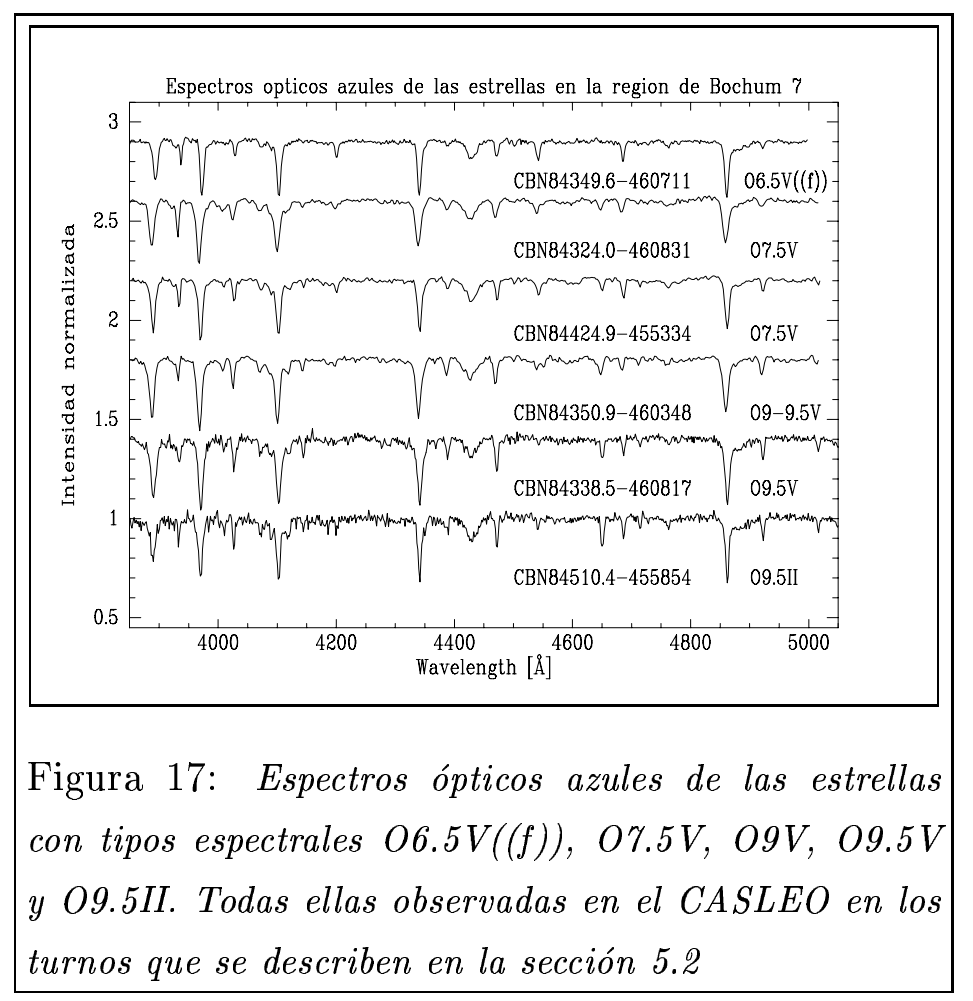

del grupo de estrellas con TE B, encontramos 44 estrellas de secuencia principal yendo de B0 a B8, donde una de ellas muestra líneas de emisión y otras 13 estrellas subgigantes y gigantes con una gigante con líneas de emisión en su espectro. Las Figuras 17, 18, 19, 20, $21,22,23,24,25$ y 26, que se muestran a continuación, contienen un espectro óptico azul de cada una de las estrellas de tipo espectral O y B que hemos observado en la región de Bochum 7.

Tanto en los espectros de las estrellas distantes de clase espectral O como en las de clase espectral B, se encuentra la prominente banda interestelar difusa $\lambda 4428$ (DIB - diffuse interestellar band)(ampliada en la subsección 5.2.3), la cual está originada en el gas interestelar que se encuentra entre la estrella y el observador, lo mismo sucede con las líneas interestelares $\mathrm{H}(\lambda 3968)$ y $\mathrm{K}(\lambda 3933)$ del CaII.

En el espectro de CBN84404.4-455316 (LS 1140) de TE = B0III, vemos la presencia de NIII $\lambda 4097$ en absorción y el cociente NIII $\lambda 4640 /$ CIII $\lambda 4650$ con un valor pequeño. Las líneas bien definidas son el resultado de un medio con baja presión, lo cual es característico de las estrellas gigantes.

\subsubsection{Análisis de las Velocidades Radiales}

\section{Espectros digitales}




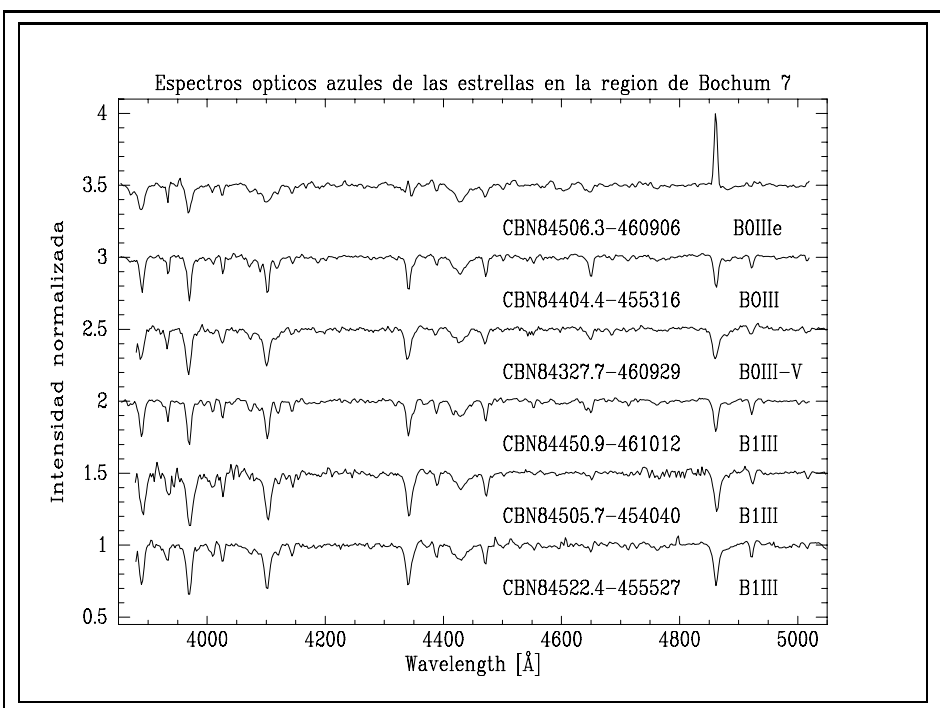

Figura 18: Espectros ópticos azules de las estrellas con tipos espectrales B0IIIe, B0III, B0III-V y B1III. Todas ellas observadas en el CASLEO en los turnos que se describen en la sección 5.2

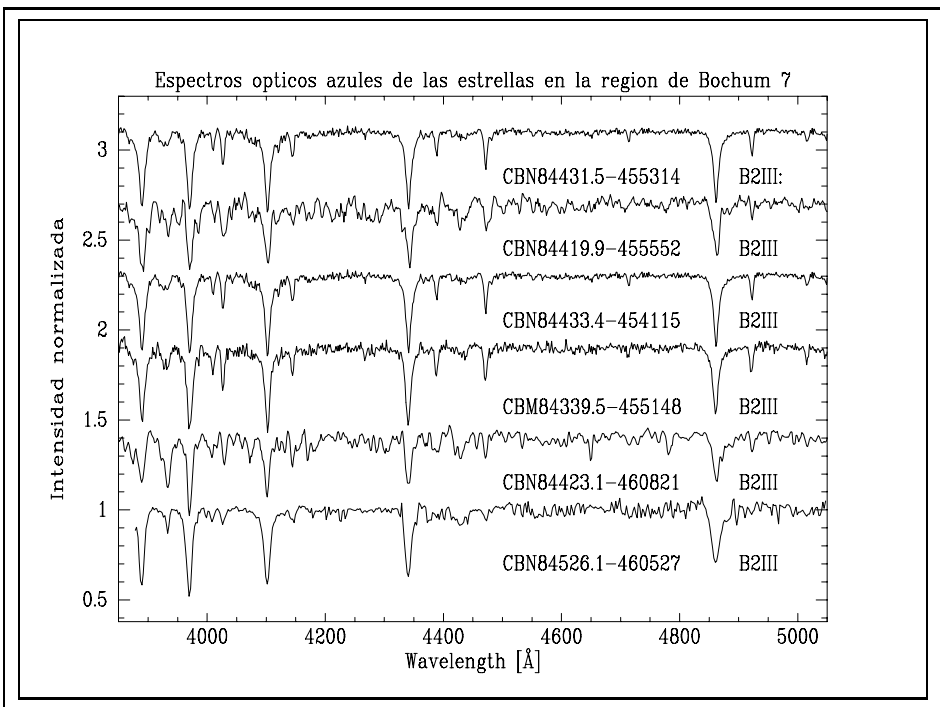

Figura 19: Espectros ópticos azules de las estrellas con tipos espectrales B2III. Todas ellas observadas en el CASLEO en los turnos que se describen en la sección 5.2 


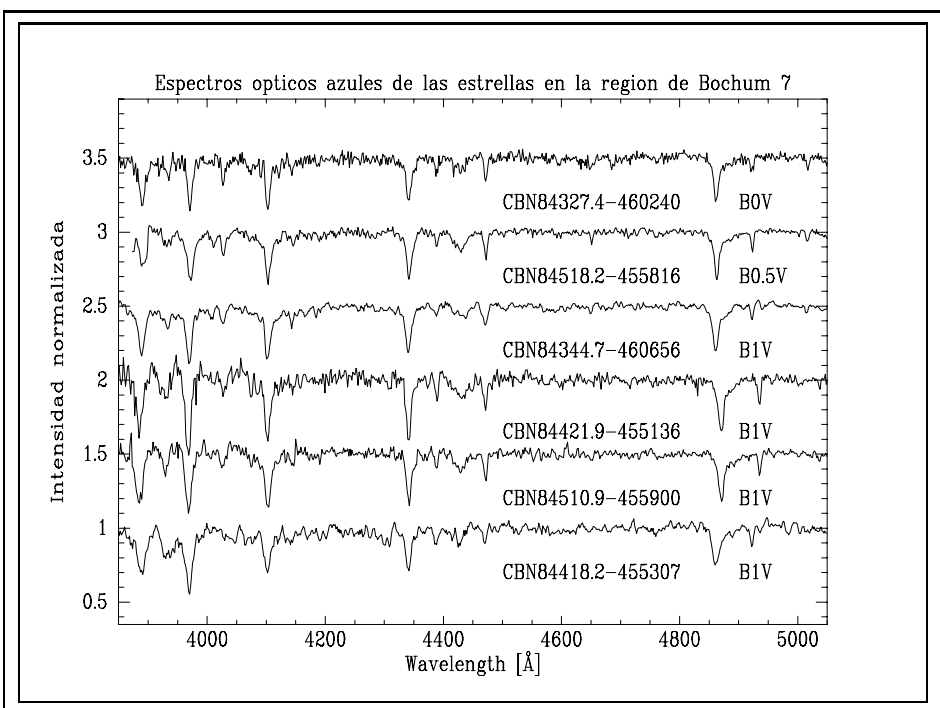

Figura 20: Espectros ópticos azules de las estrellas con tipos espectrales B0V, B0.5V y B1V. Todas ellas observadas en el CASLEO en los turnos que se describen en la sección 5.2

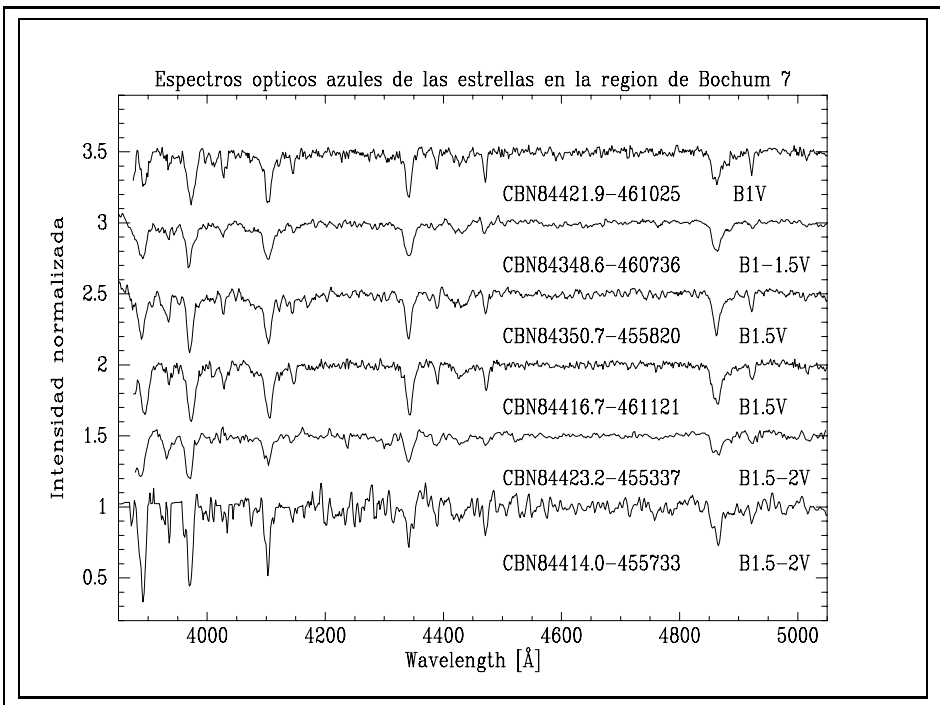

Figura 21: Espectros ópticos azules de las estrellas con tipos espectrales $B 1 \mathrm{~V}, \mathrm{~B} 1.5 \mathrm{~V}$ y B2 V. Todas ellas observadas en el CASLEO en los turnos que se describen en la sección 5.2 


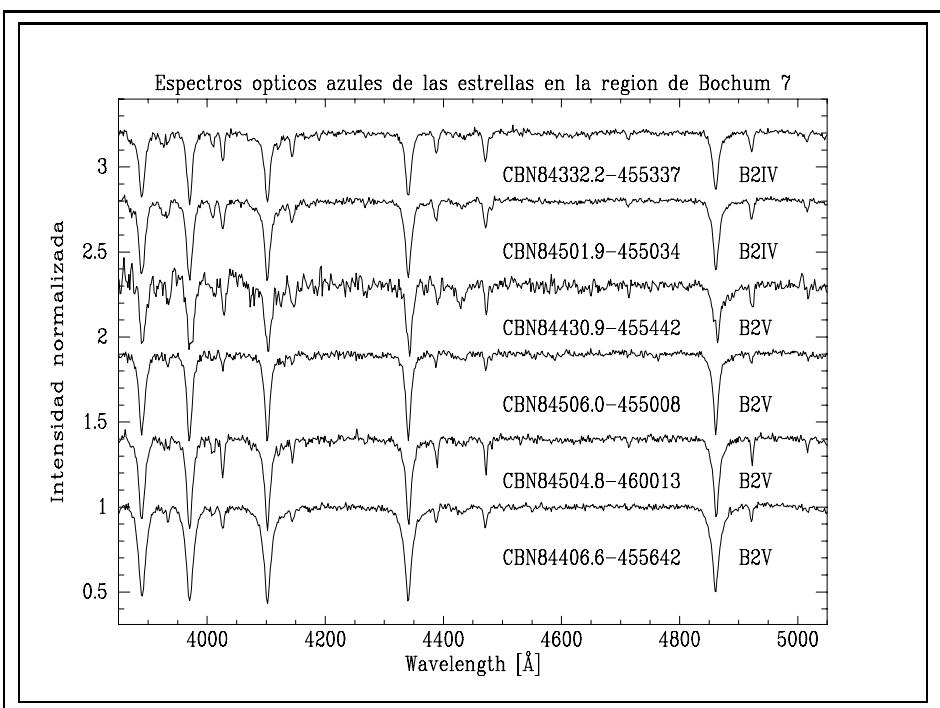

Figura 22: Espectros ópticos azules de las estrellas con tipos espectrales B2IV y B2V. Todas ellas observadas en el CASLEO en los turnos que se describen en la sección 5.2

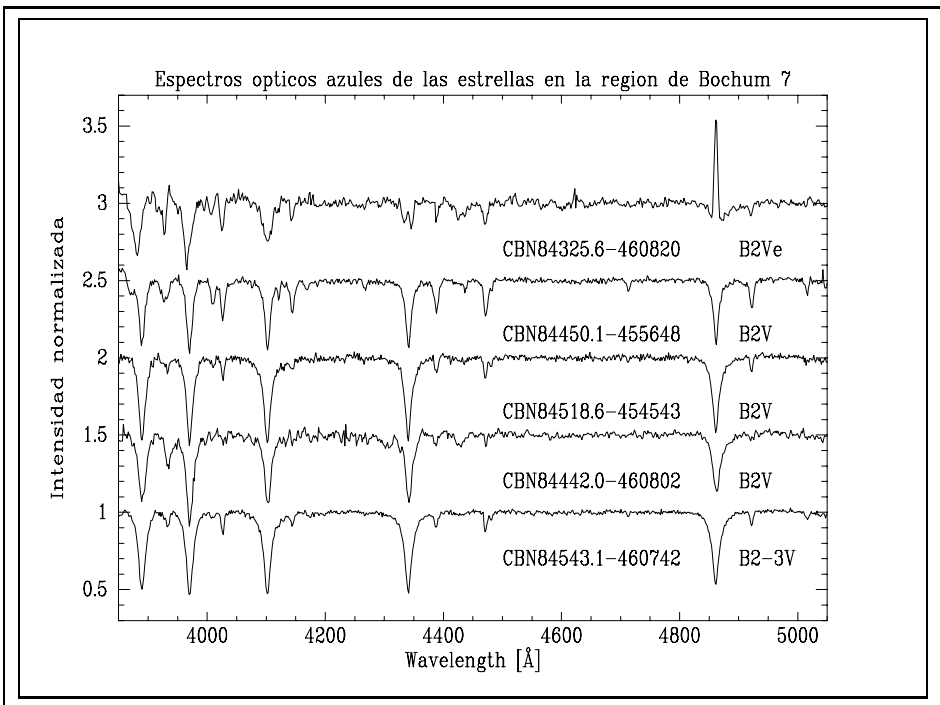

Figura 23: Espectros ópticos azules de las estrellas con tipos espectrales B2Ve, B2V y B3V. Todas ellas observadas en el CASLEO en los turnos que se describen en la sección 5.2 


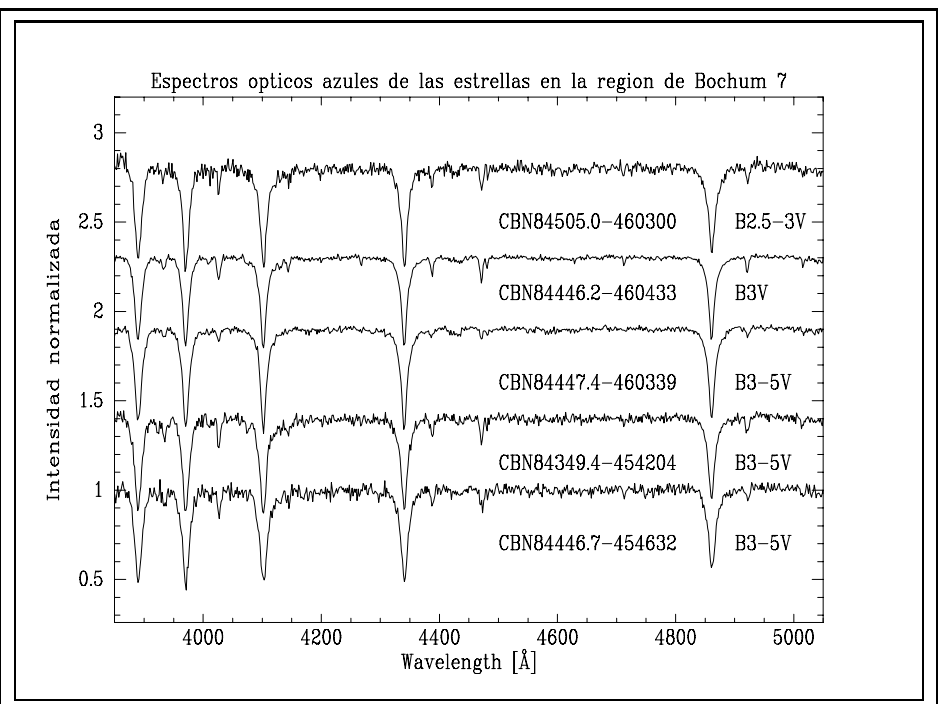

Figura 24: Espectros ópticos azules de las estrellas con tipos espectrales B2.5V, B3V y B5V. Todas ellas observadas en el CASLEO en los turnos que se describen en la sección 5.2

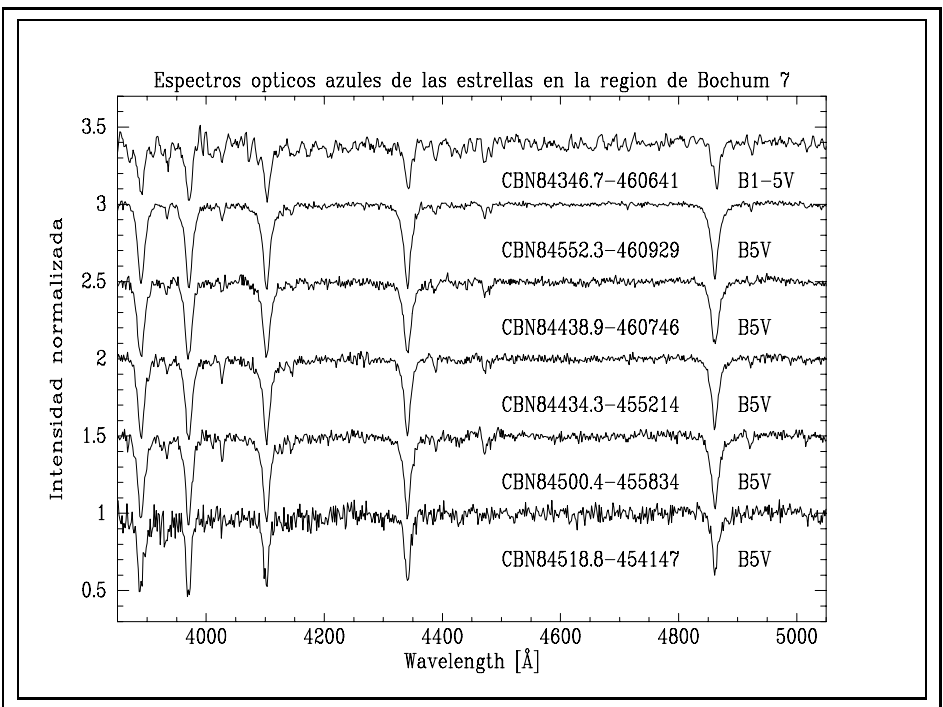

Figura 25: Espectros ópticos azules de las estrellas con tipos espectrales B5V. Todas ellas observadas en el CASLEO en los turnos que se describen en la sección 5.2 


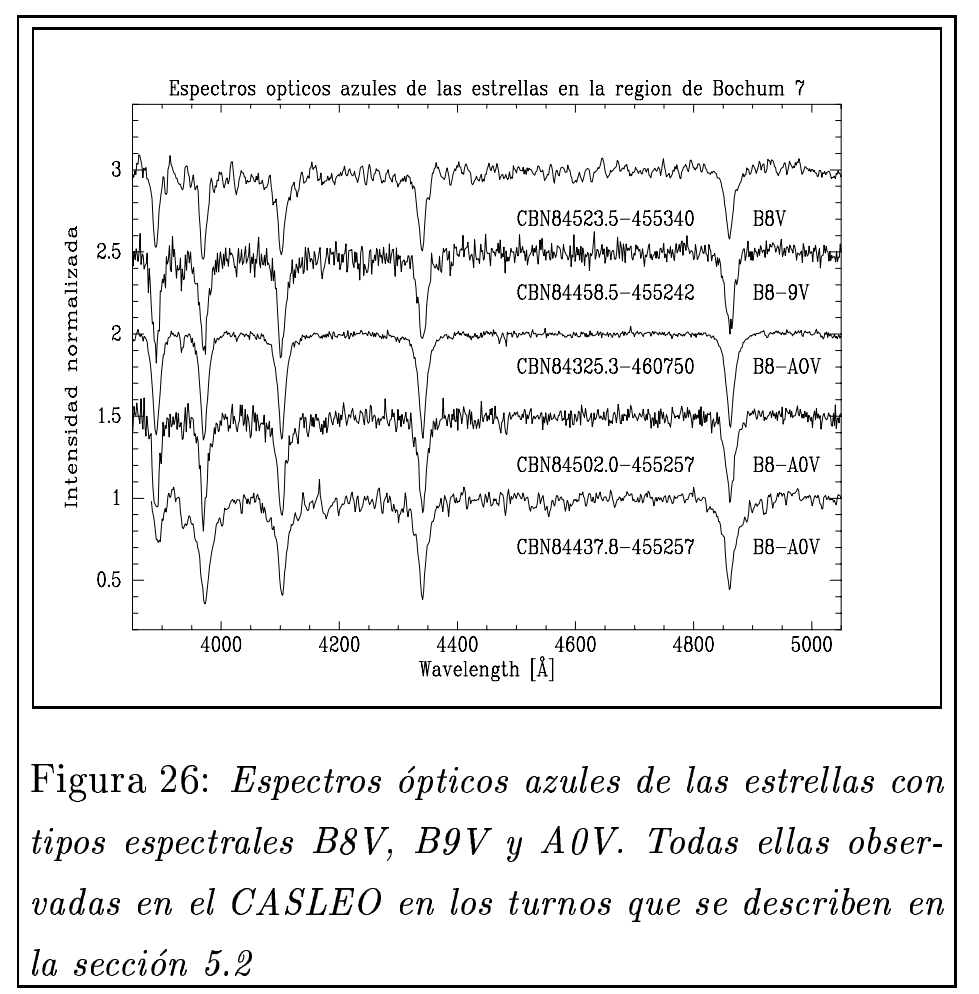

Cuando a los espectros se los quiere emplear para calcular velocidades radiales, el aspecto mencionado anteriormente sobre la confiabilidad de la calibración en longitud de onda, es un punto clave. Para las estrellas del presente estudio se observó un espectro de comparación inmediatamente antes de cada espectro estelar. Por medio de líneas espectrales del arco de He-Ar o Th-Ar (espectros de comparación empleados para espectrógrafos con DS o DC, respectiv.) de longitud de onda conocida, se determina un polinomio (en este caso de $3^{\circ}$ o $4^{\circ}$ grado) entre la posición de las líneas en px y la longitud de onda. Dicho polinomio es la función de coordenadas que la tarea DISPCOR asocia al espectro unidimensional de la estrella.

Para verificar la estabilidad del sistema de velocidades radiales de los espectrógrafos, cada noche se observaron estándares de velocidad radial. Las estrellas elegidas como tales en los distintos turnos fueron HR 2806, HR 1996, HR 5694, IC 418 (NP), por su velocidad radial probablemente constante. El resultado de las observaciones efectuadas a las estrellas HR 2806, HR 1996 y IC 418 es el resumido en las Tablas 9, 10 y 11, respectivamente. En las sucesivas columnas de las tablas se presentan: la Fecha Juliana, la velocidad radial obtenida del promedio de las velocidades radiales de todas las líneas posibles de medir en cada espectro, el número de líneas promediadas en cada espectro y la desviación estándar resul- 
tante del promedio de las velocidades radiales de cada espectro. La estándar HR 2806 en los distintos turnos en los que fue observada presentó una velocidad radial $25 \mathrm{~km} \mathrm{~s}^{-1} \leq V_{r} \leq$ $28 \mathrm{~km} \mathrm{~s}^{-1}$, indicando con dicha estabilidad la confiabilidad del funcionamiento de la configuración instrumental DC empleada. La estándar HR 1996 presentó una velocidad radial constante dentro de los errores de observación entre las distintas noches de un turno, las mismas fueron $94 \mathrm{~km} \mathrm{~s}^{-1} \leq V_{r} \leq 108 \mathrm{~km} \mathrm{~s}^{-1}$. Asimismo las diferencias en velocidad radial obtenidas con el $\mathrm{B} \& \mathrm{C}$, quedan dentro del rango de variación aceptable para el mismo.

La Nebulosa Planetaria IC 418 empleada como estándar de velocidad radial en los turnos de observación en los cuales se trabajó con el espectrógrafo Reosc DS, presenta valores de velocidad radial heliocéntrica comprendidos entre $55 \mathrm{~km} \mathrm{~s}^{-1} \leq V_{r} \leq 72 \mathrm{~km} \mathrm{~s}^{-1}$. 
Tabla 9: Velocidad radial heliocéntrica de HR 2806 medida en distintos turnos de observación empleando el espectrógrafo REOSC DC

\begin{tabular}{cccc}
\hline \hline $\begin{array}{c}\text { Fecha Juliana } \\
(2450000+)\end{array}$ & $\begin{array}{c}\bar{V}_{\text {observ. }} \\
\left(\mathrm{km} \mathrm{s}^{-1}\right)\end{array}$ & $\mathrm{n}$ & $\begin{array}{c}\sigma \\
\left(\mathrm{km} \mathrm{s}^{-1}\right)\end{array}$ \\
\hline 494.687 & 26 & 30 & 3 \\
497.710 & 26 & 36 & 3 \\
498.695 & 26 & 29 & 4 \\
506.591 & 27 & 31 & 6 \\
507.605 & 25 & 36 & 4 \\
508.597 & 25 & 33 & 5 \\
847.629 & 27 & 27 & 3 \\
851.619 & 28 & 27 & 2 \\
\hline \hline
\end{tabular}

Las velocidades radiales publicadas previamente para HR 2806 son:

$+28\left[\mathrm{~km} \mathrm{~s}^{-1}\right]$ Garmany et al. 1982

$+26\left[\mathrm{~km} \mathrm{~s}^{-1}\right]$ Penny et al. 1993

$+27\left[\mathrm{~km} \mathrm{~s}^{-1}\right]$ García et al. 1998

A los espectros digitales también se les aplica la tarea RVCORRECT del paquete ASTUTIL, para obtener, la fecha juliana (HJD) y las correcciones a la $\mathrm{V}_{r}$, que permitan obtener velocidades radiales heliocéntricas y velocidades radiales referidas al Local Standard of Rest (LSR).

En las Tablas 12, 13, 14, 15, 16, 17, 18, 19, 20, 21, 22, 23, 24 y 25 se presentan las velocidades radiales heliocéntricas obtenidas para las estrellas CBN84506.3-460906, CBN84349.6460711, CBN84324.0-460831, CBN84424.9-455334, CBN84450.9-461012, CBN84404.4-455316, CBN84350.9-460348, CBN84510.4-455854, CBN84419.9-455552, CBN84438.9-460746, CBN84423.2-455337, CBN84348.6-460736, CBN84325.6-460820 у CBN84504.8-460013, respectivamente. La velocidad radial de cada estrella, es el resultado de haber realizado un promedio entre las velocidades radiales medidas en las líneas de $\mathrm{H}_{\gamma}$, HeI $4471 \AA, \mathrm{H}_{\beta}$ y $\mathrm{HeI} 4922 \AA$ de cada espectro. Para esto se aplicó la ley de Doppler y se emplearon las longitudes de onda en reposo de Bolton \& Rogers (1978). En las sucesivas columnas de las Tablas se indican, Fecha Juliana de la observación, configuración instrumental empleada para obtener el espectro, velocidad radial heliocéntrica promedio y entre paréntesis la cantidad de líneas que se pudieron medir de las cuatro que se eligieron para promediar. En la última columna se indica la desviación estándar del promedio (ecuaciones 37 y 38, respectivamente). En la 
Tabla 10: Velocidad radial heliocéntrica de HR 1996 medida en un turno de observación empleando el espectrógrafo $\mathbf{B} \& \mathbf{C}$

\begin{tabular}{cccc}
\hline \hline $\begin{array}{c}\text { Fecha Juliana } \\
(2450000+)\end{array}$ & $\begin{array}{c}\bar{V}_{\text {observ. }} \\
\left(\mathrm{km} \mathrm{s}^{-1}\right)\end{array}$ & $\mathrm{n}$ & $\begin{array}{c}\sigma \\
\left(\mathrm{km} \mathrm{s}^{-1}\right)\end{array}$ \\
\hline 537.487 & 98 & 8 & 32 \\
538.487 & 94 & 13 & 29 \\
539.479 & 103 & 7 & 16 \\
541.475 & 108 & 13 & 22 \\
\hline \hline
\end{tabular}

Las velocidades radiales publicadas previamente para HR 1996 son:

$+110\left[\mathrm{~km} \mathrm{~s}^{-1}\right]$ Garmany et al. 1982

$+107\left[\mathrm{~km} \mathrm{~s}^{-1}\right]$ Penny et al. 1993

$+108\left[\mathrm{~km} \mathrm{~s}^{-1}\right]$ Bosch 1994

Tabla 11: Velocidad radial heliocéntrica de IC 418 medida en distintos turnos de observación empleando el espectrógrafo REOSC DS

\begin{tabular}{cccc}
\hline \hline $\begin{array}{c}\text { Fecha Juliana } \\
(2450000+)\end{array}$ & $\begin{array}{c}\bar{V}_{\text {observ. }} \\
\left(\mathrm{km} \mathrm{s}^{-1}\right)\end{array}$ & $\mathrm{n}$ & $\begin{array}{c}\sigma \\
\left(\mathrm{km} \mathrm{s}^{-1}\right)\end{array}$ \\
\hline 1556.567 & 62 & 23 & 24 \\
1557.530 & 66 & 18 & 21 \\
1558.524 & 61 & 20 & 18 \\
1559.526 & 60 & 17 & 21 \\
1560.524 & 67 & 17 & 35 \\
1561.524 & 66 & 19 & 28 \\
1944.610 & 55 & 15 & 17 \\
1945.555 & 66 & 15 & 29 \\
1946.544 & 72 & 15 & 20 \\
\hline \hline
\end{tabular}

Las velocidades radiales publicadas previamente para IC 418 son:

$+64\left[\mathrm{~km} \mathrm{~s}^{-1}\right]$ Mendez et al. 1986

$+56\left[\mathrm{~km} \mathrm{~s}^{-1}\right]$ Kohoutek L. \& Pauls R. 1995

Estudio de una Asociación $O B$ distante en la Vía Láctea 
Tabla 26 se presentan las velocidades radiales heliocéntricas obtenidas para el resto de las estrellas con $\mathrm{TE}=\mathrm{O}$ y B, estudiadas de la imagen CCD directa de un área de 30'x30', centrada en $\alpha=8^{h} 44^{m} 23^{s}, \delta=-45^{\circ} 56^{\prime} 22^{\prime \prime}$. Sólo fue posible obtener un espectro de cada una de ellas. La velocidad radial de cada estrella que se muestra en esta Tabla también se obtuvo promediando las velocidades radiales medidas en las líneas de $\mathrm{H}_{\gamma}$, HeI $4471 \AA$, $\mathrm{H}_{\beta}$ y HeI $4922 \AA$ de sus espectros. En las sucesivas columnas se indican, la identificación de la estrella, Fecha Juliana de la observación, configuración instrumental empleada para obtener el espectro, velocidad radial heliocéntrica promedio en $\mathrm{km} \mathrm{s}^{-1}$ y entre paréntesis la cantidad de líneas que se pudieron medir de las cuatro que se eligieron para promediar. En la última columna se indica la desviación estándar del promedio en $\mathrm{km} \mathrm{s}^{-1}$ (ecuaciones 37 y 38, respectivamente). En todas las Tablas que aquí se mencionan sólo se muestran los resultados de los espectros digitales. 
Las velocidades radiales individuales fueron determinadas para cada perfil de las líneas de absorción en orden a verificar, por la presencia de diferencias sistemáticas entre las líneas de diferentes iones, cuál podía ser causada por binariedad o expansión atmosférica.

Las cuatro estrellas del Catálogo LS: 1131 (CBN84324.0-460831), 1144 (CBN84424.9455334), 1146 (CBN84450.9-461012) y 1147 (CBN84506.3-460906) muestran variaciones en la velocidad radial medida en los espectros obtenidos en diferentes fechas. En las Tablas 12, 14, 15 y 16 se presentan los valores de velocidad radial heliocéntrica obtenida para cada una de ellas del promedio de las velocidades medidas en las líneas $\mathrm{H}_{\gamma}, \mathrm{HeI} 4471 \AA$, $\mathrm{H}_{\beta}$ y $\mathrm{HeI} 4922 \AA$ Los espectros empleados para las cuatro estrellas fueron los obtenidos con las configuraciones instrumentales I y II. A continuación se presenta una descripción de los resultados obtenidos:

LSS 1131: los espectros de esta estrella muestran una dispersión de valores de Vr entre $-45 \mathrm{~km} \mathrm{~s}^{-1}<\mathrm{Vr}<160 \mathrm{~km} \mathrm{~s}^{-1}$ por lo que consideramos a LSS 1131 una candidata a ser binaria, para la cual es necesario obtener observaciones con mejor resolución. Esta estrella presenta una caracteristica adicional típica de sistemas binarios, la cual es una variación de la relación de intensidades de $\mathrm{HeI} 4471 / \mathrm{HeII} 4541$, conocido en sistemas binarios como efecto Struve-Sahade. Los cocientes de intensidad obtenidos entre las líneas de HeI 4471 y HeII 4541 varian entre 1.6 y 2.4 .

LSS 1144: se determinaron velocidades radiales $(\mathrm{Vr})$ con valores entre $-26 \mathrm{~km} \mathrm{~s}^{-1}<\mathrm{Vr}<$ $100 \mathrm{~km} \mathrm{~s}^{-1}$. Debido a esta dispersión de valores de Vr esta estrella entra en la categoria de posible sistema binario. Sin embargo, será necesario disponer de observaciones espectrales con mejor resolución para confirmar las variaciones, y determinar el período.

LSS 1146: los espectros de esta estrella presentan una variación de Vr comprendida entre los valores $-4 \mathrm{~km} \mathrm{~s}^{-1}<\mathrm{Vr}<76 \mathrm{~km} \mathrm{~s}^{-1}$. Aunque aquí la dispersión de los valores de $\mathrm{Vr}$ es algo menor que la presentada en las otras posibles binarias, al comprenderse dentro de aproximadamente $80 \mathrm{~km} \mathrm{~s}^{-1}$, podría estar indicando igualmente la presencia de un posible sistema binario, tal vez con período más largo.

LSS 1147: esta es una estrella con líneas de emisión en las líneas de Balmer, de tipo espectral B0IIIe, y tiene una gran dispersión de valores de $\mathrm{Vr}$, quedando comprendida la misma entre $-32 \mathrm{~km} \mathrm{~s}^{-1}<\mathrm{Vr}<57 \mathrm{~km} \mathrm{~s}^{-1}$ Para esta estrella también será necesario obtener más espectros de mejor resolución para confirmar las variaciones y determinar el período. 
Tabla 12: Velocidades radiales heliocéntricas $\left(\mathrm{km} \mathrm{s}^{-1}\right)$ de la estrella CBN84506.3-460906 (LS 1147)

\begin{tabular}{|r|r|r|c|}
\hline \hline $\begin{array}{c}\text { HJD } \\
(2450000+)\end{array}$ & CI & $\begin{array}{c}\text { V } \\
\mathrm{km} \mathrm{s}^{-1}\end{array}$ & $\begin{array}{c}\sigma \\
\mathrm{km} \mathrm{s}^{-1}\end{array}$ \\
\hline \hline 868.641 & I & $-9(2)$ & \pm 06 \\
1203.752 & I & $-32(3)$ & \pm 30 \\
1205.788 & I & $3(3)$ & \pm 19 \\
1219.654 & I & $-4(3)$ & \pm 07 \\
1220.857 & I & $26(3)$ & \pm 10 \\
1221.848 & I & $-2(4)$ & \pm 21 \\
1555.770 & II & $12(3)$ & \pm 25 \\
1556.757 & II & $15(3)$ & \pm 24 \\
1557.750 & II & $25(3)$ & \pm 03 \\
1558.636 & II & $57(3)$ & \pm 34 \\
1559.617 & II & $11(3)$ & \pm 07 \\
1560.623 & II & $11(3)$ & \pm 29 \\
1561.613 & II & $19(3)$ & \pm 17 \\
1565.670 & II & $-21(3)$ & \pm 33 \\
1566.792 & II & $0(3)$ & \pm 20 \\
1572.790 & II & $15(3)$ & \pm 21 \\
1575.865 & II & $2(3)$ & \pm 48 \\
1924.760 & I & $-18(3)$ & \pm 11 \\
1926.735 & I & $14(3)$ & \pm 28 \\
1946.606 & II & $14(4)$ & \pm 37 \\
\hline \hline
\end{tabular}


Tabla 13: Velocidades radiales heliocéntricas $\left(\mathrm{km} \mathrm{s}^{-1}\right)$ de la CBN84349.6-460711 (LS 1135)

\begin{tabular}{|r|c|c|c|}
\hline \multicolumn{1}{c|}{ HJD } & CI & \multicolumn{1}{|c|}{$\mathrm{V}_{r}$} & $\sigma$ \\
$(2450000+)$ & & $\mathrm{km} \mathrm{s}^{-1}$ & $\mathrm{~km} \mathrm{~s}^{-1}$ \\
\hline 494.778 & III & $154(3)$ & \pm 18 \\
495.795 & III & $-50(3)$ & \pm 05 \\
497.810 & III & $128(3)$ & \pm 07 \\
506.550 & III & $-8(2)$ & \pm 07 \\
507.542 & III & $20(3)$ & \pm 09 \\
508.549 & III & $178(3)$ & \pm 11 \\
537.590 & I & $-29(4)$ & \pm 20 \\
538.586 & I & $143(4)$ & \pm 17 \\
540.596 & I & $-24(3)$ & \pm 02 \\
541.567 & I & $109(3)$ & \pm 14 \\
542.553 & I & $-58(3)$ & \pm 09 \\
841.659 & III & $192(3)$ & \pm 26 \\
842.647 & III & $-53(3)$ & \pm 09 \\
843.620 & III & $54(3)$ & \pm 06 \\
844.608 & III & $141(3)$ & \pm 10 \\
845.620 & III & $-69(3)$ & \pm 10 \\
846.662 & III & $124(2)$ & \pm 01 \\
847.602 & III & $86(3)$ & \pm 10 \\
848.609 & III & $-69(3)$ & \pm 23 \\
849.612 & III & $168(3)$ & \pm 15 \\
851.585 & III & $-33(3)$ & \pm 02 \\
854.700 & I & $25(4)$ & \pm 23 \\
855.608 & I & $76(2)$ & \pm 21 \\
858.601 & I & $73(4)$ & \pm 30 \\
859.600 & I & $-57(4)$ & \pm 13 \\
860.652 & I & $95(4)$ & \pm 36 \\
861.721 & I & $23(3)$ & \pm 10 \\
963.442 & I & $-30(4)$ & \pm 18 \\
964.436 & I & $-31(4)$ & \pm 21 \\
965.447 & I & $142(3)$ & \pm 10 \\
2322.658 & II & $194(4)$ & \pm 14 \\
2324.576 & II & $12(4)$ & \pm 06 \\
\hline
\end{tabular}

Con la CI III no se incluyó la línea HeI 4922 en el cálculo de la velocidad radial promedio. Estudio de una Asociación $O B$ distante en la Vía Láctea 
Tabla 14: Velocidades radiales heliocéntricas $\left(\mathrm{km} \mathrm{s}^{-1}\right)$ de la estrella CBN84324.0-460831 (LS 1131)

\begin{tabular}{|c|c|r|c|}
\hline \hline $\begin{array}{c}\text { HJD } \\
(2450000+)\end{array}$ & CI & \multicolumn{1}{|c|}{$\mathrm{V}_{r}$} & $\sigma$ \\
$\mathrm{km} \mathrm{s}^{-1}$ & $\mathrm{~km} \mathrm{~s}^{-1}$ \\
\hline \hline 1202.832 & I & $16(4)$ & \pm 26 \\
1204.850 & I & $43(4)$ & \pm 10 \\
1219.586 & I & $52(4)$ & \pm 15 \\
1555.641 & II & $18(4)$ & \pm 16 \\
1556.733 & II & $47(4)$ & \pm 29 \\
1557.773 & II & $-21(4)$ & \pm 04 \\
1558.649 & II & $71(4)$ & \pm 21 \\
1559.641 & II & $51(4)$ & \pm 11 \\
1560.671 & II & $49(4)$ & \pm 08 \\
1561.636 & II & $48(4)$ & \pm 05 \\
1565.707 & II & $121(4)$ & \pm 10 \\
1572.809 & II & $20(4)$ & \pm 08 \\
1573.750 & II & $51(4)$ & \pm 10 \\
1574.782 & II & $15(4)$ & \pm 23 \\
1924.712 & I & $160(4)$ & \pm 44 \\
1927.845 & I & $-23(4)$ & \pm 34 \\
1945.806 & II & $25(4)$ & \pm 33 \\
1946.575 & II & $106(4)$ & \pm 16 \\
2293.774 & II & $-45(4)$ & \pm 16 \\
2296.861 & II & $28(4)$ & \pm 39 \\
2298.726 & II & $38(4)$ & \pm 19 \\
2299.725 & II & $130(4)$ & \pm 25 \\
2300.699 & II & $30(4)$ & \pm 24 \\
2301.674 & II & $60(4)$ & \pm 34 \\
2302.671 & II & $33(4)$ & \pm 28 \\
2322.733 & II & $-16(4)$ & \pm 07 \\
2323.614 & II & $87(4)$ & \pm 04 \\
2324.538 & II & $74(4)$ & \pm 09 \\
\hline \hline
\end{tabular}


Tabla 15: Velocidades radiales heliocéntricas $\left(\mathrm{km} \mathrm{s}^{-1}\right)$ de la estrella CBN84424.9-455334 (LS 1144)

\begin{tabular}{|c|c|r|c|}
\hline \hline $\begin{array}{c}\text { HJD } \\
(2450000+)\end{array}$ & CI & $\begin{array}{c}\mathrm{V}_{r} \\
\mathrm{~km} \mathrm{~s}^{-1}\end{array}$ & $\begin{array}{c}\sigma \\
\mathrm{km} \mathrm{s}^{-1}\end{array}$ \\
\hline \hline 1203.793 & I & $48(4)$ & \pm 15 \\
1219.604 & I & $26(4)$ & \pm 04 \\
1221.834 & I & $82(4)$ & \pm 15 \\
1555.834 & II & $60(4)$ & \pm 14 \\
1556.720 & II & $29(4)$ & \pm 13 \\
1557.818 & II & $19(4)$ & \pm 16 \\
1558.671 & II & $46(4)$ & \pm 19 \\
1559.666 & II & $66(4)$ & \pm 15 \\
1560.711 & II & $64(4)$ & \pm 10 \\
1561.647 & II & $18(4)$ & \pm 09 \\
1565.658 & II & $37(4)$ & \pm 05 \\
1566.781 & II & $0(4)$ & \pm 18 \\
1573.761 & II & $56(4)$ & \pm 03 \\
1574.767 & II & $26(3)$ & \pm 07 \\
1575.853 & II & $-26(4)$ & \pm 22 \\
1924.867 & I & $87(4)$ & \pm 14 \\
1925.807 & I & $55(4)$ & \pm 19 \\
1927.863 & I & $42(4)$ & \pm 15 \\
1945.824 & II & $62(4)$ & \pm 15 \\
1946.560 & II & $39(4)$ & \pm 12 \\
2293.672 & II & $100(4)$ & \pm 10 \\
2296.687 & II & $23(4)$ & \pm 16 \\
2323.594 & II & $60(4)$ & \pm 04 \\
2324.556 & II & $77(4)$ & \pm 13 \\
\hline \hline & & & \\
\hline
\end{tabular}


Tabla 16: Velocidades radiales heliocéntricas $\left(\mathrm{km} \mathrm{s}^{-1}\right)$ de la estrella CBN84450.9-461012 (LS 1146)

\begin{tabular}{|r|c|c|c|}
\hline \hline $\begin{array}{c}\text { HJD } \\
(2450000+)\end{array}$ & CI & $\begin{array}{c}\mathrm{V}_{r} \\
\mathrm{~km} \mathrm{~s}^{-1}\end{array}$ & $\begin{array}{c}\sigma \\
\mathrm{km} \mathrm{s}^{-1}\end{array}$ \\
\hline \hline 868.657 & I & $27(3)$ & \pm 15 \\
1203.729 & I & $16(4)$ & \pm 11 \\
1205.772 & I & $-4(4)$ & \pm 05 \\
1220.841 & I & $47(4)$ & \pm 32 \\
1555.755 & II & $36(4)$ & \pm 11 \\
1556.745 & II & $48(4)$ & \pm 12 \\
1557.761 & II & $49(4)$ & \pm 19 \\
1558.625 & II & $27(4)$ & \pm 24 \\
1559.628 & II & $37(4)$ & \pm 27 \\
1560.658 & II & $38(4)$ & \pm 15 \\
1561.624 & II & $39(4)$ & \pm 38 \\
1565.689 & II & $26(4)$ & \pm 15 \\
1570.853 & II & $23(4)$ & \pm 24 \\
1572.800 & II & $12(4)$ & \pm 19 \\
1574.687 & II & $26(4)$ & \pm 20 \\
1924.785 & I & $41(4)$ & \pm 23 \\
1926.756 & I & $37(3)$ & \pm 23 \\
1946.591 & II & $76(4)$ & \pm 25 \\
\hline \hline
\end{tabular}

Tabla 17: Velocidades radiales heliocéntricas $\left(\mathrm{km} \mathrm{s}^{-1}\right)$ de la estrella CBN84404.4-455316 (LS 1140)

\begin{tabular}{|c|c|c|c|}
\hline \hline $\begin{array}{c}\text { HJD } \\
(2450000+)\end{array}$ & CI & $\begin{array}{c}\mathrm{V}_{r} \\
\mathrm{~km} \mathrm{~s}^{-1}\end{array}$ & $\begin{array}{c}\sigma \\
\mathrm{km} \mathrm{s}^{-1}\end{array}$ \\
\hline \hline 1203.773 & $\mathrm{I}$ & $40(4)$ & \pm 10 \\
1219.826 & $\mathrm{I}$ & $53(4)$ & \pm 21 \\
1558.682 & $\mathrm{II}$ & $74(4)$ & \pm 17 \\
\hline \hline
\end{tabular}


Tabla 18: Velocidades radiales heliocéntricas $\left(\mathrm{km} \mathrm{s}^{-1}\right)$ de la estrella CBN84350.9-460348 (LS 1137)

\begin{tabular}{|c|c|c|c|}
\hline \hline $\begin{array}{c}\text { HJD } \\
(2450000+)\end{array}$ & CI & $\begin{array}{c}\mathrm{V}_{r} \\
\mathrm{~km} \mathrm{~s}^{-1}\end{array}$ & $\begin{array}{c}\sigma \\
\mathrm{km} \mathrm{s}^{-1}\end{array}$ \\
\hline \hline 1202.814 & $\mathrm{I}$ & $57(4)$ & \pm 16 \\
1204.835 & $\mathrm{I}$ & $37(4)$ & \pm 24 \\
1558.660 & $\mathrm{II}$ & $72(4)$ & \pm 09 \\
\hline \hline
\end{tabular}

Tabla 19: Velocidades radiales heliocéntricas $\left(\mathrm{km} \mathrm{s}^{-1}\right)$ de la estrella CBN84510.4-455854

\begin{tabular}{|c|r|r|c|}
\hline \hline $\begin{array}{c}\text { HJD } \\
(2450000+)\end{array}$ & CI & $\begin{array}{c}\mathrm{V}_{r} \\
\mathrm{~km} \mathrm{~s}^{-1}\end{array}$ & $\begin{array}{c}\sigma \\
\mathrm{km} \mathrm{s}^{-1}\end{array}$ \\
\hline \hline 1557.731 & II & $54(4)$ & \pm 07 \\
1559.653 & II & $57(4)$ & \pm 12 \\
1560.683 & II & $41(4)$ & \pm 10 \\
\hline \hline
\end{tabular}

Tabla 20: Velocidades radiales heliocéntricas $\left(\mathrm{km} \mathrm{s}^{-1}\right)$ de la estrella CBN84419.9-455552

\begin{tabular}{|c|c|c|c|}
\hline \hline $\begin{array}{c}\text { HJD } \\
(2450000+)\end{array}$ & CI & $\begin{array}{c}\mathrm{V}_{r} \\
\mathrm{~km} \mathrm{~s}^{-1}\end{array}$ & $\begin{array}{c}\sigma \\
\mathrm{km} \mathrm{s}^{-1}\end{array}$ \\
\hline \hline 1561.696 & II & $35(4)$ & \pm 09 \\
2296.783 & II & $58(4)$ & \pm 26 \\
\hline \hline
\end{tabular}

Tabla 21: Velocidades radiales heliocéntricas $\left(\mathrm{km} \mathrm{s}^{-1}\right)$ de la estrella CBN84438.9-460746

\begin{tabular}{|c|c|c|c|}
\hline \hline $\begin{array}{c}\text { HJD } \\
(2450000+)\end{array}$ & CI & $\begin{array}{c}\mathrm{V}_{r} \\
\mathrm{~km} \mathrm{~s}^{-1}\end{array}$ & $\begin{array}{c}\sigma \\
\mathrm{km} \mathrm{s}^{-1}\end{array}$ \\
\hline \hline 1558.779 & II & $49(4)$ & \pm 18 \\
1946.654 & II & $73(4)$ & \pm 22 \\
\hline \hline
\end{tabular}


Tabla 22: Velocidades radiales heliocéntricas $\left(\mathrm{km} \mathrm{s}^{-1}\right)$ de la estrella CBN84423.2-455337

\begin{tabular}{|c|c|c|c|}
\hline \hline $\begin{array}{c}\text { HJD } \\
(2450000+)\end{array}$ & CI & $\begin{array}{c}\mathrm{V}_{r} \\
\mathrm{~km} \mathrm{~s}^{-1}\end{array}$ & $\begin{array}{c}\sigma \\
\mathrm{km} \mathrm{s}^{-1}\end{array}$ \\
\hline \hline 1925.807 & $\mathrm{I}$ & $78(4)$ & \pm 10 \\
2293.672 & $\mathrm{II}$ & $28(4)$ & \pm 09 \\
\hline \hline
\end{tabular}

Tabla 23: Velocidades radiales heliocéntricas $\left(\mathrm{km} \mathrm{s}^{-1}\right)$ de la estrella CBN84348.6-460736

\begin{tabular}{|c|c|c|c|}
\hline \hline $\begin{array}{c}\text { HJD } \\
(2450000+)\end{array}$ & CI & $\begin{array}{c}\mathrm{V}_{r} \\
\mathrm{~km} \mathrm{~s}^{-1}\end{array}$ & $\begin{array}{c}\sigma \\
\mathrm{km} \mathrm{s}^{-1}\end{array}$ \\
\hline \hline 2322.778 & II & $40(3)$ & \pm 32 \\
1560.726 & II & $108(3)$ & \pm 25 \\
\hline \hline
\end{tabular}

Tabla 24: Velocidades radiales heliocéntricas $\left(\mathrm{km} \mathrm{s}^{-1}\right)$ de la estrella CBN84325.6-460820

\begin{tabular}{|c|c|c|c|}
\hline \hline $\begin{array}{c}\text { HJD } \\
(2450000+)\end{array}$ & CI & $\begin{array}{c}\mathrm{V}_{r} \\
\mathrm{~km} \mathrm{~s}^{-1}\end{array}$ & $\begin{array}{c}\sigma \\
\mathrm{km} \mathrm{s}^{-1}\end{array}$ \\
\hline \hline 1925.730 & $\mathrm{I}$ & $-13(4)$ & \pm 36 \\
2293.774 & $\mathrm{II}$ & $-27(4)$ & \pm 32 \\
\hline \hline
\end{tabular}

Tabla 25: Velocidades radiales heliocéntricas $\left(\mathrm{km} \mathrm{s}^{-1}\right)$ de la estrella CBN84504.8-460013

\begin{tabular}{|c|c|c|c|}
\hline \hline $\begin{array}{c}\text { HJD } \\
(2450000+)\end{array}$ & CI & $\begin{array}{c}\mathrm{V}_{r} \\
\mathrm{~km} \mathrm{~s}^{-1}\end{array}$ & $\begin{array}{c}\sigma \\
\mathrm{km} \mathrm{s}^{-1}\end{array}$ \\
\hline \hline 1557.720 & II & $55(4)$ & \pm 09 \\
1558.728 & II & $43(4)$ & \pm 09 \\
\hline \hline
\end{tabular}


Tabla 26: Velocidades radiales heliocéntricas $\left(\mathrm{km} \mathrm{s}^{-1}\right)$ de las estrellas observadas en la región de Bochum 7 de las cuales se posee sólo un espectro

\begin{tabular}{|c|c|c|c|c|c|c|c|c|c|}
\hline $\begin{array}{c}\text { ID } \\
\text { CBN }\end{array}$ & $\begin{array}{c}\text { HJD } \\
(2450000+)\end{array}$ & CI & $\mathrm{V}_{r}$ & $\sigma$ & $\begin{array}{c}\text { ID } \\
\text { CBN }\end{array}$ & $\begin{array}{c}\text { HJD } \\
(2450000+)\end{array}$ & CI & $\mathrm{V}_{r}$ & $\sigma$ \\
\hline $84325.3-460750$ & 1555.661 & II & $72(4)$ & \pm 46 & $84431.5-455314$ & 1559.744 & II & $85(4)$ & \pm 19 \\
\hline $84338.5-460817$ & 1555.684 & II & $56(4)$ & \pm 17 & $84502.0-455257$ & 1559.769 & II & $56(4)$ & \pm 20 \\
\hline 84543.1-460742 & 1555.791 & II & $15(4)$ & \pm 10 & $84458.5-455242$ & 1559.769 & II & $22(2)$ & \pm 14 \\
\hline 84552.3-460929 & 1555.810 & II & $28(4)$ & \pm 26 & $84327.4-460240$ & 1559.851 & II & $55(4)$ & \pm 27 \\
\hline $84443.0-455130$ & 1556.642 & II & $-3(4)$ & \pm 22 & $84350.7-4$ & 1560.593 & II & $39(4)$ & \pm 36 \\
\hline $84501.9-455034$ & 1556.656 & II & $10(4)$ & \pm 12 & $84346.7-460641$ & 1560.743 & II & $106(4)$ & \pm 51 \\
\hline $84506.0-4$ & 155 & II & $16(4)$ & \pm 08 & $84344.7-4$ & 0.743 & II & $3(4)$ & \pm 31 \\
\hline $84518.6-454543$ & 1556.692 & II & $2(4)$ & \pm 14 & $84318.7-460742$ & 1560.764 & II & $17(3)$ & \pm 34 \\
\hline 84433.4-454115 & 1556.711 & II & $41(4)$ & \pm 08 & $84418.2-$ & 1.660 & II & $29(3)$ & \pm 07 \\
\hline 84359.6-460237 & 1556.770 & II & $28(4)$ & \pm 33 & $84518.8-454147$ & 1561.710 & II & $49(3)$ & \pm 16 \\
\hline $84406.6-455642$ & 1556.801 & II & $-4(4)$ & \pm 07 & $84527.2-455360$ & 1561.833 & II & $98(4)$ & \pm 13 \\
\hline $84446.2-460433$ & 1556.828 & II & $-13(4)$ & \pm 13 & $84523.5-455340$ & $\$ 1.851$ & II & $-19(3)$ & \pm 20 \\
\hline 84447.4-460339 & 1556 . & II & $-1(4)$ & \pm 09 & $84327.7-460929$ & & $\mathrm{I}$ & $-41(4)$ & \pm 21 \\
\hline $84509.0-455530$ & 1557.676 & II & $36(4)$ & \pm 11 & $84505.7-454040$ & 1924.818 & $\mathrm{I}$ & $112(4)$ & \pm 17 \\
\hline $84519.3-455733$ & 1557.698 & II & $23(4)$ & \pm 10 & $84522.4-455527$ & 1926.808 & $\mathrm{I}$ & $32(4)$ & \pm 04 \\
\hline $84510.5-460219$ & 1557.713 & II & $9(3)$ & \pm 10 & $84526.1-460527$ & 1927.776 & $\mathrm{I}$ & $33(3)$ & \pm 15 \\
\hline $84450.1-455648$ & 1557.796 & II & $29(4)$ & \pm 09 & $84442.0-460802$ & & II & $69(4)$ & \pm 34 \\
\hline 84426.0-455749 & 1557.807 & II & $28(3)$ & \pm 15 & $84423.1-460821$ & 1946.742 & II & $55(4)$ & \pm 32 \\
\hline $84332.2-455337$ & 1557.841 & II & $-2(4)$ & \pm 17 & $84416.7-461121$ & 1959.733 & II & $107(4)$ & \pm 37 \\
\hline $84339.5-455148$ & 1557.849 & II & $-10(4)$ & \pm 14 & 84421.9-461025 & 1960.765 & II & $1(4)$ & \pm 32 \\
\hline 84349.4-454204 & 1558.717 & II & $-8(4)$ & \pm 13 & $84518.2-455816$ & 1961.718 & II & $88(4)$ & \pm 33 \\
\hline 84500.4-455834 & 1558.742 & II & $28(4)$ & \pm 18 & $84437.8-455257$ & 1962.729 & II & $27(2)$ & \pm 04 \\
\hline $84505.0-460300$ & 1558.755 & II & $13(4)$ & \pm 08 & 84430.9-455442 & 2287.798 & II & $102(4)$ & \pm 36 \\
\hline $84446.7-454632$ & 1558.836 & II & $38(4)$ & \pm 17 & $84414.0-455733$ & 2294.706 & II & $88(4)$ & \pm 51 \\
\hline $84410.6-455452$ & 1559.677 & II & $50(2)$ & \pm 02 & $84421.9-455136$ & 2296.704 & II & $81(4)$ & \pm 24 \\
\hline 84434.3-455214 & 559.730 & II & $21(4)$ & \pm 05 & & & & & \\
\hline
\end{tabular}


De confirmarse la binaridad de estos objetos, la obtención de la velocidad baricentral del sistema será esencial para confirmar cinemáticamente su pertenencia a la asociación OB.

LS 1135 es un sistema binario a un espectro de tipo espectral O con un período orbital de 2.7532 días (Corti et al., 2003), sobre la misma se presenta una amplia discusión en la subsección 9.3 .

En la Tabla 28 se muestran las velocidades radiales heliocéntricas que fueron posibles obtener de los espectros digitales de cada estrella, en aquellas con dos o más espectros se calculó una Vr heliocéntrica promedio. Las líneas de absorción empleadas en cada espectro para realizar el promedio que se comenta fueron $\mathrm{H} \gamma$, HeI $4471 \AA$,H $\beta$ y HeI $4922 \AA$ Luego promediando la Vr heliocéntrica resultante para cada estrella con tres o más espectros, se obtuvo una Vr heliocéntrica promedio para las estrellas candidatas a miembros de Bo 7 de $\overline{V_{r}}$ $=51 \pm 11 \mathrm{kms}^{-1}$ (sin considerar a la estrella de emisión CBN84506.3-460906). El sistema binario LS 1135 también fue considerado. El histograma de la Figura 27 muestra la cantidad de estrellas cuya Vr obtenida analizando los espectros digitales, resulta coincidente dentro de un rango de variación de la misma de $\Delta \mathrm{V}_{r}=20 \mathrm{~km} \mathrm{~s}^{-1}$. Es evidente aquí que la mayor coincidencia se da para el valor de velocidad radial promedio.

Con los datos de velocidad radial de las 63 estrellas con tipos espectrales O y B en la zona de Bo 7, llevados al sistema de referencia LSR, graficamos su correspondencia con la distancia al Sol a la que cada una de esas estrellas se encuentra, mostrado en la Figura 28. Para los valores de velocidad radial y distancia de cada estrella incluimos las barras de error correspondientes. En el gráfico, incorporamos los modelos de curva de rotación de la Galaxia de Fich et al (1989), en color azul y de Clemens (1985), en color verde. Para ello empleamos un programa cedido por el Dr. Marcelo Arnal que calcula las velocidades radiales usando los campos de velocidades propios de cada modelo de curva de rotación Galáctica. En el programa no se ha tenido en cuenta la propagación de los errores de los coeficientes de ajuste de las curvas de rotación y los valores iniciales usados en este programa fueron $1=265^{\circ} \mathrm{y} \mathrm{b}=-2^{\circ}$ con un rango de distancia yendo de 1 a $13 \mathrm{kpc}$ con un intervalo de $1 \mathrm{kpc}$. En la Figura 28 se ve que las estrellas CBN 84349.4-454204, CBN 84446.2-460433, CBN 84339.5-455148, CBN 84523.5-455340, CBN 84327.7-460929, CBN 84510.9-455900, CBN 84418.2-455307, CBN 84421.9-461025, CBN 84505.0-460300, CBN 84505.7-454040 y CBN 84527.2-455360 presentan velocidades anómalas que no se ajustan al modelo de curva de rotación de la 


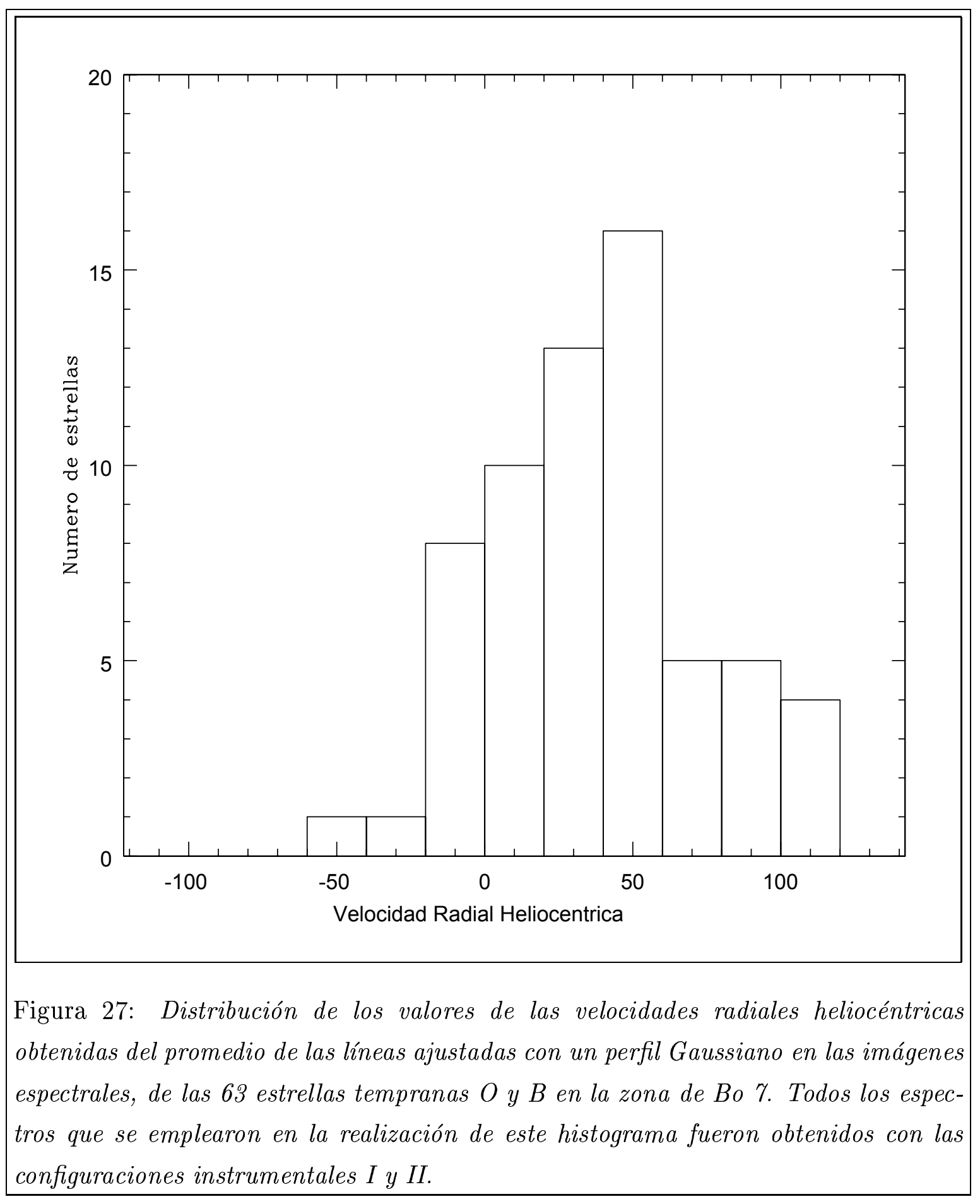

Estudio de una Asociación $O B$ distante en la Vía Láctea 
Galaxia, debido a lo cual tienen alta probabilidad de pertenecer a sistemas binarios. En la Tabla 28 se pueden encontrar las estrellas que aquí se mencionan con sus correspondientes valores de velocidad radial heliocéntrica y distancia. La pertenencia o no a sistemas binarios de estas 11 estrellas no es posible de confirmar con la poca cantidad de espectros que se han logrado reunir para cada una de ellas y pueden quedar como candidatas a ser estudiadas en el futuro.

\section{Espectros fotográficos}

Las velocidades radiales fueron determinadas ajustando un perfil Gaussiano a cada línea espectral. En la Tabla 27 se lista la velocidad radial heliocéntrica de cada estrella del catálogo LS con las que hemos trabajado en esta Tesis. La misma es el resultado de haber realizado un promedio entre las velocidades radiales medidas en todas las líneas del espectro. En esta Tabla sólo se muestran los resultados de los espectros fotográficos y en las sucesivas columnas de la misma se indican, la identificación de la estrella, Fecha Juliana de la observación, velocidad radial heliocéntrica promedio y entre paréntesis se indica la cantidad de líneas que fueron posible promediar en el espectro. En los espectros de la estrella CBN84349.6-460711 (LS 1135) se promediaron las líneas de HeI $\lambda 4471$, HeII $\lambda 4199, \lambda 4541$ y $\lambda 4685$. En la última

columna se presenta la desviación estándar del promedio (ecuaciones 37 y 38, respectivamente).

$$
\begin{gathered}
\overline{V_{r}}=\left[\sum_{i=1}^{n}\left(V_{r}\right)_{i}\right] \cdot n^{-1} \\
\sigma_{n}=\sqrt{\frac{\sum_{i=1}^{n}\left[\left(V_{r}\right)_{i}-\overline{V_{r}}\right]^{2}}{n}}
\end{gathered}
$$

En la Tabla 28 se presentan algunos de los parámetros físicos comentados en el desarrollo de las secciones 5.1 y 5.2. En las sucesivas columnas se muestra: la identificación de las estrellas, la magnitud visual, los colores (B - V), (U - B) y (V - K) el cual fue obtenido de K83, el exceso de color $\mathrm{E}(\mathrm{B}-\mathrm{V})$, los tipos espectrales encontrados para las estrellas descubiertas en la zona de Bo 7, la magnitud visual absoluta de cada estrella, los valores del ancho equivalente de la DIB 4428, la velocidad radial heliocéntrica obtenida para cada estrella promediando

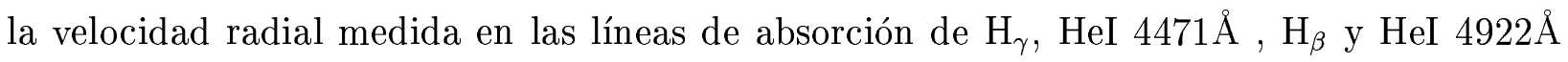
Entre paréntesis se indica la cantidad de espectros de cada estrella con los que se contó para obtener la velocidad radial. En la columna siguiente se muestra la desviación estándar con 


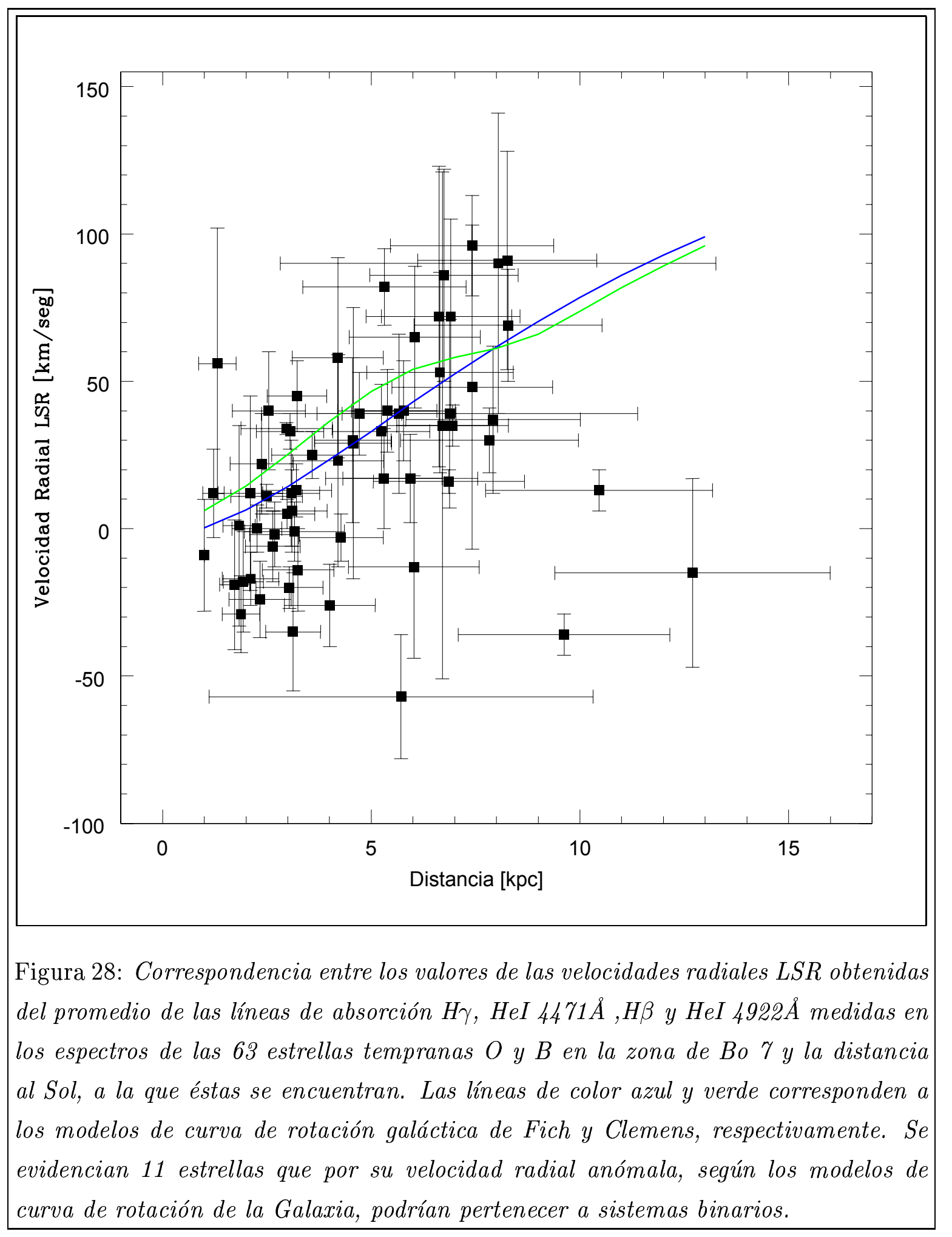

Estudio de una Asociación $O B$ distante en la Vía Láctea 
Tabla 27: Velocidades radiales medidas en los 37 espectros fotográficos obtenidos para las ocho estrellas del catálogo LS (se incluye a CBN84332.2-455337 (LS 1132)).

\begin{tabular}{|c|c|c|c|c|c|r|c|}
\hline \hline $\begin{array}{c}\text { ID } \\
\text { CBN... }\end{array}$ & $\begin{array}{c}\text { HJD } \\
(2440000+)\end{array}$ & $\begin{array}{c}V_{r} \\
\mathrm{~km} \mathrm{~s}^{-1}\end{array}$ & $\begin{array}{c}\sigma \\
\mathrm{km} \mathrm{s}^{-1}\end{array}$ & $\begin{array}{c}\text { ID } \\
\text { CBN }\end{array}$ & $\begin{array}{c}\text { HJD } \\
(2440000+)\end{array}$ & $\begin{array}{c}V_{r} \\
\mathrm{~km} \mathrm{~s}^{-1}\end{array}$ & $\begin{array}{c}\sigma \\
\mathrm{km} \mathrm{s}^{-1}\end{array}$ \\
\hline \hline $84424.9-455334$ & 5013.687 & $74(11)$ & \pm 26 & $84349.6-460711$ & 5510.456 & $21(4)$ & \pm 60 \\
$84424.9-455334$ & 5017.621 & $78(7)$ & \pm 37 & $84349.6-460711$ & 5511.453 & $187(4)$ & \pm 16 \\
$84424.9-455334$ & 5126.514 & $57(8)$ & \pm 38 & $84349.6-460711$ & 5512.452 & $-37(3)$ & \pm 55 \\
& & & & $84349.6-460711$ & 5769.686 & $125(4)$ & \pm 37 \\
$84404.4-455316$ & 5013.709 & $73(10)$ & \pm 21 & $84349.6-460711$ & 5769.703 & $147(3)$ & \pm 37 \\
$84404.4-455316$ & 5017.649 & $40(6)$ & \pm 23 & $84349.6-460711$ & 5773.689 & $28(4)$ & \pm 27 \\
& & & & $84349.6-460711$ & 5775.634 & $181(4)$ & \pm 74 \\
$84332.2-455337$ & 5017.665 & $3(11)$ & \pm 47 & $84349.6-460711$ & 5842.494 & $45(4)$ & \pm 20 \\
& & & & $84349.6-460711$ & 5844.487 & $132(4)$ & \pm 32 \\
$84350.9-460348$ & 5017.682 & $56(10)$ & \pm 28 & $84349.6-460711$ & 5847.508 & $173(4)$ & \pm 47 \\
& & & & $84349.6-460711$ & 6132.582 & $38(4)$ & \pm 40 \\
$84506.3-460906$ & 5017.722 & $41(2)$ & \pm 33 & $84349.6-460711$ & 6132.724 & $2(2)$ & \pm 30 \\
$84506.3-460906$ & 5071.610 & $55(2)$ & \pm 39 & $84349.6-460711$ & 6133.661 & $150(4)$ & \pm 48 \\
& & & & $84349.6-460711$ & 6134.569 & $-23(4)$ & \pm 48 \\
$84450.9-461012$ & 5509.484 & $49(4)$ & \pm 43 & $84349.6-460711$ & 6134.639 & $-2(4)$ & \pm 39 \\
$84450.9-461012$ & 5512.474 & $33(8)$ & \pm 55 & $84349.6-460711$ & 6135.647 & $57(4)$ & \pm 30 \\
& & & & $84349.6-460711$ & 6135.739 & $103(4)$ & \pm 33 \\
$84324.0-460831$ & 5510.472 & $64(6)$ & \pm 33 & $84349.6-460711$ & 6136.639 & $123(4)$ & \pm 20 \\
$84324.0-460831$ & 5511.466 & $90(9)$ & \pm 43 & $84349.6-460711$ & 6136.772 & $27(4)$ & \pm 22 \\
& & & & $84349.6-460711$ & 6137.664 & $-40(4)$ & \pm 21 \\
$84349.6-460711$ & 5508.463 & $211(4)$ & \pm 53 & $84349.6-460711$ & 6138.663 & $121(3)$ & \pm 43 \\
$84349.6-460711$ & 5509.464 & $29(3)$ & \pm 19 & $84349.6-460711$ & 6139.773 & $17(3)$ & \pm 46 \\
\hline \hline
\end{tabular}


que se obtuvo cada valor de velocidad radial promedio y en las útimas tres columnas están el módulo de distancia de cada estrella, las distancias de las mismas calculadas empleando la ecuación 5 y las referencias cruzadas encontradas para algunas estrellas, aquellas con $\mathrm{V}$ $\leq 12$. Dichas referencias fueron buscadas utilizando Aladin (http://aladin.u-strasbg.fr) en el Catálogo de Córdoba Durchmusterng (CD) y en el Catálogo Cape Photographic Durchmusterng (CPD). En ambos encontramos las coordenadas ecuatoriales celestes en distintas épocas y las coords. galácticas, junto a la magnitud visual V. En las estrellas cuyo tipo espectral no pudo definirse entre dos posibles, los valores de $\mathrm{E}(\mathrm{B}-\mathrm{V}), \mathrm{Mv}, \mathrm{Vo}-\mathrm{Mv}$ y $\mathrm{D}_{B V}$ se obtuvieron del promedio entre los correspondientes para cada tipo espectral. 


\begin{tabular}{|c|c|c|c|c|c|c|c|c|c|c|c|c|c|}
\hline & & & & $\begin{array}{l}\text { las } 63 \\
\text { estrel }\end{array}$ & $\begin{array}{l}\text { strellas } \\
\text { WR } 12\end{array}$ & emprana & ana & adas er & este tra & ho & $\begin{array}{l}\text { para } \\
\text { y la }\end{array}$ & & \\
\hline $\begin{array}{c}\text { ID } \\
\text { CBN }\end{array}$ & $\mathrm{V}$ & $(B-V)$ & $(\mathrm{U}-\mathrm{B})$ & $\begin{array}{c}(\mathrm{V}-\mathrm{K}) \\
\mathrm{K} 83\end{array}$ & $\mathrm{E}(\mathrm{B}-\mathrm{V})$ & $\mathrm{TE}$ & $\mathrm{Mv}$ & eqw4428 & $\mathrm{Vr}$ & $\sigma$ & $\mathrm{Vo}-\mathrm{Mv}$ & $\mathrm{D}_{B V}$ & Refer.Cruzadas \\
\hline $84332.2-455337$ & 10.1 & 0.30 & -0.41 & 0.8 & 0.54 & B2IV & -3.1 & 0.60 & $-2(1)$ & 17 & 11.40 & 1.9 & LS1132, CD-454451, CPD-452903 \\
\hline $84433.4-454115$ & 10.4 & 0.23 & -0.47 & $\ldots$ & 0.47 & B2III & -3.9 & 0.85 & $41(1)$ & 8 & 12.77 & 3.6 & \\
\hline $84501.9-455034$ & 10.4 & 0.18 & -0.45 & 0.5 & 0.47 & B2IV & -3.1 & 0.73 & $10(1)$ & 12 & 12.11 & 2.6 & CD-454491, CPD-452969 \\
\hline $84446.2-460433$ & 10.7 & 0.08 & -0.49 & 0.2 & 0.28 & $\mathrm{~B} 3 \mathrm{~V}$ & -1.6 & 0.60 & $-13(1)$ & 13 & 11.37 & 1.9 & CD-454481, CPD-452955 \\
\hline $84324.0-460831$ & 10.8 & 0.50 & -0.50 & 1.2 & 0.78 & $\mathrm{O} 7.5 \mathrm{~V}$ & -5 & 1.90 & $45(28) \mathrm{v}:$ & 46 & 13.30 & 4.6 & LS1131 \\
\hline $84447.2-455856$ & 10.8 & 0.51 & -0.36 & $\ldots$ & $\ldots$ & WN8 $8^{4}$ & $\ldots$ & $\ldots$ & $\ldots$ & $\ldots$ & $\ldots$ & $\ldots$ & LS1145, WR12 \\
\hline $84506.0-455008$ & 10.9 & 0.25 & -0.35 & 0.7 & 0.49 & $\mathrm{~B} 2 \mathrm{~V}$ & -2.4 & 0.60 & $16(1)$ & 8 & 11.77 & 2.3 & CD-454493, CPD-452970 \\
\hline $84349.6-460711$ & 10.9 & 0.34 & -0.61 & 1.2 & 0.67 & $\mathrm{O} 6.5 \mathrm{~V}((\mathrm{f}))$ & -5.4 & 1.60 & $71(32)$ & 1 & 14.13 & 6.7 & $\operatorname{LS} 1135^{\varnothing}$ \\
\hline $84447.4-460339$ & 11.1 & 0.09 & -0.39 & 0.3 & 0.28 & B3-5V & -1.4 & 0.70 & $-1(1)$ & 9 & 11.62 & 2.1 & CD-454483, CPD-452958 \\
\hline $84510.4-455854$ & 11.2 & 0.55 & -0.48 & 1.7 & 0.85 & O9.5II & -5.8 & 2.50 & $51(3)$ & 7 & 14.21 & 6.9 & CPD-452977 \\
\hline $84504.8-460013$ & 11.2 & 0.14 & -0.44 & 0.4 & 0.38 & $\mathrm{~B} 2 \mathrm{~V}$ & -2.4 & 0.70 & $49(2)$ & 6 & 12.42 & 3.0 & CD-454492, CPD-452971 \\
\hline $84406.6-455642$ & 11.3 & 0.17 & -0.32 & 0.5 & 0.41 & $\mathrm{~B} 2 \mathrm{~V}$ & -2.4 & 0.80 & $-4(1)$ & 7 & 12.41 & 3.0 & CD-454466?, CPD- 452927 \\
\hline $84424.9-455334$ & 11.3 & 0.61 & -0.44 & 1.8 & 0.93 & $\mathrm{O} 7.5 \mathrm{~V}$ & -5 & 1.90 & $46(24) \mathrm{v}:$ & 28 & 13.29 & 4.6 & LS1144, CD-454472, CPD-452937 \\
\hline $84426.0-455749$ & 11.4 & 0.25 & -0.16 & 0.7 & 0.36 & $\mathrm{~B} 8 \mathrm{~V}$ & -0.2 & 0.60 & $28(1)$ & 49 & 10.43 & 1.2 & CD-454473, CPD-452939 \\
\hline $84450.1-455648$ & 11.4 & 0.16 & -0.51 & 0.4 & 0.40 & $\mathrm{~B} 2 \mathrm{~V}$ & -2.4 & 0.80 & $29(1)$ & 9 & 12.53 & 3.2 & CD-454484, CPD-452959 \\
\hline $84350.9-460348$ & 11.4 & 0.45 & -0.49 & 1.4 & 0.76 & O9-9.5V & -4.4 & 1.90 & $55(3)$ & 14 & 13.37 & 4.7 & LS1137, CD-454462, CPD-452921 \\
\hline $84506.3-460906$ & 11.5 & 0.55 & -0.47 & 2.5 & 0.84 & BoIIIe & $-4.2:$ & 1.90 & $7(20) \mathrm{v}:$ & 19 & 12.92: & 3.8: & LS1147, CD-454494, CPD-452973 \\
\hline $84543.1-460742$ & 11.5 & 0.10 & -0.42 & 0.3 & 0.32 & $\mathrm{~B} 2-3 \mathrm{~V}$ & -2 & 0.40 & $15(1)$ & 10 & 12.50 & 3.2 & CPD-453000 \\
\hline $84450.9-461012$ & 11.6 & 0.47 & -0.48 & $\ldots$ & 0.73 & B1III & -4.4 & 2.38 & $33(18) \mathrm{v}:$ & 17 & 13.62 & 5.3 & LS1146 \\
\hline $84404.4-455316$ & 11.7 & 0.68 & -0.33 & $\ldots$ & 0.97 & B0III & -5.1 & 2.27 & $56(3)$ & 14 & 13.66 & 5.4 & LS1140 \\
\hline $84339.5-455148$ & 11.7 & 0.54 & -0.14 & $\ldots$ & 0.78 & B2III & -3.9 & 0.74 & $-10(1)$ & 14 & 13.01 & 4.0 & CPD-452909 \\
\hline $84518.6-454543$ & 11.8 & 0.27 & -0.30 & 0.8 & 0.51 & $\mathrm{~B} 2 \mathrm{~V}$ & -2.4 & 0.48 & $2(1)$ & 14 & 12.56 & 3.2 & CPD-452984 \\
\hline $84325.3-460750$ & 11.8 & 0.25 & -0.05 & 1.0 & 0.32 & $\mathrm{~B} 8-\mathrm{A} 0 \mathrm{~V}$ & 0.2 & 0.40 & $72(1)$ & 46 & 10.59 & 1.3 & CPD-452901 \\
\hline $84552.3-460929$ & 11.8 & 0.10 & -0.41 & $\ldots$ & 0.27 & $\mathrm{~B} 5 \mathrm{~V}$ & -1.2 & 0.44 & $28(1)$ & 26 & 12.14 & 2.7 & \\
\hline $84359.6-460237$ & 12.0 & 0.20 & -0.28 & 0.6 & 0.34 & B5-8V & -0.7 & 0.70 & $28(1)$ & 33 & 11.61 & 2.1 & CPD-452926 \\
\hline $84338.5-460817$ & 12.0 & 0.45 & -0.52 & 1.4 & 0.75 & $09.5 \mathrm{~V}$ & -4.3 & 1.90 & $56(1)$ & 17 & 13.81 & 5.8 & CPD-452910 \\
\hline 84349.4-454204 & 12.0 & 0.29 & -0.25 & 0.8 & 0.47 & $\mathrm{~B} 3-5 \mathrm{~V}$ & -1.4 & $\ldots$ & $-8(1)$ & 13 & 11.84 & 2.3 & CPD-452917 \\
\hline
\end{tabular}




\begin{tabular}{|c|c|c|c|c|c|c|c|c|c|c|c|c|c|}
\hline \multicolumn{14}{|c|}{ Tabla 28: (continuación) } \\
\hline $\begin{array}{c}\text { ID } \\
\text { CBN }\end{array}$ & $\mathrm{V}$ & $(B-V)$ & $(\mathrm{U}-\mathrm{B})$ & $\begin{array}{c}(\mathrm{V}-\mathrm{K}) \\
\mathrm{K} 83 \\
\end{array}$ & $E(B-V)$ & $\mathrm{TE}$ & $\mathrm{Mv}$ & eqw4428 & $\mathrm{Vr}$ & $\sigma$ & Vo - Mv & $\mathrm{D}_{B V}$ & Refer.Cruzadas \\
\hline $84443.0-455130$ & 12.0 & 0.21 & -0.28 & 0.7 & 0.32 & $\mathrm{~B} 8 \mathrm{~V}$ & -0.2 & 0.50 & $-3(1)$ & 22 & 11.19 & 1.7 & CPD-452953 \\
\hline $84318.7-460742$ & 12.2 & 0.24 & -0.19 & 0.9 & 0.35 & B8V & -0.2 & $\ldots$ & $17(1)$ & 34 & 11.32 & 1.8 & CPD-452895 \\
\hline $84438.9-460746$ & 12.2 & 0.10 & -0.36 & 0.4 & 0.27 & B5V & -1.2 & 0.50 & $61(2)$ & 12 & 12.54 & 3.2 & \\
\hline $84327.7-460929$ & 12.3 & 0.63 & -0.58 & 1.0 & 0.93 & B0V-III & -4.5 & 2.20 & $-41(1)$ & 21 & 13.78 & 5.7 & \\
\hline $84348.6-460736$ & 12.3 & 0.40 & -0.47 & 1.4 & 0.66 & $\mathrm{~B} 1-1.5 \mathrm{~V}$ & -3 & 1.70 & $74(2)$ & 34 & 13.12 & 4.2 & \\
\hline $84434.3-455214$ & 12.5 & 0.23 & -0.30 & 0.62 & 0.40 & B5V & -1.2 & 1.40 & $21(1)$ & 5 & 12.38 & 3.0 & \\
\hline $84505.0-460300$ & 12.6 & 0.16 & -0.37 & 0.4 & 0.37 & B2.5-3V & -1.8 & 0.40 & $13(1)$ & 8 & 13.12 & 4.3 & \\
\hline $84446.7-454632$ & 12.6 & 0.46 & -0.09 & 1.2 & 0.64 & B3-5V & -1.4 & 0.40 & $38(1)$ & 17 & 11.88 & 2.4 & \\
\hline $84327.4-460240$ & 12.6 & 0.56 & -0.44 & 1.6 & 0.86 & BOV & -4 & 1.60 & $55(1)$ & 27 & 13.77 & 5.7 & \\
\hline $84500.4-455834$ & 12.6 & 0.24 & -0.34 & 0.6 & 0.41 & B5V & -1.2 & 0.70 & $28(1)$ & 18 & 12.44 & 3.1 & \\
\hline $84505.7-454040$ & 12.7 & 0.60 & -0.31 & $\ldots$ & 0.86 & B1III & -4.4 & 2.60 & $112(1)$ & 17 & 14.35 & 7.4 & \\
\hline $84526.1-460527$ & 12.9 & 0.66 & -0.09 & 2.1 & 0.90 & B2III & -3.9 & 2.10 & $33(1)$ & 15 & 13.86 & 5.9 & \\
\hline $84350.7-455820$ & 12.9 & 0.55 & -0.34 & 1.7 & 0.80 & $\mathrm{~B} 1.5 \mathrm{~V}$ & -2.8 & 2.60 & $39(1)$ & 36 & 13.12 & 4.2 & \\
\hline $84344.7-460656$ & 12.9 & 0.43 & -0.44 & 1.4 & 0.70 & B1V & -3.2 & 1.90 & $3(1)$ & 31 & 13.90 & 6.0 & \\
\hline $84522.4-455527$ & 13.0 & 0.72 & -0.24 & 2.2 & 0.98 & B1III & -4.4 & 2.60 & $32(1)$ & 4 & 14.18 & 6.9 & \\
\hline $84502.0-455257$ & 13.2 & 0.23 & -0.11 & 0.8 & 0.30 & B8-A0V & 0.2 & 0.70 & $56(1)$ & 20 & 12.03 & 2.5 & \\
\hline $84410.6-455452$ & 13.3 & 0.37 & -0.08 & 1.2 & 0.51 & B5-8V & -0.7 & 0.80 & $50(1)$ & 2 & 12.36 & 3.0 & \\
\hline 84419.9-455552 & 13.5 & 0.65 & -0.08 & 1.9 & 0.89 & B2III & -3.9 & 2.90 & $46(2)$ & 11 & 14.47 & 7.8 & \\
\hline $84458.5-455242$ & 13.5 & 0.24 & -0.11 & 0.8 & 0.33 & B8-9V & 0 & $\ldots$ & $22(1)$ & 14 & 12.46 & 3.1 & \\
\hline $84431.5-455314$ & 13.5 & 0.61 & -0.34 & $\ldots$ & 0.85 & B2III: & -3.9 & 2.36: & $85(1)$ & 19 & 14.59: & 8.3 & \\
\hline $84518.2-455816$ & 13.6 & 0.65 & -0.32 & 1.9 & 0.93 & B $0.5 \mathrm{~V}$ & -3.6 & 3.00 & $88(1)$ & 33 & 14.19 & 6.9 & \\
\hline $84423.1-460821$ & 13.7 & 0.65 & -0.33 & $\ldots$ & 0.92 & B1-2/V-III & -3.4 & 1.80 & $55(1)$ & 32 & 14.19 & 6.9 & \\
\hline $84325.6-460820$ & 13.7 & 0.62 & -0.34 & 2.4 & 0.86 & $\mathrm{~B} 2 \mathrm{Ve}$ & $-4.0:$ & 2.00 & $-20(2)$ & 7 & 14.90: & $9.6:$ & \\
\hline $84421.9-455136$ & 13.7 & 0.66 & -0.24 & $\ldots$ & 0.92 & B1V & -3.2 & 3.48 & $81(1)$ & 46 & 13.91 & 6.0 & \\
\hline $84437.8-455257$ & 13.8 & 0.43 & -0.32 & 1.1 & 0.49 & B8-A0V & 0.2 & 0.30 & $27(1)$ & 4 & 12.00 & 2.5 & \\
\hline $84510.9-455900$ & 14.0 & 0.61 & -0.31 & $\cdots$ & 0.87 & B1V & -3.2 & 2.32 & $64(1)$ & 55 & 14.35 & 7.4 & \\
\hline $84442.0-460802$ & 14.1 & 0.51 & -0.14 & 2.0 & 0.75 & $\mathrm{~B} 2 \mathrm{~V}$ & -2.4 & 1.10 & $69(1)$ & 34 & 14.11 & 6.6 & \\
\hline $84346.7-460641$ & 14.2 & 0.37 & -0.43 & 1.4 & 0.58 & B1-5V & -2.2 & 2.20 & $106(1)$ & 51 & 14.53 & 8.0 & \\
\hline $84430.9-455442$ & 14.2 & 0.53 & -0.30 & $\ldots$ & 0.77 & $\mathrm{~B} 2 \mathrm{~V}$ & -2.4 & 1.77 & 102(1) & 36 & 14.14 & 6.7 & \\
\hline $84523.5-455340$ & 14.3 & 0.51 & -0.06 & 1.4 & 0.62 & $\mathrm{~B} 8 \mathrm{~V}$ & -0.2 & 1.80 & $-19(1)$ & 20 & 12.48 & 3.1 & \\
\hline $84416.7-461121$ & 14.3 & 0.53 & -0.25 & 1.5 & 0.78 & B1.5V & -2.8 & 1.90 & 107(1) & 37 & 14.58 & 8.3 & \\
\hline $84423.2-455337$ & 14.5 & 0.58 & -0.24 & 1.9 & 0.82 & B1.5-2V & -2.6 & 1.15 & $53(2)$ & 25 & 14.49 & 7.9 & \\
\hline
\end{tabular}


Tabla 28: (continuación)

\begin{tabular}{|c|c|c|c|c|c|c|c|c|c|c|c|c|c|}
\hline $\begin{array}{c}\text { ID } \\
\mathrm{CBN}\end{array}$ & $\mathrm{V}$ & $(B-V)$ & $(\mathrm{U}-\mathrm{B})$ & $\begin{array}{c}(\mathrm{V}-\mathrm{K}) \\
\mathrm{K} 83\end{array}$ & $\mathrm{E}(\mathrm{B}-\mathrm{V})$ & $\mathrm{TE}$ & $\mathrm{Mv}$ & eqw4428 & $\mathrm{Vr}$ & $\sigma$ & $\mathrm{Vo}-\mathrm{Mv}$ & $\mathrm{D}_{B V}$ & Refer.Cruzadas \\
\hline $84418.2-455307$ & 14.6 & 0.56 & -0.32 & 1.9 & 0.82 & $\mathrm{~B} 1 \mathrm{~V}$ & -3.2 & 1.30 & $29(1)$ & 7 & 15.10 & 10.5 & \\
\hline $84414.0-455733$ & 14.7 & 0.76 & -0.16 & 2.4 & 1.01 & $\mathrm{~B} 1.5-2 \mathrm{~V}$ & -2.6 & 1.90 & $88(1)$ & 51 & 14.10 & 6.6 & \\
\hline $84421.9-461025$ & 14.8 & 0.49 & -0.27 & 2.3 & 0.75 & $\mathrm{~B} 1 \mathrm{~V}$ & -3.2 & 2.00 & $1(1)$ & 32 & 15.52 & 12.7 & \\
\hline $84518.8-454147$ & 14.8 & 0.57 & -0.13 & 1.8 & 0.74 & $\mathrm{~B} 5 \mathrm{~V}$ & -1.2 & 0.87 & $49(1)$ & 16 & 13.60 & 5.2 & \\
\hline $84527.2-455360$ & 14.9 & 0.49 & -0.01 & 1.4 & 0.63 & B5-8V & -0.7 & 1.14 & $98(1)$ & 13 & 13.63 & 5.3 & \\
\hline
\end{tabular}

Columna 1 muestra la identificación de las estrellas de acuerdo a las pautas establecidas para ello por la IAU, siendo las letras mayúsculas las iniciales de los autores y los números las coordenadas celestes J2000.0. Columnas 2, 3 y 4 presentan la magnitud V y colores. El color (V - K) $k 83$ en la columna 5 es el color (V - K) referido al sistema fotométrico de K83. En la columna 6 se muestran los valores de $\mathrm{E}(\mathrm{B}-\mathrm{V})$, los cuales fueron promediados para las estrellas cuyo tipo espectral no pudo ser definido entre dos posibles. La clasificación espectral MK está presente en la columna 7. En la columna 8 se muestra la magnitud absoluta visual que fue interpolada para las estrellas con dos tipos espectrales posibles. El ancho equivalente de $\lambda 4428$ se muestra en Å en la columna 9. Las velocidades radiales heliocéntricas se muestran en la columna 10 con el número de espectros promediados entre paréntesis, se obtuvieron de medir los perfiles espectrales en los espectros digitales. La desviación estándar correspondiente a cada medida de velocidad radial obtenida está en la columna 11. La columna 12 muestra el módulo de distancia y la columna 13 las distancias obtenidas con el valor de E(B - V) presentado en tabla. La columna 14 tiene las referencias cruzadas para algunas de estas estrellas, donde LS indica estrellas en el Luminous Star Catalogue (Stephenson \& Sanduleak, 1971), CD indica estrellas en el catálogo Córdoba Durchmusterung y CPD indica estrellas en el catálogo Cape Photographic Durchmusterung. $\triangle$ según van der Hucht K.A. (2001)

$\varnothing$ Sistema binario a un espectro con un período orbital de 2.7532 días, ver Corti et al. (2003) 


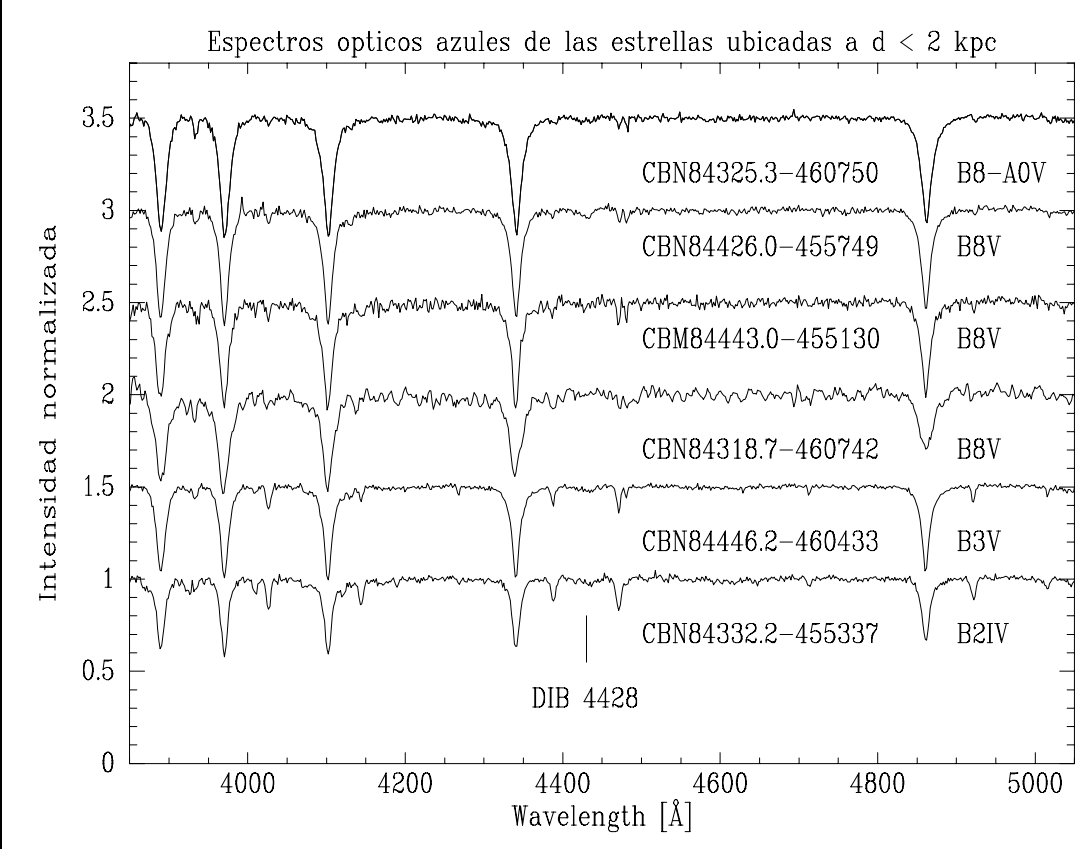

Figura 29: Espectros ópticos azules de las estrellas ubicadas a una distancia menor a 2 kpc. En ellos se observa la intensidad relativamente pequeña que presenta la banda interestelar difusa en $\lambda 4428 \AA$

\subsubsection{Banda Interestelar Difusa $4428 \AA$}

Estudiamos el comportamiento de la DIB $4428 \AA$ en los espectros de resolución media de las estrellas tempranas. Ajustamos una función Gaussiana al perfil de la misma en 6 estrellas de tipo espectral O y 54 estrellas de tipo espectral B de nuestra muestra, y medimos el ancho equivalente (EW) de la DIB en cada uno de estos espectros. Los anchos equivalentes están enumerados en la Tabla 28.

Esta DIB es bien evidente en los espectros digitales azules en dispersión simple de las Figuras 17, 18, 19, 20, 21, 22 y 23. Los espectros de las Figuras 29, 30 y 31 corresponden a estrellas con distintos tipos espectrales O y B ubicadas a una distancia del Sol mayor a $1 \mathrm{kpc}$ y menor a $3 \mathrm{kpc}$. En ellos se evidencia la menor intensidad que presenta la DIB 4428 cuando se trata de estrellas cercanas. En la Tabla 29 están indicadas la identificación, ancho equivalente de la DIB 4428 y distancia que poseen las estrellas a cuyos espectros hago referencia.

Las estrellas de tipos espectrales muy tempranos, tales como las estudiadas en esta Tesis, son verdaderamente útiles para estudiar la banda difusa porque tienen imágenes espectrales 


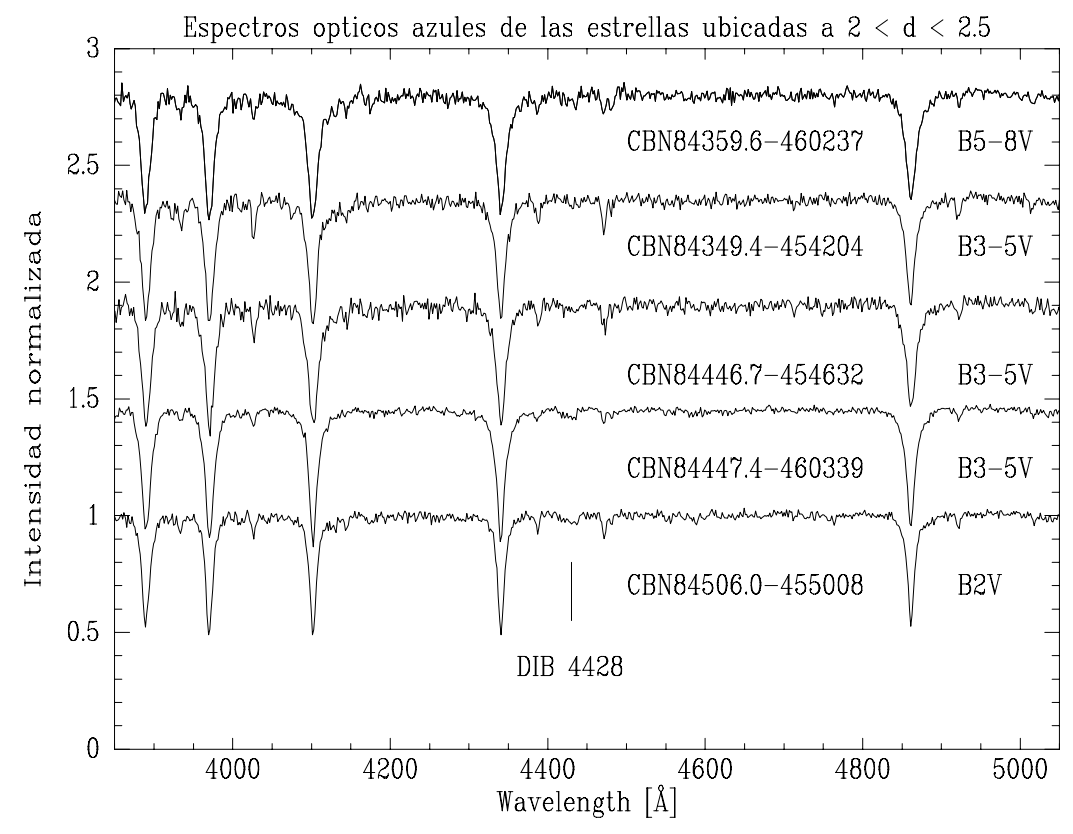

Figura 30: Espectros ópticos azules de las estrellas ubicadas a una distancia comprendida entre 2 kpc y $2.5 \mathrm{kpc}$. En ellos se observa la intensidad relativamente pequeña que presenta la banda interestelar difusa en $\lambda 4428 \AA$

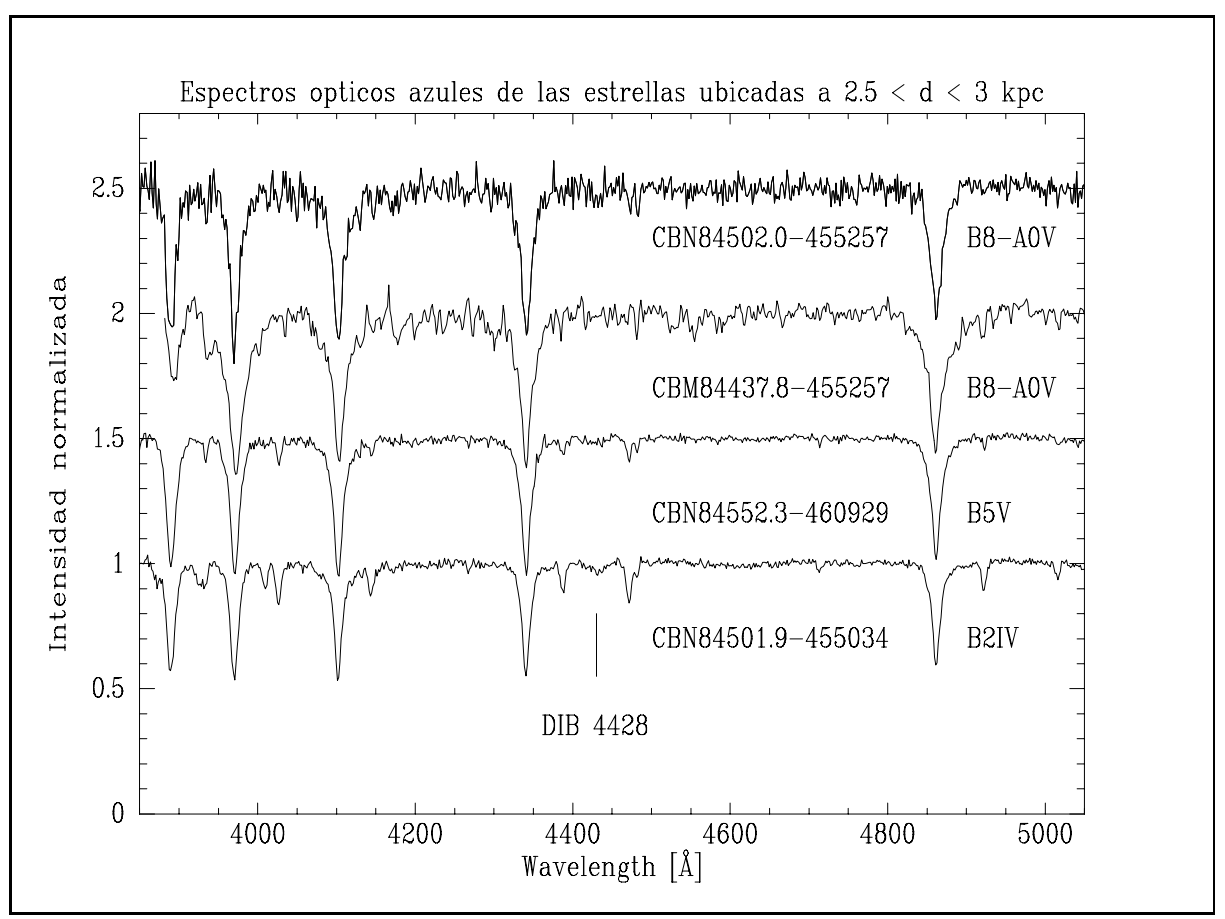

Figura 31: Espectros ópticos azules de las estrellas ubicadas a una distancia comprendida entre $2.5 \mathrm{kpc}$ y $3 \mathrm{kpc}$. En ellos se observa la intensidad relativamente pequeña que presenta la banda interestelar difusa en $\lambda 4428 \AA$ 
Tabla 29: Estrellas ubicadas a una distancia del Sol comprendida entre $1.2 \mathrm{kpc}$ y $2.7 \mathrm{kpc}$. Todas ellas en sus espectros muestran una DIB 4428 con poca intensidad.

\begin{tabular}{|c|c|c|}
\hline \hline $\begin{array}{c}\text { ID } \\
\text { CBN }\end{array}$ & eqw4428 & $\begin{array}{c}\text { Distancia } \\
\mathrm{kpc}\end{array}$ \\
\hline $84426.0-455749$ & 0.60 & 1.2 \\
$84325.3-460750$ & 0.40 & 1.3 \\
$84443.0-455130$ & 0.50 & 1.7 \\
$84318.7-460742$ & - & 1.8 \\
$84446.2-460433$ & 0.60 & 1.9 \\
$84332.2-455337$ & 0.60 & 1.9 \\
$84447.4-460339$ & 0.70 & 2.1 \\
$84359.6-460237$ & 0.70 & 2.1 \\
$84506.0-455008$ & 0.60 & 2.3 \\
$84349.4-454204$ & - & 2.3 \\
$84446.7-454632$ & 0.40 & 2.4 \\
$84502.0-455257$ & 0.70 & 2.5 \\
$84437.8-455257$ & 0.30 & 2.5 \\
$84501.9-455034$ & 0.73 & 2.6 \\
$84552.3-460929$ & 0.44 & 2.7 \\
\hline \hline
\end{tabular}


con continuos relativamente claros.

La Figura 32 muestra la correlación del ancho equivalente del perfil en $\lambda 4428$ con el exceso de color, E(B - V). En la Figura 32 se ve que el ancho equivalente de $\lambda 4428$ crece linealmente con el $\mathrm{E}(\mathrm{B}-\mathrm{V})$ hasta un valor aproximado de $\mathrm{E}(\mathrm{B}-\mathrm{V})=1$ magnitud, siendo a partir de esa cantidad donde se terminan nuestros datos y comienzan los de Snow et al. (2002). Después de ese punto el ancho equivalente de la DIB se mantiene aproximadamente constante para el resto de los valores del E(B - V). Aplicándole sólo a nuestros datos un ajuste de mínimos cuadrados, observamos que la pendiente de la recta de regresión obtenida, es mayor que la correspondiente al ajuste de los datos de Herbig (1975). Con este resultado podemos decir que para un valor de $\mathrm{E}(\mathrm{B}-\mathrm{V}) \simeq 1$ nuestros datos se complementan con los obtenidos por Snow et al. (2002).

\subsubsection{Extinción interestelar}

La combinación de información fotométrica y espectroscópica provee un medio confiable de determinar excesos de color individuales de las estrellas OB del programa. De ese modo resulta posible analizar el comportamiento de la extinción interestelar en la línea de la visual. La Figura 33 muestra la distribución de:

$$
\frac{E_{(U-B)}}{E_{(B-V)}}-0.05 \cdot E_{(B-V)}=S-0.05 \cdot E_{(B-V)}
$$

lo cual según la ley canónica de extinción del medio interestelar (Schmidt-Kaler,1982), debería ser de 0.72. Como puede verse fácilmente en la Figura 33, la mayoría de las estrellas de nuestra muestra de 63 estrellas con tipos espectrales $\mathrm{OB}$, yacen en la región 0.6-0.8, lo cual nos permite extender el uso de este valor a las estrellas que carecen de información espectroscópica.

Una de las primeras pruebas hechas con nuestros tipos espectrales fue chequear la certeza del parámetro libre de enrojecimiento Q, mencionado previamente. El resultado obtenido

puede verse en la Figura 34 donde hemos comparado los valores obtenidos para el parámetro libre de enrojecimiento, ecuación 40, calculado de la información fotométrica y aquellos obtenidos del conocimiento de sus colores intrínsecos, ecuación 41. Las barras de error en la ordenada se deben a la incerteza fotométrica de aproximadamente 0.15 magnitudes (ecuaciones 42 y 43$)$. 


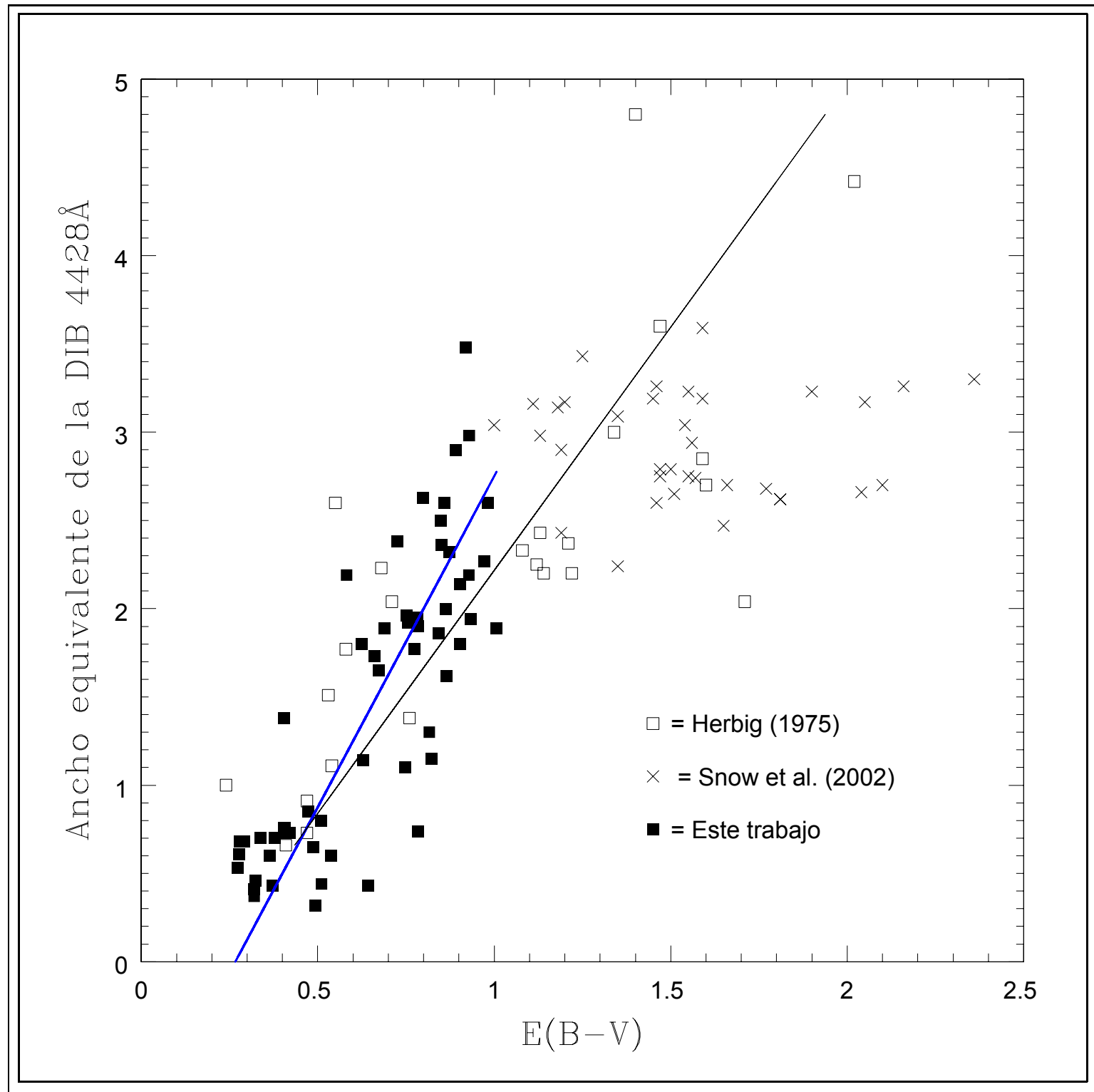

Figura 32: Correlación del ancho equivalente de $\lambda 4428$ con el exceso de color $E(B-$ $V)$. 


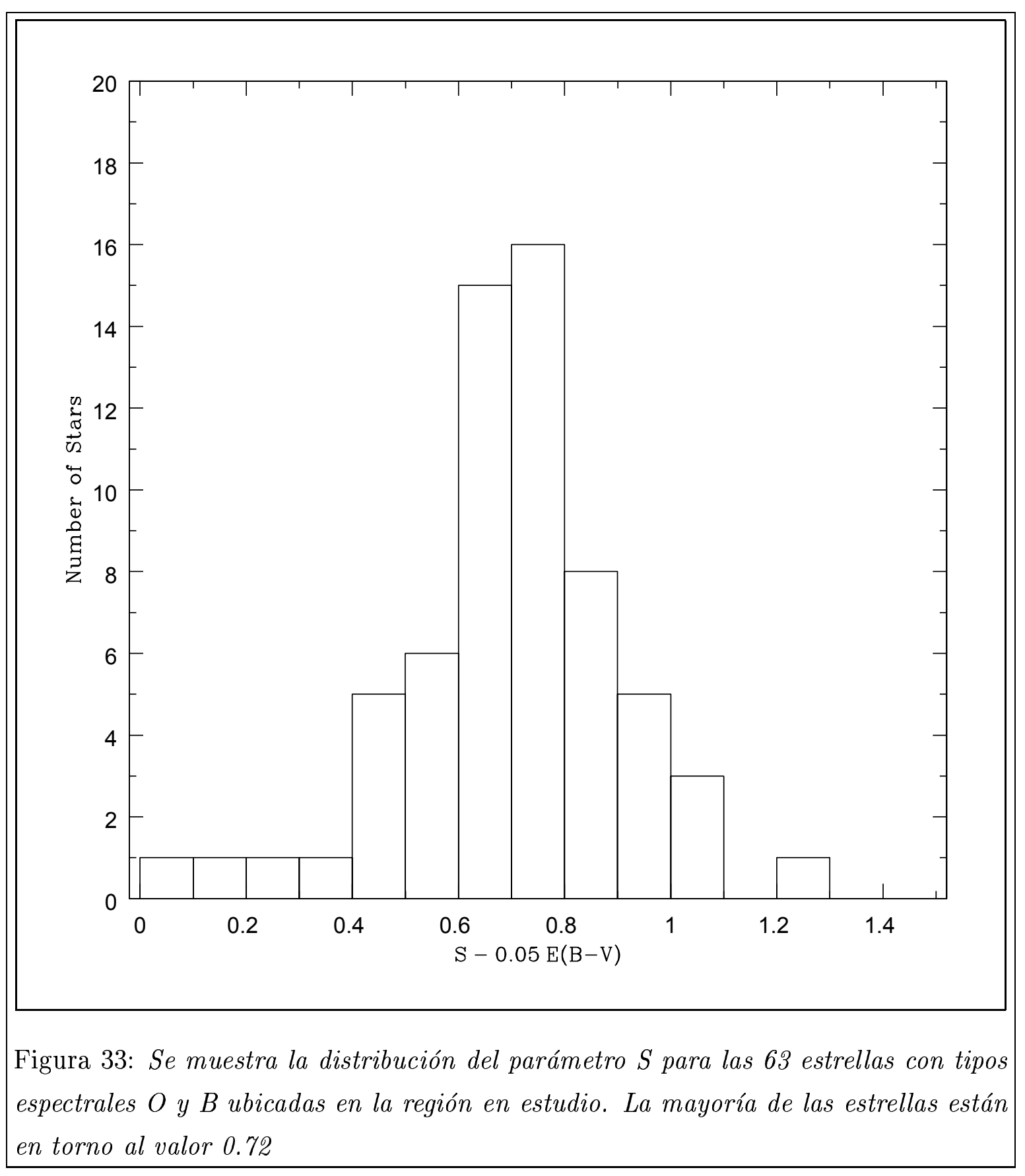

Estudio de una Asociación $O B$ distante en la Vía Láctea 
En caso de tratarse de estrellas con enrojecimientos muy altos, para la ecuación 40 el cociente $\mathrm{E}_{(U-B)} / \mathrm{E}_{(B-V)}$ debe ser reemplazado por la ley de extinción (ecuación 17), con lo cual se agregaría el término $0.05 \mathrm{E}_{(B-V)}(B-V)$. Considerando a las estrellas con mayor enrojecimiento del grupo de 63 estrellas $\mathrm{OB}$ con las que se trabajó en esta Tesis, el agregado de este último término en la ecuación 40, sólo modifica el resultado de la misma en una cantidad tan pequeña que queda dentro del error cometido al calcular el valor de $Q_{f}$, por dicha razón no fue considerado.

$$
\begin{gathered}
Q_{f}=(U-B)-0.72 \cdot(B-V) \\
Q_{i}=(U-B)_{\circ}-0.72 \cdot(B-V)_{\circ}
\end{gathered}
$$

El correspondiente error de $Q_{f}$ viene dado por:

$$
\delta Q_{f}=\sqrt{(\delta(U-B))^{2}+(0.72 \cdot \delta(B-V))^{2}}=\sqrt{(\delta U)^{2}+(\delta B)^{2}+(0.72)^{2} \cdot\left((\delta B)^{2}+(\delta V)^{2}\right)}
$$

Siendo así:

$$
\delta Q_{f}=\sqrt{(0.18)^{2}+(0.1)^{2}+(0.72)^{2} \cdot\left((0.1)^{2}+(0.08)^{2}\right)}=0.15
$$

Claramente se ve que ambos parámetros libres de enrojecimientos concuerdan desde -0.9 a -0.5 y comienzan a diferenciarse desde los valores de $Q_{f}>-0.5$. Este era un resultado esperado como consecuencia de que los colores intrínsecos de las estrellas con tipo espectral $\mathrm{F}$ son similares a los colores observados en estrellas enrojecidas con tipos espectrales B tardíos.

Esto puede verse también en el diagrama color - color (Figura 35), donde se han graficado las estrellas de tipos espectrales tempranos con figuras hexagonales llenas y las estrellas con tipos espectrales tardíos con figuras triangulares vacías. Allí es posible ver que $Q$ es un método extremadamente eficiente para detectar estrellas más tempranas que B8 pero la contaminación se incrementa rápidamente cuando bajamos hacia estrellas con tipo espectral A0. Posiblemente sea una consecuencia de los errores con los que hemos obtenido los colores $(\mathrm{U}$ - B) y $(\mathrm{B}-\mathrm{V})$ de las estrellas que estamos estudiando, generando una contaminación hasta $\mathrm{Q} \simeq-0.5(1 \sigma)$ ó $-0.6(2 \sigma)$. La curva del diagrama color-color se consigue con la posición de las estrellas según sean sus propiedades físicas intrínsecas. Estos datos se buscaron en 


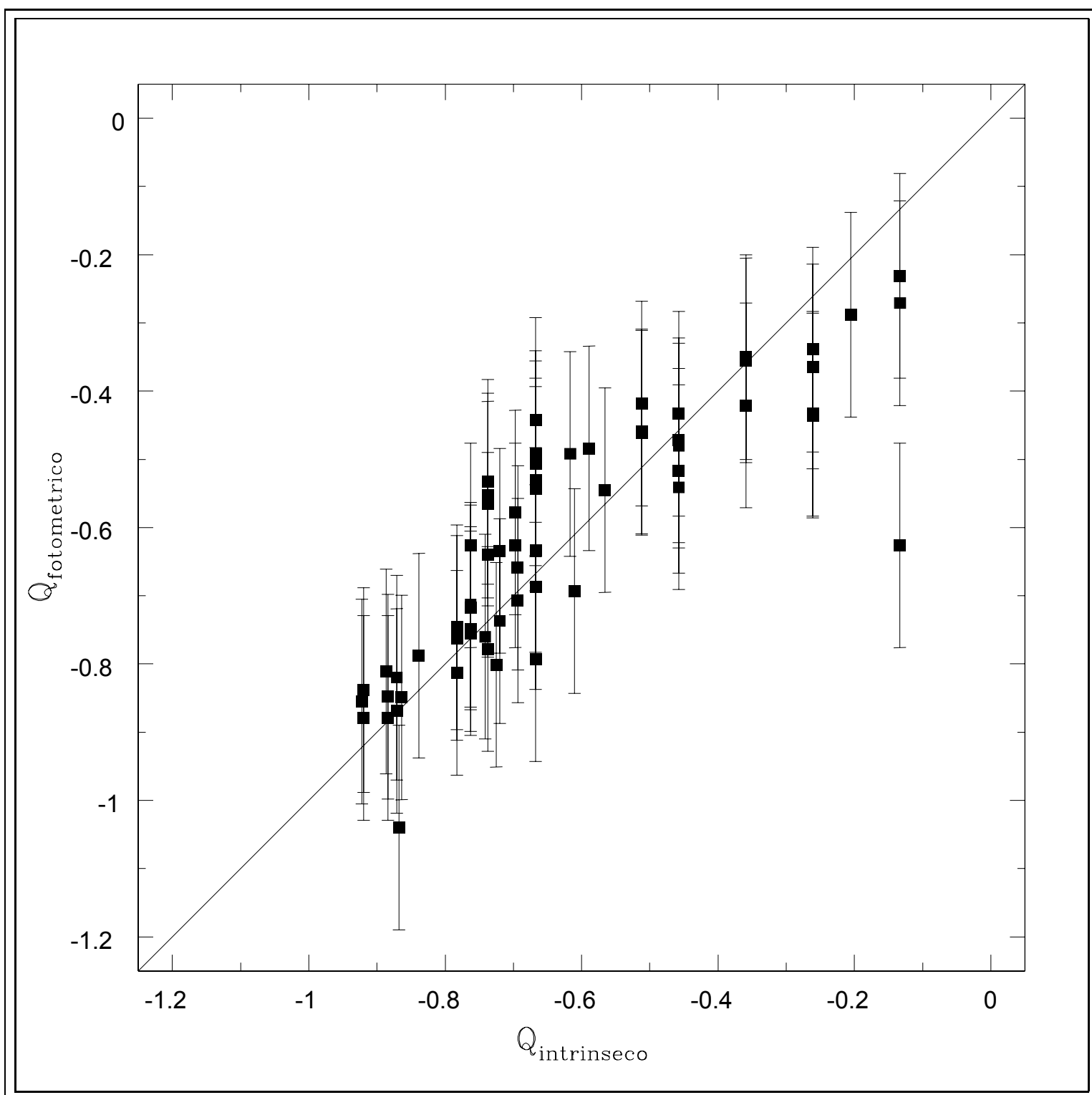

Figura 34: Muestra la buena correlación entre los valores del parámetro libre de enrojecimiento $Q$ obtenido con los índices de color $(U-B)$ y $(B-V)$ y el mismo parámetro $Q$ obtenido con los índices de color intrínsecos $(U-B)$ 。 $(B-V)$ 。 
las Tablas de Schmidt - Kaler (Lundstrom \& Stenholm, 1984) para las estrellas de secuencia principal con tipos espectrales yendo de $\mathrm{TE}=\mathrm{O}$ a $\mathrm{TE}=\mathrm{M}$.

En el diagrama color - color hay dos estrellas identificadas como CBN84431.8-455813 y CBN84446.0-45544, cuyas posiciones en el mismo no resultan compatibles con sus tipos espectrales tardíos. Nosotros revisamos sus datos fotométricos y comparamos los colores (B - V) y (U - B) obtenidos para las mismas en nuestra fotometría con los correspondientes de la fotometría de Sung et al. Para ambas estrellas el color (B - V) de las dos fotometrías mencionadas, difiere en $\simeq 0.03$ y el color $(\mathrm{U}-\mathrm{B})$ difiere en $\simeq 0.12$. Con el color $(\mathrm{U}-\mathrm{B})$ que estas estrellas tienen, $(\mathrm{U}-\mathrm{B})=-0.13$ para la estrella CBN84431.8-455813 y (U - B) $=-0.1$ para la estrella CBN84446.0-45544, según Sung et al., en el diagrama color-color de la Figura 35 se ubicarian en el sector correspondiente a las estrellas con tipo espectral A. Asi mismo, las diferencias entre los colores de ambas fotometrías quedan dentro del error de nuestra fotometría. Del mismo modo, revisamos sus espectros y ambos tienen sólamente perfiles de absorción y todos ellos con buena relación señal a ruido. Lo que aquí se comenta respecto de estas dos estrellas es la razón por la cual se observaron estrellas de TE $=$ A, F y G, creyendo que sus TEs eran O y B.

Considerando estos resultados se acudió a los turnos de observación descriptos en la sección 5.2 y en el transcurso de los mismos se obtuvieron, en general, un espectro para cada una de las 95 estrellas que se pudieron observar, todas ellas por primera vez y más de un espectro para las estrellas del catálogo LS con las que se trabaja en esta Tesis.

Debido a un considerable porcentaje de tiempo perdido en cada uno de los turnos de observación en el CASLEO como consecuencia de los problemas climáticos, no fue posible obtener imágenes espectrales de las 137 estrellas seleccionadas inicialmente. Así es que las estrellas $\mathrm{O}$ y $\mathrm{B}$ del campo fueron identificadas a través de sus espectros o de sus colores fotométricos $(U-B) y(B-V)$.

La clasificación espectral de las 102 estrellas observadas espectroscópicamente se obtuvo como se comenta en la subsección 5.2.1). De ellas, 63 fueron identificadas como estrellas de tipos espectrales O y B: 50 objetos de secuencia principal y 13 subgigantes, gigantes y supergigantes. Las 39 estrellas restantes resultaron tener tipos espectrales comprendidos entre A0 y G3, con clases de luminosidad yendo de $\mathrm{CL}=\mathrm{I}$ a $\mathrm{CL}=\mathrm{V}$.

Los tipos espectrales de las estrellas que no pudieron ser observadas, fueron estimados 


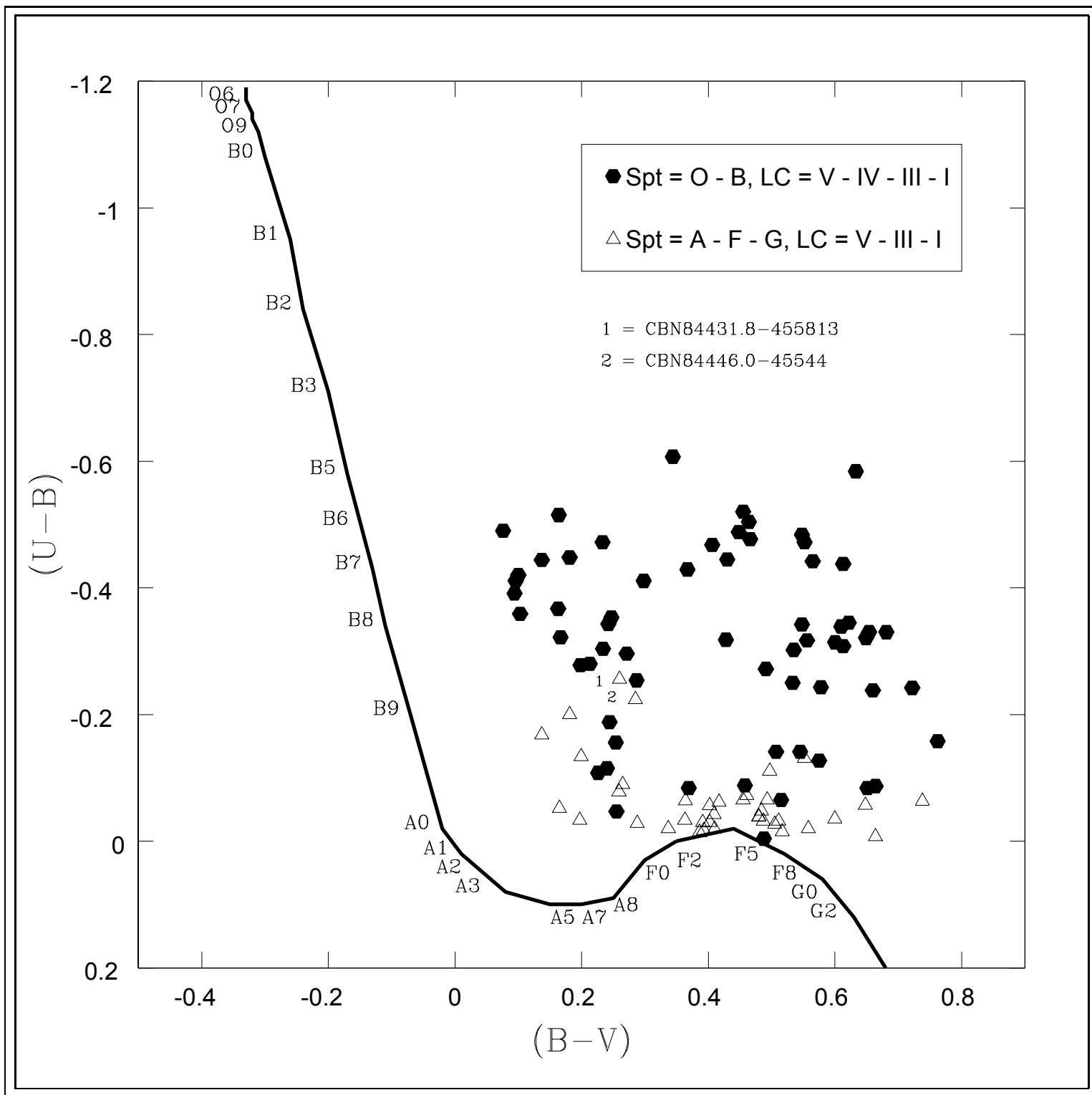

Figura 35: Diagrama color - color para las 102 estrellas clasificadas espectralmente empleando los criterios que se mencionan en el texto. 
empleando el diagrama color-color. Una submuestra de estrellas de secuencia principal con tipos espectrales O y B obtenidos espectroscópicamente, fueron ubicadas en el diagrama color-color y fueron trazados sus vectores de enrojecimiento (ver Figura 36). Un alto porcentaje $(\sim 65 \%)$ de las estrellas OB de la submuestra parecen seguir la curva de extinción estándar, verificando de este modo el resultado mostrado en la Figura 33. Con esto podemos concluir que la ecuación 44 es una aproximación aceptable para la extinción asociada con las estrellas OB en la región de interés (Schmidt - Kaler, 1982):

$$
\frac{E(U-B)}{E(B-V)}=0.72+0.05 \cdot E(B-V)
$$

representada por la línea gris gruesa en la Figura 36. En ella los distintos colores de la curvas de enrojecimiento representan los distintos grupos que se pueden observar de la misma, formados por tener distintas pendientes. El grupo de color verde es aquel cuya pendiente se aproxima más al valor de la pendiente de la recta de extinción estándar.

Este resultado nos permite usar el diagrama color-color para estimar con razonable exactitud el tipo espectral y la extinción visual de las estrellas más tempranas obtenidas de la fotometría de abertura. Con base en la Figura 36 y con un análisis detallado del comportamiento de extinción para todas las estrellas O y B de la muestra espectroscópica, usando este método esperamos conseguir un índice de acierto de aproximadamente un $70 \%$.

Aunque los errores en el color (U - B) sean grandes, debido a la baja relación señal a ruido del filtro $\mathrm{U}$, fue posible identificar una muestra adicional de $\sim 300$ estrellas de tipo espectral O y B.

Siendo la longitud del vector de enrojecimiento un indicador de la cantidad de polvo y habiendo elegido una submuestra de estrellas ubicadas a diferentes distancias del Sol, en la Figura 36 obtenemos como resultado vectores de enrojecimiento con diferentes longitudes. Las pendientes de los mismos resultan ser muy similares entre sí, lo cual era esperado debido a que ésta indica el tipo de polvo en esa dirección y éste se mantiene medianamente uniforme en toda la visual a Bo 7 . 


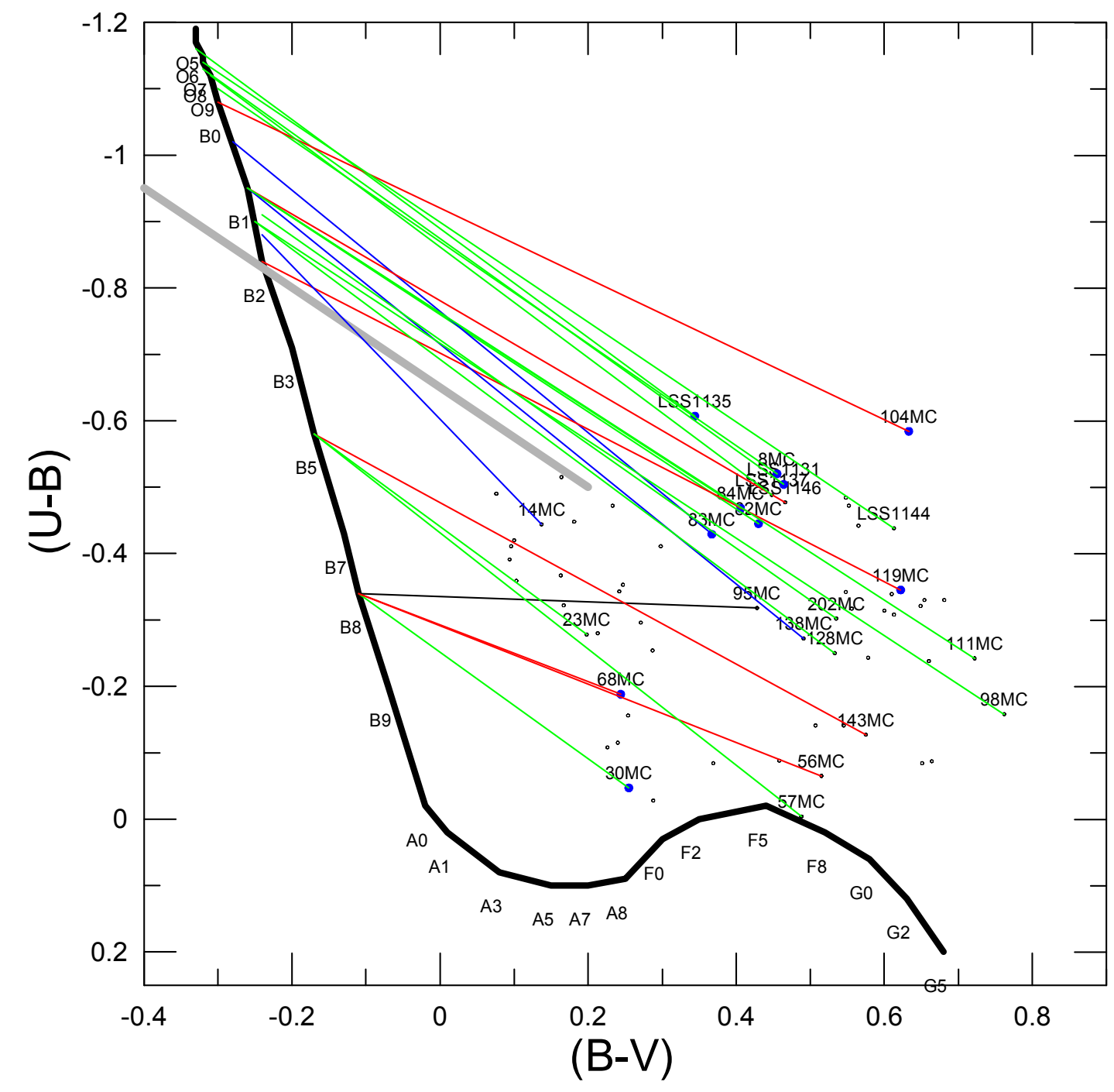

Figura 36: Diagrama color-color para estrellas de secuencia principal. Se presenta una submuestra de estrellas $O B$ con tipos espectrales determinados espectroscópicamente junto con sus correspondientes vectores de enrojecimiento. La mayoría de las estrellas $O B$ en el campo parecen seguir la curva de extinción estándar (ver ecuación 41). De las 24 estrellas ploteadas aqui, solamente 8 se apartan de la curva de extinción estándar esperada y dos de ellas realmente no son de secuencia principal. 


\subsection{Astrometría}

El agregar movimientos propios a la identificación de miembros de asociaciones estelares, es un procedimiento estándar. A distancias relativamente cortas, los métodos simples como ser el de punto convergente (subsección 4.5), dan resultados muy claros.

El método Spaghetti (Hoogerwerf \& Aguilar, 1999) es otro método considerablemente elaborado que da resultados excelentes en asociaciones próximas, en el análisis incorpora simultáneamente posiciones, movimientos propios y paralajes. Para cada estrella, la velocidad tangencial determina la distancia mínima del spaghetti al origen del espacio de velocidades y su elipse de error define la forma del spaghetti, cuya longitud es infinita debido a la falta de información sobre la componente de velocidad radial. Los objetos pertenecientes a la misma asociación, los cuales se mueven coherentemente en el espacio, tendrían intersección en sus spaghettis. En nuestro caso, los errores en las paralajes son tan grandes que, combinados con la ya grande elipse de error del movimiento propio, transformarían al spaghetti en un tubo grueso, haciéndose muy difícil así la aplicación del método.

\subsubsection{Movimiento propio}

En nuestro caso, debido a que los datos con los que trabajamos cubren un intervalo de algunos kpc, para determinar los movimientos propios de las estrellas usamos los siguientes catálogos: AC2000.2 (Urban et al., 1998), USNO-A2.0 (Monet et al., 1998) para los cuales se supuso una precisión de $\sigma=0.25^{\prime \prime}$, Tycho-2 (Hog et al., 2000) con $\sigma=0.03^{\prime \prime}$, UCAC2 (Zacharias et al., 2003) y 2MASS (Cutri et al., 2003). Los vectores de la Figura 37 son el resultado de componer el movimiento de rotación de la galaxia relativo al Sol con el movimiento peculiar de la estrella. La determinación y aplicación de movimientos propios fueron efectuadas en colaboración con los Dres. Medina-Tanco y Teixeira. Los mismos fueron hechos en el modo usual, empleando el método de mínimos cuadrados pesado (ecuaciones 45 a 49)

$$
\begin{gathered}
t_{0}=\frac{\sum p_{i} t_{i}}{\sum p_{i}} \\
\alpha_{0}=\frac{\sum \alpha_{i} p_{i}}{\sum p_{i}} \\
\mu_{\alpha}=\frac{\sum p_{i} \alpha_{i}\left(t_{i}-t_{o}\right)}{\sum p_{i}\left(t_{i}-t_{o}\right)^{2}}
\end{gathered}
$$




$$
\begin{gathered}
\sigma_{\alpha 0}^{2}=\frac{1}{\sum p_{i}} \\
\sigma_{\mu \alpha}^{2}=\frac{1}{\sum p_{i}\left(t_{i}-t_{o}\right)^{2}}
\end{gathered}
$$

donde $p_{i}=\frac{1}{\sigma_{i}^{2}}$ y $t_{i}$ es la época de la posición para una dada estrella $i$. Para la declinación se hicieron los mismos cálculos.

La precisión del resultado final depende de la combinación particular de catálogos usada para cada objeto. La mejor precisión se consigue cuando las posiciones están disponibles en el catálogo AC2000.2, el cual provee una base de tiempo muy grande (la época promedio es 1907 y el rango de la misma va de 1881 a 1950). Por lo tanto, limitamos nuestro análisis a aquellas estrellas que están incluidas en el catálogo AC2000.2. Consecuentemente, estimamos que los errores de nuestros movimientos propios, calculados como el error medio cuadrático de los puntos que definen el movimiento propio, en promedio, son más pequeños que 3.0 mas/yr. 


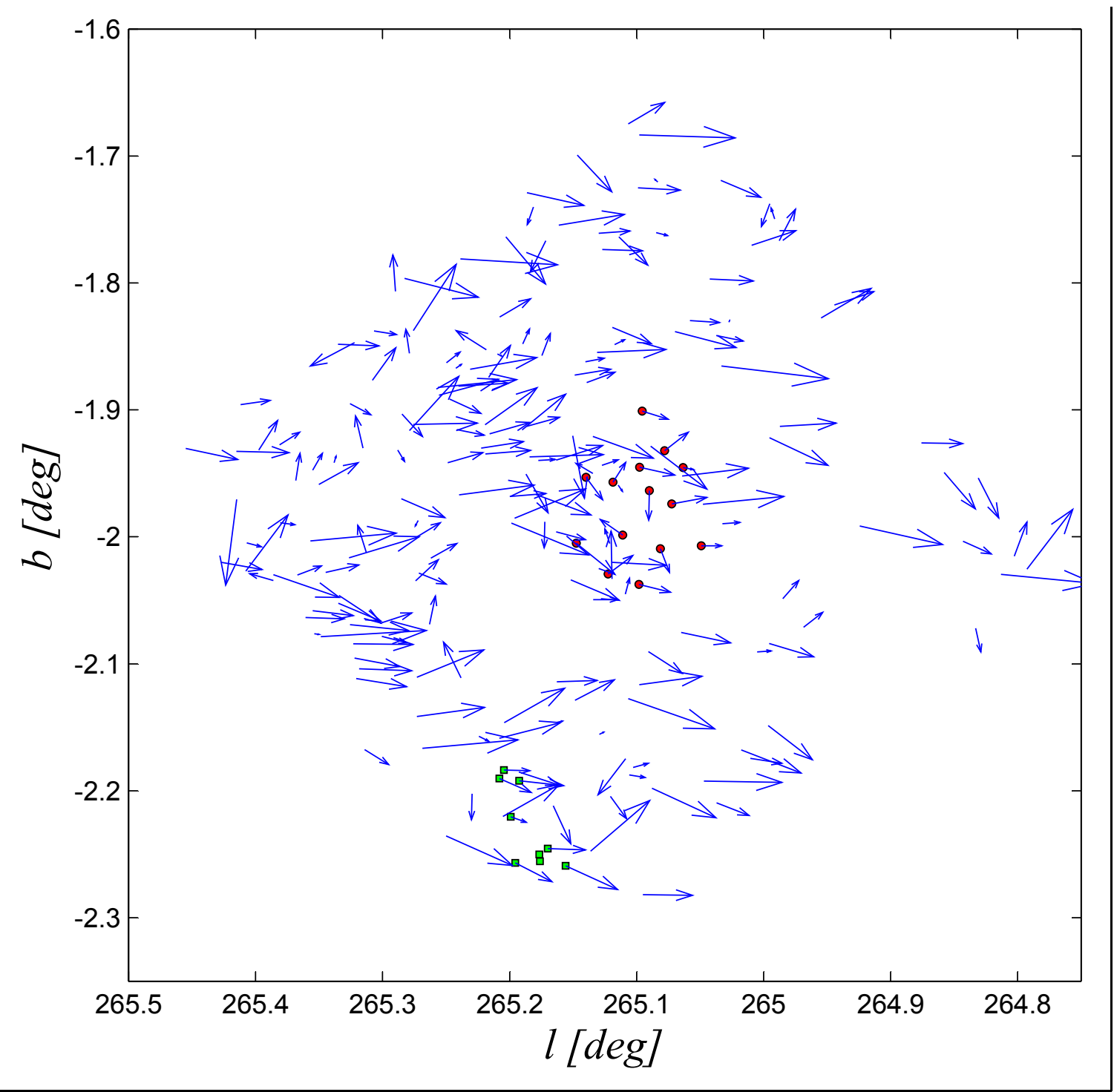

Figura 37: Movimientos propios en coordenadas galácticas para 205 (de las 261 con $\mu$ disponible) de nuestras estrellas $O B$ espectroscópicas y fotométricas con movimiento propio $\mu \lesssim 20$ mas/yr. Los cuadrados indican las estrellas en la Tabla 35, definiendo C1, y los círculos indican las estrellas en la Tabla 36 para C2. 


\subsection{Datos de literatura y catálogos}

Se consultaron diversas bases de datos disponibles en INTERNET, para buscar imágenes centradas en las coordenadas ecuatoriales celestes $\alpha=8^{h} 44^{m} 20^{s}, \delta=-45^{\circ} 55^{\prime} 52^{\prime \prime}$ y con un tamaño de $3^{\circ} \times 3^{\circ}$. También se buscaron datos de catálogos en distintas longitudes de onda. Las longidudes de onda investigadas fueron:

\subsubsection{Infrarrojo: IRAS y 2MASS}

\section{IRAS}

En este trabajo se consultó la base de datos de los resultados del satélite IRAS y se extrajeron imágenes en $100 \mu \mathrm{m}, 60 \mu \mathrm{m}, 25 \mu \mathrm{m}$ y $12 \mu \mathrm{m}$. Las Figuras 38, 39, 40 y 41 muestran la superposición de las imágenes IRAS indicadas por contornos de emisión sobre la imagen óptica en la región de Bochum 7. Se han empleado colores para hacer referencia a las zonas con distintas intensidades de emisión. Los contornos azules refieren emisión más intensa y los rojos más débil. En estas imágenes azules del DSS (Digital Sky Survey) la zona de Bochum 7 investigada se indica con una figura cuadrada de $0.5^{\circ} \times 0.5^{\circ}$ centrada aprox. en las coordenadas mencionadas al principio de esta subsección.

En los sectores S y SO de las imágenes en los cuatro filtros y el sector NO de la imagen obtenida en $12 \mu \mathrm{m}$, se observan gradientes de intensidad correspondientes a la presencia de polvo, con un máximo en las fuentes puntuales sobre las que me referire luego. En la imagen en $60 \mu \mathrm{m}$ al gradiente de intensidad se lo ve mayor hacia la zona exterior a la región de la Asociación.

\section{Fuentes IRs extendidas}

La Figura 42 ( Ryter et al., 1987) se aplica a una región extendida en la que se puede ver como varía la intensidad relativa de la radiación en $60 \mu \mathrm{m}, \Gamma_{60}$ (ecuación 50), en función del aumento de la densidad del campo de radiación $U V, \mathrm{u}_{U V}^{e q}$. Los símbolos $\varphi_{i}$ de la ecuación de $\Gamma_{60}$ representan la intensidad medida por el instrumento, integrada en toda la línea de la visual y aislada de la emisión de fondo por una línea de base apropiada.

$$
\Gamma_{60}=\frac{\lambda_{100} \cdot \varphi_{60}}{\lambda_{60} \cdot \varphi_{100}}
$$

La línea fina más baja que se observa en la Figura 42 corresponde a la distribución de 


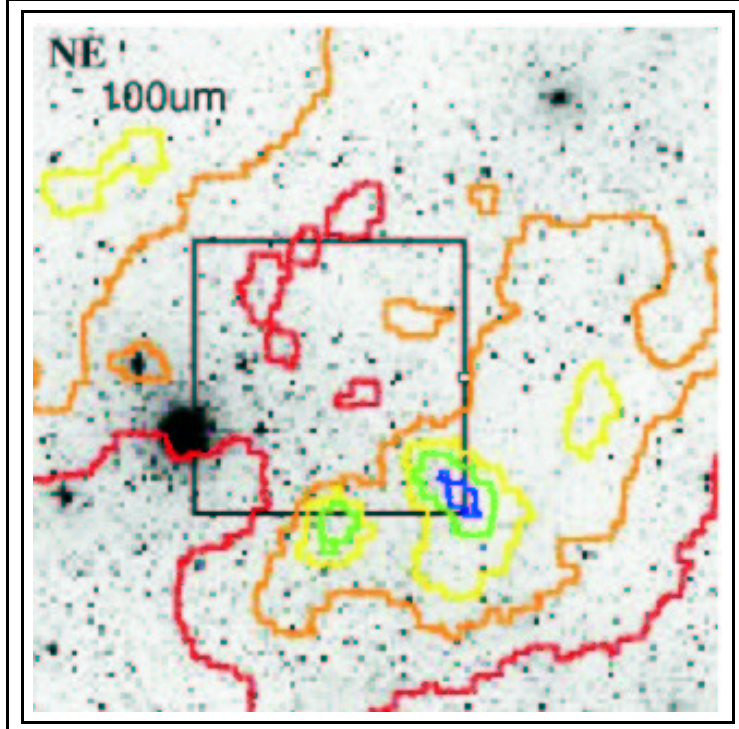

Figura 38: Contornos que indican las distintas intensidades de emisión obser-

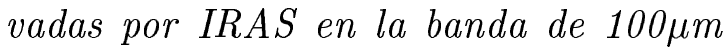
superpuestos a la imagen óptica del DSS de $1.5^{\circ} \times 1.5^{\circ}$. El cuadrado negro indica la zona del cielo estudiada en nuestra fotometría. Los contornos azules refieren emisión más intensa y los rojos más débil

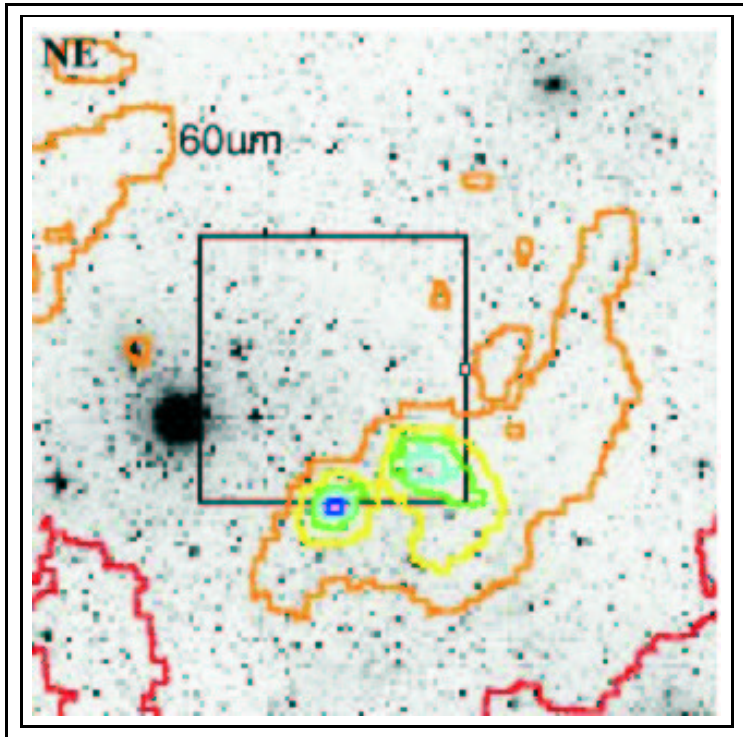

Figura 39: Idem Figura 38 para banda IRAS $60 \mu \mathrm{m}$ 


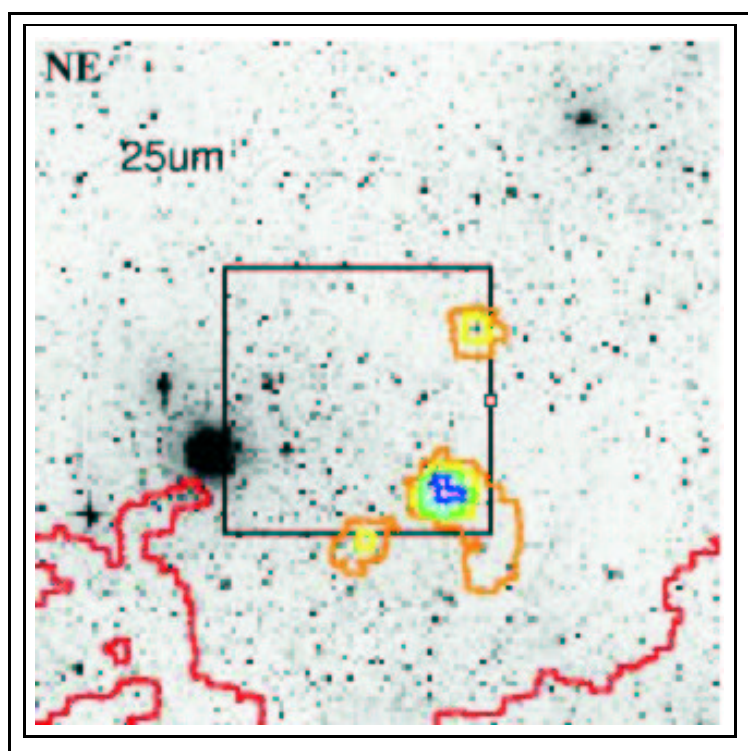

Figura 40: Idem Figura 38 para banda IRAS $25 \mu \mathrm{m}$.

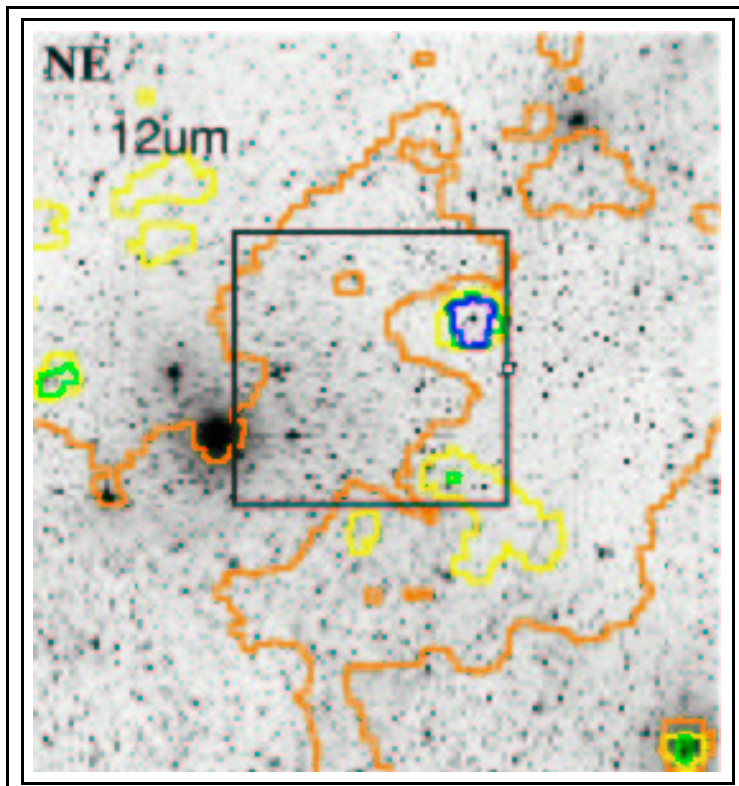

Figura 41: Idem Figura 38 para banda

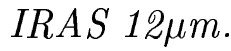




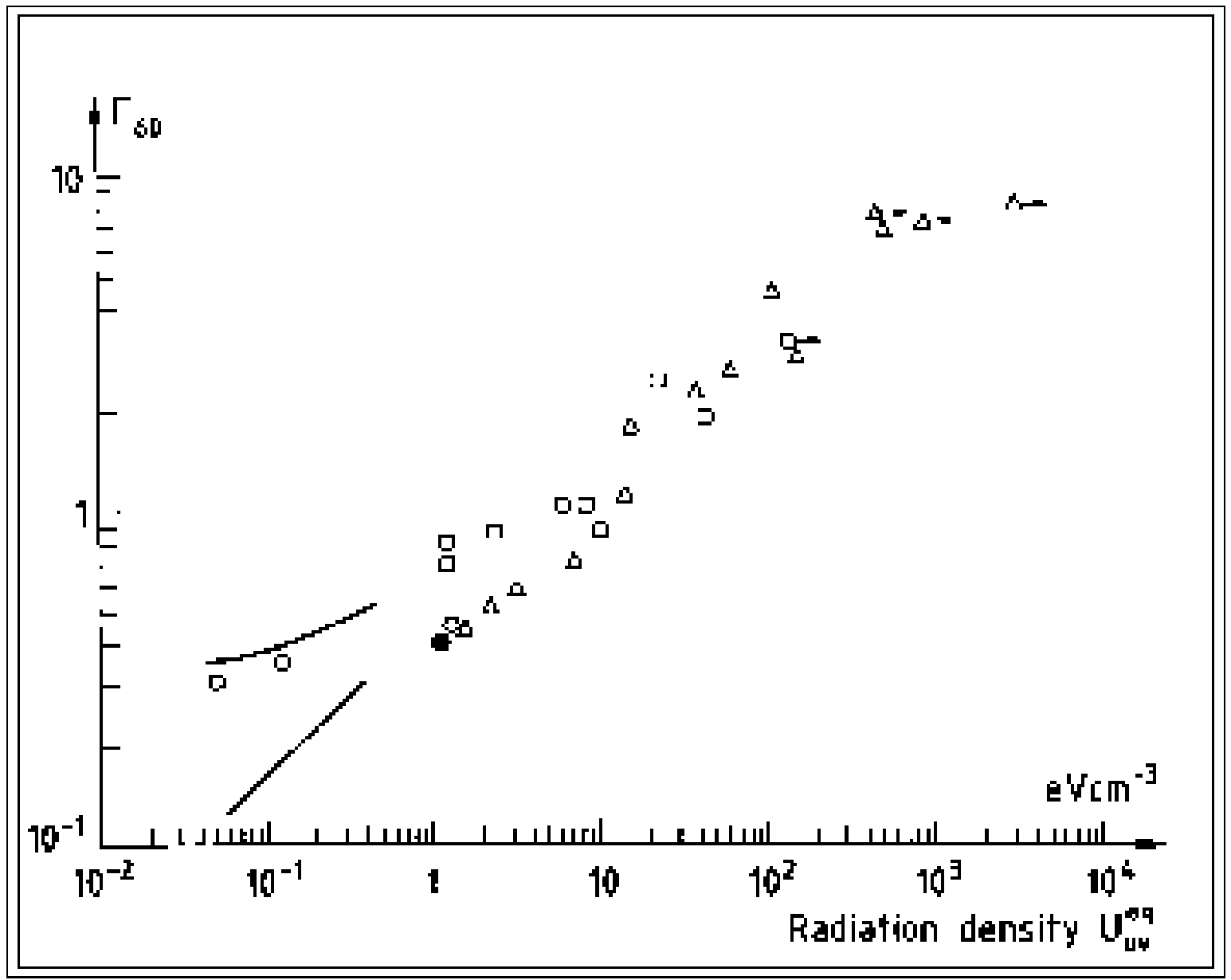

Figura 42: Valores de $\Gamma_{60}$ (ecuación 50) expresados en $\nu I_{\nu}$ como una función de la densidad del campo de radiación $u_{U V}^{e q}$. Los simbolos hacen referencia a: triángulos: $\sigma$ Sco; cuadrados: HD147889; círculos llenos: Lynds 1712; círculos vacíos: cirrus a $5 \mathrm{kpc}$ desde el centro

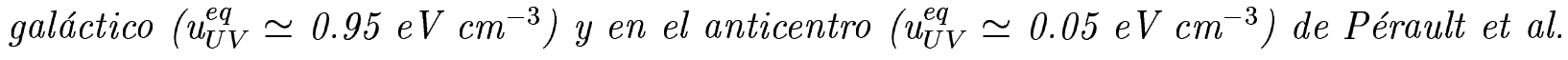
(1987); cirrus en la vecindad solar ( $\left.u_{U V}^{e q} \simeq 0.13 \mathrm{eV} \mathrm{cm}^{-3}\right)$ de Boulanger y Pérault (1988). Las líneas son los dos casos extremos del modelo de polvo de Draine y Anderson (1985), con $y$ sin un exceso de partículas de radio $0.3 \mathrm{~nm}$ 
granos de tamaño normal, con una partícula de radio mínimo de 10nm. Esta exhibe la misma pendiente que los datos observacionales obtenidos para distintos objetos, representados ellos con diferentes símbolos, correspondientes todos a $\mathrm{u}_{U V}^{e q}>1 \mathrm{eV} \mathrm{cm}^{-3}$. Esto último indica que el modelo, el cual involucra solamente granos grandes, es una buena representación del polvo radiando a longitudes de onda largas en un campo de radiación relativamente intenso. Debajo de $\mathrm{u}_{U V}^{e q}=1 \mathrm{eV} \mathrm{cm}^{-3}$, se percibe un achatamiento de la pendiente del factor $\Gamma_{60}$, verdaderamente bien ajustado por el otro caso extremo del modelo, el cual incluye un exceso de granos muy pequeños, con un radio mínimo de $0.3 \mathrm{~nm}$. Esto indica que en una longitud de onda, $\lambda=60 \mu \mathrm{m}$, granos muy pequeños sometidos a fluctuaciones de temperatura juegan un rol apreciable en el mecanismo de radiación del polvo.

De este modo, sabiendo además que a menor tamaño del grano se intensifica la radiación de mayor frecuencia, se puede llegar a pensar que en esa zona los granos de polvo son algo menores que en el resto de la región.

Para interpretar el máximo de emisión IR observada en la imagen en $12 \mu \mathrm{m}$ empleamos la discusión de las propiedades físicas del polvo representada por la Figura 43 del trabajo de Ryter et al.(1987), siendo $\Gamma_{12}$ la cantidad obtenida con el empleo de la ecuación 51.

$$
\Gamma_{12}=\frac{\lambda_{12}^{-1} \cdot \varphi_{12}}{\lambda_{60}^{-1} \cdot \varphi_{60}+\lambda_{100}^{-1} \cdot \varphi_{100}}
$$

En la Figura 43 la línea continua representa el caso extremo del modelo de Draine \& Anderson (1985), basado en un exceso de granos esféricos con un radio mínimo de $0.3 \mathrm{~nm}$. $\mathrm{Al}$ igual que en los casos más favorables, el valor del factor $\Gamma_{12}$ de dicho modelo en su comparación con las observaciones resulta ser menor, enfatizando la gran eficiencia que tiene la emisión en $12 \mu \mathrm{m}$ a densidad de radiación de baja excitación $\left(\mathrm{u}_{U V}^{e q}<10 \mathrm{eV} \mathrm{cm}{ }^{-3}\right)$.

Esto último no sorprende, ya que los PAHs (Hidrocarburos Aromáticos Policíclicos) son muy eficientes en la emisión producida a esa longitud de onda. Se trata de moléculas que una vez calentadas por la radiación UV de la estrella próxima producen líneas de emisión en $3.3 \mu \mathrm{m}, 6.2 \mu \mathrm{m}, 7.7 \mu \mathrm{m}, 8.6 \mu \mathrm{m}$ y $11.3 \mu \mathrm{m}$, conocidas como AIR (Aromatic InfraRed) (Ryter et al., 1987). Es suficiente con que absorban un fotón para producir la emisión que se ve en $12 \mu \mathrm{m}$, en cuyo caso la banda en dicha longitud de onda estaría representando la distribución espacial de los PAHS.

A densidades de radiación más alta, la intensidad relativa de $12 \mu \mathrm{m}$ decrece, con un 


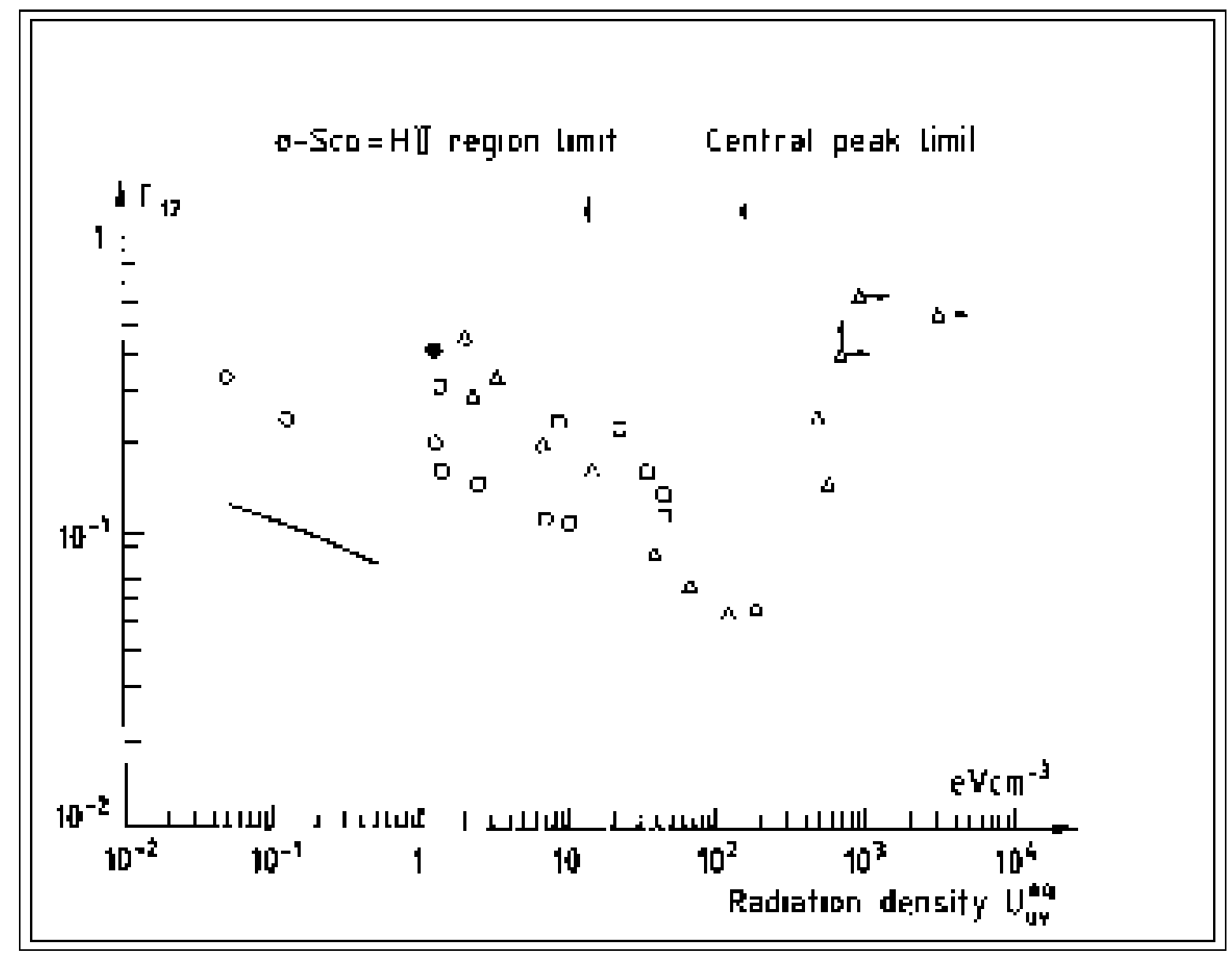

Figura 43: Valores de $\Gamma_{12}$ (ecuación 51) expresados en $\nu I_{\nu}$ como una función de la densidad del campo de radiación $u_{U V}^{e q}$. El significado de los símbolos es el mismo que el de la Figura 42. La línea clarita es el caso más favorable del modelo de polvo de Draine y Anderson (1985), incluyendo un exceso de partículas con un diámetro de $0.3 \mathrm{~nm}$. Note que la eficiencia de radiación del polvo, la cual es producida por los PAHS, es aún mayor que el modelo más favorable. La depresión en torno de lo $u_{U V}^{e q}=100 \mathrm{eV} \mathrm{cm} \mathrm{cm}^{-3}$ se atribuye a una destrucción de las partículas por el intenso campo de radiación. El rápido crecimiento a densidades de radiación UV más altas es producido por los granos más grandes, calentados intensamente por la radiación de la estrella. 
mínimo obvio en torno de $u_{U V}^{e q} \simeq 100 \mathrm{eV} \mathrm{cm}^{-3}$. Para las estrellas luminosas OB, tal densidad de radiación es alcanzada en torno de la región HII. El decrecimiento de $\Gamma_{12}$ es debido ciertamente a la deflección de las partículas radiantes en la banda de $12 \mu \mathrm{m}$. Los autores notaron que en un campo de radiación de $100 \mathrm{eV} \mathrm{cm}^{-3}$, el modelo de Puget et al. (1985) indica que los copos de grafito hechos de menos que 100 átomos de carbono se evaporan en menos de un millón de años y así no sobreviven más cerca que aprox. 5 pc de una estrella B0. Un modelo más elaborado, incluyendo un tratamiento microcanónico de la evaporación por partículas pequeñas y aisladas y una tasa de acreción de carbono plausible (Desert et al., 1987), reduce el mínimo a aprox. 40 átomos de carbono por molécula.

Basado en la razón de la intensidad de los perfiles de 3.3 a $11.3 \mu \mathrm{m}$, Allamandola et al. (1985) estimaron que los PAHs contienen entre 20 y 50 átomos de carbono. En cualquier caso, los resultados obtenidos aquí indican que más allá del $80 \%$ del carbono encerrado en los PAHs debe permanecer en partículas hechas de no menos que aprox. 20 a 40 átomos, las cuales son destruidas en campos de radiación UV intensos. No obstante, cierta cantidad de PAHs deben sobrevivir en campos de radiación mucho más intensos, donde los perfiles AIR han sido observados. En una densidad de campo de radiación UV mayor que $100 \mathrm{eV} \mathrm{cm}^{-3}$, el pico principal de la radiación del polvo se mueve hacia longitudes de onda más cortas que $60 \mu \mathrm{m}$, y la suma de las bandas de $60 \mu \mathrm{m}$ y $100 \mu \mathrm{m}$ no es más representativa de la totalidad del poder de radiación, como puede verse fácilmente en Puget et al. (1985, Figs. 3 y 4).

En el sector NO de la imagen obtenida en $12 \mu \mathrm{m}$ se evidencia una alta intensidad de emisión, esto indica que la densidad de radiación UV es menor a $100 \mathrm{eV} \mathrm{cm}^{-3}$ ya que además tal máximo de intensidad no se hace presente en las imágenes obtenidas en las bandas de $60 \mu \mathrm{m}$ y $100 \mu \mathrm{m}$.

La baja densidad de polvo en el resto de la región en las cuatro imágenes se hace evidente en la baja emisión aún en las longitudes de onda mayores.

\section{Fuentes puntuales IRAS}

Las fuentes puntuales observadas por el satélite IRAS, ya catalogadas, las buscamos en el Gator Catalogue Query de IRAS dentro de la página irsa.ipac.caltech.edu/missions. En la sección IRAS Point Source Catalog v2.1 (PSC) completamos la tabla que nos proporciona escribiendo en ella las coordenadas del centro de la región, el tamaño de la misma dando 
el radio angular y elegimos las características que queriamos conocer de cada una de las fuentes puntuales IRAS. El resultado de dicha búsqueda consistió en un total de 19 fuentes puntuales IRAS. De este modo, nos fue posible obtener los datos necesarios para calcular los valores de $\Gamma_{60}$ (ecuación 50) y $\Gamma_{12}$ (ecuación 51) de cada fuente, luego entrar con ellos a los gráficos de las figuras 42 y 43, respectivamente, con el fin de conocer la densidad del campo de radiación, $\mathrm{u}_{U V}^{e q}$, en cada sector de la región en estudio, donde la emisión en las bandas de IRAS se presenta con alta intensidad. Conociendo esto seria posible estimar el tipo espectral del objeto estelar causante de dicha emisión para luego obtener una imagen espectral del mismo. El problema fue que al ingresar a las figuras 42 y 43 con los correspondientes valores de $\Gamma$, la $u_{U V}^{e q}$ sólo se obtenia con un error muy grande, lo suficiente como para que el tipo espectral de la fuente quedara indefinido entre varios posibles. En conclusión no nos fue posible obtener ningún tipo espectral de las fuentes puntuales IRAS.

En la Tabla 30 se presentan la identificación IRAS y coordenadas ecuatoriales celestes J2000 de las 19 fuentes. De las mismas solamente 4 fuentes puntuales coinciden con los máximos de intensidad de la emisión IR visualizada en las cuatro bandas del IRAS. En la imagen en $60 \mu \mathrm{m}$ el máximo en intensidad se visualiza en la ubicación de la fuente IRAS 08426-4601, en la imagen en $100 \mu \mathrm{m}$ lo presenta 08412-4600, el máximo registrado en la imagen en $12 \mu \mathrm{m}$ corresponde a la fuente IRAS 08414-4537 y en $25 \mu \mathrm{m}$ lo presenta la fuente IRAS08417-4555. Por dicha razón, sólo nos resultaron confiables las fuentes mencionadas y a ellas limitamos nuestro estudio.

Con el fin de conocer algunas características físicas de las cuatro fuentes en estudio, empleamos ecuaciones recopiladas de la Tesis de Schwering P., del IRAS Explanatory Supplements (IRAS, 1986), de los papers que en cada una de ellas se hace referencia y de varios reviews de IRAS, disponibles en la página web de M. Sauvage (http://marc.sauvage.free.fr). Con dichas ecuaciones fue posible calcular:

- La temperatura y la masa, las cuales se pueden conocer siempre que se tengan las propiedades espectrales del polvo, considerando sólo la emisión en las bandas de $60 \mu \mathrm{m}$ y $100 \mu \mathrm{m}$ y que las densidades de flujo de IRAS son monocromáticas (lo cual está lejos de la verdad si se examinan las respuestas de los anchos de banda) (Tesis de Schwering P.). La temperatura del polvo puede obtenerse como:

$$
T_{p}(\kappa)=\frac{95.94}{\ln \left[(1.67)^{3+n} \frac{f_{\nu}(100)}{f_{\nu}(60)}\right]}
$$


Tabla 30: Fuentes puntuales IRAS

\begin{tabular}{|c|c|c|}
\hline$I R A S$ & $\alpha(\mathrm{J} 2000)$ & $\delta(\mathrm{J} 2000)$ \\
\hline $08402-4600$ & 084154.5 & -461116 \\
\hline 08406-4604 & 084218.2 & -461450 \\
\hline 08410-4559 & 084241.0 & -461031 \\
\hline X0841-4590 & 084320.1 & -460722 \\
\hline 08412-4600 & 084257.4 & $\begin{array}{llll}-46 & 11 & 16\end{array}$ \\
\hline $08412-4607$ & 084257.4 & -461758 \\
\hline 08414-4537 & 084307.9 & -454833 \\
\hline 08416-4606 & 084317.8 & -461700 \\
\hline 08417-4555 & 084327.8 & -460640 \\
\hline 08426-4556 & 084417.6 & -460706 \\
\hline 08426-4601 & 084417.6 & -461205 \\
\hline 08427-4533 & 084429.3 & -454358 \\
\hline 08427-4545 & 084425.4 & -455612 \\
\hline $08437-4551$ & 084528.0 & -460210 \\
\hline 08439-4526 & 084541.0 & -453744 \\
\hline 08441-4533 & 084551.5 & -454422 \\
\hline $08442-4544$ & 084554.5 & -455538 \\
\hline X0842-4600 & 084429.9 & -461436 \\
\hline 08443-4551 & 084601.9 & -460228 \\
\hline
\end{tabular}


según los trabajos de Draine (1990) y Dwek \& Arendt (1992), entre otros.

- Una vez que se conoce la temperatura, la masa puede obtenerse siempre que se esté trabajando en el régimen ópticamente delgado (caso usual $60 \mu \mathrm{m}$ y $100 \mu \mathrm{m}$ ). La masa del polvo es dada por:

$$
M_{p, \nu}=\frac{f_{\nu} D^{2}}{\kappa_{\nu} B_{\nu}\left(T_{p}\right)}
$$

Es posible obtener la ecuación 53 si se supone una nube ópticamente delgada en el infrarrojo lejano, en cuyo caso la intensidad $\mathrm{I}_{\nu}$ es dada por:

$$
I_{\nu}=\Sigma_{i} \int_{0}^{\infty} d s \rho_{i} \kappa_{i}(\nu) B_{\nu}\left(T_{i}\right)
$$

donde $\mathrm{T}_{i}$ es la temperatura de granos de tipo $i, \rho$ es la densidad de masa total y

$$
B_{\nu}\left(T_{i}\right)=\frac{2 \pi h \nu^{3}}{c^{2}} \frac{1}{e^{\frac{h \nu}{k T_{i}}}-1}
$$

es la función de Planck.

Por simplicidad, la opacidad $\kappa_{i}(\nu)$ debida a la componente $i$ se supone independiente de $\mathrm{T}_{i}$. La misma se puede estimar con el empleo de la ecuación:

$$
\kappa_{\nu}=4\left(\frac{\nu}{3 \times 10^{12}[\mathrm{~Hz}]}\right)^{n}\left[k g^{-1} m^{2}\right]
$$

Siendo el índice espectral $n=1$ ó 1.5. También se la conoce como coeficiente de absorción del polvo.

Siendo $a / \lambda \ll 1$ para el polvo interestelar (radio $a \leq 0.25 \mu \mathrm{m}$ ) en el Infrarrojo lejano $(\lambda \geq 10 \mu \mathrm{m})$, la sección eficaz de absorción $\mathrm{C}_{a b s} \propto a^{3} \mathrm{y}$ la opacidad $\kappa_{\lambda}$ dependen solamente del volumen total de polvo por átomo de $\mathrm{H}$ (y su composición), y no dependen detalladamente de la distribución de tamaños de los granos (en principio la función dieléctrica $\epsilon$ puede depender del tamaño del grano (Draine \& Lee, 1984) pero los efectos probablemente no sean grandes comparados con otras incertezas) (Draine, 1990). 
Si la nube se encuentra a una distancia D, y a la ecuación 54 la integramos en todo el haz del telescopio, $\Omega$, entonces la densidad de flujo es:

$$
f_{\nu}=\int_{\Omega} d \Omega I_{\nu}=\frac{M}{D^{2}} \sum_{i} \kappa_{i}(\nu) B_{\nu}\left(T_{i}\right)
$$

donde $\mathrm{M}$ es la masa de la nube. Así es que si suponemos un valor $\kappa_{\nu}$ promedio para toda la nube con componentes $i$, de la ecuación 57 despejamos la ecuación 53 para estimar la masa de polvo de la nube (Draine, 1990).

En las nubes que resultan ser opacas a la luz de las estrellas, el único método conocido para determinar la masa de polvo sin suponer cierto cociente de gas y polvo es medir la emisión térmica. Este método depende de una suposición en la densidad de granos y de una estimación de la distribución en el tamaño de los granos basado en la curva de extinción. Cambios en el tamaño y la forma de los granos no son importantes excepto en casos extremos. La exactitud de la determinación de la masa del polvo ahora está limitada principalmente por las incertezas en el tamaño y emisividad de los granos. Las mediciones de la emisión térmica deben por si mismas servir como pruebas de modelos alternativos. En particular, éstas deben explicar la separación en temperatura de acuerdo a la emisividad, las complicadas mezclas de componentes y probar la relación entre las propiedades dieléctricas y magnéticas de las especies principales (Hildebrand, 1983).

La ecuación 58 se obtiene luego de efectuar operaciones matemáticas tales como un desarrollo en serie de potencias de Taylor de la ecuación 55 en torno al valor $\nu=0$ y quedarse sólo con los dos primeros términos de la misma. Luego en dicho polinomio la variable $\mathrm{T}_{p}$ se reemplaza por la ecuación 52. Este último resultado junto a la expresión del coeficiente de absorción del polvo según ecuación 56, se sustituyen en la ecuación 53 , la misma se normaliza en frecuencia y el resultado es la fórmula semiempírica dependiente del índice espectral $n$, que se muestra a continuación.

$$
M_{p, \nu}\left(M_{\odot}\right)=25.8 \times 3^{n} \nu_{12}^{-(3+n)} f_{\nu}(J y) D_{M p c}^{2}\left[\left[(1.67)^{3+n} \frac{f_{100}(J y)}{f_{60}(J y)}\right]^{0.5 \nu_{12}}-1\right]
$$

- Para calcular el valor de luminosidad que tenía cada fuente, en la ecuación 59 reemplazamos cada término por las expresiones indicadas en las ecuaciones 60, 61 y 62 . Finalmente a la ecuación de la luminosidad se la dividió por el valor de la luminosidad 
solar, $\mathrm{L} \odot=3.826 \times 10^{26}[\mathrm{~W}]$ y obtuvimos la ecuación 63 que fue con la que trabajamos. Para la ecuación 60 fue necesario conocer el $\Delta \nu$ correspondiente a cada banda IR del satélite IRAS, siendo $\Delta \nu=13.48$ para $\lambda=12 \mu \mathrm{m}, \Delta \nu=5.16$ para $\lambda=25 \mu \mathrm{m}, \Delta \nu=$ 2.58 para $\lambda=60 \mu \mathrm{m}$ y $\Delta \nu=1$ para $\lambda=100 \mu \mathrm{m}$, según la página digital mencionada previamente.

$$
\begin{gathered}
L_{\nu}=\Delta \nu f_{\nu} 4 \pi D^{2} \\
\Delta \nu=\|\Delta \nu\|_{12} \times 10^{12}[H z] \\
D=D_{M p c} 3.08 \times 10^{22}[m] \\
f_{\nu}(J y)=10^{-26} \times f_{\nu}\left(W \cdot m^{-2} \cdot H z^{-1}\right) \\
L_{\nu}(L \odot)=3.14 \times 10^{5}\|\Delta \nu\|_{12} f_{\nu}(J y) D_{M P C}^{2}
\end{gathered}
$$

Para trabajar con las ecuaciones 50, 51, 52, 58 y 63 necesitamos conocer el valor del flujo corregido $f$ para cada banda. Para ello fue necesario entrar a la página irsa.ipac.caltech.edu/missions de IRAS y obtener datos como: fnu-n, que es la densidad de flujo en una cierta longitud de onda no corregido por color; cc-n, que es el coeficiente de correlación con la fuente puntual, con este coeficiente se indica qué tan bien correlacionado está el objeto en estudio con una fuente puntual estándar, esto último se indica con letras, tomando $A=100$, $\mathrm{B}=99, \mathrm{C}=98$ y asi siguiendo. El valor de fcor-n, que es el factor de corrección del flujo para cada banda y en la tabla electrónica se indica multiplicado por 1000. Información sobre los mismos es posible encontrarla en el Infrared Astronomical Satellite (IRAS) Catalogs and Atlases, Vol.1 Explanatory Supplement, pag.VI-27. En las imágenes del IRAS los flujos están dados en MJy/str y los mismos se necesitan en Jy, de modo que debió hacerse un cambio de unidades. El cálculo realizado para ello fue el siguiente:

$$
1 M J y / s t r=\frac{10^{6}[\mathrm{Jy}]}{1.182 \times 10^{7}\left[{ }^{\prime 2}\right]} \quad \text { porque } \quad 1 \text { str }=\left(\frac{180^{\circ}}{\pi[r]} \times 60^{\prime}\right)^{2}=1.182 \times 10^{7}\left[^{2}\right]
$$

Luego se multiplicó por el ángulo sólido de la antena, el cual se obtiene de integrar en $4 \pi$ al diagrama de antena $\operatorname{Pn}(\varphi, \theta)$ 


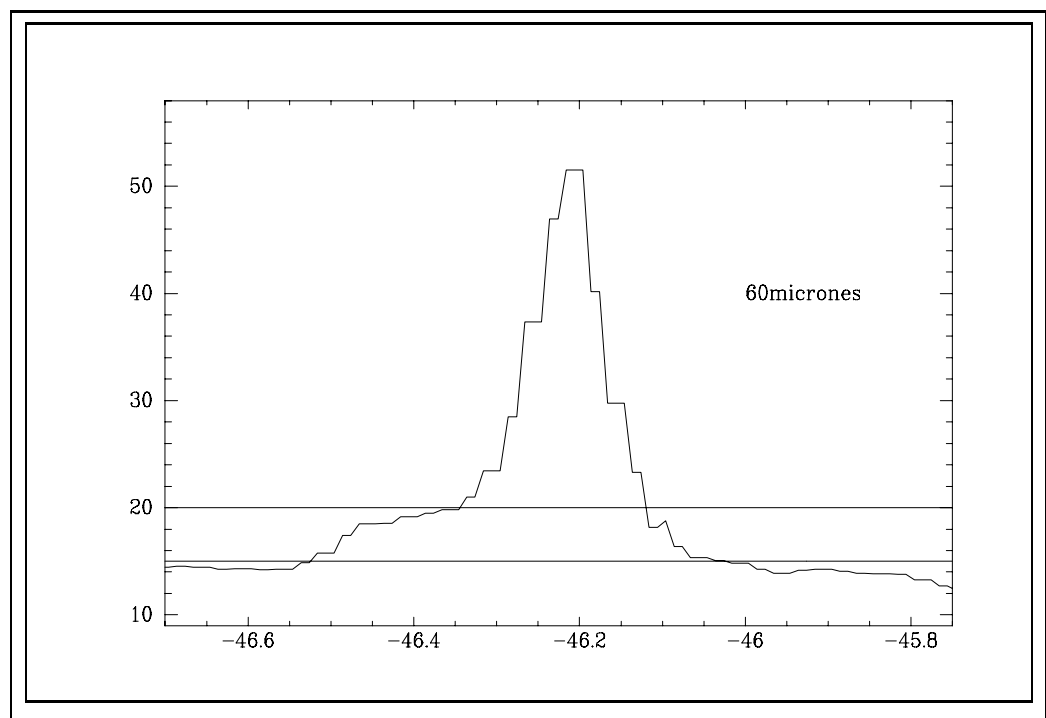

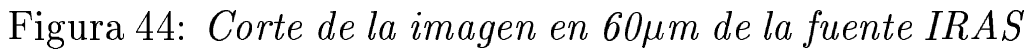
$08426-4601$

$$
\Omega_{a}=1.133 \cdot \varphi \cdot \theta
$$

siendo los valores de estos ángulos la resolución de 2' de la antena. De modo que el valor de $\Omega_{a}$ es $4.532\left[{ }^{2}\right]$

Realizando la siguiente operación:

$$
0.0846[\mathrm{Jy}] /\left[^{2}\right] \cdot 4.532\left[^{2}\right]=0.383[\mathrm{Jy}]
$$

Obtuvimos el valor por el cual es necesario multiplicar al flujo de la fuente IRAS para cambiar sus unidades de MJy/str a Jy. Ahora el valor que interesa es el flujo de la fuente sola, es decir, hay que restarle el fondo, lo cual se hace mirando en la imagen cuál es el valor que representa la intensidad del fondo. La Figura 44 muestra un corte hecho en la imagen en $60 \mu \mathrm{m}$ de la fuente IRAS 08426-4601. En ella se ve claramente donde comienza el flujo de la fuente. El valor del fondo es (promedio entre los dos laterales de la línea) $(20+15) / 2$ $\simeq 17$ y la intensidad de la fuente sobre el fondo es $\simeq 50$, entonces la intensidad de la fuente sería $\simeq 50-17=33$, que en Jy queda:

$$
S[J y]=33 \cdot 0.383 \simeq 13
$$

Antes de hacer el mismo trabajo con las imágenes de la misma fuente en otras longitudes de onda nos detuvimos a ver por qué razón este valor de densidad de flujo era tan distinto 
al obtenido al bajar de la página del IRAS los datos para esa fuente. Notamos que la suposición de fuente puntual no es correcta, ya que el HPBW de la imagen no coincide con el haz de la antena, que sólo es de 2'. Por otro lado los filtros IRAS son muy anchos $(\Delta \lambda / \lambda \leq$ 0.7). Luego entonces probamos de calcular el ángulo sólido de una fuente extendida, valor posible de obtener multiplicando el número de pixeles de la imagen por el tamaño angular de cada pixel. En la imagen de la fuente en $60 \mu \mathrm{m}$ el valor del ángulo sólido de la fuente es de 180 pixeles multiplicado por 36". Nosotros, en realidad, usamos el tamaño angular del pixel en esteroradianes siendo c/pixel $=3.046^{-8}$ [str]. El flujo promedio (por no ser puntual) en este caso es 38.35 [MJy/str], siendo este un valor obtenido empleando el software AIPS (Astronomical Image processing System), disponible en esta Facultad. Luego le restamos el flujo del fondo de 30 [MJy/str]. Finalmente, a los $8.35[\mathrm{MJy} / \mathrm{str}]$ resultantes de esta resta los multiplicamos por el ángulo sólido de la fuente y por $10^{6}$ para pasarlo a Jy, el resultado fue un flujo de 46 [Jy]. Ahora si este valor de flujo coincidia muy bien con aquel obtenido de consultar la página del satélite IRAS. Sin hacer este mismo trabajo para las otras imágenes de la fuente, ya pudimos asegurarnos que el valor del flujo que nos proporciona la tabla es correcto y que se trata del flujo de la fuente con sus unidades corregidas de [MJy/str] a [Jy] y con el flujo del fondo restado, suponiendo siempre fuente extendida, no puntual.

De este modo ya era posible calcular la temperatura de la fuente. Para estimar los valores de masa y luminosidad se necesitó conocer también la distancia de la fuente, dato que no fue posible conseguir para la fuente IRAS 08412-4600.

La fuente con identificación 08414-4537 en el catálogo IRAS está indicada como dos fuentes superpuestas. Buscando en INTERNET más información sobre ella, encontramos que también está identificada como estrella HD74600 con magnitud azul B = 9.89 y visual $\mathrm{V}=7.8$, y tipo espectral TE $=$ M3Ib/II. Teniendo en cuenta estos datos de TE y V empleamos la ecuación módulo de distancia y calculamos los valores de su paralaje espectroscópica obteniendo $\mathrm{d}=3.3 \mathrm{kpc}$ como supergigante $\mathrm{y} \mathrm{d}=1.2 \mathrm{kpc}$ como gigante luminosa. Si bien no sabemos con certeza cual es la distancia a la que Bo 7 se encuentra del Sol, si podemos decir que es mayor a $3.3 \mathrm{kpc}$, con lo cual concluimos que la ubicación de esta fuente no coincide con la de la Asociación en estudio, Bochum 7.

En la Tabla 31 se presentan las características físicas que fueron posibles conocer de las cuatro fuentes IRAS visualizadas en las imágenes mostradas en las Figuras 38, 39, 40 y 41. Los valores 1 y 1.5 que en las columnas de la Temperatura y las Masas se escriben dentro 
Tabla 31: Características físicas de las cuatro fuentes IRAS identificadas

\begin{tabular}{|c|c|c|c|c|c|c|c|c|}
\hline IRAS & Flujos [Jy] & $\mathrm{D}[\mathrm{kpc}]$ & $\Gamma_{60}$ & $\Gamma_{12}$ & $\mathrm{~T}[\mathrm{k}]$ & $\mathrm{M}_{100}(M \odot)$ & $\mathrm{M}_{60}(M \odot)$ & Lumin. $(L \odot)$ \\
\hline $08412-4600$ & $\begin{array}{l}00.5 \pm 0.0(12 \mu m) \\
00.9 \pm 0.0(25 \mu m) \\
06.3 \pm 2.4(60 \mu m) \\
41.1 \pm 20.5(100 \mu m)\end{array}$ & - & $0.3 \pm 0.0$ & $0.1 \pm 0.0$ & $\begin{array}{l}24 \pm 1(1) \\
23 \pm 1(1.5)\end{array}$ & - & - & - \\
\hline $08414-4537$ & $\begin{array}{l}17.9 \pm 0.9(12 \mu m) \\
11.8 \pm 0.6(25 \mu m) \\
05.2 \pm 0.7(60 \mu m) \\
31.2 \pm 0.0(100 \mu m)\end{array}$ & - & $0.3 \pm 0.0$ & $3.7 \pm 0.1$ & $\begin{array}{l}25 \pm 1(1) \\
23 \pm 1(1.5)\end{array}$ & - & - & - \\
\hline $08417-4555$ & $\begin{array}{l}04.4 \pm 0.1(12 \mu m) \\
26.0 \pm 1.0(25 \mu m) \\
25.1 \pm 3.8(60 \mu m) \\
49.5 \pm 0.0(100 \mu m)\end{array}$ & $4.3 \pm 0.6$ & $0.8 \pm 0.1$ & $0.4 \pm 0.0$ & $\begin{array}{l}35 \pm 2(1) \\
32 \pm 2(1.5)\end{array}$ & $\begin{array}{l}0.05(1) \\
0.08(1.5)\end{array}$ & $\begin{array}{l}-\overline{-} \\
0.08(1.5)\end{array}$ & $\begin{array}{l}343.6(12 \mu m) \\
778.9(25 \mu m) \\
376.0(60 \mu m) \\
287.4(100 \mu m)\end{array}$ \\
\hline $08426-4601$ & $\begin{array}{l}01.3 \pm 0.1(12 \mu m) \\
05.8 \pm 0.3(25 \mu m) \\
44.6 \pm 4.0(60 \mu m) \\
93.0 \pm 0.0(100 \mu m)\end{array}$ & $4.3 \pm 0.6$ & $0.8 \pm 0.1$ & $0.7 \pm 0.0$ & $\begin{array}{l}34 \pm 1(1) \\
32 \pm 1(1.5)\end{array}$ & $\begin{array}{l}0.10(1) \\
0.15(1.5)\end{array}$ & $\begin{array}{l}-\overline{0} \\
0.15(1.5)\end{array}$ & $\begin{array}{l}103.0(12 \mu m) \\
173.8(25 \mu m) \\
668.5(60 \mu m) \\
538.9(100 \mu m)\end{array}$ \\
\hline
\end{tabular}

del par de paréntesis hacen referencia al índice espectral $n$. Los valores de las masas del polvo calculadas con los datos obtenidos en $60 \mu \mathrm{m}$ y $100 \mu \mathrm{m}$ y las luminosidades calculadas con los datos de las cuatro bandas IRAS, no tienen su error en la Tabla 31 porque ellos son del orden del milésimo. El error en el flujo se encuentra dado como un porcentaje del mismo en la Tabla del IRAS. El resto de los errores que se indican en la Tabla 31 se obtuvieron considerando la propagación de errores.

Bronfman \& May, (1996) publicaron un relevamiento espectroscópico del CS(2-1) en dirección a fuentes puntuales IRAS ubicadas en el plano galáctico. La línea CS(2-1) a 97.981 $\mathrm{GHz}$ producida por transición rotacional es trazadora de la alta densidad volumétrica del gas molecular observada hacia fuentes puntuales IRAS propuestas como regiones de formación de estrellas OB en la Galaxia (Wood \& Churchwell, 1989). Si bien la línea de CS(2-1) resulta más difícil de ser detectada que la línea de $\mathrm{CO}$, la emisión de esta última puede utilizarse como trazadora de la masa molecular total pero nos dará poca información sobre la densidad interior de las nubes moleculares. Se espera que el estudio de la línea CS(2-1) resulte una herramienta útil para el estudio de la distribución y características generales de la formación de estrellas de alta masa en nuestra galaxia.

En una tabla con fuentes puntuales, publicada en el trabajo de Bronfman \& May (1996), se encuentra la fuente puntual IRAS 08426-4601 con coordenadas galácticas $\mathrm{l}=265^{\circ} .318 \mathrm{y}$ 
$\mathrm{b}=-2.1725^{\circ}$ coincidentes con las de la Asociación. La velocidad radial (respecto al LSR) de la misma es de $43.8 \mathrm{~km} \mathrm{~s}^{-1}$, la cual coincide muy bien con el valor de velocidad radial LSR que tienen los probables miembros de Bo 7. Basándonos en las coincidencias en coordenadas galácticas y velocidad radial LSR presentes entre la fuente IRAS 08426-4601 y los posibles miembros de Bo 7, supusimos que la distancia a la cual dicha fuente IRAS se encuentra es de $4.3 \pm 0.6 \mathrm{kpc}$, ampliado en la sección 7 .

Para la fuente IRAS 08417-4555 no nos fue posible encontrar publicado el dato de su distancia, supusimos que la nube en la cual está se ubica a la misma distancia que su nube vecina. Si esto es así tendría una $\mathrm{d}=4.3 \pm 0.6 \mathrm{kpc}$. Fue con esta suposición hecha sobre su distancia que se pudieron calcular los valores de masa y luminosidad de la fuente.

Junkes et al. (1992), investigaron la relación entre SNRs y regiones de formación estelar, como también el impacto que los SNRs tienen en los procesos de formación estelar. La identificación de objetos protoestelares es posible a través de los resultados del satélite IRAS y sus mapas de todo el cielo en infrarojo lejano. De acuerdo al trabajo de Wilking et al. (1989), los candidatos a protoestrellas pueden ser identificados por los siguientes criterios:

a) Casi toda su energía es radiada en el IR lejano.

b) Aún las fuentes IR más brillantes no tienen asociada una region HII.

c) Las protoestrellas están asociadas con discos circumestelares.

d) Están asociadas también con flujos moleculares.

Para establecer los SRNs candidatos a interactuar con el medio interestelar, Junkes et al. (1992) correlacionaron las posiciones de todos los SNRs conocidos de declinación - $26^{\circ}$ con el Catálogo de fuentes puntuales IRAS y seleccionaron las fuentes siguiendo los siguientes criterios:
a) $\mathrm{S}_{100} \geq 20 \mathrm{Jy}$
b) $\mathrm{S}_{100} / \mathrm{S}_{60}=1$ ó 2 ó ....6 ó 0 , o bien $\mathrm{Tp}=24 \ldots \ldots . .45 \mathrm{~K}$
c) $\mathrm{S}_{60} / \mathrm{S}_{25} \geq 1$
d) $\mathrm{Q}_{60}+\mathrm{Q}_{100} \geq 4$
e) $\mathrm{D}_{I R A S} \leq 2 \cdot D_{\text {radio }}$

$\mathrm{S}_{\lambda}$ denota la densidad de flujo IR no corregido en las bandas de diferentes longitudes de onda del IRAS donde la condición indicada en el punto a) da un flujo límite para seleccionar 
las fuentes más intensas. El cociente de densidades de flujo entre las longitudes de onda de $60 \mu \mathrm{m}$ y $100 \mu \mathrm{m}$, punto b), es la medida para la temperatura del polvo. Ellos obtuvieron los valores de temperatura del polvo iterativamente desde el espectro de emisión del polvo (Telesco \& Harper, 1980): $\mathrm{S}_{\nu} \sim \nu^{n} \cdot B_{\nu}(T p)$, donde $B_{\nu}$ es la función de Planck. En estos criterios han supuesto un índice espectral $n=1$. Los valores para la temperatura del polvo fueron calculados de acuerdo al método descripto por Wunderlich et al. (1987). Los valores $\mathrm{Q}_{\lambda}$ desde el IRAS-PSC describen la calidad de los flujos IRAS en las diferentes bandas. Los criterios b) y c) proveen una clasificación de las fuentes IRAS de acuerdo a su naturaleza física. El trabajo de investigación que realizaron estuvo apuntado a condensaciones de polvo y candidatos a protoestrellas y no se relaciona de ningun modo con estrellas frías, nebulosas planetarias y otras, los cuales tienen el máximo de emisión a longitudes de onda más cortas.

El criterio de selección elegido por Junkes et al. (1992) incluye valores para estrellas de TE tempranas (T-Tau) como también para núcleos densos de nubes moleculares. No obstante el límite superior de $\mathrm{S}_{100} / \mathrm{S}_{60}=6$ excluye a la mayoria de los cirrus interplanetarios y galácticos, es decir, emisión de polvo frío con el máximo a longitudes de onda de más de $100 \mu \mathrm{m}$. El criterio de selección debe incluir también polvo calentado en los "shocks" de SNR (Arendt 1989).

En el caso de las fuentes mencionadas anteriormente:

08426-4601

a) $\mathrm{S} 100=92.82 \mathrm{Jy}$

b) $\mathrm{S} 100 / \mathrm{S} 60=92.82 / 44.631=2.08$

c) $\mathrm{Tp}=34.5 \mathrm{~K}$

d) $\mathrm{S} 60 / \mathrm{S} 25=44.631 / 5.79=7.71$

e) $\mathrm{Q} 60+\mathrm{Q} 100=2+1=3$

f) $\mathrm{Mp}=0.10 \mathrm{M}_{\odot}$
08417-4555

a) $\mathrm{S} 100=49.5 \mathrm{Jy}$

b) $\mathrm{S} 100 / \mathrm{S} 60=49.5 / 25.1=1.97$

c) $\mathrm{Tp}=35.14 \mathrm{~K}$

d) $\mathrm{S} 60 / \mathrm{S} 25=25.1 / 26=0.97$

e) $\mathrm{Q} 60+\mathrm{Q} 100=3+1=4$

f) $\mathrm{Mp}=0.05 \mathrm{M}_{\odot}$

Con esto se puede decir que ambas fuentes podrían tratarse de una región de formación estelar.

La Figura 45 representa la ampliación de la distribución espacial de los posibles miembros de Bochum 7 con clase de luminosidad V. Es de notar la aparente correspondencia que existe entre las fuentes IRAS y el grupo de estrellas tempranas en el extremo SO de la imagen óptica. 


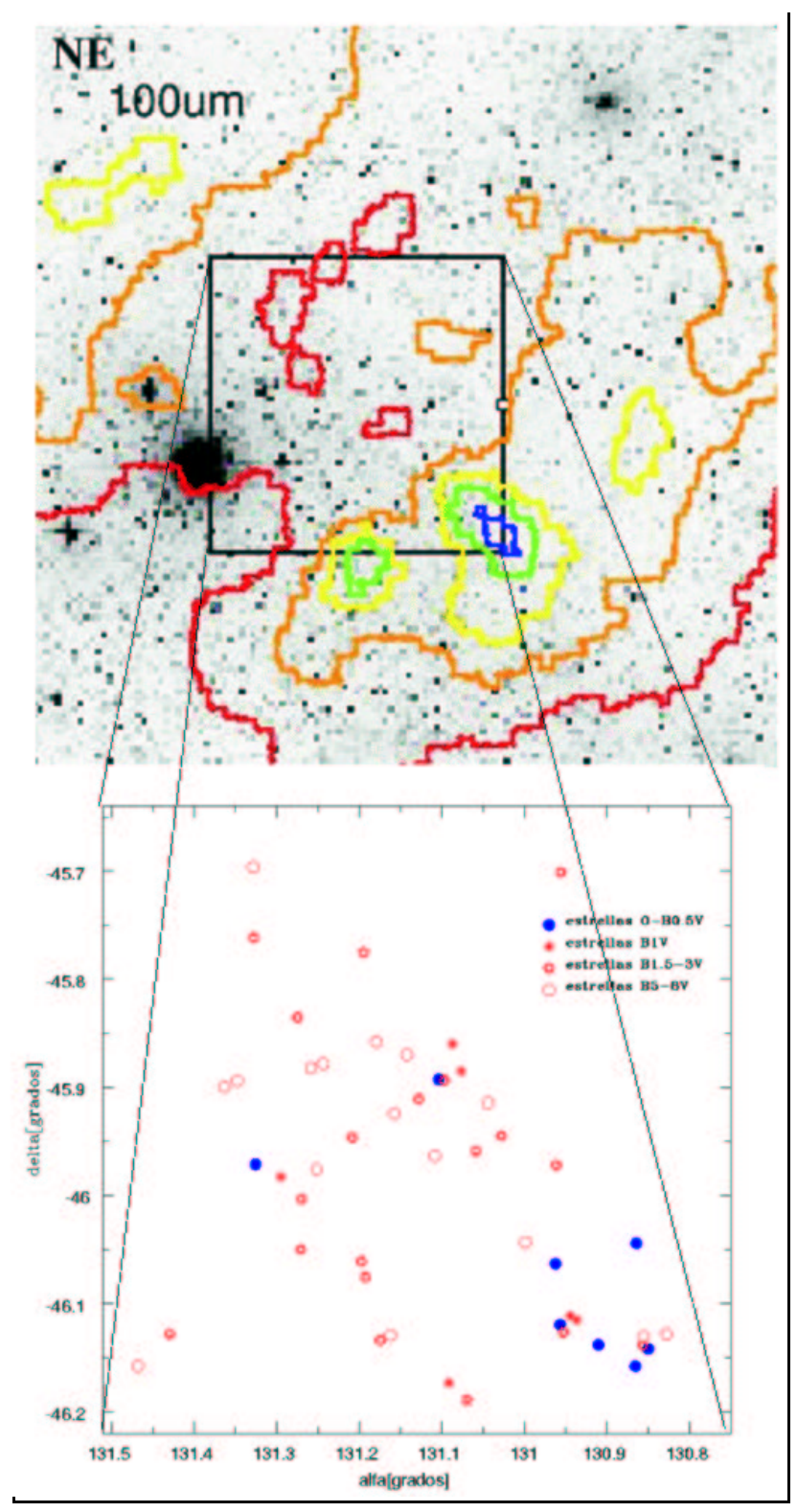

Figura 45: Ampliación de la distribución espacial de los posibles miembros de Bochum 7. 


\section{MASS}

La fotometría infrarroja terrestre se divide naturalmente en dos regímenes de longitud de onda: JHKLM en las longitudes de onda más cortas y NQ en las más largas. La primera de estas corresponde al rango de sensibilidad de los detectores InSb (antimoniuro indio). La primera publicación en estas bandas fotométricas fue hecha por Johnson (1962) y cubría K $(2.2 \mu \mathrm{m})$ y L $(3.6 \mu \mathrm{m})$. Luego Johnson en un trabajo posterior (1964) publicó fotometría J $(1.2 \mu \mathrm{m}), \mathrm{K}(2.2 \mu \mathrm{m}), \mathrm{L}(3.5 \mu \mathrm{m})$ y M $(5.0 \mu \mathrm{m})$ para 256 estrellas, las cuales se convirtieron en el conjunto de estándares para el sistema JKLM de Arizona. Con la introducción general de los detectores fotovoltaicos InSb, algunos observatorios decidieron cambiar de la banda original L a L' $(3.8 \mu \mathrm{m})$.

Hoy en día también son usadas las variaciones de la banda $\mathrm{K}$, designadas $\mathrm{K}^{\prime}$ y $\mathrm{K}_{S}$. Estas tienen una longitud de onda de corte algo menor, en orden a reducir la contribución de fondo térmica terrestre, la cual comienza a ser significante en esta parte del espectro (Wainscoat \& Cowie, 1992). El pasabanda de $\mathrm{K}_{S}$ es de 2.0 a $2.30 \mu \mathrm{m}$ mientras que el de $\mathrm{K}^{\prime}$ es de 1.9 a $2.30 \mu \mathrm{m}$.

Mientras las bandas J y $\mathrm{H}$ no son afectadas por la radiación térmica ambiental, la sensibilidad en las bandas K, L y M es degradada por esta.

Las fuentes más significantes de opacidad atmosférica son el vapor de agua y el dióxido de carbono. El contenido del vapor de agua, en particular, varia considerablemente con la latitud, altitud, temperatura y época del año. Las más bajas extinciones son obtenidas en los sitios que se encuentran a varios metros por sobre el nivel del mar, tales como Mauna Kea, Hawaii (4200 m), durante la época más fría del año, pero sitios cercanos al Polo Sur y también a varios metros sobre el nivel del mar, serían mejores (Glass, 1999).

El proyecto Two Micron All Sky Survey (2MASS) se realizó utilizando dos telescopios idénticos (1.3 metros Cassegrain Ecuatorial), ubicados en Mt. Hopkins, cerca de Tucson (USA) y Cerro Tololo (Chile). Cada telescopio está equipado con una cámara que tiene tres arreglos en infrarrojo cercano, de tal forma que el cielo sea observado simultáneamente en J (1.25 micrones), H (1.65 micrones) y $\mathrm{K}_{s}$ (2.16 micrones). El tamaño del pixel para el survey es de $2^{\prime \prime}$. 2MASS provee un catálogo fotométrico completo de todo el cielo hasta $\mathrm{J}=20$, $\mathrm{H}=20, \mathrm{~K}=20$. En la Figura 46 se muestra la distribución de magnitud de todas la fuentes 


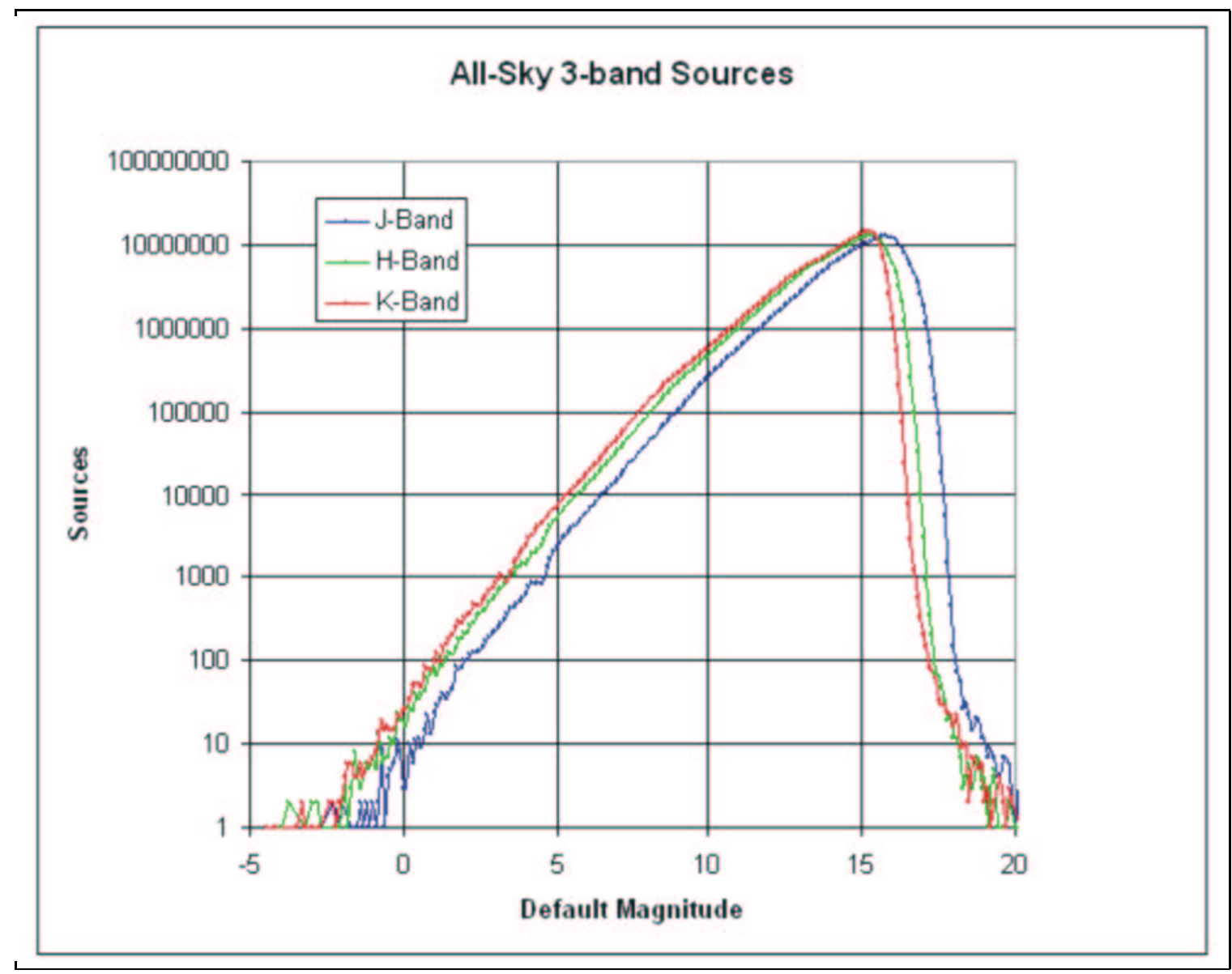

Figura 46: Esta figura muestra la distribución en magnitud de las fuentes del catálogo 2MASS de todo el cielo realizado con el empleo de las tres bandas. La posición y rango de los diferentes perfiles de calibración no son los mismos en las tres bandas debido a que la sensibilidad del arreglo del detector varia para cada una. Esto es particularmente cierto en la banda $H$ donde en la mitad de un survey realizado con la cámara del norte se instaló una segunda banda $H$

del cielo catalogadas por 2MASS en sus 3 bandas.

Una dificultad en comparar directamente la fotometría 2MASS con otras observaciones del IR cercano es que estos datos que se comparan a menudo serán obtenidos con un conjunto de filtros que tienen diferentes perfiles de transmisión y longitud de onda efectiva que los filtros adoptados para el survey 2MASS. Este problema no es exclusivo de la fotometría 2MASS ya que sucede siempre en toda banda UBVRIJHK. Por esa razón, cualquier comparación detallada entre los datos del 2MASS y aquellos obtenidos con otros telescopios, requerirá que ambos datos fotométricos sean puestos en un sistema fotométrico común. 
La diferencia principal entre el 2MASS y cualquier otro sistema fotométrico es que la transmisión del filtro $\mathrm{K}_{s}$ del $2 \mathrm{MASS}$ fue diseñada especialmente para cortar en $2.3 \mu \mathrm{m}$, en orden a reducir la contribución al ruido del fondo térmico. De este modo el ruido en las observaciones hechas en la banda $\mathrm{K}_{s}$ del 2MASS será menos sensible a las variaciones en la temperatura ambiente, permitiendo un survey fotométrico más uniforme. En comparación, los filtros más tradicionales de Johnson tienen una transmisión significante hasta $2.4 \mu \mathrm{m}$. Las transformaciones del color entre la fotometría del 2MASS y la de otros telescopios han sido derivadas haciendo un ajuste lineal entre la fotometría publicada de estrellas estándares fotométricas y las observaciones hechas a las mismas con el 2MASS (según página web ipac.caltech.edu/2mass/releases/allsky/doc/sec6-4b.html).

Usando la interface disponible en INTERNET de catálogos del survey infrarrojo 2MASS se buscó la tabla de fuentes IR en las bandas JHK del IR cercano, que tuviera observaciones en la zona en estudio. Correlacionando estos datos con los que poseiamos del estudio fotométrico óptico, que previamente efectuaramos en ese lugar, encontramos 145 estrellas en común entre la tabla de fuentes IR extraídas del survey 2MASS y nuestra tabla con fotometría UBV, pero solamente 52 estrellas tenían tipos espectrales O y B (Tabla 32).

Los colores intrínsecos de la fotometría del IR cercano los buscamos en el trabajo de K83, donde no se encuentran los valores correspondientes a las estrellas de tipos espectrales O y B gigantes. De este modo las 52 estrellas se redujeron a sólo 47 estrellas para las cuales obtuvimos el valor del exceso $\mathrm{E}(\mathrm{V}$ - K), representado gráficamente en la Figura 47. Por lo dicho al principio de esta subsección respecto a que todos los datos fotométricos deben referirse a un mismo sistema fotométrico, empleamos las ecuaciones de transformación, ecuaciones 68 y 69, proporcionadas en la página electrónica del 2MASS, para con ellas referir los resultados al sistema fotométrico de K83.

$$
\begin{gathered}
(J-K)_{K 83}=\frac{\left(J-K_{s}\right)+0.011}{0.974} \\
K_{K 83}=K_{s}+0.046-0.036 \cdot(J-K)_{K 83}
\end{gathered}
$$

La ley de enrojecimiento adoptada para la fotometría de K83 es la indicada en la ecuación 70

$$
E(B-V)=\frac{E(V-K)}{2.82}
$$

Obteniéndose de este modo para la absorción en el visual, $\mathrm{A}_{v}$, la expresión (ecuación 71) 


$$
A_{v}=1.107 \cdot E(V-K)
$$

Las distancias calculadas usando dicha extinción son las presentadas en la Figura 11 de la subsección 5.1.1

Con estas 47 estrellas (donde están incluidas las 4 estrellas del catálogo LS, 1135, 1131, $1137,1144)$ el valor de la distancia media es $4.4 \mathrm{kpc}$ y $4.2 \mathrm{kpc}$ con $\mathrm{E}(\mathrm{B}-\mathrm{V})$ y $\mathrm{E}(\mathrm{V}-\mathrm{K})$, respectivamente.

Las 52 estrellas con tipos espectrales O y B encontradas en el catálogo 2MASS en común con nuestra fotometría están indicadas en la Tabla 32 con los siguientes datos: Identificación de la estrella, clasificación espectral, magnitud visual (de Johnsons) e IR (del 2MASS), color de las bandas JHK de los telescopios $2 \mathrm{MASS}$, el color $(\mathrm{V}-\mathrm{K})_{k 83}$ obtenido con la magnitud K de K83 (ecuaciones 68 y 69), el color intrínseco (V - K)。(Koornneef, 1983), el E(V - K) obtenido con los valores de las dos columnas anteriores y en la última columna el valor de la distancia obtenida empleando la ecuación 71 .

Tabla 32: Datos fotométricos en las bandas V (Johnson) y JHK del IR cercano

(2MASS y K83) de las fuentes IR encontradas en la zona en estudio

\begin{tabular}{|c|c|c|c|c|c|c|c|c|c|c|c|}
\hline $\begin{array}{c}\text { ID } \\
\text { CBN... }\end{array}$ & $\mathrm{TE}$ & $\mathrm{V}$ & $\mathrm{J}$ & $\mathrm{H}$ & $\mathrm{K}$ & $(\mathrm{J}-\mathrm{K})_{2}$ & $(\mathrm{H}-\mathrm{K})_{2}$ & $(\mathrm{~V}-\mathrm{K})_{K 83}$ & $(\mathrm{~V}-\mathrm{K})_{\mathrm{o}}$ & $\mathrm{E}(\mathrm{V}-\mathrm{K})$ & $\begin{array}{c}\mathrm{D}_{v k} \\
{[\mathrm{kpc}]}\end{array}$ \\
\hline $84332.2-455337$ & B2IV & 10.1 & 09.4 & 09.3 & 09.2 & 0.14 & 0.03 & 0.81 & -0.67 & 1.48 & 2.0 \\
\hline $84501.9-455034$ & B2IV & 10.4 & 09.9 & 09.9 & 09.8 & 0.08 & 0.05 & 0.49 & -0.67 & 1.16 & 2.7 \\
\hline $84446.2-460433$ & B3V & 10.7 & 10.4 & 10.4 & 10.4 & 0.04 & 0.00 & 0.24 & -0.57 & 0.81 & 1.9 \\
\hline $84324.0-460831$ & $\mathrm{O} 7.5 \mathrm{~V}$ & 10.8 & 09.8 & 09.7 & 09.6 & 0.25 & 0.07 & 1.22 & -0.93 & 2.15 & 4.9 \\
\hline $84506.0-455008$ & $\mathrm{~B} 2 \mathrm{~V}$ & 10.9 & 10.3 & 10.2 & 10.1 & 0.19 & 0.05 & 0.75 & -0.67 & 1.42 & 2.3 \\
\hline $84349.6-460711$ & $06.5 \mathrm{~V}((\mathrm{f}))$ & 10.9 & 09.9 & 09.7 & 9.6 & 0.24 & 0.05 & 1.25 & -0.93 & 2.18 & 6.1 \\
\hline $84447.4-460339$ & B3-5V & 11.1 & 10.8 & 10.8 & 10.7 & 0.05 & 0.03 & 0.33 & -0.57 & 0.83 & 2.1 \\
\hline $84510.4-455854$ & O9.5II & 11.2 & 09.7 & 09.5 & 09.4 & 0.29 & 0.07 & 1.71 & 一 & - & - \\
\hline $84504.8-460013$ & $\mathrm{~B} 2 \mathrm{~V}$ & 11.2 & 10.8 & 10.8 & 10.8 & 0.04 & 0.00 & 0.39 & -0.67 & 1.06 & 3.1 \\
\hline $84406.6-455642$ & $\mathrm{~B} 2 \mathrm{~V}$ & 11.3 & 10.8 & 10.8 & 10.7 & 0.04 & 0.01 & 0.49 & -0.67 & 1.16 & 3.1 \\
\hline $84424.9-455334$ & $\mathrm{O} 7.5 \mathrm{~V}$ & 11.3 & 09.8 & 09.6 & 09.4 & 0.34 & 0.16 & 1.85 & -0.93 & 2.78 & 4.5 \\
\hline $84426.0-455749$ & $\mathrm{~B} 8 \mathrm{~V}$ & 11.4 & 10.7 & 10.7 & 10.6 & 0.07 & 0.08 & 0.73 & -0.25 & 0.98 & 1.3 \\
\hline $84450.1-455648$ & $\mathrm{~B} 2 \mathrm{~V}$ & 11.4 & 11.0 & 11.0 & 10.9 & 0.03 & 0.03 & 0.41 & -0.67 & 1.08 & 3.4 \\
\hline $84350.9-460348$ & O9-9.5V & 11.4 & 10.2 & 10.0 & 09.9 & 0.24 & 0.09 & 1.45 & -0.88 & 2.33 & 4.5 \\
\hline $84506.3-460906$ & B0IIIe & 11.5 & 09.6 & 09.3 & 09.0 & 0.68 & 0.34 & 2.49 & - & - & - \\
\hline $84543.1-460742$ & $\mathrm{~B} 2-3 \mathrm{~V}$ & 11.5 & 11.1 & 11.2 & 11.2 & -0.03 & 0.04 & 0.34 & -0.62 & 0.95 & 3.1 \\
\hline $84518.6-454543$ & $\mathrm{~B} 2 \mathrm{~V}$ & 11.8 & 11.0 & 10.9 & 10.9 & 0.10 & 0.02 & 0.84 & -0.67 & 1.51 & 3.2 \\
\hline $84325.3-460750$ & $\mathrm{~B} 8-\mathrm{A} 0 \mathrm{~V}$ & 11.8 & 11.0 & 10.9 & 10.8 & 0.17 & 0.10 & 0.97 & -0.12 & 1.1 & 1.2 \\
\hline $84359.6-460237$ & B5-8V & 12.0 & 11.4 & 11.3 & 11.3 & 0.05 & 0.01 & 0.59 & -0.35 & 0.93 & 2.2 \\
\hline $84338.5-460817$ & $09.5 \mathrm{~V}$ & 12.0 & 10.7 & 10.6 & 10.5 & 0.23 & 0.07 & 1.45 & -0.87 & 2.32 & 5.5 \\
\hline $84349.4-454204$ & B3-5V & 12.0 & 11.2 & 11.1 & 11.1 & 0.12 & 0.04 & 0.85 & -0.45 & 1.35 & 2.4 \\
\hline $84443.0-455130$ & $\mathrm{~B} 8 \mathrm{~V}$ & 12.0 & 11.4 & 11.3 & 11.3 & 0.13 & 0.05 & 0.67 & -0.25 & 0.92 & 1.7 \\
\hline
\end{tabular}




\begin{tabular}{|c|c|c|c|c|c|c|c|c|c|c|c|}
\hline $\begin{array}{c}\text { ID } \\
\text { CBN... }\end{array}$ & $\mathrm{TE}$ & $\overline{\mathrm{V}}$ & $\overline{\mathrm{J}}$ & $\mathrm{H}$ & $\bar{K}$ & $(\mathrm{~J}-\mathrm{K})_{2}$ & $(\mathrm{H}-\mathrm{K})_{2}$ & $(\mathrm{~V}-\mathrm{K})_{K 83}$ & $(\mathrm{~V}-\mathrm{K})_{\mathrm{o}}$ & $E(V-K)$ & $\begin{array}{c}\mathrm{D}_{v k} \\
{[\mathrm{kpc}]}\end{array}$ \\
\hline $84318.7-460742$ & $\mathrm{~B} 8 \mathrm{~V}$ & 12.2 & 11.5 & 11.4 & 11.2 & 0.20 & 0.16 & 0.93 & -0.25 & 1.18 & 1.7 \\
\hline $84438.9-460746$ & $\mathrm{~B} 5 \mathrm{~V}$ & 12.2 & 11.8 & 11.8 & 11.8 & 0.02 & -0.01 & 0.34 & -0.43 & 0.83 & 3.2 \\
\hline $84327.7-460929$ & B0V-III & 12.3 & 11.5 & 11.3 & 11.3 & 0.23 & 0.05 & 0.97 & -0.85 & 1.82 & 9.1 \\
\hline $84348.6-460736$ & B1-1.5V & 12.3 & 11.0 & 10.9 & 10.8 & 0.20 & 0.06 & 1.43 & -0.74 & 2.17 & 3.8 \\
\hline $84434.3-455214$ & $\mathrm{~B} 5 \mathrm{~V}$ & 12.5 & 11.9 & 11.8 & 11.8 & 0.05 & 0.02 & 0.62 & -0.43 & 1.05 & 3.2 \\
\hline $84505.0-460300$ & $\mathrm{~B} 2.5-3 \mathrm{~V}$ & 12.6 & 12.2 & 12.1 & 12.1 & 0.07 & 0.00 & 0.38 & -0.60 & 0.98 & 4.6 \\
\hline $84446.7-454632$ & B3-5V & 12.6 & 11.5 & 11.4 & 11.3 & 0.17 & 0.06 & 1.21 & -0.50 & 1.70 & 2.6 \\
\hline $84327.4-460240$ & $\mathrm{~B} 0 \mathrm{~V}$ & 12.6 & 11.2 & 11.0 & 10.9 & 0.29 & 0.11 & 1.64 & -0.85 & 2.49 & 5.8 \\
\hline $84500.4-455834$ & $\mathrm{~B} 5 \mathrm{~V}$ & 12.6 & 12.0 & 12.0 & 11.9 & 0.07 & 0.07 & 0.65 & -0.43 & 1.08 & 3.3 \\
\hline $84526.1-460527$ & B2III & 12.9 & 11.1 & 10.9 & 10.8 & 0.32 & 0.10 & 2.06 & - & - & - \\
\hline $84350.7-455820$ & $\mathrm{~B} 1.5 \mathrm{~V}$ & 12.9 & 11.5 & 11.3 & 11.2 & 0.36 & 0.13 & 1.71 & -0.71 & 2.42 & 4.1 \\
\hline $84344.7-460656$ & B1V & 12.9 & 11.7 & 11.5 & 11.5 & 0.24 & 0.05 & 1.45 & -0.76 & 2.21 & 5.5 \\
\hline $84522.4-455527$ & B1III & 13.0 & 11.1 & 10.8 & 10.7 & 0.37 & 0.11 & 2.23 & - & - & - \\
\hline $84502.0-455257$ & $\mathrm{~B} 8-\mathrm{A} 0 \mathrm{~V}$ & 13.2 & 12.5 & 12.4 & 12.3 & 0.15 & 0.05 & 0.82 & -0.20 & 1.00 & 2.4 \\
\hline $84410.6-455452$ & $\mathrm{~B} 5-8 \mathrm{~V}$ & 13.3 & 12.2 & 12.1 & 12.1 & 0.18 & 0.03 & 1.17 & -0.35 & 1.50 & 3.0 \\
\hline $84419.9-455552$ & B2III & 13.5 & 11.8 & 11.6 & 11.5 & 0.32 & 0.08 & 1.93 & - & - & - \\
\hline $84458.5-455242$ & $\mathrm{~B} 8-9 \mathrm{~V}$ & 13.5 & 12.8 & 12.7 & 12.7 & 0.12 & 0.00 & 0.82 & -0.2 & 1.20 & 3.0 \\
\hline $84518.2-455816$ & $\mathrm{~B} 0.5 \mathrm{~V}$ & 13.6 & 12.0 & 11.8 & 11.7 & 0.29 & 0.09 & 1.91 & -0.79 & 2.70 & 7.0 \\
\hline $84325.6-460820$ & $\mathrm{~B} 2 \mathrm{Ve}$ & 13.7 & 12.0 & 11.7 & 11.3 & 0.75 & 0.43 & 2.45 & -0.67 & 3.11 & 7.2 \\
\hline $84437.8-455257$ & $\mathrm{~B} 8-\mathrm{A} 0 \mathrm{~V}$ & 13.8 & 12.8 & 12.6 & 12.6 & 0.18 & 0.01 & 1.12 & -0.12 & 1.22 & 2.8 \\
\hline $84442.0-460802$ & $\mathrm{~B} 2 \mathrm{~V}$ & 14.1 & 12.5 & 12.8 & 12.0 & 0.41 & 0.72 & 2.02 & -0.67 & 2.69 & 5.2 \\
\hline $84346.7-460641$ & $\mathrm{~B} 1-5 \mathrm{~V}$ & 14.2 & 13.0 & 12.8 & 12.8 & 0.22 & 0.07 & 1.43 & -0.60 & 2.00 & 6.9 \\
\hline $84523.5-455340$ & $\mathrm{~B} 8 \mathrm{~V}$ & 14.3 & 13.0 & 12.8 & 12.8 & 0.20 & 0.02 & 1.41 & -0.25 & 1.66 & 3.4 \\
\hline $84416.7-461121$ & $\mathrm{~B} 1.5 \mathrm{~V}$ & 14.3 & 13.1 & 12.8 & 12.8 & 0.28 & 0.04 & 1.52 & -0.71 & 2.23 & 8.6 \\
\hline $84423.2-455337$ & B1.5-2V & 14.5 & 13.0 & 12.8 & 12.6 & 0.37 & 0.18 & 1.91 & -0.70 & 2.60 & 7.2 \\
\hline $84418.2-455307$ & $\mathrm{~B} 1 \mathrm{~V}$ & 14.6 & 12.9 & 12.7 & 12.6 & 0.31 & 0.07 & 1.93 & -0.76 & 2.69 & 9.0 \\
\hline $84414.0-455733$ & B1.5-2V & 14.7 & 12.7 & 12.4 & 12.4 & 0.37 & 0.09 & 2.37 & -0.70 & 3.06 & 6.3 \\
\hline $84421.9-461025$ & $\mathrm{~B} 1 \mathrm{~V}$ & 14.8 & 13.0 & 12.6 & 12.5 & 0.54 & 0.12 & 2.27 & -0.76 & 3.03 & 8.4 \\
\hline $84518.8-454147$ & $\mathrm{~B} 5 \mathrm{~V}$ & 14.8 & 13.3 & 13.0 & 13.0 & 0.32 & 0.06 & 1.83 & -0.43 & 2.26 & 5.1 \\
\hline $84527.2-455360$ & B5-8V & 14.9 & 13.7 & 13.5 & 13.5 & 0.21 & 0.07 & 1.42 & -0.35 & 1.75 & 5.6 \\
\hline
\end{tabular}

La extinción en las bandas del IR se considera aproximadamente una decima parte de la extinción en el visual, $\mathrm{A}_{k} \sim 0.1 \mathrm{~A}_{v}$. En el gráfico de la Figura 47 se observa que una buena parte de las estrellas con extinción mayor a 1.8 magnitudes se encuentran en la zona de la nube de polvo con algunas fuentes IRAS, sector SO de la imagen.

Las imágenes JHK de 2MASS también se usaron para inspeccionar las regiones alrededor de las fuentes IRAS. La Figura 48 es una imagen estelar de $\sim 3^{\prime} \times 3^{\prime}$ centrada en $\alpha=8^{h} 43^{m}$ $25^{s}, \delta=-46^{\circ} 06^{\prime} 49^{\prime \prime}, \mathrm{J} 2000$. La misma fue producida usando Aladin indicando con el color rojo las estrellas observadas por el 2MASS en la banda $\mathrm{K}$, con el color verde las estrellas observadas por el 2MASS en la banda J y con el color azul las estrellas observadas por el SuperCosmos (SSS) empleando el filtro R. Es evidente que algunas estrellas han sido vistas 


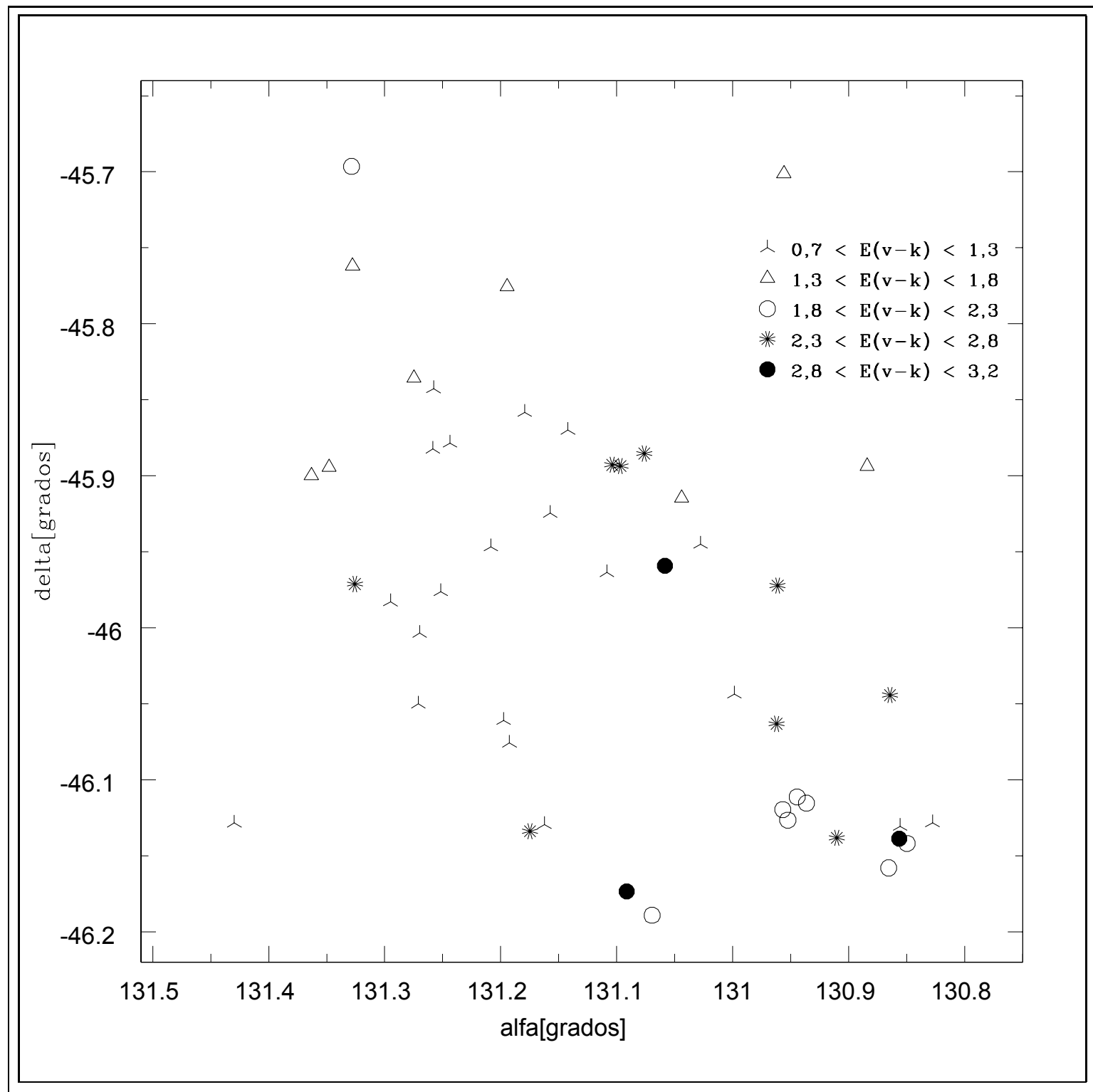

Figura 47: Representación del $E(V-K)$ corregido al sistema fotométrico de Koornneef, causado en la radiación de cada estrella por la presencia de polvo en la región 
en todas las longitudes de onda mencionadas (estrellas con centro en color blanco), mientras que las otras sólo se han observado con el filtro R (estrellas en color azul).

La estrella azul con centro en tono violeta de la Figura 48 es la fuente IRAS 08417-4555 que presenta las características consideradas en el criterio de selección de regiones de formación estelar de Junkes et al. (1992), mencionado previamente en este capitulo. Siendo esta fuente un objeto con brillo en la banda $\mathrm{K}$ es posible asociar el color de su centro a una emisión Br $\gamma$, identificada en la longitud de onda del rojo. El simbolo en ella que coincide con la referencia presentada en el margen superior derecho, indica que en el trabajo de Kerber et al (2003) la han identificado como la Nebulosa Planetaria Ve26 de coordenadas ecuatoriales celestes J2000, $\alpha=08: 43: 28$ y $\delta=-46: 06: 40$. Se buscó más información al respecto en el catálogo de NP publicado por Kohoutek L. (2001). Allí se encontró otra referencia (Velghe, 1957) donde se publica que Ve26 posee coords. ecuatoriales celestes $\alpha=8: 43: 24.13$ y $\delta=$ -46:08:28.9 y es una Nebulosa Planetaria de forma compacta con intensa emisión en H $\alpha$. Esta no resulta distinguible en las placas sensibles al azul. Según el catálogo astrométrico USNO2 donde se identifica como 0375-06432704, tiene magnitudes $\mathrm{V}=15.6$ y $\mathrm{R}=13.1$, razón por la cual, probablemente, al buscarla en nuestra imágenes fotométricas UBV no la hemos encontrado.

Debido a que la emisión Br $\gamma$ es un evento comunmente observable en una Nebulosa Planetaria, es posible que lo que se esté viendo sea a Ve26 ubicada delante del nudo de polvo donde se encuentran las fuentes IRAS asociadas a la región de formación estelar, que al proyectarla en el plano, coinciden su ubicación.

En la imagen mostrada en la Figura 48, también se indica la fuente IRAS X841-459 con coords. ecuatoriales celestes J2000: $\alpha=08: 43: 20$ y $\delta=-46: 07: 22$. Las cuatro fuentes del 2MASS que se ven en la imagen son las que se han encontrado en torno a la Nebulosa Planetaria, según la proyección en el plano, y que cumplen con tener un color $\mathrm{H}-\mathrm{K}>0.5$ magnitudes, lo cual indica que se trata de estrellas enrojecidas, como es posible ver en un diagrama J - H vs H - K. Estas estrellas enrojecidas manifiestan la presencia de mucho polvo el cual puede ser calentado por estrellas de pre-secuencia con emisión $\operatorname{Br} \gamma$, cubiertas por éste polvo o por gigantes rojas que se encuentren exactamente detrás. En la Tabla 33 se indican la identificación de la fuente según 2MASS, la cual se basa en las coordenadas ecuatoriales celestes J2000 de las mismas y el valor de sus magnitudes J, H y K. 


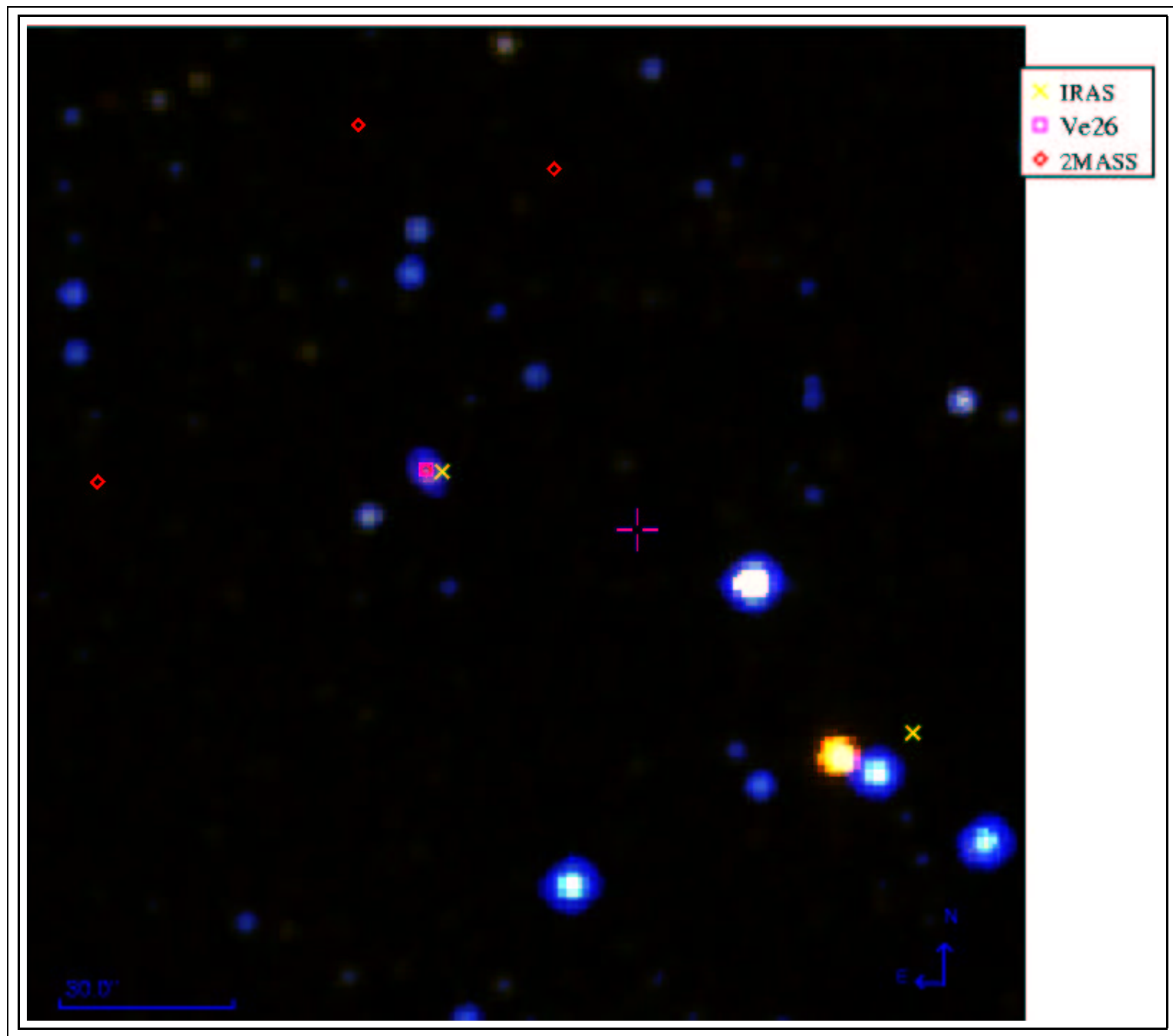

Figura 48: Imagen en colores de $\sim$ 3'× З' tomada a la región en estudio. En ella se observa una Nebulosa Planetaria y se indican dos fuentes IRAS y cuatro fuentes 2MASS

Tabla 33: Identificación y magnitudes de las cuatro fuentes del 2MASS con color H - K > 0.5 mag. Todas ellas ubicadas en la región de IRAS 08417-4555

\begin{tabular}{|l|l|l|l|}
\hline \hline 2MASS & $\mathrm{J}$ & $\mathrm{H}$ & $\mathrm{K}$ \\
\hline $8432617-4605485$ & 16.2 & 15.4 & 14.8 \\
$8432807-4606399(\mathrm{Ve} 26)$ & 13.7 & 12.6 & 11.4 \\
$8432935-4605420$ & 16.5 & 15.7 & 15.1 \\
$8433339-4606436$ & 16.0 & 15.5 & 14.7 \\
\hline
\end{tabular}




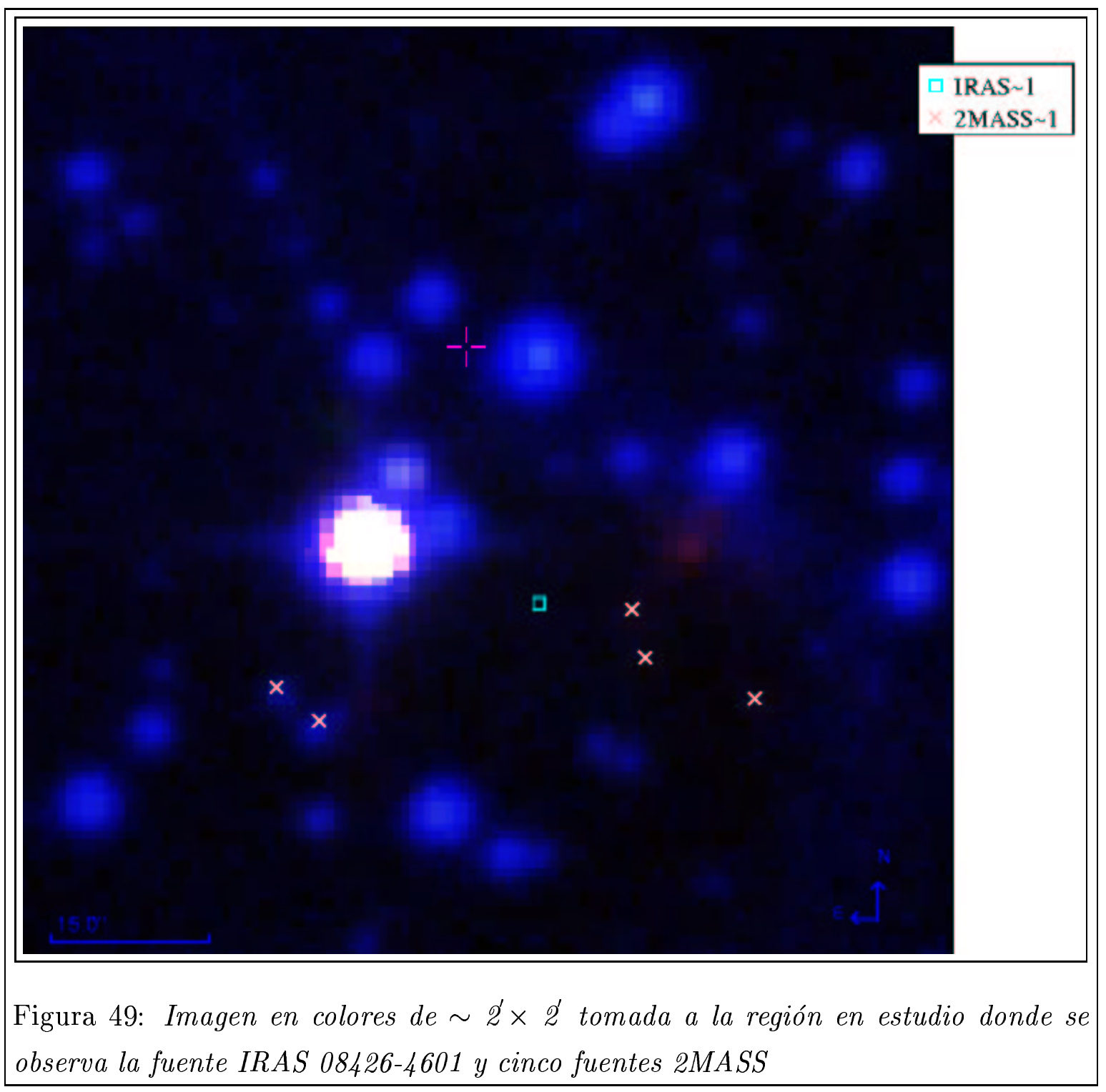

En la imagen mostrada en la Figura 49, se indican la fuente IRAS 08426-4601 y las cinco fuentes del 2MASS que se han encontrado en torno a dicha fuente IRAS, según la proyección en el plano, y que cumplen con tener un color $\mathrm{H}-\mathrm{K}>0.7$ magnitudes, evidenciando asi otra región con presencia de mucho polvo. En la Tabla 34 se indican la identificación de las fuentes según 2MASS, la cual se basa en las coordenadas ecuatoriales celestes J2000 de las mismas y el valor de sus magnitudes J, H y K. 
Tabla 34: Identificación y magnitudes de las cinco fuentes del 2MASS con color H - K > 0.7 mag. Todas ellas ubicadas en la región de la fuente IRAS 08426-4601

\begin{tabular}{|l|l|l|l|}
\hline \hline 2MASS & $\mathrm{J}$ & $\mathrm{H}$ & $\mathrm{K}$ \\
\hline $8441680-4612050$ & 15.6 & 15.0 & 14.1 \\
$8441570-4612126$ & 17.3 & 15.3 & 14.5 \\
$8441668-4612093$ & 15.8 & 15.8 & 14.8 \\
$8441986-4612129$ & 16.1 & 15.7 & 14.4 \\
$8441948-4612158$ & 16.1 & 15.4 & 13.9 \\
\hline
\end{tabular}

\section{MSX}

El Midcourse Space eXperiment es un satélite de defensa balística que fue lanzado en 1996. Los primeros 10 meses de la misión estuvieron dedicados a observaciones en el IR mediano con el empleo de un telescopio enfriado con hidrógeno sólido. Este instrumento trabajó en la región espectral de 4.2 a 26 micrones, siendo en la banda de $8.3 \mu \mathrm{m}$ aproximadamente cuatro veces más sensible que los detectores en $12 \mu \mathrm{m}$ de IRAS (http://irsa.ipac.caltech.edu/applications/MSX/MSX/mission.htm).

Obtuvimos imágenes de la zona en estudio en las bandas $\mathrm{A}=8.30 \mu \mathrm{m}, \mathrm{C}=12.1 \mu \mathrm{m}, \mathrm{D}=$ $14.7 \mu \mathrm{m}$ y $\mathrm{E}=21.30 \mu \mathrm{m}$. En la imagen de la banda A mostrada en la Figura 50, se observó que la intensidad crece hacia la fuente puntual IRAS 8426-4601 con coordenadas J2000: $\alpha$ $=08: 44: 17.6$ y $\delta=-46: 12: 05$. Dicha imagen está centrada en $\alpha=08: 45: 07, \delta=-46: 12: 06 \mathrm{y}$ su tamaño es de $\sim 25^{\prime} \times 25^{\prime}$. En ella se indica con curvas de nivel la intensidad de emisión en esta longitud de onda como también la ubicación que en la misma tiene la fuente IRAS que se menciona.

La Figura 51 es una imagen estelar tomada en el filtro de banda angosta $\mathrm{H} \alpha$, de la misma región de Bochum 7 que se observa en la Figura 50, aquí se indican con curvas de nivel la intensidad de emisión en la banda A del MSX y la ubicación de la fuente IRAS. Es interesante observar que esta última coincide con la imagen de una especie de cola que sale de una cabeza de mayor intensidad. Sobre la misma se comenta un poco más en la subsección 5.4.2.

En las imágenes del MSX de las otras tres bandas, estas fuentes no aparecen. Con todo esto resulta evidente que en el sector SO de la región en estudio hay material interestelar 


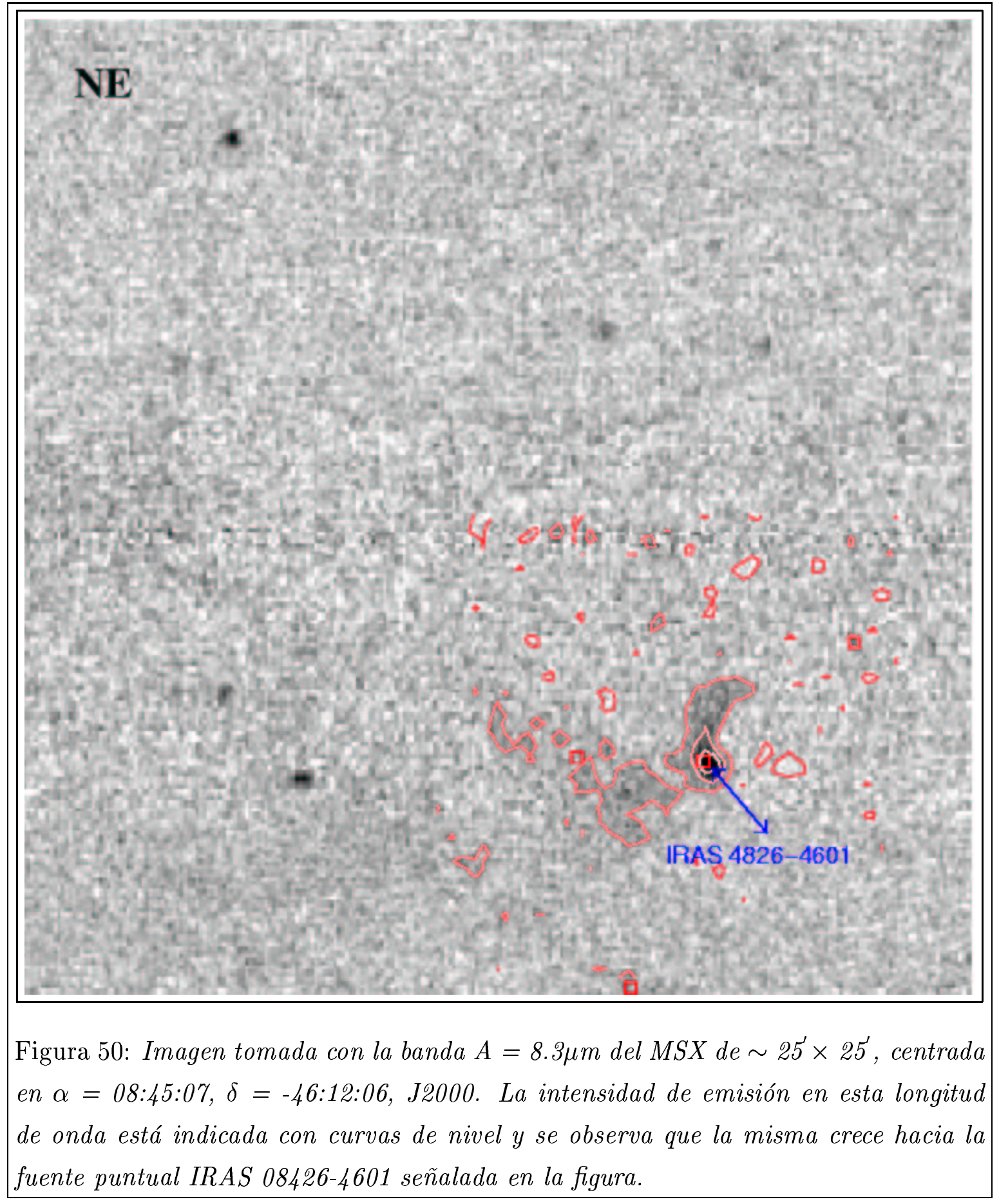

Estudio de una Asociación OB distante en la Vía Láctea 


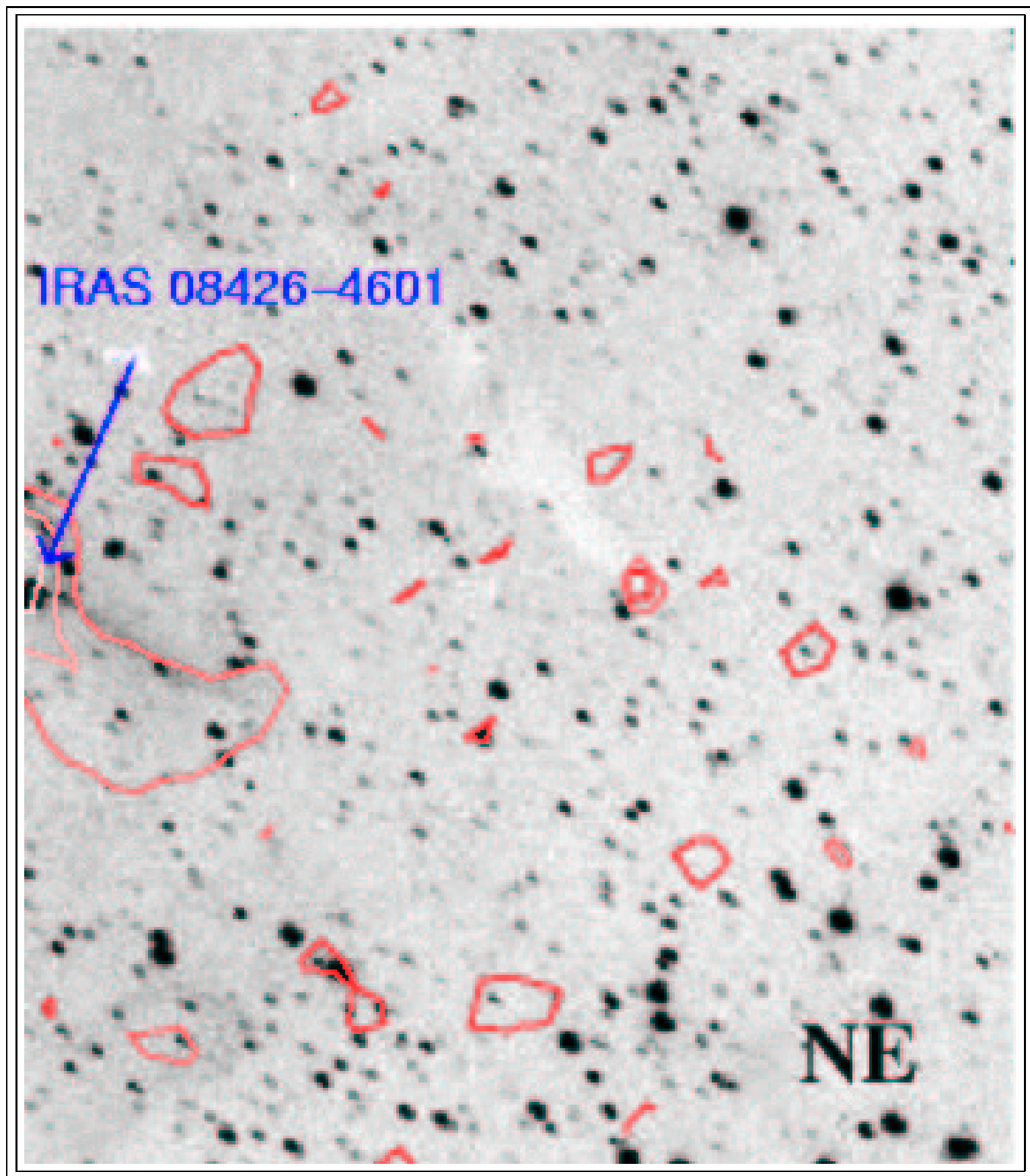

Figura 51: Imagen estelar tomada en $H \alpha$ a la región en estudio, centrada en $\alpha=$ 08:44:00, $\delta=-46: 04: 18$, J2000 y con un tamaño de $\sim 15^{\prime} \times 15^{\prime}$. Con curvas de nivel se indica la intensidad de emisión en la banda A del MSX que crece hacia la fuente IRAS. 


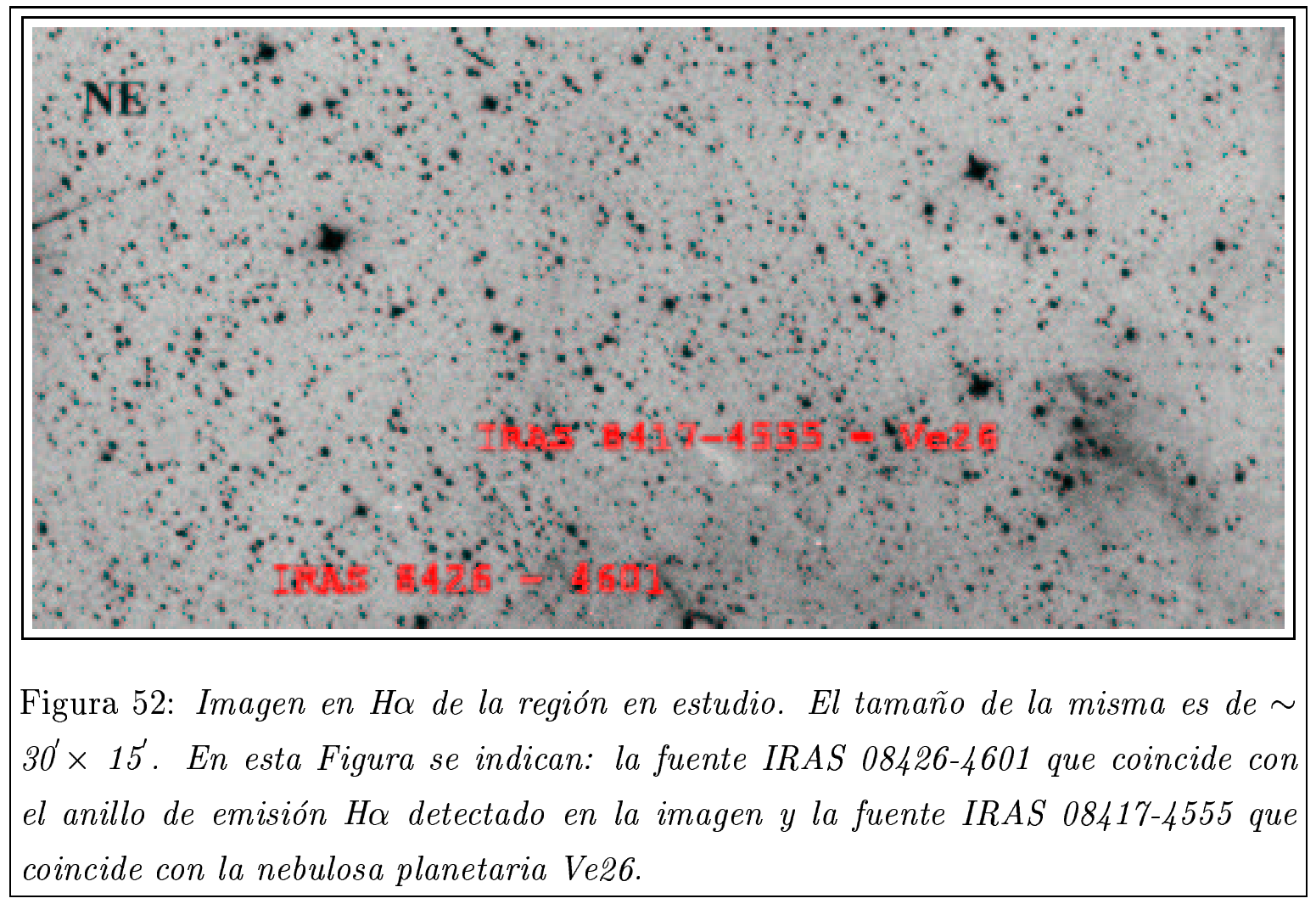

que se observa con alta intensidad en CS, en $60 \mu \mathrm{m}$ del IR más que en las demás longitudes de onda y sólo en la banda A del MSX.

\subsubsection{Longitudes de onda Ópticas y Milimétricas}

Se empleó la imagen $\mathbf{H} \alpha$ obtenida previamente por la Dra. V. Niemela, con el telescopio Curtis-Schmidt del CTIO, referenciada en la subsección 4.1. Con ella se confeccionó la Figura 52 donde de la región en estudio se muestra sólo el sector en el que la fuente IRAS 08426-4601 coincide con la figura del anillo, lamentablemente cortado por quedar en el borde del campo, el cual se encuentra centrado en aprox. $\alpha=08: 44: 16$ y $\delta=-46: 11: 47$ y la estrella más al sur de la región de la cual se tienen datos fotométricos es CBN84416.7-461121 con $\mathrm{TE}=\mathrm{B} 1.5 \mathrm{~V}$, de coords. $\alpha=08: 44: 17$ y $\delta=-46: 11: 21$. También se observa la fuente IRAS 08417-4555 la cual coincide con Ve26.

Consultamos el SHASSA (Southern H $\alpha$ Sky Survey Atlas) en la siguiente dirección electrónica: http://amundsen.swarthmore.edu/SHASSA/. El mismo es el producto de un relevamiento de imágenes digitales de emisión en $\mathrm{H} \alpha$ del gas interestelar ionizado de nuestra Galaxia. El Atlas cubre el cielo del hemisferio sur (declinaciones menores que $\left.+15^{\circ}\right)($ Gaustad 
et al., 2001). Obtuvimos la imagen en $\mathrm{H} \alpha$ con el continuo restado que se muestra en la Figura 53, donde es posible ver la zona de mayor intensidad de emisión ubicada en aprox. $\alpha=$ 08:43:21 y $\delta=-46: 08: 00$. Dicha zona es aproximadamente coincidente con la ubicación de la figura del anillo.

En una emisión a $\lambda<3 \mathrm{~mm}$ comienza a aparecer la emisión en el IR, ya que el polvo absorbe los fotones radiados por la estrella excitante, se calienta y emite en IR. Esta radiación crece por encima de la radiación térmica free-free y alcanza un máximo en $\lambda \simeq 100 \mu \mathrm{m}$. Las regiones HII ultra compactas (UCHIIRs) están entre los objetos más brillantes y luminosos en la Galaxia en longitud de onda del IR lejano y radio. Ellas son manifestaciones de estrellas de alta masa formadas recientemente que aún están inmersas en su nube molecular de origen. En el relevamiento de Wood \& Churchwell (1989a), de ahora en más WCa, encontraron que el $20 \%$ de la muestra de regiones UCHII estudiadas tenía morfología cometaria como la observada en la imagen en $\mathrm{H} \alpha$ de la Figura 52. Las estructuras cometarias son sugerentes de "bowshocks". El relevamiento de WCa sugiere que las estrellas O inmersas están probablemente en movimiento relativo a la nube molecular del ambiente y han formado un "bowshock" molecular neutro apoyado por el viento estelar de una estrella ionizante. Un "bowshock"se comporta como un guante el cual confina la radiación estelar ionizante, su viento y fenómenos energéticos tales como excitación de altos estados energéticos moleculares a una pequeña región en torno de la estrella, aislando de este modo al resto de la nube molecular del efecto destructivo de la estrella. La presión del gas de choque producida por la fuente de gas molecular del ambiente en torno al "bowshock" (debido a los movimientos de la estrella a través de la nube molecular), es balanceada por la presión del viento estelar sobre el gas ionizado. Este balance de fuerzas resulta en la característica forma parabólica del frente con intensos bordes brillantes en la dirección del movimiento de la estrella y una suave disminución de brillo en la dirección opuesta. La estrella abre un túnel ionizado caliente a través de la nube molecular. El gráfico de la Figura 54 es una representación de lo descripto previamente.

Nos preguntamos si no sería posible que la figura que en nuestra imagen en $\mathrm{H} \alpha$ vemos como un anillo con una estructura cometaria, pudiera tratarse de una región HII, de modo que buscamos en el catálogo de RHII disponible en Aladin. La única RHII que encontramos en un radio de 20 minutos de arco medidos desde el centro de la región de nuestra fotometría UBV, fue una identificada como nSFR (Star Formation Region name) 265.32 -2.17, coincidente con la fuente IRAS 08426-4601. En el catálogo también se menciona la presencia 


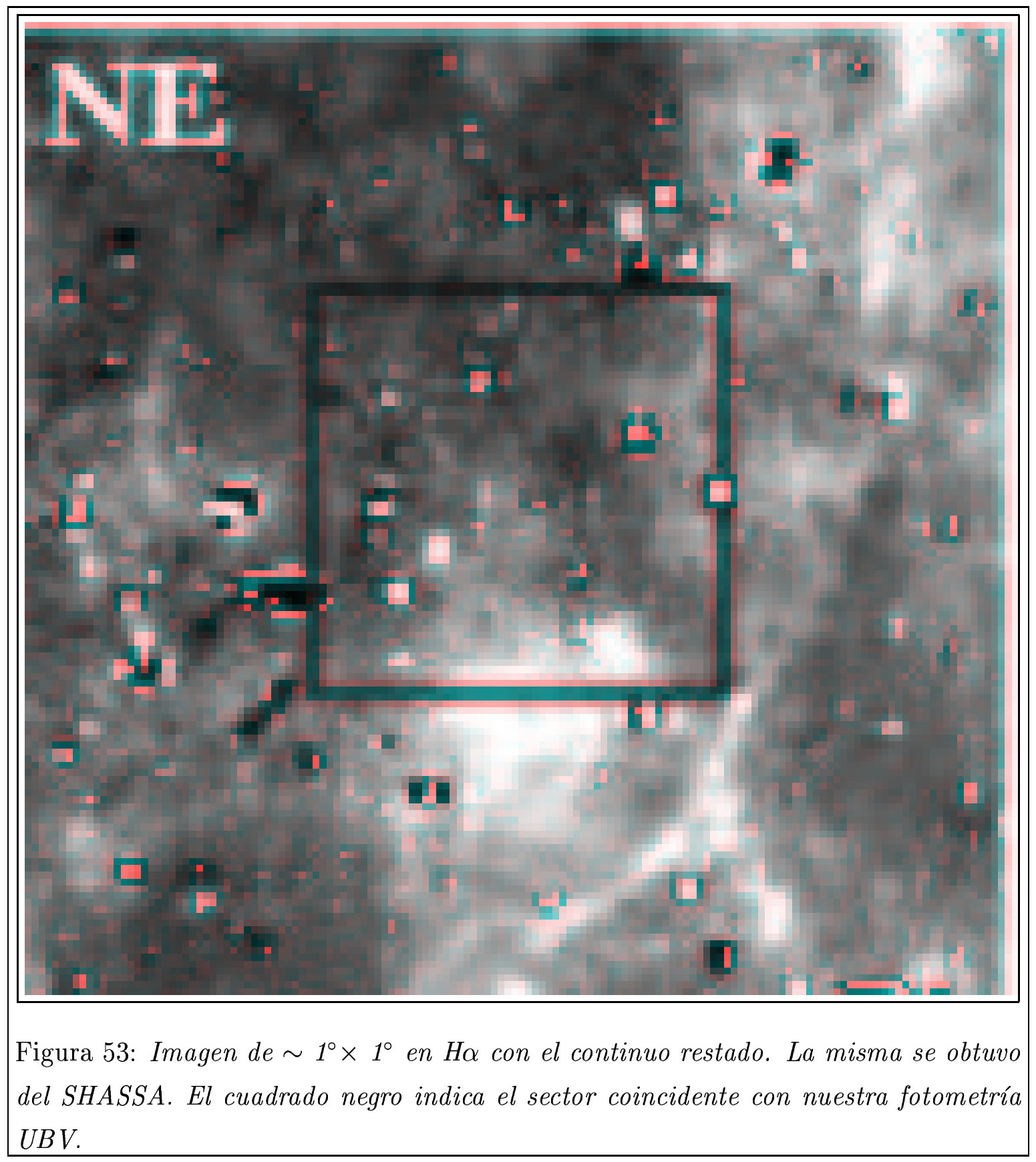


de otras tres fuentes infrarrojas y cuatro nubes moleculares. En la Figura 55 se muestra una comparación de los colores IR de RHII ultra compactas conocidas (puntos llenos) con fuentes puntuales IRAS, dentro de una caja de $2^{\circ} \times 2^{\circ}$ centrada en el plano galáctico a $40^{\circ}$ de longitud galáctica (cuadrados abiertos) y fuentes puntuales IRAS que se ubican entre $13^{h}$ $00^{m}$ y $13^{h} 10^{m}$ en ascención recta (cruces). Dicha Figura fue tomada del trabajo de Wood \& Churchwell (1989b), de ahora en más WCb, e ilustra que las UCHIIRs se ubican en una región claramente definida en el diagrama color-color obtenido a partir de los brillos medidos en el infrarrojo mediano. Los límites usados para seleccionar regiones UCHII por colores del IR mediano están indicados por la línea punteada en la esquina superior derecha de la figura. WCb supusieron que todas las fuentes puntuales IRAS con razón de densidad de flujo log $\left(\mathrm{F}_{60} / \mathrm{F}_{12}\right) \geq 1.3 \mathrm{y} \log \left(\mathrm{F}_{25} / \mathrm{F}_{12}\right) \geq 0.57$ son potenciales estrellas $\mathrm{O}$ inmersas. Los valores de estas razones de flujo obtenidos para la fuente IRAS 08426-4601 son $\log \left(\mathrm{F}_{60} / \mathrm{F}_{12}\right)=1.5 \mathrm{y}$ $\log \left(\mathrm{F}_{25} / \mathrm{F}_{12}\right)=0.64$, con lo cual ella quedaría dentro del sector seleccionado en la Figura 55 para UCHIIRs. Fueron detectadas regiones UCHII en el 85\% del campo investigado por WCb, las cuales coincidieron con el $70 \%$ de las posiciones en el campo de fuentes IRAS. Aproximadamente en el $22 \%$ de la región fueron encontradas las mofologías cometarias. La alta incidencia de este tipo de morfología apoya el modelo de "bowshock" de las regiones UCHII, lo cual explica el largo tiempo de vida dinámico (Kurtz et al., 1990).

De la coincidencia de la fuente IRAS 08426-4601 con la cabeza de mayor intensidad observada en el anillo de emisión en $\mathrm{H} \alpha$, del cual se desprende una cola cometaria, observada en la imagen en banda A del MSX, pensamos que la fuente IRAS 08426-4601 podría ser una RHII ultra compacta.

\section{$\mathrm{CO}$}

Las pequeñas nubes en las que se encuentra concentrado el dióxido de carbono (CO), están en el plano de la galaxia, restringidas a longitudes galácticas comprendidas dentro de $100^{\circ}$ de la dirección del centro galáctico. La emisión de CO está confinada a regiones de alta densidad, las condiciones para producir líneas de emisión las proporcionan las nubes densas, entendiendo como tales a las nubes pequeñas con cantidades de masa mayores a $10 M \odot$.

La línea de CO a $115 \mathrm{GHz}$ y la de CS a $48 \mathrm{GHz}$ son importantes para delinear la compleja estructura cerca del centro de la galaxia. En la mayoría de las direcciones las nubes de CO son ópticamente delgadas, donde esto no sucede pueden observarse las especies menos abun- 


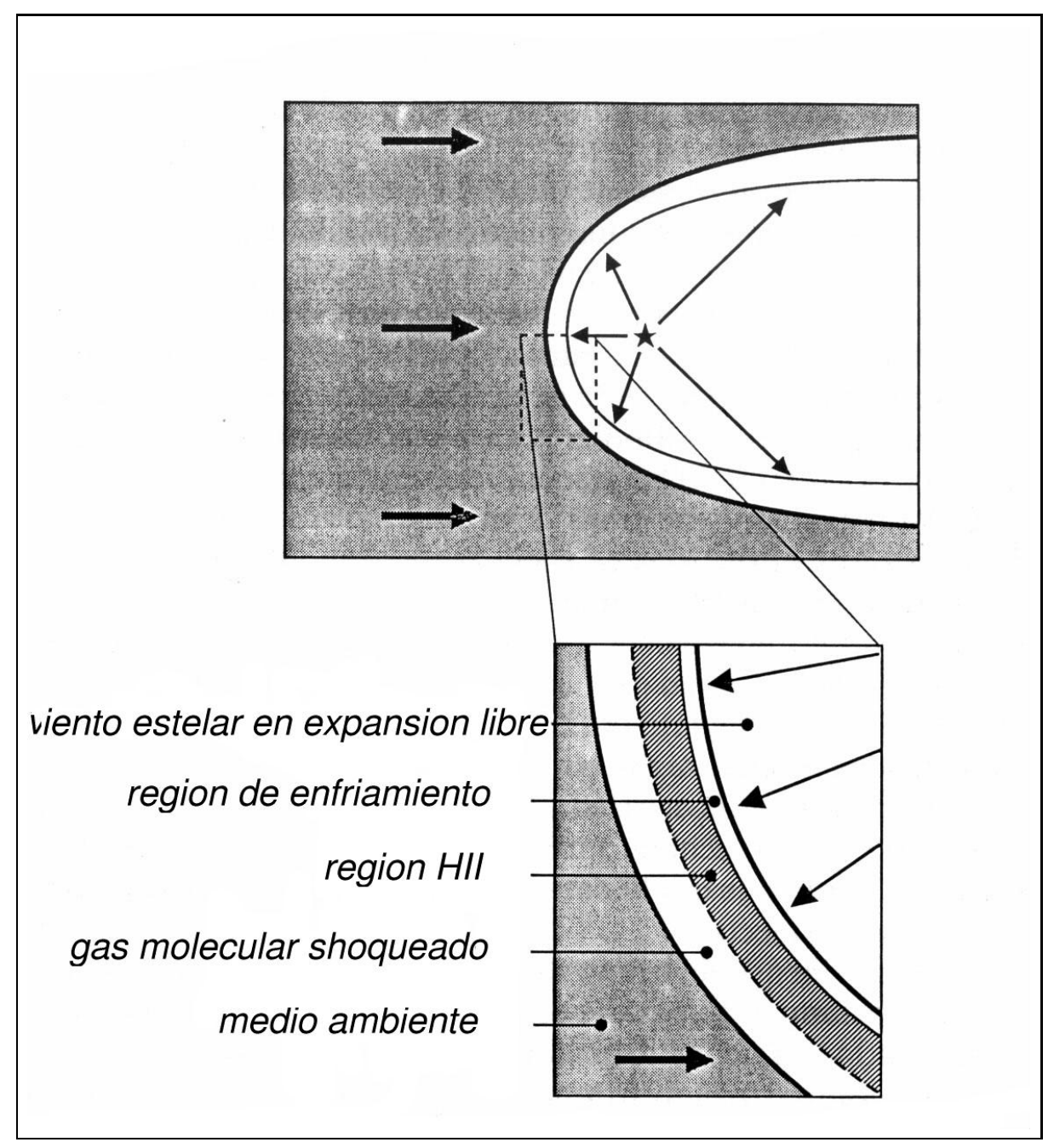

Figura 54: El panel superior muestra la forma del "bowshock" en relación a la estrella ionizante. Las flechas apuntando lejos de la estrella representan las partículas del viento estelar. El área representada por la cajita punteada está expandida en el panel de abajo, donde se identifican cinco regiones del viento estelar en el "bowshock". La región con viento estelar en expansión libre es altamente shoqueada y probablemente tiene una temperatura en exceso de $10^{7} \mathrm{~K}$ y una densidad por debajo de $10^{2} \mathrm{~cm}^{-3}$. La región de enfriamiento está cerca de la terminal del viento de choque. Aquí hay una gran fluctuación en densidad y flujo de gas caliente ionizado hacia la estrella, el cual es frenado después de una corta distancia por el momento del viento saliente. La región HII es una cáscara delgada y espesa donde son absorbidos los fotones ionizantes de la estrella. La curva punteada es el límite de la RHII, es decir, la parte más externa de la penetración de los fotones estelares ionizantes. Fuera de ella, está el "bowshock"neutro donde deben residir los masers OH, $\mathrm{CH}_{3} \mathrm{OH}$ y posiblemente $\mathrm{H}_{2} \mathrm{O}$, como también especies en alto estado excitado rotacional y vibracional. La nube molecular del ambiente rodea al "bowshock". 


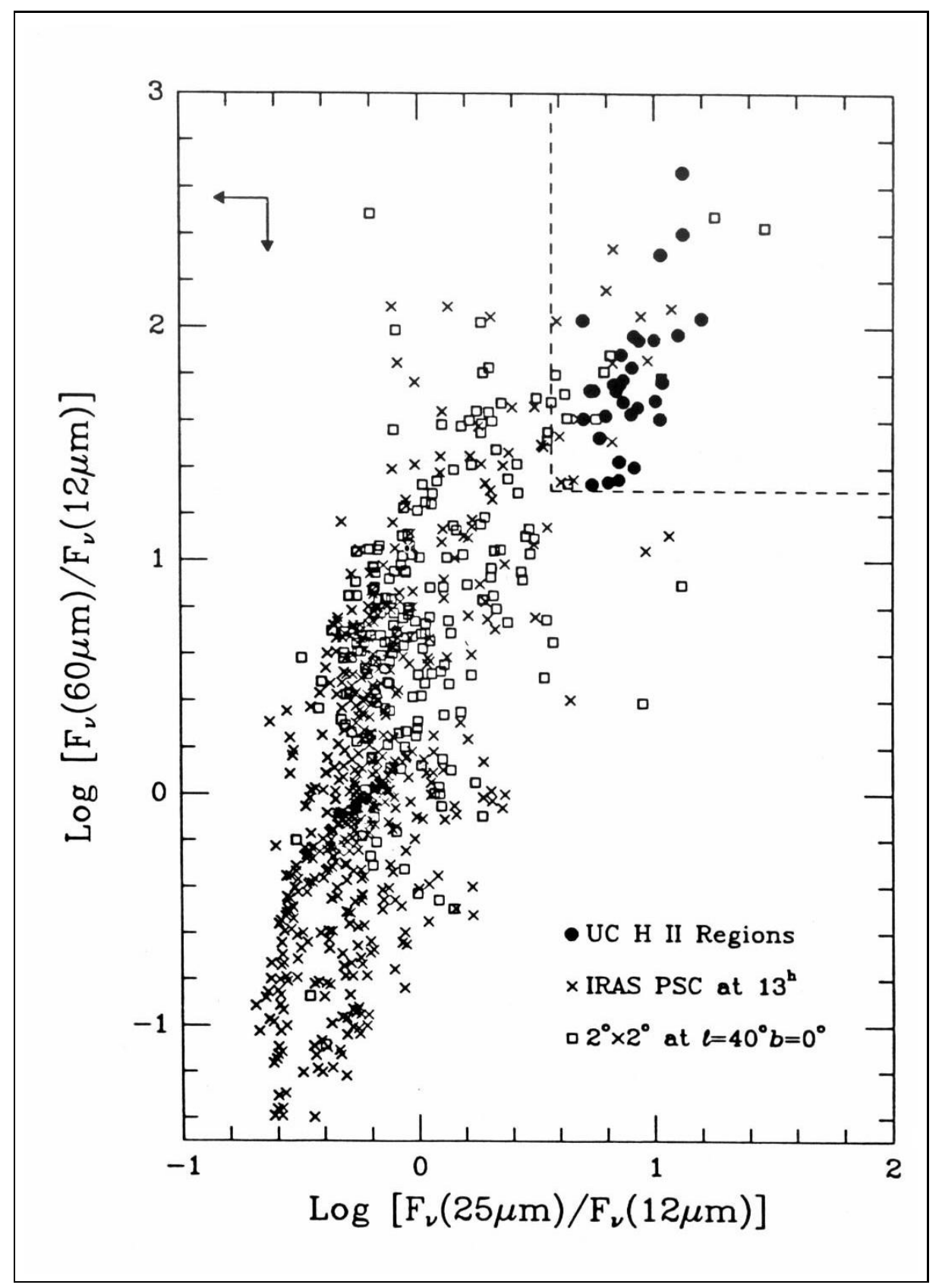

Figura 55: Comparación de los colores IR de regiones UCHII conocidas (puntos llenos) con fuentes puntuales IRAS en una caja de $\mathscr{2}^{\circ} \times \mathscr{2}^{\circ}$ centrada en el plano galáctico a $40^{\circ}$ de longitud galáctica (cuadrados abiertos) y fuentes puntuales IRAS que se ubican entre $13^{h} 00^{m}$ y $13^{h} 10^{m}$ en ascención recta (cruces). La Figura fue tomada del trabajo de Wood $\&$ Churchwell (1989b) e ilustra que las UCHIIRs se ubican en una región claramente definida en el diagrama color-color obtenido a partir de los brillos medidos en el infrarrojo mediano. Los límites usados para seleccionar regiones UCHII por colores del IR mediano están indicados por la línea punteada en la esquina superior derecha de la figura. 
dantes de $\mathrm{C}^{13} \mathrm{O}$. Los niveles excitados de estas moléculas pueden ser poblados solamente en regiones donde hay una alta frecuencia colisional. Esto requiere una densidad de $100 \mathrm{~cm}^{-3}$ para CO y $10^{4} \mathrm{~cm}^{-3}$ para CS.

La Figura 56 es una imagen estelar centrada en las coordenadas ecuatoriales celestes $\alpha$ $=8^{h} 44^{m} 20^{s}, \delta=-45^{\circ} 55^{\prime} 52^{\prime \prime}$, con un tamaño de $3^{\circ} \times 3^{\circ}$. En ella también se muestran los resultados de un relevamiento de $115 \mathbf{~ G H z}$ (Dame et al., 2001) efectuado en toda la Vía Láctea, combinando relevamientos hechos con el telescopio CfA de 1.2 metros y otros llevados a cabo con telescopios similares localizados en Cerro Tololo, Chile. Dichos resultados se evidencian en los contornos que se observan con una variación de colores acorde a la intensidad, según se indica en el margen superior derecho, indicando la $\mathrm{T}_{b}$ del haz principal integrado en velocidad en unidades de $\mathrm{K} \mathrm{km} \mathrm{s}^{-1}$. Es interesante ver en esta imagen proyectada que los contornos de CO muestran un incremento hacia el centro de la nube. Se observa también que el sector SO de la región de Bo 7 en la cual se ubican las estrellas más tempranas y las fuentes IRAS, como también la parte central de Bo 7 donde se encuentra la WR12, están próximas al contorno exterior de la nube de CO. Es sabido que en las nubes moleculares la formación estelar tiene lugar en su periferia, con lo cual nos interesamos en conocer la distancia de esta nube de CO. En caso de resultar similar a la de aquellas estrellas posibles miembros de la Asociación, nos encontrariamos efectivamente con una región de formación estelar.

El Dr. Tom Dame del Harvard-Smithsonian CfA, en comunicación privada, nos informó que el espectro de $\mathrm{CO}$ más próximo a nuestra posición de interés $\left(\mathrm{l}=265^{\circ} .125, \mathrm{~b}=-2^{\circ} .625\right)$ muestra componentes en velocidad en LSR próximas a $4.6 \mathrm{~km} \mathrm{~s}^{-1}$. Otro espectro promediado en un grado cuadrado en torno a la posición $1=264^{\circ} .625-265^{\circ} .625, \mathrm{~b}=-2^{\circ} .125-$ $-3^{\circ} .125$ indica una velocidad LSR próxima a $16.3 \mathrm{~km} \mathrm{~s}^{-1}$. Empleando el modelo de la curva de rotación galáctica de Fich et al., pudimos saber que estas velocidades corresponden a una distancia al Sol de $\simeq 1.8 \mathrm{kpc} \mathrm{y} \simeq 3.3 \mathrm{kpc}$, respectivamente.

Encontrándose la distribución de CO en las distancias mencionadas, sólo podemos concluir que ella no se vincula con los miembros de la Asociación en estudio porque efectivamente se encuetra delante de ellos. En consecuencia, de tratarse las nubes de CO de nubes ópticamente delgadas, como se indica aquí en párrafos anteriores, resulta posible observar las fuentes IRAS que se encuentran en esa dirección de la galaxia y a mayor distancia del Sol. El hecho de que estas fuentes se ubiquen detrás del CO, incluso una de ellas con emisión en CS(2-1), no impide que su emisión en el IR nos resulte observable. 


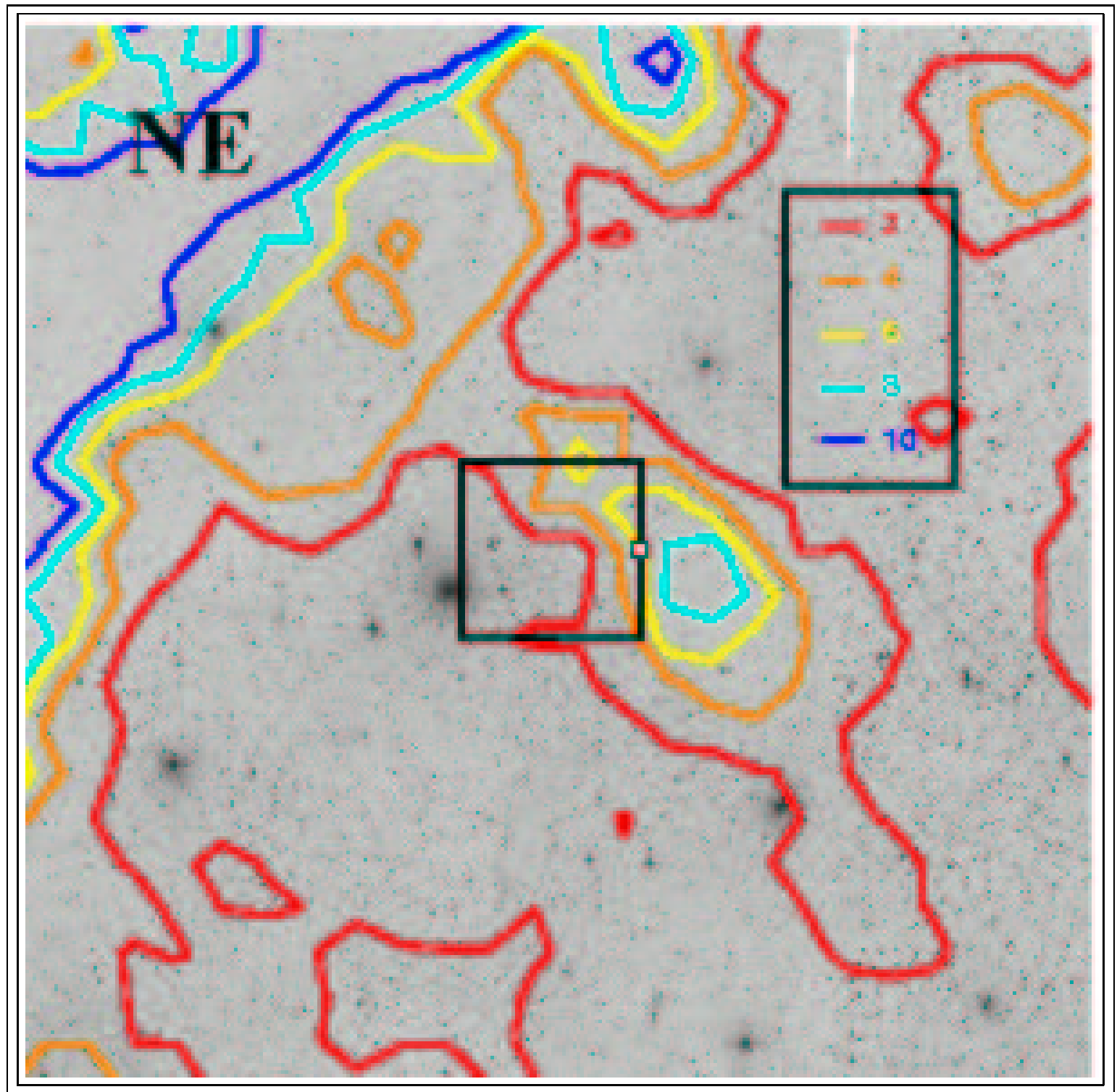

Figura 56: Imagen estelar de $3^{\circ} \times 3^{\circ}$ centrada en la región en estudio con la superposición de los contornos que indican la intensidad de la $T_{b}$ generada por la presencia de $C O$. 
Investigamos también en el continuo de radio de $4.8 \mathrm{GHz}$ y $408 \mathrm{MHz}$ y no encontramos información que le aportara algún dato al trabajo que se desarrolla en esta Tesis.

\subsubsection{Radio: HI, SNR y otros}

Se trabajó con un cubo de datos de HI que en su cara posterior tiene los ejes longitud galáctica y latitud galáctica correspondientes a la región de Bo 7 y un tercer eje indica la velocidad LSR (Testori et al., 2001). Esta imagen es el producto de un relevamiento realizado con la Antena de 30 metros del Instituto Argentino de Radioastronomía (IAR) del CONICET. La sensibilidad del mismo es de $50 \mathrm{mK}$ en la escala de temperatura de brillo, $\mathrm{T}_{b}$, en la línea de $21 \mathrm{~cm}(1420 \mathrm{MHz})$ del hidrógeno neutro. El mismo se efectuó para una declinación $-90^{\circ}<\delta<-10^{\circ}$ y ascención recta $0^{h}<\alpha<24^{h}$. Este relevamiento fue realizado en coordenadas galácticas y cubrió un rango de velocidades comprendido entre -450 y +400 $\mathrm{km} \mathrm{s}^{-1}$.

Al cubo de datos de HI se le hicieron cortes en intervalos de velocidad empleando para ello la ecuación:

$$
\mathrm{Vn}=-458.6+(\mathrm{n}-1) 1.03055
$$

Siendo Vn la velocidad LSR de cada corte, -458.6 la velocidad para la primera capa, con n se indica el número de la capa y 1.03055 es el paso que hay entre una capa de velocidad y la siguiente. Se realizaron 60 cortes en velocidad al cubo de datos de HI yendo de 30 $\mathrm{km} \mathrm{s}^{-1}$ a $90 \mathrm{~km} \mathrm{~s}^{-1}$ y se notó una cavidad o "burbuja de HI", que comenzaba a definirse en aproximadamente $68 \mathrm{~km} \mathrm{~s}^{-1}$, ampliándose la misma manteniendo una forma esférica hasta los $72 \mathrm{~km} \mathrm{~s}^{-1}$, aprox., luego se rompe la esfericidad y es en aprox. $80 \mathrm{~km} \mathrm{~s}^{-1}$ cuando parece que comenzara a retomar la forma esférica, buscando de cerrarse nuevamente. Las imágenes que responden a lo que aquí se comenta están mostradas en la Figura 57. Usando el software AIPS, se marcó de modo aprox. la región ocupada por la esfera en la imagen en que ésta se ve bien definida y se midió un área de $\simeq 221$ pixeles, con lo cual el radio de la misma sería: $(221 / \pi)^{1 / 2}=8.4 \mathrm{px}$. Como cada pixel equivale a $5 \cdot 10^{-2}$ grados, se tiene un radio de la burbuja de aprox. $0.42^{\circ}$ o $25^{\prime}$.

Los valores de $\mathrm{V}_{L S R}$ en los que parece definirse la burbuja de HI corresponden a una 
distancia cinemática de $\mathrm{d}=8.7 \mathrm{kpc}\left(\right.$ para $\left.\mathrm{V}_{L S R}=68 \mathrm{~km} \mathrm{seg}^{-1}\right)$ y d $=9.2 \mathrm{kpc}\left(\right.$ para $\mathrm{V}_{L S R}=$ $72 \mathrm{~km} \mathrm{seg}^{-1}$ ), según la curva de rotación de la galaxia. Si bien las velocidades en LSR donde parece estar definida la burbuja de HI coinciden bien con la posición de la WR12 (Dubner et al., 1992), según el trabajo de van der Hucht (2001) esta estrella tiene una distancia espectrofotométrica de $5 \mathrm{kpc}$, con lo cual considerando esto aún no es posible relacionar a la burbuja de HI con la estrella WR12.

Aunque resulta evidente que las estrellas de Bo 7 están a una distancia menor que la burbuja de HI, realizamos un rápido análisis de la misma. La cavidad en la nube de HI que comienza a verse en el corte en $\mathrm{V}_{L S R}=68 \mathrm{~km} \mathrm{seg}^{-1}$ efectuado en la imagen de la misma, se continua hasta el corte en $\mathrm{V}_{L S R}=88 \mathrm{~km} \mathrm{seg}^{-1}$, donde desaparece. Empleando los modelos de curva de rotación de la galaxia fue posible determinar que la longitud de dicha cavidad es de aproximadamente $2.5 \mathrm{kpc}$. De este modo la geometría de la misma se asemeja más a la de un tubo que a la de una burbuja. Por otro lado, la resolución angular de este relevamiento es de 30', coincidiendo así con el tamaño de nuestra imagen fotométrica. Esto produce que la resolución no sea la adecuada para divisar pequeñas estructuras en la imagen de HI, en el caso en que éstas estuvieran presentes. Conocemos la existencia de un relevamiento en la línea de $21 \mathrm{~cm}$ del hidrógeno neutro del Plano Galáctico Sur (McClure-Griffiths et al, 2004). El mismo combina datos interferométricos de alta resolución obtenidos con el Australia Telescope Compact Array (ATCA) y datos de baja resolución obtenidos con el Radiotelescopio de Parkes. Nuestra intención es realizar un trabajo a futuro con él, buscando una respuesta a nuestra pregunta sobre la existencia de alguna relación entre la formación de los miembros de Bochum 7 y esa nube de HI.

Otros trabajos realizados han sido:

Una búsqueda de Remanente de Supernova (SNR) en la página digital:

www.mrao.cam.ac.uk/surveys/index.html, en la zona de la galaxia donde se encuentra la Asociación y no se encontró ninguno ubicado por el lugar.

Nos preguntamos también si no seria posible que encontraramos radiación sincrotrón pero nuevamente obtuvimos un resultado negativo.

En la página digital: www.atnf.csiro.au/research/pulsar/catalogue/ se encuentra el ATNF Pulsar Catalogue, donde realizamos una búsqueda de radiopulsars y nuevamente no 


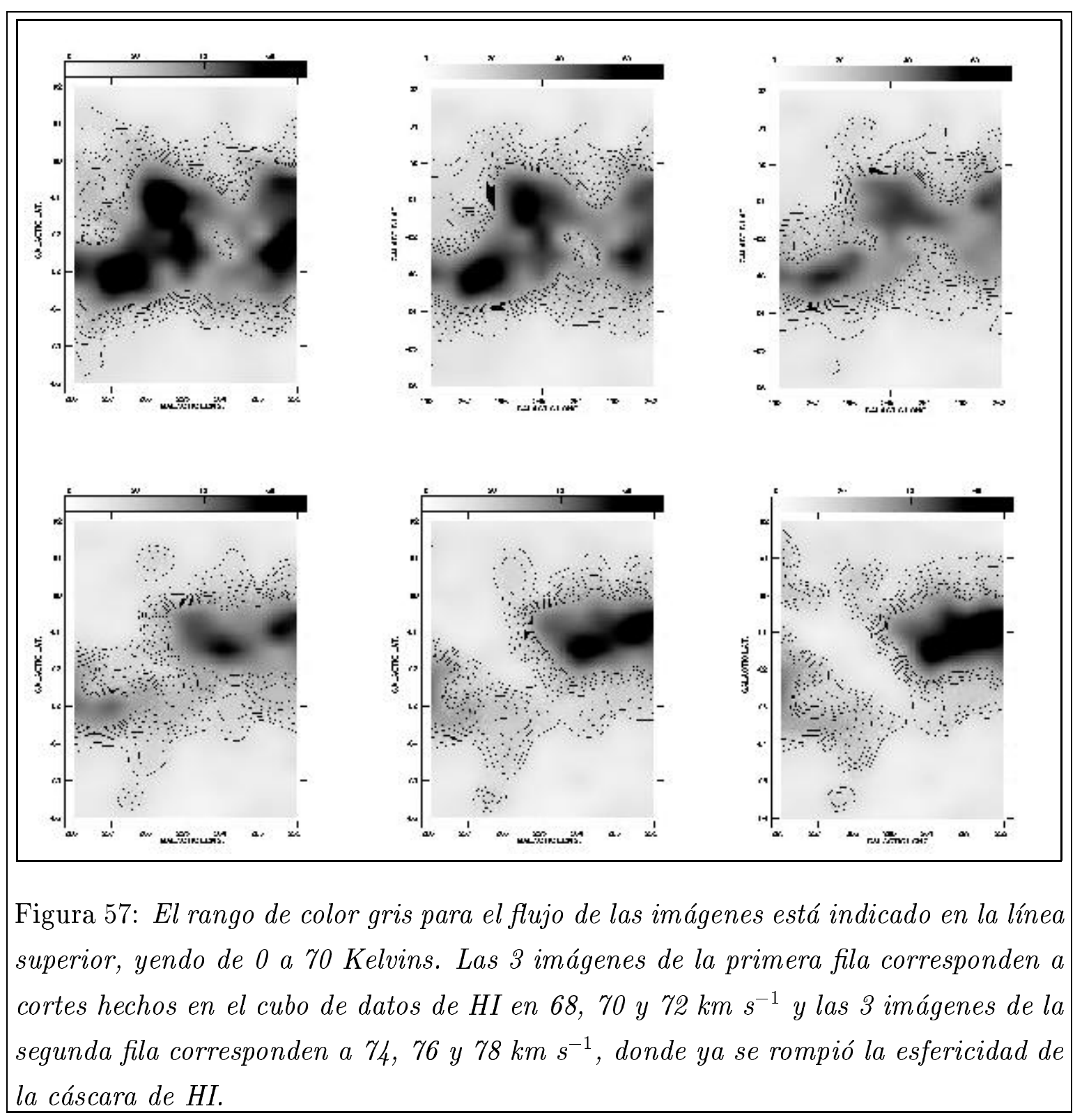

Estudio de una Asociación $O B$ distante en la Vía Láctea 
encontramos ninguno cuya ubicación coincidiera con la zona en estudio. Obtuvimos el mismo resultado como consecuencia de una investigación realizada en el tema en la página de EGRET: Energetic Gamma Ray, http://cossc.gsfc. nasa.gov/egret/

En el Observatorio virtual skyview disponible en INTERNET, en el cual es posible encontrar imágenes de cualquier sector del cielo a longitudes de onda de todos los regímenes yendo de Radio a Rayos Gama, se buscaron imágenes en rayos $\mathbf{X}$ de la zona de la Asociación. El satélite ROSAT obtuvo una imagen en rayos X blando de la región en la galaxia en la cual estamos investigando la existencia de Bochum 7. De ella es posible concluir que en las coordenadas de la Asociación no se encuentra ninguna fuente de rayos X. 


\section{ANÁLISIS DE LAS POSIBLES ESTRUCTURAS EN EL CAMPO DE INTERÉS}

De la discusión anterior sobre la realidad de Bo 7 y de la identificación de sus miembros, resulta evidente que los métodos tradicionales de análisis aplicados a cúmulos cercanos puede generar ambigüedades al extenderlos a regiones más distantes e intrínsecamente ricas. Lo que decimos resulta evidente de las conclusiones a las que Moffat \& Vogt (1975), Lundstrom \& Stenholm (1984) y Sung et al. (1999) llegan en sus trabajos. Las mismas difieren respecto de las características que posee la asociación Bochum 7, caso ella sea real.

Esto probablemente no se restringe sólo al caso de Bo 7 , sino que surgiría en cualquier otro análisis equivalente realizado a una región distante en cualquier otra dirección del plano galáctico.

Es claro que, para trabajar adecuadamente en regiones ubicadas a algunos kiloparsecs, se hace necesaria una estrategia diferente a la habitual. Tres puntos básicos deben ser reconocidos a este efecto:

(a) A medida que se investigan estructuras estelares a distancias cada vez mayores, los errores observacionales crecen en forma considerable y por esta razón resulta prudente y hasta inevitable, la utilización simultánea de diferentes métodos cuya evaluación conjunta indique la probabilidad de existencia de una asociación en particular;

(b) El análisis estadístico sin preconceptos de los datos: a grandes distancias, regiones de pequeño tamaño angular incluyen grandes volúmenes de espacio, dentro de los cuales es de esperar que existan estructuras estelares, incluso más de una estructura a diferentes distancias. Las cuales puede que no tengan soluciones simples o triviales;

(c) Tanto la existencia de una dada asociación como la adjudicación de determinados miembros a una asociación en particular, sólo podrá hacerse y cuantificarse en forma probabilística. Esto se dejará para ser realizado en trabajos futuros a este.

En este capítulo mostraremos el desarrollo de un análisis que aplica los lineamientos anteriores a nuestra región de interés. Nuestro objetivo será la caracterización, por medio de diversos métodos, algunos ya existentes y otros originales, de toda y cualquier estructura que 
pueda ser identificada dentro de nuestra imagen hasta las mayores distancias observadas. A lo largo del análisis discutiremos estas estructuras y, paralelamente, su posible relación con Bo 7 .

\subsection{Agrupación espacial: radial y angular}

La identificación de una asociación OB significa, idealmente, la detección de una agrupación espacial de estrellas tempranas. Nosotros aquí trataremos separadamente las componentes radial (a lo largo de la línea de la visual) y angular (perpendicular a la línea de la visual).

\section{Radial}

Las distancias son difíciles de medir y tienen inherentemente errores grandes. Nuestros errores son del orden de $\sim 1 \mathrm{kpc}$ para distancias de $\sim 6 \mathrm{kpc}$, y los mismos varían linealmente con la distancia. Por lo tanto, no podemos esperar detectar una asociación con un diámetro de unos pocos parsecs o unas pocas decenas de parsecs como un grupo localizado a la distancia medida.

Consecuentemente, para tener en cuenta del modo adecuado los errores y distancias promedios, con la colaboración del Dr. Gustavo Medina Tanco, recurrimos a un esquema de simulación muy simple. El mismo consiste en reemplazar cada estrella individual OB por $10^{3}$ estrellas simuladas, las cuales siguen una distribución Gaussiana caracterizada por la distancia promedio de la estrella original. La desviación estándar de dicha distribución es el error estadístico inferido en la determinación de la distancia de la estrella. La Figura 58 esquematiza la simulación de la que se habla.

La función de distribución en distancia resultante se muestra en la Figura 59. La distribución de estrellas OB espectroscópicas se comporta suavemente hasta los $\sim 5.3 \mathrm{kpc}$ como puede verse por una comparación directa con el ajuste a las distancias más pequeñas (curva a rayas: $\mathrm{N}=\mathrm{a} \cdot \mathrm{b}^{R} \cdot \mathrm{R}^{c}$ ). A mayores distancias, la figura (b) muestra que, tanto la distribución en distancias de las estrellas OB espectroscópicas como la de las fotométricas se alejan considerablemente de las sugeridas por el modelo de síntesis de poblaciones estelares de la Galaxia de Besançon en la misma dirección $\left(l \bumpeq 265^{\circ}\right)$. Este modelo no incluye la estructura de brazo espiral (Robin et al., 2003) y, por lo tanto, podemos suponer que el primer exceso más allá de $\sim 5.3 \mathrm{kpc}$ corresponde a la continuación del brazo espiral Perseo dentro del tercer 


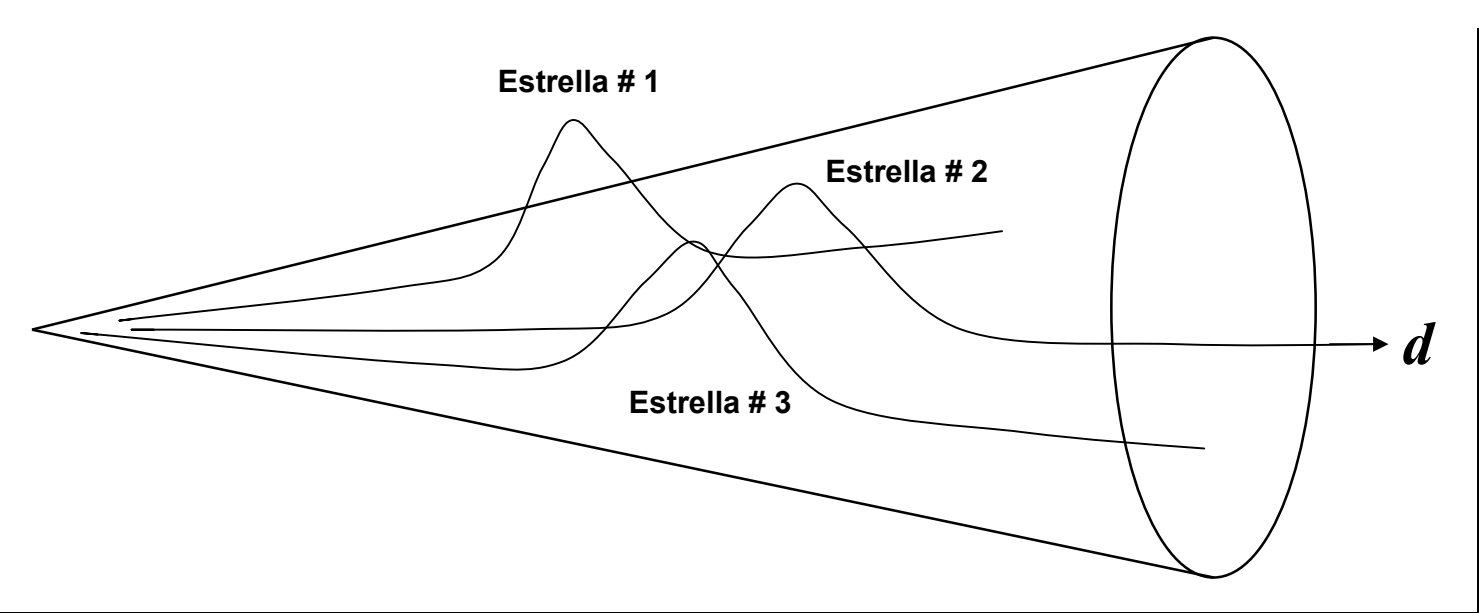

Figura 58: Esquema de simulación consistente en reemplazar cada estrella individual $O B$ por $10^{3}$ estrellas que siguen una distribución Gaussiana, caracterizada por la distancia promedio de la estrella original y una desviación estándar, igual al error de la distancia de la estrella.

cuadrante de la Galaxia. Uno también está tentado a especular que el segundo exceso más allá de $\sim 10 \mathrm{kpc}$ es o la continuación del brazo más externo o el nuevo brazo postulado por McClure-Griffiths et al. (2004) en la investigación realizada por ellos en la línea de $21 \mathrm{~cm}$ con el ATNF.

En caso de que exista una evidencia de Bochum $7 \mathrm{a} \mathrm{d} \geqslant 5.3 \mathrm{kpc}$, ésta está embebida en el incremento de densidad general asociado con el brazo de Perseo y, dados los grandes errores involucrados, es imposible detectar esto sólo como una agrupación en la función de distribución de la distancia. Existe, no obstante, una visible intensificación en la distribución radial de estrellas OB fotométricas a $\mathrm{d} \sim 2.5-4 \mathrm{kpc}$. No es claro por qué este exceso no está presente en la muestra de estrellas OB espectroscópicas (aún cuando una insinuación de esto pueda existir en la figura (a)). No obstante, es posible que la diferencia sistemática observada por Hipparcos entre las distancias fotométricas y especroscópicas estimadas previamente, ya mencionadas, sea la responsable de la dilución de la marca en la muestra de las espectroscópicas de menos significancia estadística. Esto último debido a que la muestra espectroscópica sólo contiene 63 estrellas cuando la muestra fotométrica contiene aproximadamente 300 estrellas.

La señal a $\mathrm{d} \sim 2.5-4 \mathrm{kpc}$ corresponde a un exceso de $\sim 25$ estrellas OB (30\%), sobre una distribución suave en ese rango de distancia. No existe otra asociación conocida a esta distancia y por lo tanto esto podría ser a priori Bochum 7 (ver Figura 59).

Estudio de una Asociación OB distante en la Vía Láctea 


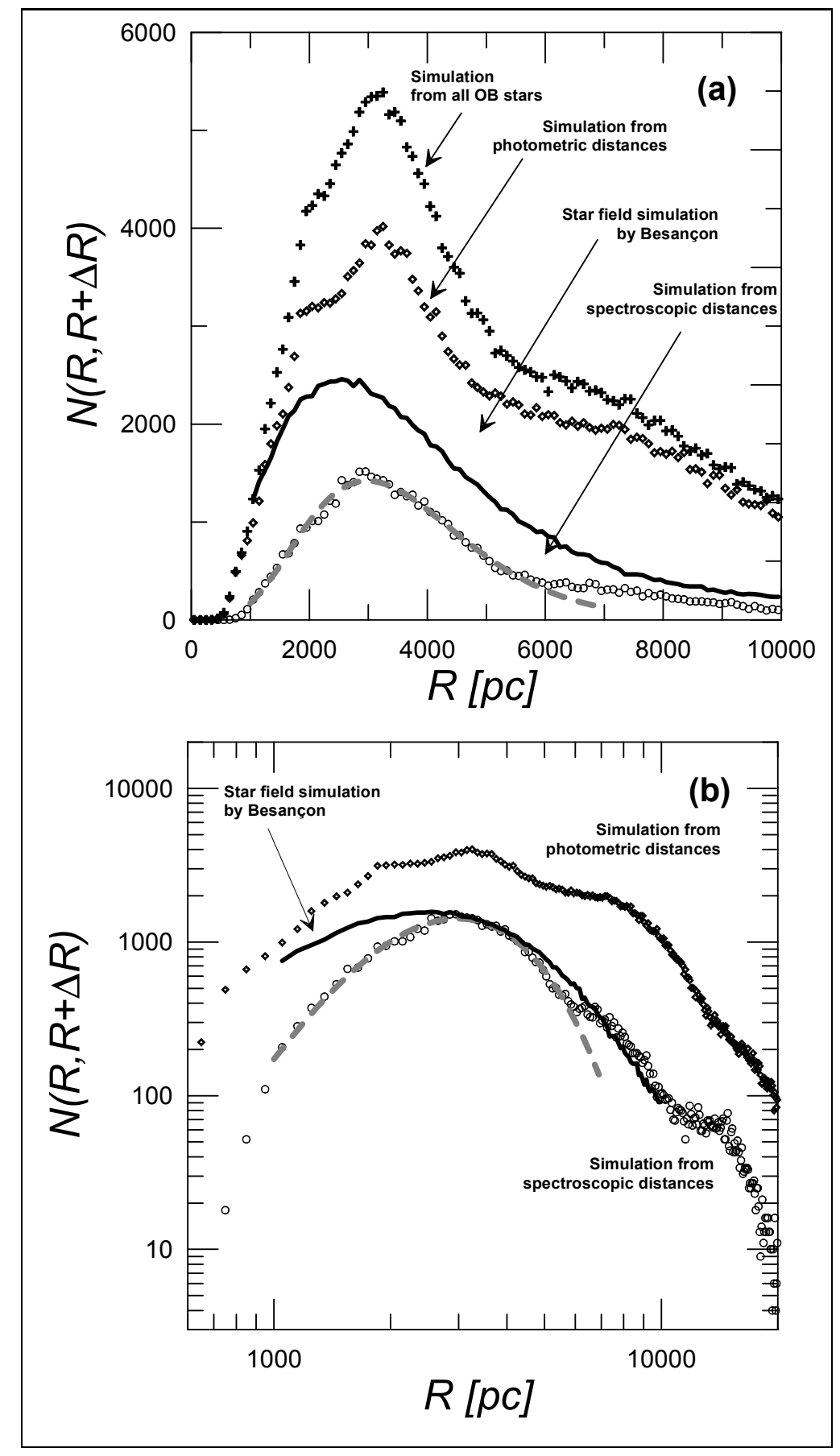

Figura 59: (a) Simulación de campo estelar construido con las estrellas OB espectroscópicas, con las $O B$ fotométricas y con todas las estrellas $O B$ combinadas, respectivamente. Con cada estrella $O B$ se generaron $10^{3}$ estrellas con las mismas coordenadas pero distancias extraídas de una distribución Gaussiana con la misma distancia promedio y desviación estándar como la distancia observada y su respectivo error. También se muestra la distribución de distancia esperada del suave modelo teórico de población estelar de la Galaxia en la misma dirección hecho en Besançon (modelo no suavizado). (b) Versión logaritmica 


\section{Angular}

En caso de existir una agrupación en la distribución radial, dado el tamaño angular de la imagen fotométrica y el tamaño esperado de la asociación OB, deberíamos ser capaces de observar algún tipo de agrupación en el plano de la imagen.

La Figura 60 muestra la posición de las estrellas OB espectroscópicas y fotométricas ubicadas a la distancia radial $\mathrm{d} \sim 2.5$ a $4 \mathrm{kpc}$, mencionada previamente. Puede verse que las estrellas no están distribuidas uniformemente sobre la imagen. Ellas parecen agruparse en torno a un punto $\mathrm{C}=\left(\alpha \sim 131.2^{\circ}, \delta \sim-45.9^{\circ}\right)$, marcado sobre la figura con un círculo. El número de estrellas OB dentro de este rango de distancia varía de $\sim 50$ a $\sim 85$, depen-

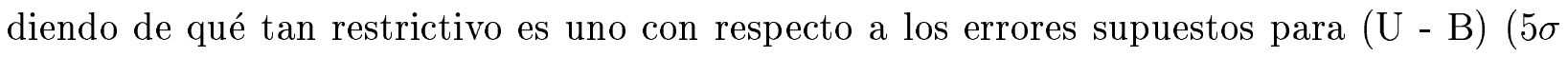
y $1 \sigma$, respectivamente), y por lo menos $\sim 30 \%$ de estas estrellas deberían pertenecer a la Asociación.

La realidad de esta agrupación angular es reforzada además considerando la distribución de densidad superficial, $n(\rho)$ como una función de la distancia angular al punto C (Figura 61). La densidad es bastante plana, $n(\rho) \propto \rho^{-0.3}$ hasta $\sim 0.1^{\circ}$ desde el centro $\mathrm{C}$ y luego cae abruptamente con la distancia, $n(\rho) \propto \rho^{-2.4}$. El quiebre en la densidad ocurre en el punto donde la densidad proyectada cae en un factor dos desde su valor central, con lo cual puede identificarse a esto como el radio del núcleo, $\rho_{o}$ (Binney \& Tremaine, 1987). A la distancia de la asociación, esto se traslada en un radio lineal del núcleo de aproximadamente $\mathrm{r}_{o} \cong 4.3$ (para $\mathrm{d}=2.5 \mathrm{kpc})$ y $7 \mathrm{pc}($ para $\mathrm{d}=4 \mathrm{kpc})$, lo cual es consistente con los valores esperados para las asociaciones OB.

Más allá del quiebre, a pocos radios del núcleo, la densidad superficial varía como $n(\rho) \propto \rho^{-2.4}$, lo cual es más pronunciada que la dependencia asintótica esperada para una esfera isotérmica, $n(\rho) \propto \rho^{-1}$. No obstante la región central y el halo pueden ajustarse mejor y en forma simultánea con un perfil de King con radio de King $\rho_{o} \sim 0.1^{\circ}$, radio tidal (cota del tamaño del cúmulo proyectado) $\rho_{t} \sim 1^{\circ}$ y una razón entre el potencial central y el cuadrado de la dispersión de velocidad $\psi_{o} / \sigma^{2} \sim 6$ (la mustra se consideró sin contaminación de estrellas de campo)(Binney \& Tremaine, 1987).

Una aproximación completamente diferente al problema de la caracterización de agrupación angular consiste en ignorar por completo a las distancias como primera aproximación y analizar directamente la distribución de las estrellas sobre la imagen fotométrica. Un punto 


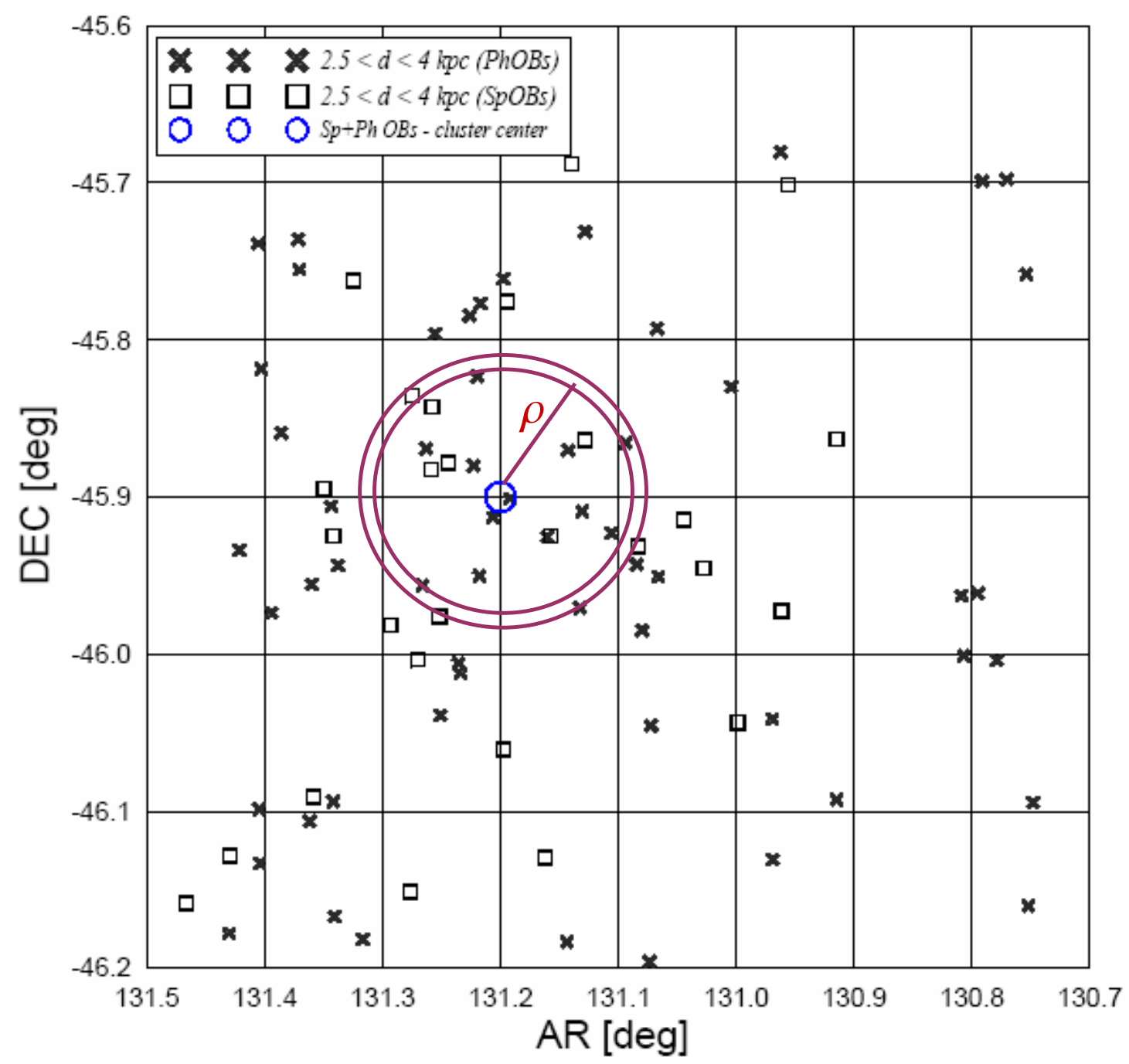

Figura 60: Mapa de estrellas $O B$ espectroscópicas y fotométricas en el intervalo 2.5 $<d<4 \mathrm{kpc}$. El círculo a $\alpha=131.2^{\circ}, \delta=-45.9^{\circ}$ es una estimación del centro del cúmulo y $\rho$ la distancia angular al punto $C$. 


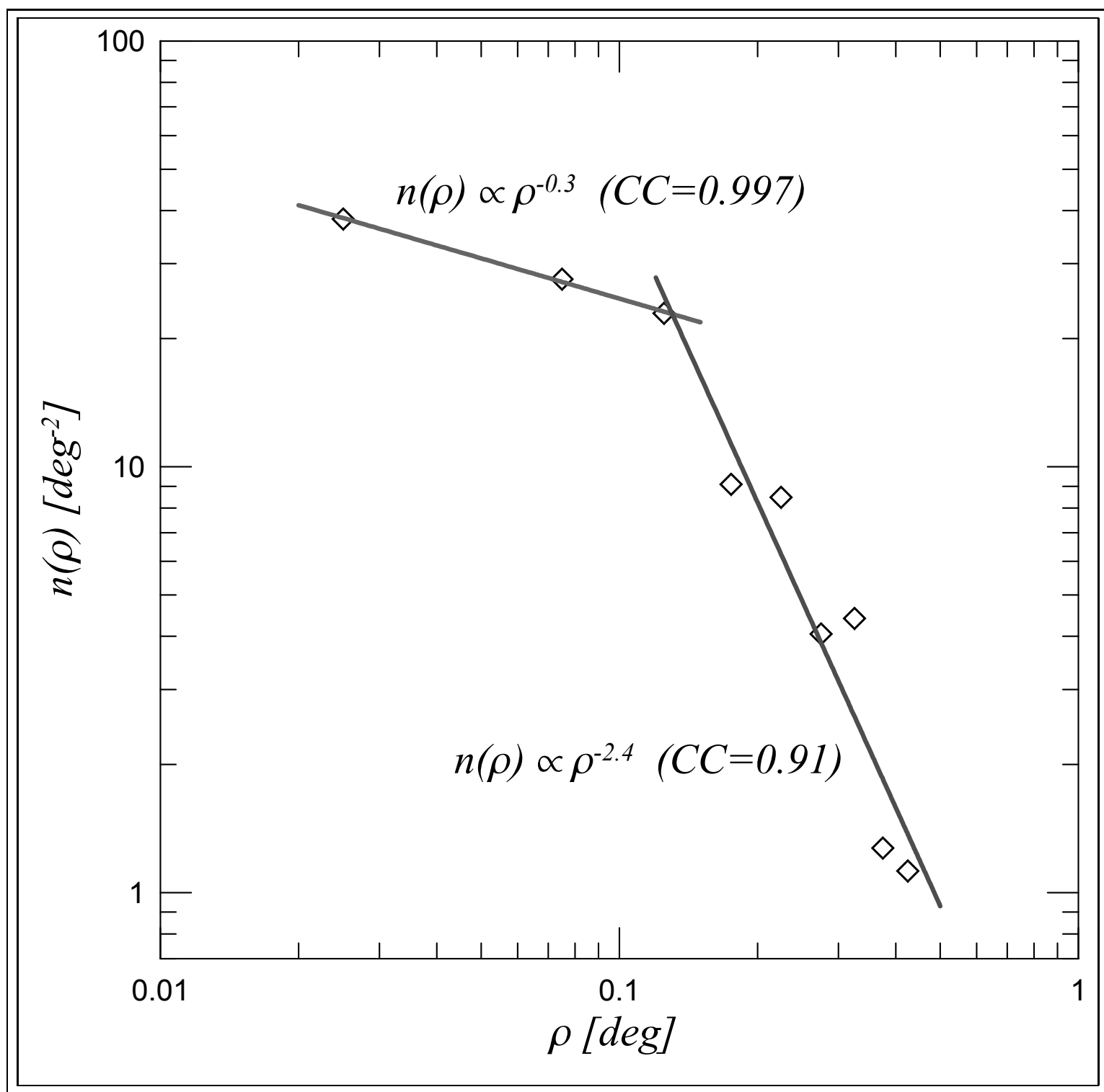

Figura 61: Distribución de densidad superficial de estrellas $O B$ en el intervalo $2.5<$ $d<4$ kpc con respecto al punto $C$ a $\alpha=131.2^{\circ}, \delta=-45.9^{\circ}$ (ver Figura 60) 
clave ahora es la definición de la escala a la cual se efectuaría el estudio. Restringiéndonos sólo a la muestra de estrellas OB espectroscópicas, tenemos 63 estrellas OB distribuidas dentro de un área de $30 \times 30$ (minutos de arco) ${ }^{2}$. La adopción de una escala de 5 (minutos de arco) nos permite satisfacer el criterio estadístico mínimo de más de una estrella por celda para una distribución angular uniforme, a la vez que se mantiene compatible con las dimensiones físicas características de una asociación en el intervalo de distancias en consideración (por ej., tamaño radial de $\sim 3$ a $\sim 9$ pc para distancias variando entre $\sim 2$ y $\sim 6 \mathrm{kpc}$ ).

Consecuentemente, dividimos la imagen en 36 celdas de $5 \times 5$ minutos de arco y calculamos la función de distribución de probabilidades del nivel de ocupación esperado de las celdas de una imagen bajo la suposición de una distribución homogénea de estrellas tempranas (es decir, ausencia de estructuras). Para estimar esta función de distribución, simulamos numéricamente un millón de imágenes con idéntica partición angular y número total de estrellas $\mathrm{O}$ y B.

La Figura 62 muestra la mediana de dicha función de distribución (línea gruesa oscura) y sus niveles de confidencia de $68 \%$ y $95 \%$ (diferentes tonos de gris). Esta función de distribución es comparada con la distribución efectivamente observada en los datos reales (cuadrados llenos).

Puede verse que la única celda con el número más grande de estrellas en ella, el cual es 8, es altamente improbable. De hecho, la probabilidad de obtener de casualidad una celda con una ocupación $\geq 8$ estrellas, fuera de una distribución angularmente homogénea dentro de la imagen es $\sim 10^{-2}$. Podemos ver también de la Figura 63 que, traslaciones de la celda a área constante nos permite obtener celdas con un nivel de ocupación de hasta 10 estrellas. Como la función de distribución mostrada en la Figura 62 depende sólo del tamaño de las celdas y no de su posición arbitraria dentro de la imagen, llegamos a la conclusión de que, en la imagen real, tenemos agrupaciones estelares con una probabilidad de sólo $\sim 10^{-4}$ de haber sido obtenidas aleatoriamente a partir de una distribución estelar homogénea.

Además, siguiendo en esta línea, uno puede barrer la imagen con una ventana de $5 \times 5$ minutos de arco y ver si puede encontrarse otra agrupación con baja chance de probabilidad. La Figura 63 muestra las dos regiones encontradas de este modo. La región centrada en $\alpha=130.89^{\circ}, \delta=-46.13^{\circ}$, contiene 10 estrellas y es coincidente con la agrupación previa $\left(\mathrm{C}_{1}\right)$. La probabilidad de chance es $\sim 10^{-4}$. El segundo grupo $\left(\mathrm{C}_{2}\right)$, puede verdaderamente 


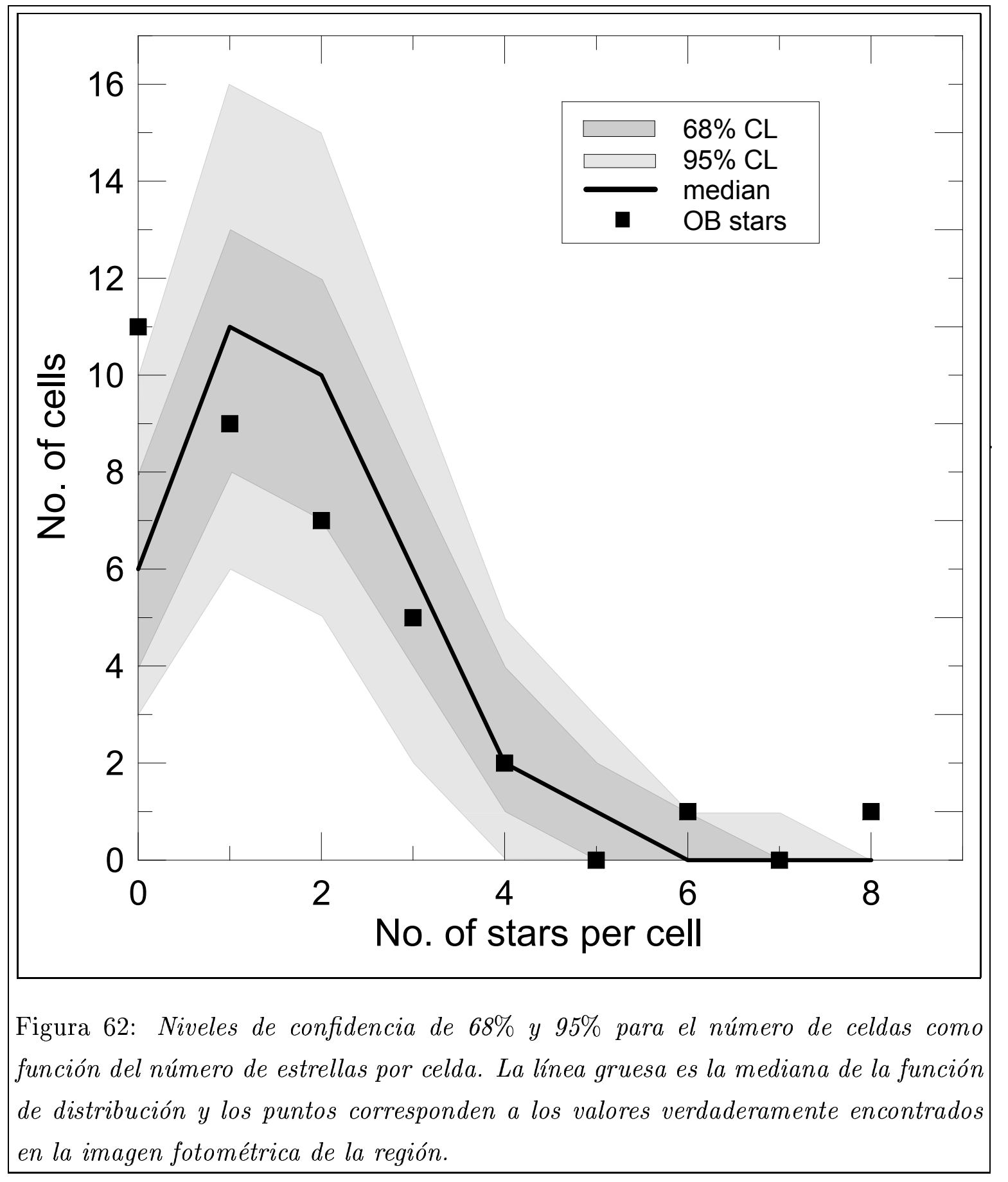

Estudio de una Asociación $O B$ distante en la Vía Láctea 
acomodar varias celdas superpuestas centradas a aproximadamente $\alpha=131.1^{\circ}, \delta=-45.9^{\circ}$, las cuales contienen entre 10 y 11 estrellas espectroscópicas OB y tienen probabilidad de chance en un rango de $\sim 10^{-4} \mathrm{a} \sim 5 \times 10^{-5}$.

La realidad de estas asociaciones se ve reforzada por un análisis de la distribución de las extinciones visuales, $\mathrm{A}_{v}$, a lo largo de la imagen (ver Figura 64). En esta figura mostramos las posiciones de las estrellas OBs espectroscópicas, graficándolas con símbolos proporcionales a sus extinciones $\mathrm{A}_{v}$. Para ayudar en el análisis cualitativo, dando un carácter continuo a la información espacialmente discreta disponible, graficamos también contornos de isoextinción ${ }^{2}$ (Journel \& Huijbrest, 1981) sobre la imagen, estimados a partir de los valores puntuales medidos. Podemos ver que las estrellas correspondientes a los grupos C1 y C2 definen regiones de extinción uniforme, delimitadas por regiones de diferente extinción. Esto es especialmente notorio para el grupo $\mathrm{C} 2$.

La región $\mathrm{C}_{1}$ incluye las siguientes estrellas espectroscópicas OB: CBN84349.6-460711, CBN84348.6-460736, CBN84346.7-460641, CBN84344.7-460656, CBN84338.5-460817, CBN84327.7-460929, CBN84325.6-460820, CBN84324.0-460831, CBN84325.3-460750 y CBN84318.7460742 (ver Tabla 35 para detalles). Podemos ver que, con la excepción de CBN84325.3460750 y CBN84318.7-460742 las cuales probablemente son miembros de Vela OB1 (d $1.7 \mathrm{kpc}$ ), las otras estrellas son consistentes con una asociación a d $=6.3 \pm 1.6 \mathrm{kpc}$. Esta es la distancia esperada para Bochum 7 y es consistente con estimaciones previas de la literatura (Moffat \& Vogt, 1975; Sung et al., 1999). Debe notarse que esta distancia, dentro de su error, es comparable con la asignada a Vela OB3, $5.3 \mathrm{kpc}$, razón por la cual algunos autores (Sung et al., 1999) han asociado esta región con Bochum 7. No obstante, Vela OB3 se encuentra en realidad a $l \sim 268^{\circ}$, lo cual incurriría en una distancia lineal entre ambas estructuras de $\sim$ 300 pc. Esto implica que ambas estructuras probablemente corresponden a episodios de formación estelar que no se encuentran relacionados físicamente, ya que el tiempo que tardaría en viajar entre ellos una onda acústica ( 30 Myr para un ISM tibio y hasta $\sim 900$ Myr para un ISM frío) sería mucho mayor que el tiempo de vida de las estrellas OB que ellas contienen.

La región $\mathrm{C}_{2}$ incluye las siguientes estrellas espectroscópicas OB: CBN84424.9-455334, CBN84404.4-455316, CBN84421.9-455136, CBN84418.2-455307, CBN84423.2-455337, CBN-

\footnotetext{
${ }^{2}$ Método de interpolación de Kriging, el cual consiste en una técnica de interpolación geoestadística que considera la distancia y el grado de variación entre los puntos datos conocidos cuando se estiman valores en áreas desconocidas. En este contexto, una estimativa es una combinación lineal pesada de los valores de una muestra conocida en torno a los puntos que serán estimados
} 


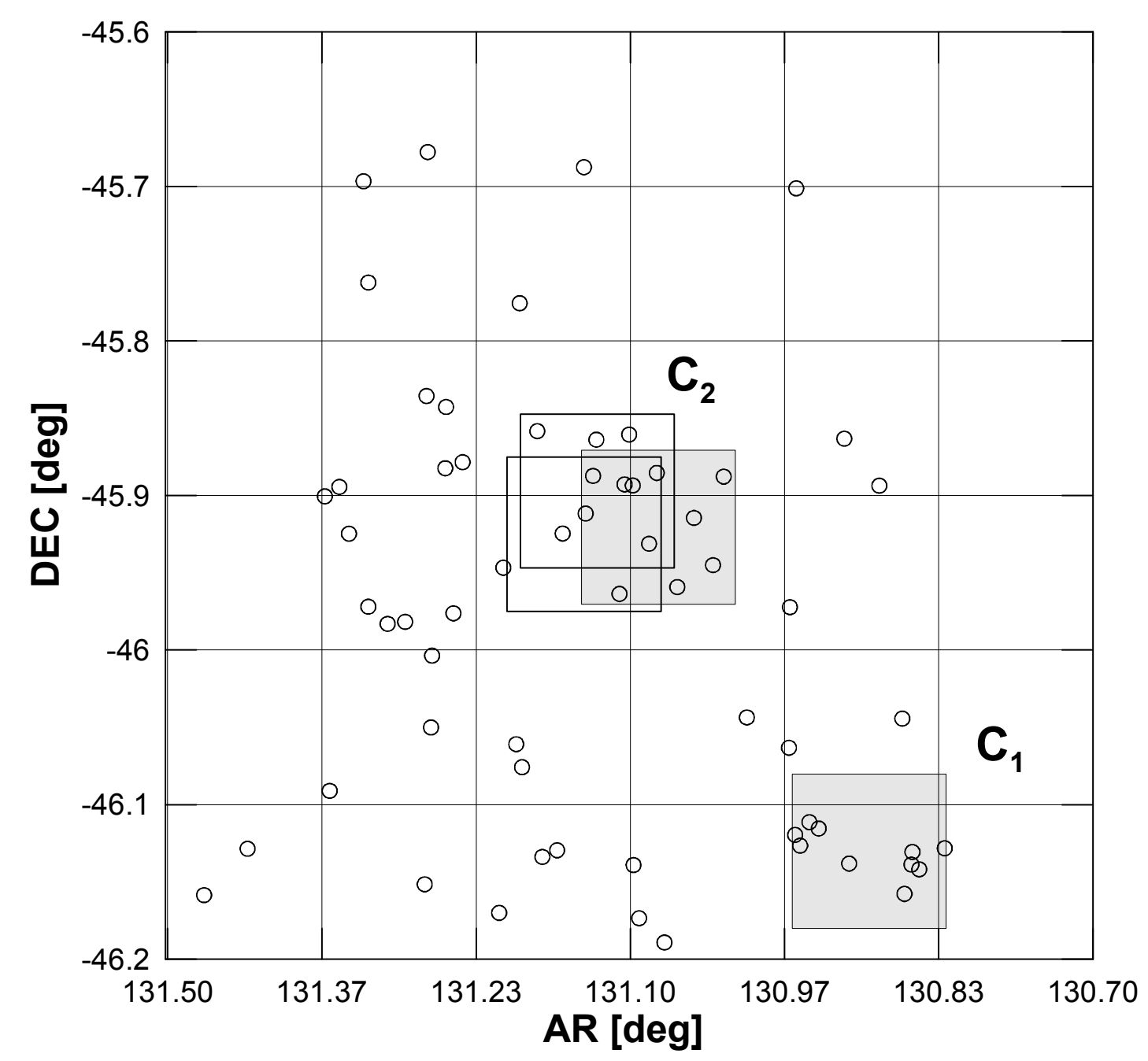

Figura 63: Regiones agrupadas en la imagen con la màs pequeña probabilidad de chance $\left(<10^{-4}\right)$ 


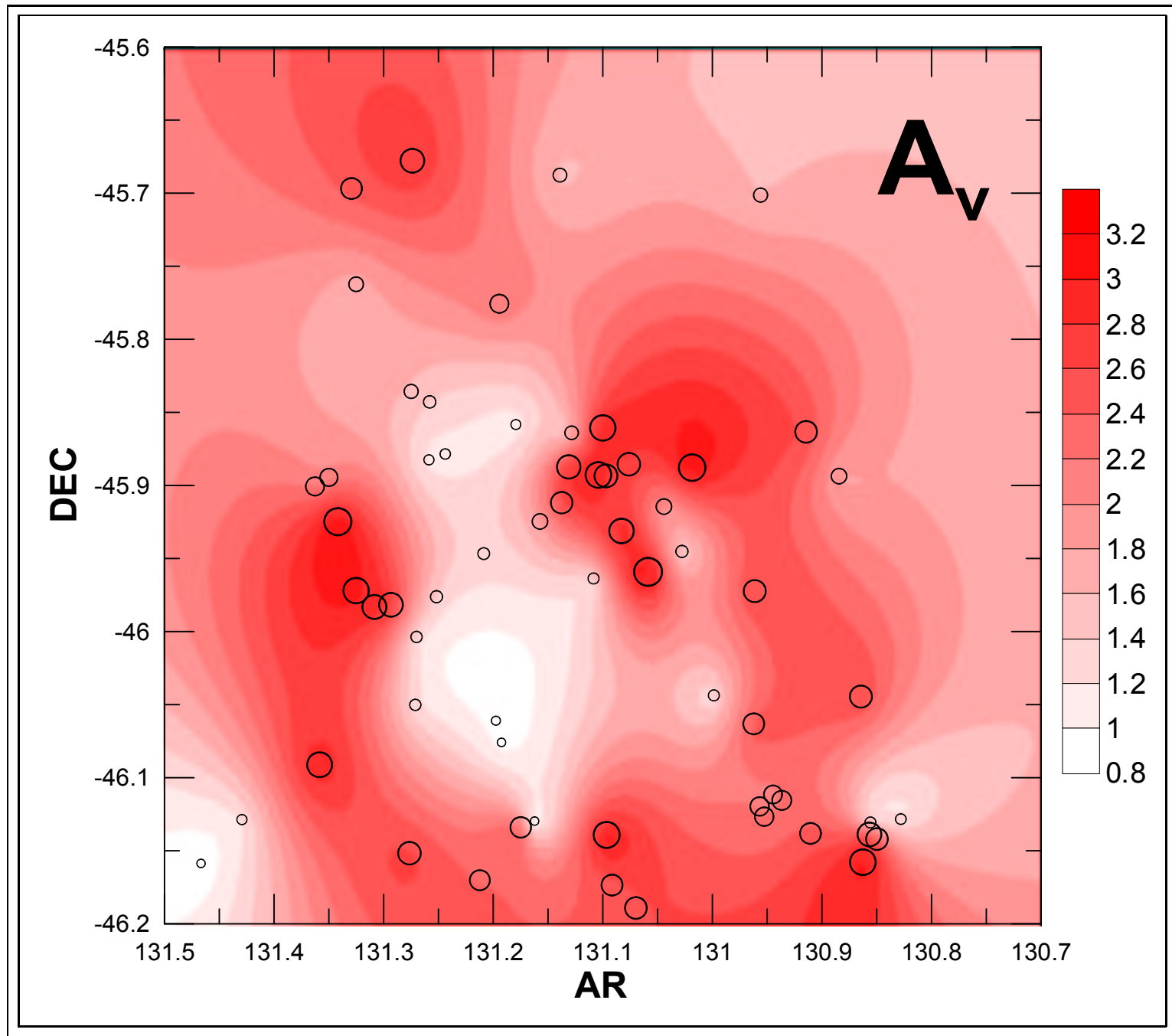

Figura 64: Extinción visual $A_{v}$ para las estrellas de la figura 25. Los tamaños de los símbolos son proporcionales a la extinción y los contornos en el fondo reflejan los valores en un modo suave y continuo. 
Tabla 35: Estrellas espectroscópicas $\mathrm{OB}$ dentro de la región $\mathrm{C}_{1}$

\begin{tabular}{|l|l|c|c|l|}
\hline$I D$ & $\alpha$ & $\delta$ & $d[k p c]$ & $A_{v}$ \\
\hline CBN84349.6-460711 & 130.95684 & -46.119612 & 6.7 & 2.2 \\
CBN84324.0-460831 & 130.84977 & -46.141893 & 4.6 & 2.5 \\
CBN84338.5-460817 & 130.91024 & -46.138188 & 5.8 & 2.5 \\
CBN84327.7-460929 & 130.8625 & -46.157778 & 5.7 & 3.0 \\
CBN84346.7-460641 & 130.94454 & -46.11137 & 8.0 & 1.9 \\
CBN84348.6-460736 & 130.95253 & -46.126567 & 4.2 & 2.2 \\
CBN84344.7-460656 & 130.93647 & -46.115478 & 6.0 & 2.2 \\
CBN84325.6-460820 & 130.8565 & -46.138849 & $9.6:$ & 2.8 \\
CBN84325.3-460750 & 130.85566 & -46.130687 & 1.3 & 1.1 \\
CBN84318.7-460742 & 130.8278 & -46.12827 & 1.8 & 1.2 \\
\hline
\end{tabular}

84414.0-455733, CBN84406.6-455642, CBN84419.9-455552, CBN84431.5-455314, CBN84430.9455442, CBN84410.6-455452, CBN84434.3-455214, CBN84443.0-455130, CBN84437.8-455257, CBN84426.0-455749. Esta región comprende cuatro celdas, y por lo tanto el número esperado de estrellas en el caso isotrópico es $\sim 8$. El número verdadero de estrellas observado es $\sim$ 16, lo cual implica un exceso de $\sim 8$ estrellas. Mirando la Tabla 36 vemos que CBN84406.6455642, CBN84410.6-455452, CBN84434.3-455214 y CBN84437.8-455257 son consistentes con la agrupación encontrada en la sección previa a partir del análisis de distribución radial. Para este grupo de cuatro estrellas, la distancia observada es $\mathrm{d}=2.9 \pm 0.2 \mathrm{kpc}$. La estrella CBN84424.9-455334 que se ubica a una distancia de $\mathrm{d}=4.6 \pm 0.9 \mathrm{kpc}$ podría ser incluida como miembro del grupo $\mathrm{C}_{1}$. Además, si la distancia a CBN84424.9-455334 es estimada usando $\mathrm{E}(\mathrm{V}-\mathrm{K})$ (con magnitudes $\mathrm{K}$ tomadas del catálogo del satélite 2MASS), en lugar del $\mathrm{E}(\mathrm{B}-\mathrm{V})$, entonces su distancia es $\mathrm{d} \sim 4.5 \pm 0.4 \mathrm{kpc}$. Estas estrellas responden muy bien a los excesos observados. Los objetos de menor distancia CBN84443.0-455130 y CBN84426.0455749 probablemente son, nuevamente, una contaminación de la asociación Vela OB1.

Es interesante notar también que CBN84423.2-455337, CBN84431.5-455314 y CBN84419.9455552 a 7.9, 7.8 y 8.3 kpc respectivamente, tienen también una extinción en el visual muy similar $\left(\mathrm{A}_{v}=2.7,2.9\right.$ y 2.8 , respectivamente) y son objetos vecinos angularmente, $\Delta \theta=2$ minutos de arco, lo cual implica una distancia lineal entre ellas de $\sim 6$ pc a $8.1 \mathrm{kpc}$. Por esta razón, ellas podrían ser indicativas de otra asociación OB a mayor distancia, quizás en el brazo espiral más externo. Por ahora nosotros llamaremos a ésta $\mathrm{C}_{3}$. 
Tabla 36: Estrellas espectroscópicas $\mathrm{OB}$ dentro de la región $\mathrm{C}_{2}$

\begin{tabular}{|l|l|c|c|l|}
\hline$I D$ & $\alpha$ & $\delta$ & $d[k p c]$ & $A_{v}$ \\
\hline CBN84424.9-455334 & 131.10396 & -45.892823 & 4.6 & 3.0 \\
CBN84404.4-455316 & 131.01842 & -45.887777 & 5.4 & 3.2 \\
CBN84421.9-455136 & 131.1 & -45.860556 & 6.0 & 3.0 \\
CBN84418.2-455307 & 131.07617 & -45.885387 & 10.5 & 2.7 \\
CBN84423.2-455337 & 131.09689 & -45.893519 & 7.9 & 2.7 \\
CBN84414.0-455733 & 131.05847 & -45.959222 & 6.6 & 3.3 \\
CBN84406.6-455642 & 131.02768 & -45.945054 & 3.0 & 1.3 \\
CBN84419.9-455552 & 131.08283 & -45.931227 & 7.8 & 2.9 \\
CBN84431.5-455314 & 131.13112 & -45.887339 & 8.3 & 2.8 \\
CBN84430.9-455442 & 131.1375 & -45.911667 & 6.7 & 2.5 \\
CBN84410.6-455452 & 131.04411 & -45.914504 & 3.0 & 1.7 \\
CBN84434.3-455214 & 131.1283 & -45.863872 & 3.0 & 1.3 \\
CBN84443.0-455130 & 131.17923 & -45.858344 & 1.7 & 1.0 \\
CBN84437.8-455257 & 131.15736 & -45.92463 & 2.5 & 1.6 \\
CBN84426.0-455749 & 131.10836 & -45.963673 & 1.2 & 1.2 \\
\hline
\end{tabular}


Como una prueba de nuestro método, nosotros analizamos las otras estrellas en la imagen fotométrica que no son clasificadas como estrellas de tipo espectral OB. A una escala con el mismo significado estadístico, lo cual corresponde a celdas con 1/32 del área total de la imagen (esto es escalas de $\sim 1$ minuto de arco) para $\sim 2000$ estrellas, no debería observarse ningún cúmulo. La Figura 65, equivalente a la Figura 62, muestra que, en efecto, la distribución de estrellas de campo a esta escala es como se esperaba, compatible con homogeneidad angular. A escalas más grandes (> 5 minutos de arco, no mostradas aquí) se observa un gradiente suave sobre la imagen, pero nada como la agrupación observada para las estrellas OB.

\subsection{Movimientos propios y calidad de miembros}

La consistencia de nuestros movimientos propios (sobre el cálculo de los mismos se discute en la subsección 4.5) puede ser apreciada en la Figura 66, donde en función de la distancia al Sol, comparamos nuestra muestra de 63 estrellas O y B espectroscópicas con los objetos de Hipparcos que poseen medidas de paralajes y movimientos propios, todos dentro de una ventana de $2^{\circ}$ de radio centrada en la misma dirección del cielo. En la Figura 66 también se muestra el movimiento propio promedio esperado como una función de la distancia debido al movimiento del Sol (Mignard, 2000) y a la combinación de la curva de rotación galáctica con el movimiento del Sol (Honma \& Sofue, 1996; Honma \& Sofue, 1997), todo en la dirección $l=270^{\circ}$.

Las distancias de Hipparcos cubren principalmente los primeros kpc, extendiéndose hasta $\simeq 3 \mathrm{kpc}$. En la Figura 66 de movimiento propio vs. distancia se ve que las estrellas espectroscópicas se funden suavemente con la muestra de Hipparcos y siguen muy bien la distribución de velocidad esperada de la combinación de la rotación Galáctica y el movimiento del Sol. Aún los objetos con los movimientos propios más bajos parecen estar ligados por la contribución del movimiento del Sol, lo cual sugiere que sus distancias y movimientos propios están medidos correctamente. Además, la dispersión en ambos conjuntos de datos parece ser consistente, incrementándose lentamente con la distancia. Este resultado nos hace confiar en el significado estadístico de nuestros movimientos propios.

Sin embargo, es difícil evaluar la incerteza en el movimiento propio de cada estrella O y B individual. Consecuentemente, realizamos primero un análisis armónico, conceptualmente simple y matemáticamente robusto, que nos permite analizar simultáneamente la consistencia 


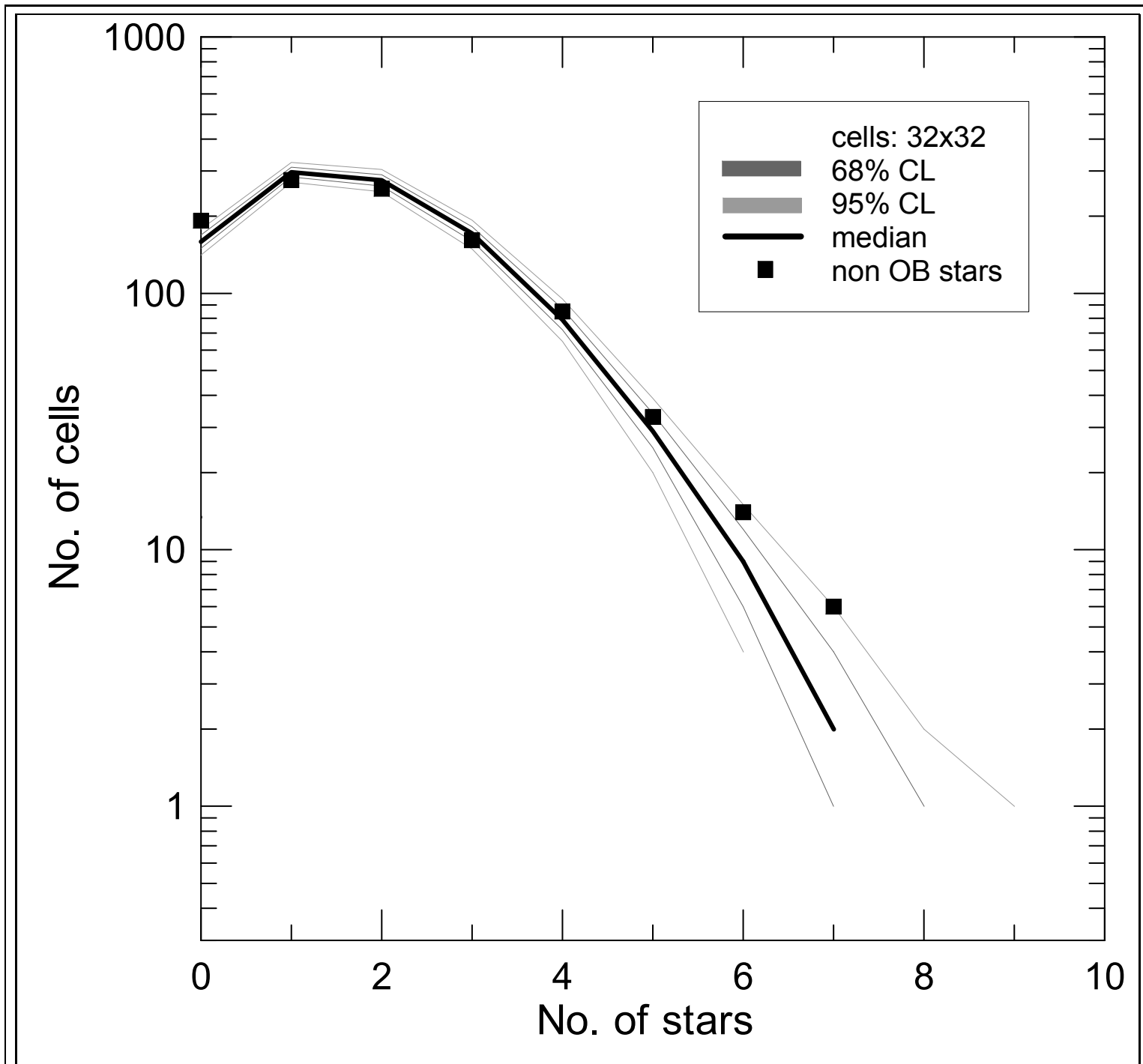

Figura 65: Idéntico a la Figura 62 para las estrellas que tienen tipos espectrales OB (principalmente estrellas de campo) 


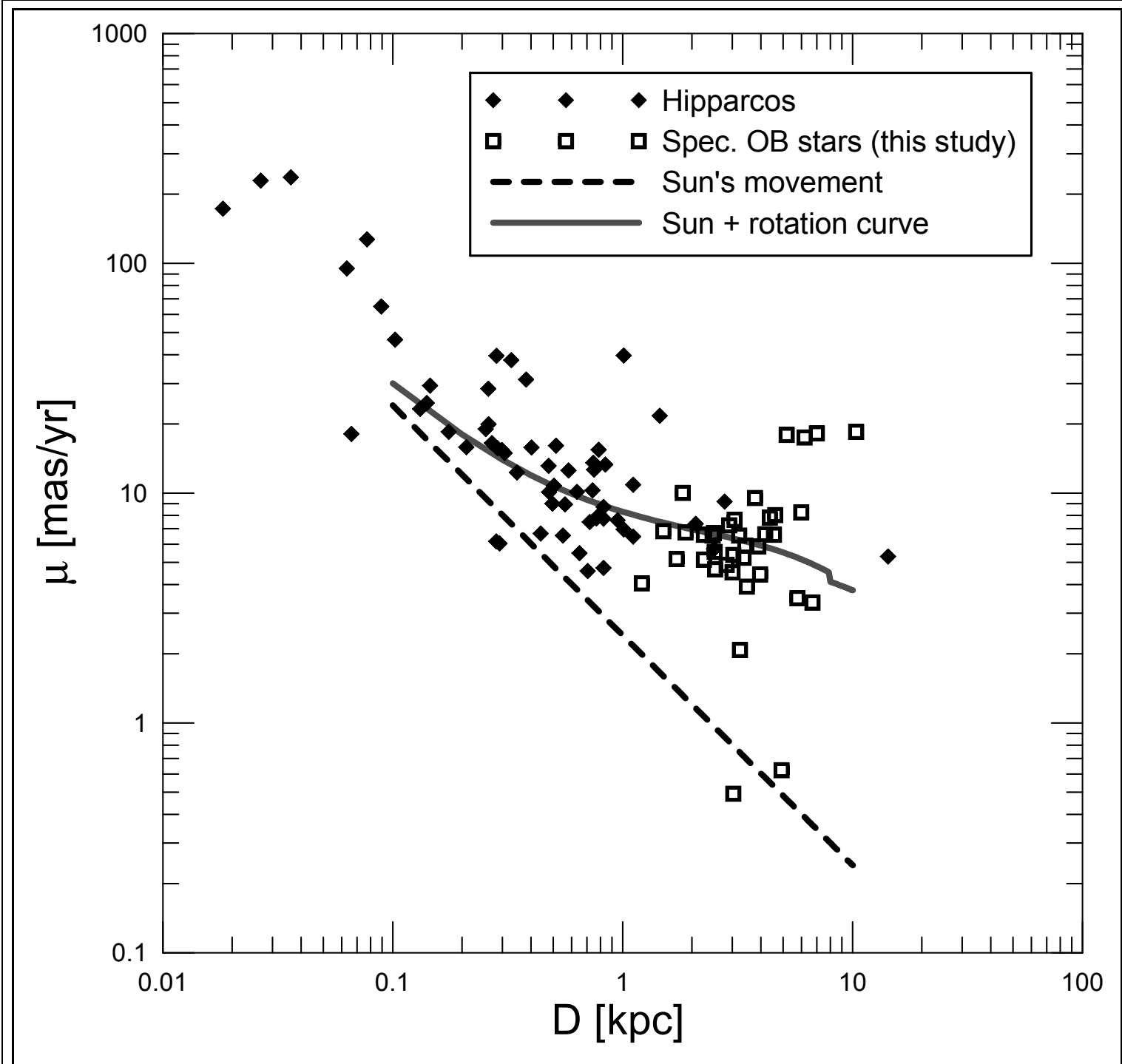

Figura 66: Comparación entre los movimientos propios de Hipparcos y nuestras determinaciones de movimiento propio para la muestra de estrellas $O$ y $B$ espectroscópicas. Se puede ver que ambos conjuntos de datos se combinan suavemente sobre un considerable intervalo de distancias yendo de $0.1 a \sim 10$ kpc siguiendo la combinación esperada de la curva de rotación y el movimiento del Sol. 
estadística de nuestros movimientos propios y la posibilidad de separar, en forma significativa, nuestra muestra de estrellas O y B en más de una componente en el espacio de las fases.

Para caracterizar la anisotropía, usamos la amplitud y fase de los primeros armónicos. Así, para el primer armónico, la amplitud es (Linsley, 1975):

$$
r_{1 h}=\sqrt{a_{1 h}^{2}+b_{1 h}^{2}}
$$

donde:

$$
a_{1 h}=\frac{2}{N} \sum_{i=1}^{N} \cos \left(\alpha_{i}\right) \quad, \quad b_{1 h}=\frac{2}{N} \sum_{i=1}^{N} \sin \left(\alpha_{i}\right)
$$

la fase es

$$
\psi_{1 h}=\tan ^{-1}\left(\frac{b_{1 h}}{a_{1 h}}\right)
$$

y $\alpha_{i}$ es el ángulo de orientación del vector movimiento propio $\mu_{i}$ de una estrella individual $\mathrm{OB}, i$. Elegimos como $\alpha_{i} \equiv 0^{\circ}$ la dirección $\left(\mu_{l}, m u_{b}\right)=(1,0)$, por ejemplo, apuntando hacia el centro Galáctico.

La dispersión cuadrática media de la amplitud $(\mathrm{rms})^{3}$ y fase del primer armónico están dados por:

$$
\Delta r=\sqrt{\frac{2}{N}}
$$

$\mathrm{y}$

$$
\Delta \psi=\frac{1}{\sqrt{2 k_{0}}}
$$

donde $k_{0}=r_{1 h}^{2} N / 4$. Otra cantidad de interés es el número de eventos requeridos para una relación señal-ruido de $n_{\sigma}$ desviaciones estándar en amplitud y fase:

$$
N_{r}\left(n_{\sigma}\right)=\frac{2 n_{\sigma}^{2}}{r_{1 h}^{2}} \quad, \quad N_{\psi}\left(n_{\sigma}\right)=\frac{2 n_{\sigma}^{2}}{r_{1 h}^{2} \psi_{1 h}^{2}}
$$

La extensión del tratamiento a armónicos de mayor orden es directa. Para el armónico $j:$

$$
r_{j h}=\sqrt{a_{j h}^{2}+b_{j h}^{2}}
$$

\footnotetext{
${ }^{3}$ error cuadrático medio

Estudio de una Asociación $O B$ distante en la Vía Láctea 
donde:

$$
a_{j h}=\frac{2}{N} \sum_{i=1}^{N} \cos \left(j \alpha_{i}\right) \quad, \quad b_{j h}=\frac{2}{N} \sum_{i=1}^{N} \sin \left(j \alpha_{i}\right)
$$

la fase es

$$
\psi_{j h}=\tan ^{-1}\left(\frac{b_{j h}}{a_{j h}}\right)
$$

Así, la distribución angular de movimientos propios puede ser expandida al orden $n$ del siguiente modo:

$$
I_{n}(\psi)=1+\sum_{j=1}^{n} r_{j}(\psi)
$$

donde:

$$
r_{j}(\psi)=a_{j h} \cos \left[j\left(\psi-\psi_{j h}\right)\right]+b_{j h} \sin \left[j\left(\psi-\psi_{j h}\right)\right]
$$

Antes de aplicar el análisis de armónicos, las estrellas fueron centradas en movimiento propio, lo que corresponde conceptualmente, a eliminar la contribución promedio integrada sobre la línea de la visual de los efectos de rotación Galáctica y movimiento solar (ver Figura $67)$ :

$$
\mu_{l}^{c}=\mu_{l}-\left\langle\mu_{l}\right\rangle \quad, \quad \mu_{b}^{c}=\mu_{b}-\left\langle\mu_{b}\right\rangle
$$

La Figura 68 muestra en un diagrama polar, un ajuste armónico de cuarto orden a la distribución angular del movimiento propio de 261 estrellas O y B espectroscópicas y fotométricas para las cuales ha sido posible calcular sus movimientos propios. No se le han hecho selecciones adicionales de objetos con base a otros parámetros.

En la Figura 68 en lo correspondiente a la distribución angular de movimiento propio, se distinguen muy bien dos lóbulos. El primero apunta a $\psi \sim 0^{\circ}$, esto es, a lo largo del plano Galáctico en la dirección del centro Galáctico (GC). El segundo apunta a $\psi \sim 230^{\circ}$, mostrando un movimiento promedio a lo largo de una línea formando un ángulo de $\sim 50^{\circ}$ con el plano Galáctico. Estos dos lóbulos podrían corresponder a la presencia de al menos dos poblaciones diferentes de estrellas O y B dominantes: estrellas O y B de campo moviéndose diferencialmente a lo largo del plano galáctico donde la figura ovalada se genera debido a las diferentes distancias al Sol a las que se encuentran todas ellas ( $\sim 70 \%$ de los objetos) y una asociación inmersa en movimiento oblicuo con respecto al mismo plano $(\sim 30 \%$ de los objetos). El hecho de que la estructura en el espacio de movimientos propios no sea circular es un 


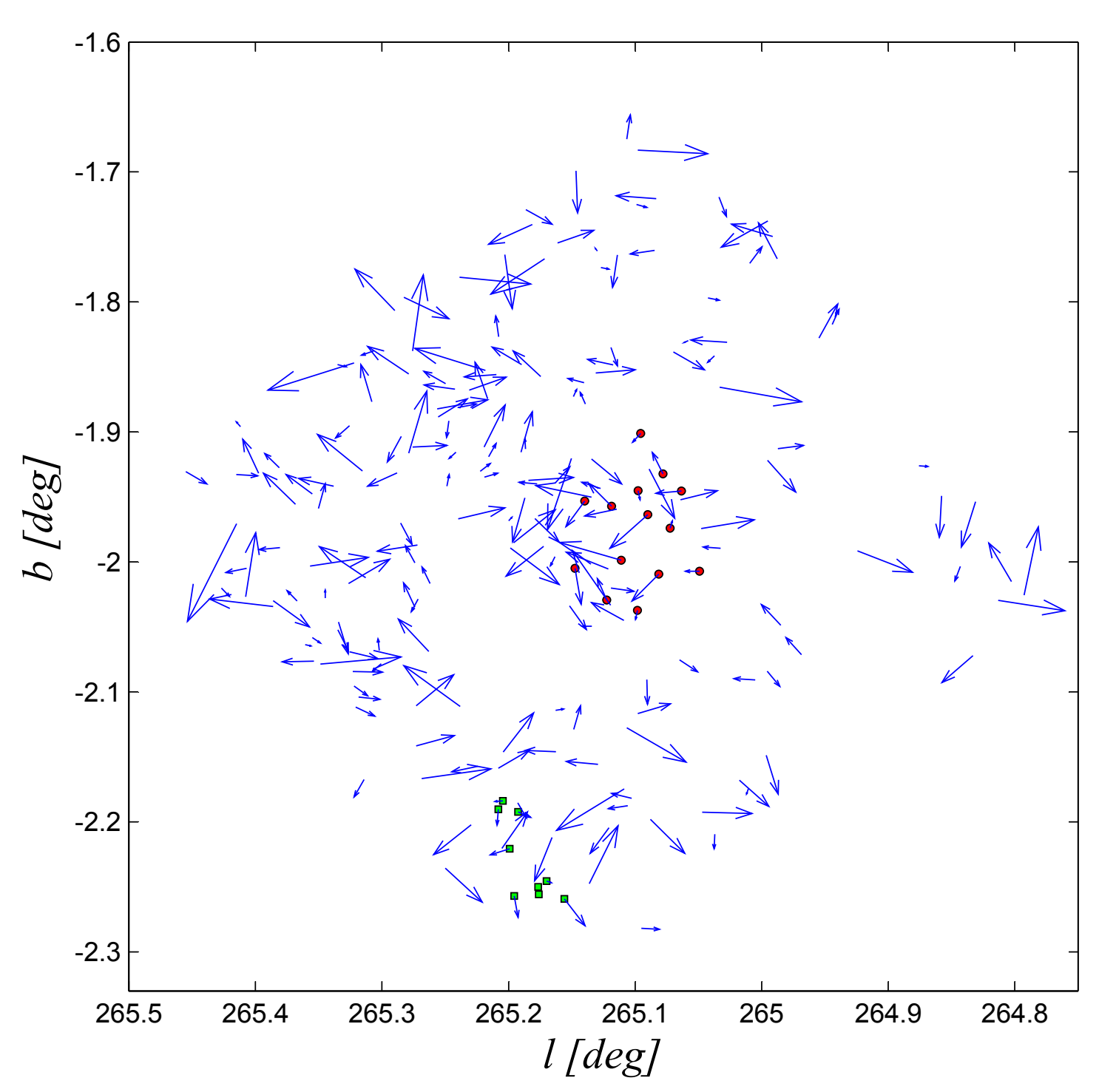

Figura 67: Idéntico a la Figura 37, aunque los movimientos propios fueron centrados de acuerdo a la ecuación 83 

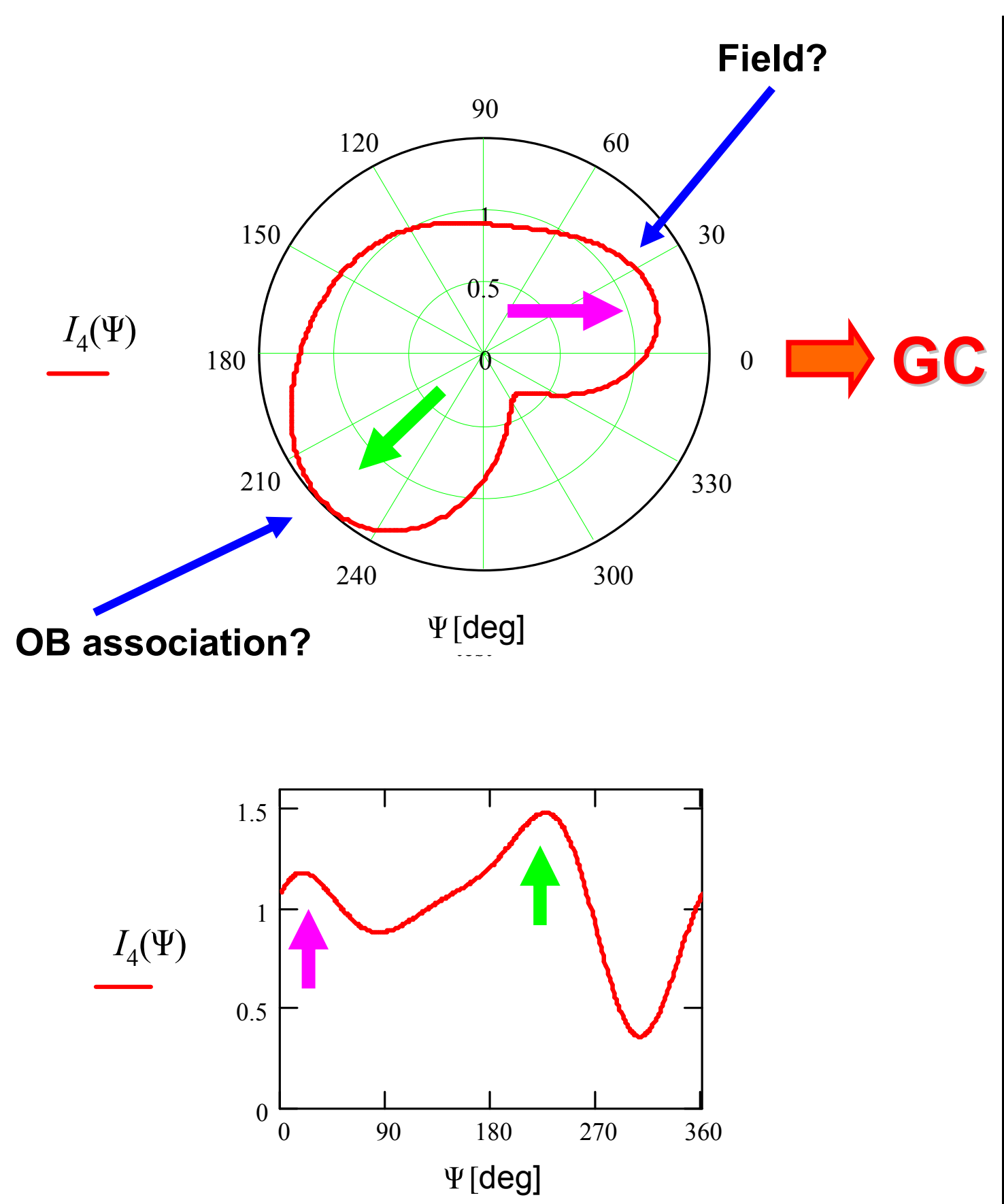

Figura 68: Expansión del armónico de cuarto orden de la distribución angular de movimiento propio del grupo $O$ y $B$ espectroscópico y fotométrico. Aquí se pueden ver al menos dos poblaciones claramente separadas: una se despliega aproximadamente paralela al plano galáctico y la otra a una dirección oblicua. La última podría estar relacionada a alguna estructura en el espacio de velocidad proyectada y asociación $O B$ ? 
muy fuerte indicativo de que la determinación de movimientos propios, aún a las distancias relativamente grandes consideradas, no está dominada por errores. En otras palabras, nuestros movimientos propios son consistentes con nuestras expectativas cualitativas para una muestra de estrellas a distancias variables, y por lo tanto, son estadísticamente significativos.

Todo esto confirma nuestro análisis previo elemental, que consistió en manifestar que la muestra de estrellas O y B que se encuentra dentro de la visual no es homogénea.

Otro método comúnmente usado para determinar pertenencia estadística en regiones vecinas es el método de Vasilevskis-Sanders (Vasilevskis et al., 1958; Sanders, 1971). Este método se basa en la suposición de que en una imagen comprendiendo estrellas de campo y una asociación, las estrellas de campo, al cubrir un intervalo de distancias mayor, serian mejor descriptas en el espacio de movimientos propios por una función normal bivariada elíptica, mientras que las estrellas de la asociación lo serian por una circular:

$$
\begin{aligned}
& \Phi\left(\mu_{x_{i}}, \mu_{y_{i}}\right)= \\
& \frac{N}{2 \pi \Sigma_{x} \Sigma_{y}} \exp \left[-\frac{1}{2}\left[\left(\frac{\mu_{x_{i}}-\mu_{X_{0}}}{\Sigma_{x}}\right)^{2}+\left(\frac{\mu_{y_{i}}-\mu_{Y_{0}}}{\Sigma_{y}}\right)^{2}\right]\right] \\
& +\frac{n}{2 \pi \sigma^{2}} \exp \left[-\frac{1}{2}\left[\left(\frac{\mu_{x_{i}}-\mu_{x_{0}}}{\sigma}\right)^{2}+\left(\frac{\mu_{y_{i}}-\mu_{y_{0}}}{\sigma}\right)^{2}\right]\right]
\end{aligned}
$$

donde $N, n, \Sigma_{x}, \Sigma_{y}, \sigma, \mu_{X_{0}}, \mu_{Y_{0}}, \mu_{x_{0}}, \mu_{y_{0}}, \mu_{x_{i}}$ and $\mu_{y_{i}}$ son, respectivamente los números de estrellas en el campo y en la asociación, las desviaciones estándar en el campo en x e y, las desviaciones estándar de la asociación, coordenadas x-y del centro del campo y del centro de la asociación y las componentes $\mathrm{x}-\mathrm{y}$ de los movimienos propios.

Mientras que un ajuste como el propuesto por la ecuación anterior funciona bien para distancias pequeñas, siempre tiende a dar falsos positivos a medida que la distancia a las estrellas de la muestra crece y los errores en movimiento propio tienden a producir una componente circular irreal. De hecho, nosotros hemos aplicado este método a las estrellas de nuestra muestra y obtuvimos dos poblaciones diferentes. No obstante, es difícil evaluar la credibilidad de este resultado. Nos parece así que, el método de análisis armónico, con su relativa simplicidad, es más fuerte para probar la existencia de más de una componente en el espacio de velocidad que el método anterior a distancias del orden de kpc.

Proponemos así un nuevo tipo de análisis, intrínsecamente simple que reune las dos características básicas esperadas de una asociación: proximidad en distancia y proximidad en 
movimiento propio (vectorial) entre sus miembros.

Hacemos entonces un análisis detallado buscando agrupaciones de estrellas vecinas viajando en aproximadamente la misma dirección del cielo proyectada. En la Figura 69 vemos el resultado de tal estudio, el cual consiste en el número de estrellas como una función de la distancia, $D$, que tienen movimientos propios apuntando a $\pm 5^{\circ}$ de la dirección $\psi$.

En la Figura 69 se pueden distinguir claramente siete cúmulos, de B1 a B8. Sus miembros están listados en las Tablas 37, 38, 39, 40, 41, 42 y 43. En estas tablas se dan dos tipos de identificación: aquellos objetos que tienen una identificación en la primera columna son estrellas O y B espectroscópicas; las otras son estrellas O y B fotométricas. En el resto de las columnas de las Tablas mencionadas previamente están las coordenadas ecuatoriales celestes, precesadas para la época J2000, las coordenadas galácticas, las componentes del vector movimiento propio en unidades de mas y en la última columna la distancia al Sol indicada en $\mathrm{kpc}$.

En el inicio de este trabajo encontramos un grupo al que denominamos B7, definido a partir de sólo tres estrellas con una distancia promedio de $3.7 \mathrm{kpc}$ y un valor $\phi \simeq 35^{\circ}$. Luego revisando la clasificación espectral de las estrellas que se estudian en esta Tesis, notamos que era necesario modificar el tipo espectral de dos de los miembros de B7. El resultado fue que las distancias de esas dos estrellas se modificaron y el grupo como tal dejó de existir.

Como puede verse de la Figura 70 la distribución espacial proyectada solamente no cuenta para los cúmulos en la Figura 69. La información cinemática necesita ser combinada con las distancias radiales.

Los cúmulos B8 y B2 son los más prominentes y probablemente los responsables principales de las dos estructuras ya detectadas en el análisis de los armónicos. B1, el cúmulo más cercano es otra vez, probablemente, una subestructura de Vela OB1. B2, B6 y B8 tienen todos ellos algunos objetos ya listados en la Tabla 36 correspondiente a la región del cúmulo C2. B4 y B8, que también se extienden a grandes distancias, contienen algunos objetos listados en la Tabla 35 referente a la región del cúmulo C1. B5, la estructura más distante podría estar relacionada con alguna continuación del brazo local externo o con el nuevo brazo externo (McClure-Griths et al., 2004). Desafortunadamente, fuimos incapaces de determinar movimientos propios para todas las estrellas O y B espectroscópicas en las 


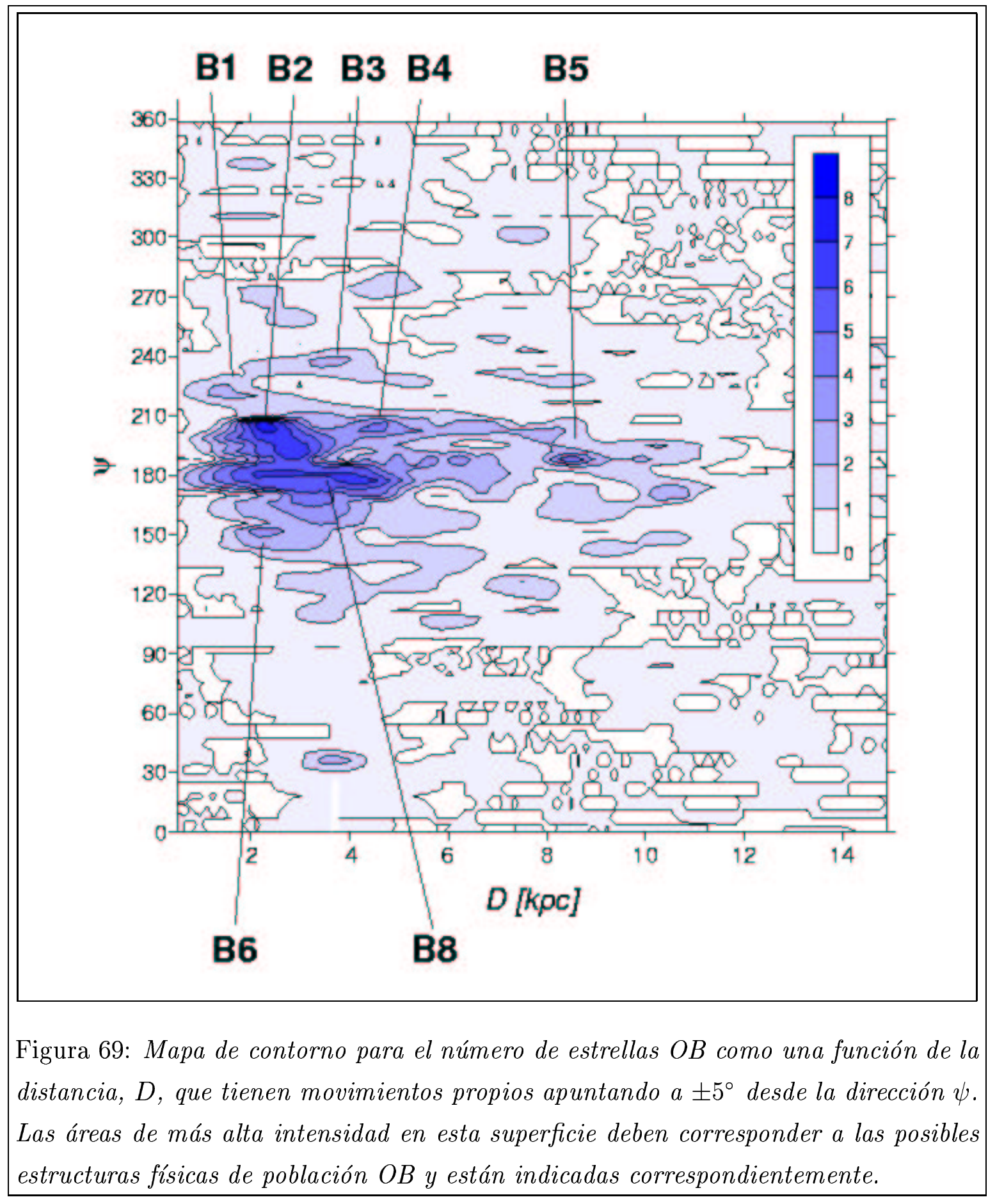

Estudio de una Asociación $O B$ distante en la Vía Láctea 


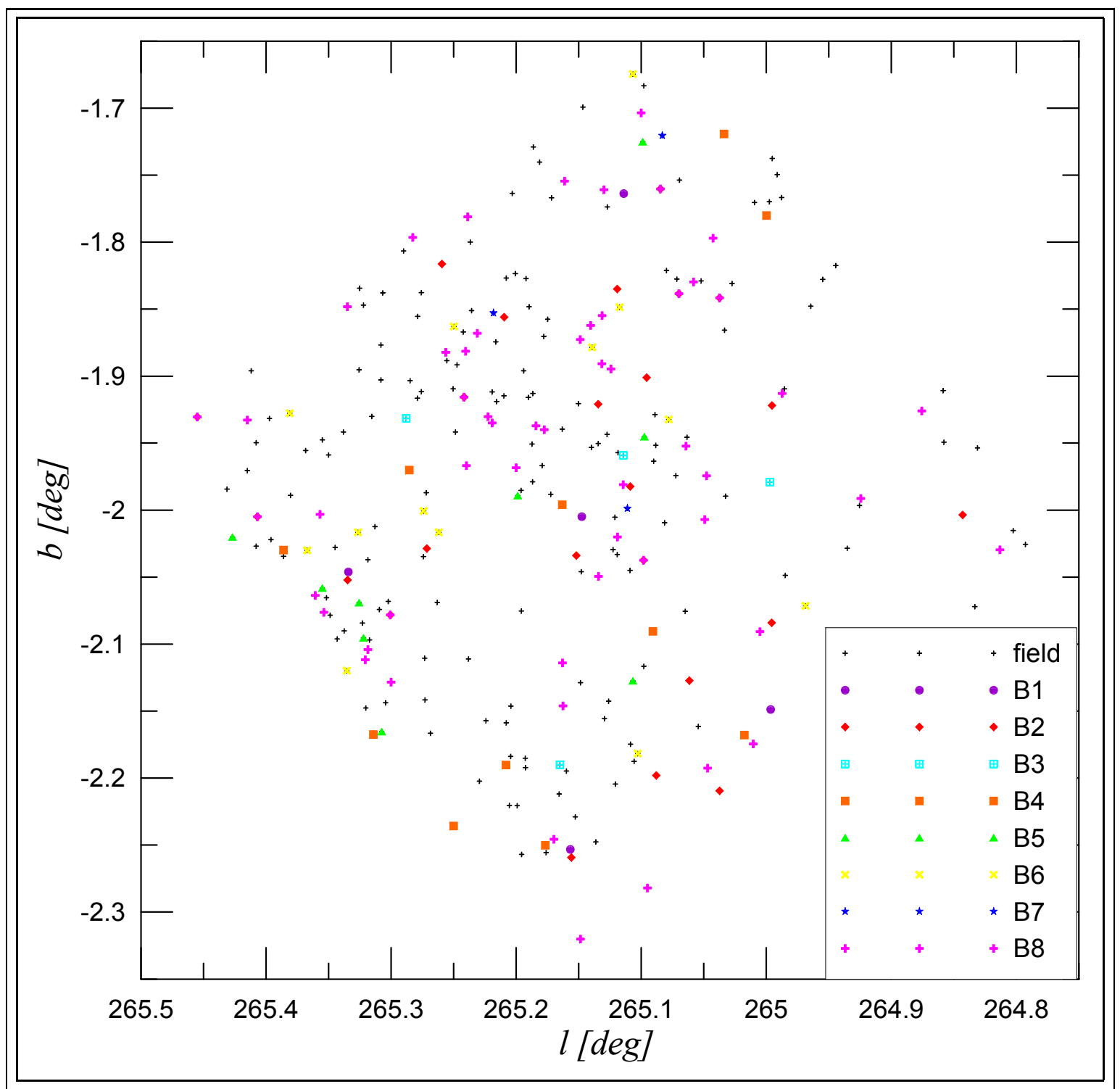

Figura 70: Distribución en el cielo en coordenadas galácticas de los cúmulos B1-B8. 
Tabla 37: En la Tabla se indican las estrellas que son miembros del Cúmulo B1, las cuales estando a aproximadamente una misma distancia coinciden cinemáticamente. En las columnas con ID1 e ID2 está la identificación de las estrellas con tipos espectrales O y B espectroscópicos y fotométricos, respectivamente. Las componentes del vector movimiento propio están dadas en mas.

\begin{tabular}{ccccccccc}
\hline \hline ID $_{1}:$ CBN... & $\mathrm{ID}_{2}$ & $\alpha$ & $\delta$ & $l$ & $b$ & $\mu_{l}$ & $\mu_{b}$ & $\mathrm{~d}[\mathrm{kpc}]$ \\
\hline \multirow{3}{*}{$84426.0-455749$} & 2686 & 131.1088145 & -45.9636362 & 265.15 & -2.00 & -6.4 & -5.2 & 1.2 \\
& 861 & 131.3504856 & -45.787515 & 265.11 & -1.76 & -4.8 & -4.7 & 1.2 \\
& 4409 & 130.8361109 & -46.1244812 & 265.16 & -2.25 & -10.5 & -10 & 1.9 \\
& 4544 & 130.8120174 & -45.9340512 & 265.00 & -2.15 & -7.3 & -5.6 & 2.0 \\
& 1808 & 131.2292795 & -46.1354973 & 265.33 & -2.05 & -6.9 & -4.6 & 2.0 \\
& & & & & & & & \\
\hline
\end{tabular}

regiones $\mathrm{C} 1$ y $\mathrm{C} 2$.

Tabla 43: Cúmulo B8 (Idem Tabla 37)

\begin{tabular}{ccccccccc}
\hline \hline $\mathrm{ID}_{1}: \mathrm{CBN} \ldots$ & $\mathrm{ID}_{2}$ & $\alpha$ & $\delta$ & $l$ & $b$ & $\mu_{l}$ & $\mu_{b}$ & $\mathrm{~d}[\mathrm{kpc}]$ \\
\hline & 4120 & 130.8853589 & -45.9050245 & 265.51 & -2.09 & -2.3 & 0.2 & 0.9 \\
& 1034 & 131.3311777 & -45.959537 & 265.24 & -1.88 & -8.3 & 0.5 & 1.2 \\
$84325.3-460750$ & 4292 & 130.8564365 & -46.1301587 & 265.17 & -2.25 & -6.2 & -0.2 & 1.3 \\
& 2406 & 131.149685 & -46.1591914 & 265.32 & -2.10 & -8.7 & -0.3 & 1.3 \\
& 2451 & 131.1428898 & -46.1656087 & 265.32 & -2.11 & -8.3 & -1.3 & 1.7 \\
& $13 \mathrm{MC}$ & 131.2980321 & -46.1266731 & 265.36 & -2.33 & -14.2 & 1.3 & 1.8 \\
& 156 & 131.4424924 & -45.8958073 & 265.24 & -1.78 & -16.1 & -1.0 & 1.8 \\
& 1785 & 131.2331983 & -46.167225 & 265.36 & -2.06 & -6.4 & -0.2 & 1.9 \\
& 2041 & 131.1970427 & -45.9820587 & 265.20 & -1.97 & -6.0 & 0.5 & 1.9 \\
& 102 & 131.4533674 & -46.0130459 & 265.33 & -1.85 & -6.8 & -0.3 & 2.0 \\
$84359.6-460237$ & 3435 & 130.9992142 & -46.0433559 & 265.16 & -2.11 & -6.7 & 0.2 & 2.1 \\
& 1801 & 131.227085 & -45.7992928 & 265.07 & -1.84 & -10.1 & -2.6 & 2.2 \\
& 3702 & 130.956175 & -45.7014928 & 264.88 & -1.93 & -6.8 & -0.1 & 2.3 \\
& 722 & 131.367773 & -45.7982439 & 265.13 & -1.76 & -5.2 & 0.4 & 2.3 \\
& 2046 & 131.194783 & -45.7759339 & 265.04 & -1.84 & -4.5 & -0.9 & 2.4 \\
\hline & & & & & & & continúa
\end{tabular}


Tabla 43: (continuación)

\begin{tabular}{|c|c|c|c|c|c|c|c|c|}
\hline $\mathrm{ID}_{1}: \mathrm{CBN} \ldots$ & $\mathrm{ID}_{2}$ & $\alpha$ & $\delta$ & $l$ & $b$ & $\mu_{l}$ & $\mu_{b}$ & $\mathrm{~d}[\mathrm{kpc}]$ \\
\hline \multirow[t]{3}{*}{$84502.0-455257$} & 1588 & 131.2591259 & -45.8826014 & 265.15 & -1.87 & -6.0 & 1.0 & 2.5 \\
\hline & 4627 & 130.7953771 & -45.9608234 & 265.01 & -2.17 & -5.2 & -0.8 & 2.6 \\
\hline & 1877 & 131.2181321 & -45.9503375 & 265.18 & -1.94 & -12.2 & 0.4 & 2.7 \\
\hline \multirow[t]{6}{*}{$84552.3-460929$} & 14 & 131.4683471 & -46.1579423 & 265.45 & -1.93 & -8.6 & -1.8 & 2.7 \\
\hline & 426 & 131.4054274 & -45.7390434 & 265.10 & -1.70 & -19.5 & -1.9 & 2.7 \\
\hline & 455 & 131.4030565 & -45.8188339 & 265.16 & -1.75 & -10.9 & 1.8 & 2.8 \\
\hline & 966 & 131.3410824 & -46.1667792 & 265.41 & -2.49 & -2.4 & -0.6 & 2.8 \\
\hline & 2975 & 131.0664227 & -45.9506556 & 265.12 & -2.03 & -8.9 & -0.5 & 2.9 \\
\hline & 2703 & 131.1064536 & -45.922917 & 265.11 & -1.98 & -18.2 & -0.4 & 3.0 \\
\hline \multirow[t]{2}{*}{$84406.6-455642$} & 3221 & 131.0282403 & -45.9449734 & 265.10 & -2.04 & -5.2 & -1.3 & 3.0 \\
\hline & 1805 & 131.2265468 & -45.7847528 & 265.06 & -1.83 & -4.9 & -0.3 & 3.0 \\
\hline \multirow[t]{3}{*}{$84500.4-455834$} & 1643 & 131.251863 & -45.9762073 & 265.22 & -1.93 & -7.5 & 0.6 & 3.1 \\
\hline & 2783 & 131.0941727 & -45.8656509 & 265.06 & -1.95 & -11 & 1.3 & 3.1 \\
\hline & 971 & 131.3379148 & -45.9439523 & 265.23 & -1.87 & -11 & 1.9 & 3.1 \\
\hline $84543.1-460742$ & 272 & 131.43153 & -46.1282348 & 265.41 & -1.93 & -8.7 & -0.2 & 3.2 \\
\hline $84438.9-460746$ & 2295 & 131.1628339 & -46.1291731 & 265.37 & -2.08 & -4.2 & -1.1 & 3.2 \\
\hline \multirow[t]{9}{*}{$84518.6-454543$} & 1042 & 131.3279489 & -45.7624089 & 265.08 & -1.76 & -1.9 & -0.5 & 3.2 \\
\hline & 1554 & 131.2633574 & -45.8693706 & 265.14 & -1.86 & -3.1 & 0.6 & 3.5 \\
\hline & 1766 & 131.2342074 & -46.0122373 & 265.24 & -1.97 & -12.4 & 1.6 & 3.7 \\
\hline & 4872 & 130.7486456 & -46.0937628 & 265.09 & -2.28 & -8.2 & -0.1 & 3.8 \\
\hline & 4570 & 130.807343 & -46.06917 & 265.05 & -2.19 & -12.9 & -0.2 & 3.8 \\
\hline & 4847 & 130.7527965 & -46.1592903 & 265.15 & -2.32 & -16.9 & -1.2 & 3.9 \\
\hline & 1838 & 131.2232953 & -45.8802112 & 265.13 & -1.89 & -16.6 & 2.4 & 4.0 \\
\hline & 1646 & 131.2493224 & -45.7522092 & 265.04 & -1.80 & -7.2 & -0.3 & 4.0 \\
\hline & 3117 & 131.04676 & -45.9808092 & 265.13 & -2.05 & -4.1 & 0.0 & 4.2 \\
\hline \multirow[t]{6}{*}{$84450.1-455648$} & 1947 & 131.2089956 & -45.946772 & 265.18 & -1.94 & -2.8 & 0.2 & 4.3 \\
\hline & 2727 & 131.1054127 & -46.1597156 & 265.30 & -2.13 & -18.4 & -0.2 & 4.3 \\
\hline & 1584 & 131.26821 & -45.975955 & 265.22 & -1.93 & -7.0 & 1.1 & 4.3 \\
\hline & 924 & 131.3444083 & -45.9726723 & 265.26 & -1.88 & -13 & 1.3 & 4.4 \\
\hline & 2945 & 131.0698898 & -45.7808909 & 264.99 & -1.91 & -9.3 & 0.5 & 4.5 \\
\hline & 1915 & 131.2123427 & -45.8769045 & 265.12 & -1.89 & -18.4 & -1.9 & 4.5 \\
\hline \multirow[t]{3}{*}{$84350.9-460348$} & 3669 & 130.9628648 & -46.0628503 & 265.16 & -2.15 & -0.9 & 0.2 & 4.7 \\
\hline & 3884 & 130.9258171 & -45.7801475 & 264.92 & -1.99 & -13.7 & -3.1 & 4.7 \\
\hline & 23 & 131.4646403 & -45.9397959 & 265.28 & -1.80 & -12.2 & -3.1 & 4.7 \\
\hline
\end{tabular}


Tabla 43: (continuación)

\begin{tabular}{ccccccccc}
\hline \hline $\mathrm{ID}_{1}: \mathrm{CBN} \ldots$ & $\mathrm{ID}_{2}$ & $\alpha$ & $\delta$ & $l$ & $b$ & $\mu_{l}$ & $\mu_{b}$ & $\mathrm{~d}[\mathrm{kpc}]$ \\
\hline & 3063 & 131.0544659 & -45.8665098 & 265.05 & -1.97 & -13.4 & 1.3 & 4.9 \\
& 1553 & 131.2635098 & -45.8575987 & 265.13 & -1.85 & -11.4 & 0.5 & 4.9 \\
$84450.9-461012$ & 1939 & 131.2126671 & -46.1696559 & 265.35 & -2.08 & -0.8 & -0.1 & 5.3 \\
& 4677 & 130.7842521 & -45.7163228 & 264.81 & -2.03 & -15.4 & -1.5 & 5.3 \\
$84404.4-455316$ & 3273 & 131.01882 & -45.8877584 & 265.05 & -2.71 & -3.4 & 0.0 & 5.4 \\
\hline
\end{tabular}


Tabla 38: Cúmulo B2 (Idem Tabla 37)

\begin{tabular}{|c|c|c|c|c|c|c|c|c|}
\hline $\mathrm{ID}_{1}: \mathrm{CBN} \ldots$ & $\mathrm{ID}_{2}$ & $\alpha$ & $\delta$ & $l$ & $b$ & $\mu_{l}$ & $\mu_{b}$ & $\mathrm{~d}[\mathrm{kpc}]$ \\
\hline $84332.2-455337$ & 4125 & 130.884658 & -45.8934559 & 265.00 & -2.08 & -7.4 & -2.2 & 2.0 \\
\hline \multirow[t]{2}{*}{ 84443.0-455130 } & 2150 & 131.1796436 & -45.8584873 & 265.09 & -1.90 & -4.3 & -1.3 & 1.7 \\
\hline & 2756 & 131.0997459 & -45.919257 & 265.11 & -1.98 & -20.9 & -5.8 & 1.4 \\
\hline $84446.2-460433$ & 2078 & 131.1928324 & -46.0755273 & 265.27 & -2.03 & -4.5 & -1.8 & 1.9 \\
\hline \multirow[t]{4}{*}{$84318.7-460742$} & 4452 & 130.8285956 & -46.1275884 & 265.16 & -2.26 & -8.6 & -3.9 & 1.8 \\
\hline & 4384 & 130.8401445 & -45.7237542 & 264.84 & -2.00 & -4.7 & -2.1 & 2.1 \\
\hline & 1857 & 131.2228024 & -46.1396889 & 265.33 & -2.05 & -7.0 & -3.0 & 2.2 \\
\hline & 1801 & 131.227085 & -45.7992928 & 265.07 & -1.84 & -10.1 & -2.6 & 2.2 \\
\hline \multirow[t]{2}{*}{$84506.0-455008$} & 1459 & 131.2751309 & -45.8359123 & 265.12 & -1.83 & -6.5 & -2.7 & 2.3 \\
\hline & 4403 & 130.8375253 & -46.0364723 & 265.09 & -2.20 & -10.6 & -4.9 & 2.3 \\
\hline \multirow[t]{3}{*}{$84446.7-454632$} & 2046 & 131.194783 & -45.7759339 & 265.04 & -1.84 & -4.5 & -0.9 & 2.4 \\
\hline & 4070 & 130.8942265 & -45.9717331 & 265.06 & -2.13 & -13.4 & -4.1 & 2.4 \\
\hline & 1025 & 131.3321459 & -45.91969 & 265.21 & -1.86 & -0.7 & -0.3 & 2.4 \\
\hline \multirow[t]{4}{*}{ 84552.3-460929 } & 14 & 131.4683471 & -46.1579423 & 265.45 & -1.93 & -8.6 & -1.8 & 2.7 \\
\hline & 2883 & 131.0801409 & -45.9849295 & 265.15 & -2.03 & -8.0 & -3.4 & 2.7 \\
\hline & 2967 & 131.0670727 & -45.792897 & 265.00 & -1.92 & -9.7 & -4.6 & 2.7 \\
\hline & 966 & 131.3410824 & -46.1667792 & 265.41 & -2.00 & -2.4 & -0.6 & 2.8 \\
\hline \multirow[t]{2}{*}{$84406.6-455642$} & 3221 & 131.0282403 & -45.9449734 & 265.10 & -2.04 & -5.2 & -1.3 & 3.0 \\
\hline & 2072 & 131.1920765 & -45.9012814 & 265.13 & -1.92 & -10 & -3.6 & 3.1 \\
\hline 84438.9-460746 & 2295 & 131.1628339 & -46.1291731 & 265.30 & -2.08 & -4.2 & -1.1 & 3.2 \\
\hline \multirow[t]{4}{*}{$84518.6-454543$} & 1042 & 131.3279489 & -45.7624089 & 265.08 & -1.76 & -1.9 & -0.5 & 3.2 \\
\hline & 4701 & 130.7793586 & -46.0035831 & 265.04 & -2.21 & -5.4 & -2.1 & 3.2 \\
\hline & 318 & 131.4214042 & -45.9340964 & 265.26 & -1.82 & -28.5 & -15.1 & 3.3 \\
\hline & 2932 & 131.0738206 & -46.1950664 & 265.31 & -2.17 & -4.0 & -2.5 & 3.3 \\
\hline
\end{tabular}


Tabla 39: Cúmulo B3 (Idem Tabla 37)

\begin{tabular}{ccccccccc}
\hline \hline $\mathrm{ID}_{1}: \mathrm{CBN} \ldots$ & $\mathrm{ID}_{2}$ & $\alpha$ & $\delta$ & $l$ & $b$ & $\mu_{l}$ & $\mu_{b}$ & $\mathrm{~d}[\mathrm{kpc}]$ \\
\hline & & & & & & & & \\
& 2518 & 131.1308556 & -45.9093525 & 265.11 & -1.96 & -0.7 & -1.0 & 3.6 \\
& 3958 & 130.9152 & -46.0921242 & 265.16 & -2.19 & -15.5 & -23.1 & 2.9 \\
& 3390 & 131.0042083 & -45.829722 & 265.00 & -1.98 & -8.3 & -12.9 & 3.7 \\
& 1153 & 131.3171848 & -46.0281278 & 265.29 & -1.93 & -1.1 & -1.9 & 4.0 \\
& & & & & & & \\
\hline
\end{tabular}

Tabla 40: Cúmulo B4 (Idem Tabla 37)

\begin{tabular}{ccccccccc}
\hline \hline $\mathrm{ID}_{1}$ : CBN ... & $\mathrm{ID}_{2}$ & $\alpha$ & $\delta$ & $l$ & $b$ & $\mu_{l}$ & $\mu_{b}$ & $\mathrm{~d}[\mathrm{kpc}]$ \\
\hline & & & & & & & & \\
& 4560 & 130.8092306 & -45.9625045 & 265.02 & -2.17 & -9.9 & -3.8 & 3.8 \\
$84348.6-460736$ & 3738 & 130.9533074 & -46.1260287 & 265.21 & -2.19 & -5.3 & -2.3 & 4.2 \\
& 2506 & 131.1329309 & -45.9704625 & 265.16 & -2.00 & -4.8 & -1.3 & 3.5 \\
$84505.0-460300$ & 1505 & 131.2713412 & -46.0499431 & 265.28 & -1.98 & -7.2 & -3.1 & 4.3 \\
$84350.7-455820$ & 3673 & 130.9618295 & -45.9720559 & 265.09 & -2.09 & -5.6 & -3.6 & 4.2 \\
& 2932 & 131.0738206 & -46.1950664 & 265.31 & -2.17 & -4.0 & -2.5 & 3.3 \\
& 3821 & 130.9391856 & -46.1869784 & 265.25 & -2.24 & -11 & -4.9 & 4.4 \\
& 1334 & 131.2941456 & -46.1658628 & 265.39 & -2.03 & -10.9 & -3.8 & 4.9 \\
$84518.8-454147$ & 1031 & 131.3286956 & -45.697057 & 265.03 & -1.72 & -6.6 & -2.8 & 5.2 \\
& 1778 & 131.2302739 & -45.7084334 & 265.00 & -1.78 & -11.8 & -6.6 & 5.1 \\
& & & & & & & & \\
\hline
\end{tabular}


Tabla 41: Cúmulo B5 (Idem Tabla 37)

\begin{tabular}{|c|c|c|c|c|c|c|c|c|}
\hline $\mathrm{ID}_{1}: \mathrm{CBN} \ldots$ & $\mathrm{ID}_{2}$ & $\alpha$ & $\delta$ & $l$ & $b$ & $\mu_{l}$ & $\mu_{b}$ & $\mathrm{~d}[\mathrm{kpc}]$ \\
\hline \multirow[t]{4}{*}{$84431.5-455314$} & 2511 & 131.1317809 & -45.8874556 & 265.10 & -1.94 & -5.8 & -1.3 & 8.3 \\
\hline & 2300 & 131.162543 & -46.1566264 & 265.32 & -2.09 & -7.5 & -1.4 & 8.4 \\
\hline & 2062 & 131.1956386 & -46.1430614 & 265.32 & -2.07 & -9.7 & -1.0 & 8.4 \\
\hline & 3849 & 130.9339586 & -46.0073939 & 265.11 & -2.13 & -14.3 & -5.0 & 8.0 \\
\hline \multirow[t]{5}{*}{$84416.7-461121$} & 2961 & 131.0701486 & -46.1885898 & 265.31 & -2.16 & -24.9 & -9.4 & 8.2 \\
\hline & 2220 & 131.1723853 & -45.9939756 & 265.20 & -1.99 & -12.8 & -5.3 & 8.1 \\
\hline & 1779 & 131.2342295 & -46.1593498 & 265.35 & -2.06 & -6.7 & -0.8 & 8.6 \\
\hline & 961 & 131.3417653 & -46.1917712 & 265.43 & -2.02 & -6.7 & -1.2 & 8.9 \\
\hline & 630 & 131.3802374 & -45.7516075 & 265.10 & -1.72 & -7.0 & -0.4 & 9.5 \\
\hline $84325.6-460820$ & 4288 & 130.8572965 & -46.1381937 & 265.18 & -2.25 & -16.8 & -7.9 & 9.6: \\
\hline
\end{tabular}

Tabla 42: Cúmulo B6 (Idem Tabla 37)

\begin{tabular}{|c|c|c|c|c|c|c|c|c|}
\hline $\mathrm{ID}_{1}: \mathrm{CBN} \ldots$ & $\mathrm{ID}_{2}$ & $\alpha$ & $\delta$ & $l$ & $b$ & $\mu_{l}$ & $\mu_{b}$ & $\mathrm{~d}[\mathrm{kpc}]$ \\
\hline \multirow{7}{*}{$84447.4-460339$} & 4169 & 130.87484 & -45.8643506 & 264.97 & -2.07 & -3.2 & 2.5 & 1.8 \\
\hline & 2038 & 131.1978671 & -46.0606592 & 265.26 & -2.02 & -4.3 & 2.4 & 2.1 \\
\hline & 135 & 131.4436874 & -45.7261925 & 265.11 & -1.67 & -6.0 & 3.5 & 1.8 \\
\hline & 1826 & 131.226573 & -46.0601064 & 265.27 & -2.07 & -4.1 & 2.5 & 2.2 \\
\hline & 4211 & 130.8690586 & -46.0379273 & 265.10 & -2.18 & -2.5 & 0.7 & 2.3 \\
\hline & 1626 & 131.2556618 & -46.1110934 & 265.33 & -2.02 & -11.6 & 3.5 & 1.6 \\
\hline & 2426 & 131.14727 & -46.1822603 & 265.34 & -2.12 & -25.3 & 7.9 & 1.7 \\
\hline $84501.9-455034$ & 1593 & 131.2582262 & -45.8428917 & 265.12 & -1.85 & -1.7 & 0.8 & 2.6 \\
\hline \multirow[t]{3}{*}{$84434.3-455214$} & 2529 & 131.1287556 & -45.8640184 & 265.08 & -1.93 & -3.9 & 3.1 & 3.0 \\
\hline & 791 & 131.3603848 & -45.9555245 & 265.25 & -1.86 & -2.3 & 1.8 & 2.9 \\
\hline & 474 & 131.40592 & -46.0983934 & 265.38 & -1.93 & -3.3 & 2.1 & 3.0 \\
\hline $84458.5-455242$ & 1699 & 131.2440359 & -45.8787109 & 265.14 & -1.88 & -4.7 & 1.7 & 3.1 \\
\hline
\end{tabular}




\section{RESUMEN Y CONCLUSIONES}

\section{RESUMEN}

Se analizaron 3 imágenes fotométricas obtenidas una con filtro U, otra con filtro B y una más con filtro V. Se clasificaron 102 estrellas estudiando para ello los 194 espectros digitales obtenidos de observar más de una vez a alguna de ellas. Empleando la ecuación de extinción y el diagrama color-color se clasificaron aproximadamente otras 300 estrellas OB. Se calcularon los movimientos propios de 261 estrellas con tipos espectrales O y B. Se emplearon: un esquema de simulación simple con distribución Gaussiana, el modelo de Galaxia de Besançon, una distribución de densidad superficial ajustada con un perfil de King, una función de distribución de probabilidades, modelo de rotación Galáctica, el tratamiento de armónicos esféricos, etc. Se emplearon los catálogos e imágenes de IRAS, 2MASS, MSX, Shassa, CO, cubo de datos de HI, etc. Se confeccionó un Atlas de Clasificación espectral y de todo ello se puede concluir lo siguiente.

Con el aporte de las mediciones del ancho equivalente de la DIB 4428, efectuadas en 60 espectros de estrellas con TE $\mathrm{O}$ y $\mathrm{B}$, confirmamos la correlación que el mismo tiene con el exceso de color $\mathrm{E}(\mathrm{B}-\mathrm{V})$ hasta un valor de aproximadamente 1. No obstante, la regresión observada en nuestros datos difiere de la presente en la literatura (Herbig 1975). Mas aún, los valores del ancho equivalente de la DIB 4428 para el rango de $\mathrm{E}(\mathrm{B}-\mathrm{V}) \leq 1$ se complementan mejor con los de Snow et al. (2002) para $E(B-V) \geq 1$.

Del análisis de velocidad radial efectuado a los espectros digitales, concluimos que existe una alta probabilidad de que 11 estrellas pertenezcan a diferentes sistemas binarios. Nos motiva a pensar así la velocidad radial anómala que las mismas presentan según los modelos de curva de rotación de la Galaxia. Las estrellas del catálogo LS; 1131, 1144, 1146 y 1147 también son candidatas a formar sistemas binarios, debido a la alta dispersión presente en la velocidad radial estudiada de las mismas en sus espectros digitales. LS 1146 muestra una dispersión de velocidades radiales de aproximadamente $80 \mathrm{~km} \mathrm{~s}^{-1}$, LS 1144 de aprox. $130 \mathrm{~km} \mathrm{~s}^{-1}$, LS 1147 de aprox. $90 \mathrm{~km} \mathrm{~s}^{-1} \mathrm{y}$ LS 1131 de aprox. $200 \mathrm{~km} \mathrm{~s}^{-1}$ junto a la presencia del efecto Struve-Sahade.

Un estudio de velocidad radial de líneas espectrales de LS 1135, un posible miembro de la asociación galáctica $\mathrm{OB}$ Bo 7, muestra que ésta es una binaria de tipo espectral $\mathrm{O}$ a un espectro, la cual clasificamos como $\mathrm{O} 6.5 \mathrm{~V}((\mathrm{f}))$. Para esta binaria encontramos un período orbital de 2.75320 días. El valor de la semi-amplitud $(\mathrm{K})$ de las variaciones de velocidad radial de las líneas de He es 122 $\mathrm{km} \mathrm{s}^{-1}$ y la función de masa $(\mathrm{F}(\mathrm{M}))$ del sistema binario es $0.52 \mathrm{M}_{\odot}$. La componente secundaria no es detectada en nuestros espectros, lo cual indica que ésta sería al menos 2 magnitudes más débil, correspondiendo a una estrella de tipo espectral B temprano. 
En el sector NO de la región en estudio, se evidencia una alta intensidad de emisión en $12 \mu \mathrm{m}$ producida como consecuencia de la presencia de los PAHs y estrellas no muy tempranas, ya que la densidad de radiación UV que producen es $<100 \mathrm{eV} \mathrm{cm}^{-3}$. En el sector S y SO de la misma región, se observan máximos de intensidad en las bandas de $60 \mu \mathrm{m}$ y $100 \mu \mathrm{m}$, lo cual indicaría la presencia de estrellas muy calientes capaces de producir una densidad de radiación $\mathrm{UV}>100 \mathrm{eV} \mathrm{cm}^{-3}$. Dichas estrellas se encontrarían rodeadas por granos de polvo grandes $(\mathrm{r} \simeq 10 \mathrm{~nm})$.

La fuente puntual IRAS 08426-4601 con colores IR de regiones HII ultra compactas (UCHIIRs), tiene asociada una distancia muy similar a la de Bo7, según resultados de la espectroscopía en el rango milimétrico (Bronfman et al., 1996). En ella se observa la alta intensidad de emisión de la banda A del MSX la cual coincide con la figura de anillo que se presenta en la imagen en $\mathrm{H} \alpha$ tomada a la región. Se observa también un grupo reducido de estrellas O - B0.5 de secuencia principal que parece corresponderse con la ubicación de la fuente puntual IRAS 08426-4601. Esta fuente junto a otras tres ubicadas en la zona, muy probablemente correspondan a sitios de nacimiento de nuevas estrellas, en una secuencia de formación estelar en la región de Bo7.

Del análisis de distribución espacial a lo largo de la visual, realizando un esquema de simulación simple, se observa que a una distancia al Sol $>5.3 \mathrm{kpc}$ las estrellas clasificadas con TE O y B, según el estudio de sus espectros o de sus datos fotométricos, se alejan de las sugeridas por el modelo de Besançon de síntesis de poblaciones estelares de nuestra Galaxia, efectuado en la misma dirección $\left(1 \simeq 265^{\circ}\right)$. Puede tratarse de la continuación del brazo espiral Perseo dentro del $3^{\circ}$ cuadrante de la Galaxia.

Estudiando la distribución radial de las estrellas con TE O y B fotométrica se observa un incremento de aproximadamente $30 \%$ respecto de la distribución suave en el rango de distancia d $\sim 2.5$ a 4 kpc. Debido a que allí no existe ninguna asociación conocida podría tratarse de Bochum 7 .

Del análisis de agrupación angular realizado a las estrellas O y B espectroscópicas y fotométricas, ubicadas a una distancia de d $\sim 2.5$ a $4 \mathrm{kpc}$ es posible identificar una distribución de densidad superficial como función de la distancia angular al centro de la misma, $\mathrm{n}(\rho)$. El resultado es un núcleo de mayor densidad con un radio lineal de aproximadamente 4.3 a 7 pc, según la distancia considerada y una disminución de la densidad superficial a algunos radios de distancia del núcleo.

Ignorando por completo las distancias de las estrellas O y B espectroscópicas y analizando la distribución que las mismas tienen sobre la imagen fotométrica, se concluye que en la imagen real hay dos agrupaciones estelares con probabilidad casi nula de haberse obtenido aleatoriamente a partir de una distribución estelar homogénea. La agrupación denominada C1 centrada en $\alpha=$ 
$130^{\circ} .89, \delta=-46^{\circ} .13$, contiene 10 estrellas de las cuales 8 se ubican a una distancia promedio de $\mathrm{d}$ $=6.3 \pm 1.6 \mathrm{kpc}$. Las otras dos con distancias de aproximadamente $1.5 \mathrm{kpc}$ podrían ser miembros de Vela OB1. La agrupación llamada C2 está centrada en $\alpha=131^{\circ} .1, \delta=-45^{\circ} .9$, contiene 15 estrellas con distancias variadas. Un subgrupo de 4 estrellas se ubica a una distancia de $\mathrm{d}=2.9 \pm$ $0.2 \mathrm{kpc}$. Otro subgrupo de 2 estrellas tienen la misma distancia que Vela OB1 ( $\mathrm{d} \simeq 1.5 \mathrm{kpc})$ y las 9 estrellas restantes se ubican a una distancia de $d=7.1 \pm 1.7 \mathrm{kpc}$. Las estrellas de los grupos C1 y $\mathrm{C} 2$ responden muy bien con los excesos observados, teniendo menor exceso las estrellas ubicadas a menor distancia.

Cuando las distancias radiales se combinan con la información cinemática que dan los movimientos propios, los datos en el espacio de las fases resultan inhomogéneos y se forman hasta 7 estructuras. La agrupación indicada como B4 con $\bar{d}=4.3 \pm 0.6 \mathrm{kpc}$ (Sung et al., $\mathrm{d}=4.8 \pm 0.2 \mathrm{kpc}$ ) y tamaño angular de aproximadamente 30', tendría un diámetro lineal $\mathrm{D} \simeq 37 \pm 5$ pc (Lundstrom \& Stenholm, $\mathrm{D} \simeq 30 \mathrm{pc}$ ). Este grupo estelar podría identificarse como Bochum 7 .

Los miembros del grupo estelar indicado como B3 y parte de B2, B6 y B8 son los responsables del exceso estelar observado en el histograma de $\mathrm{N}$ vs $\mathrm{R}$ para una distancia comprendida entre 2.5 y 4 kpc. Los grupos B2 y B6 se ubican a una distancia promedio de $\mathrm{d}=2.4 \mathrm{kpc}$ con un diámetro lineal de $\mathrm{D} \simeq 20$ pc y la amplitud del armónico de 4 orden para ambos grupos es mayor a 1 . Los grupos B2 y B3 se encuentran dentro del lóbulo de cinemática con máxima amplitud de 1.5 y fase $210 \leq \psi \leq 240$.

La estructura identificada como B1 con sólo 5 miembros, ubicada a una distancia promedio d $=1.7 \pm 0.4 \mathrm{kpc}$ y con diámetro lineal $\mathrm{D}=10 \mathrm{pc}$ podría ser parte de Vela OB1.

\section{CONCLUSIONES}

Del análisis de movimiento propio efectuado a las 261 estrellas O y B para las cuales fue posible calcularlo y contando con el dato de la distancia a la que cada una se encuentra como resultado del análisis espectrofotométrico efectuado en ellas, es posible concluir que existen dos grupos estelares. El ajuste de armónicos esféricos de cuarto orden aplicado a la distribución angular del movimiento propio determina la presencia de dos poblaciones. Una población que llamaremos Bochum 7-A con un ángulo $\phi=205^{\circ}$ y otra que llamaremos Bochum 7-B con un ángulo $\phi=180^{\circ}$. Ambas cinemáticas coinciden con el lóbulo de máxima intensidad resultante del desarrollo en armónicos esféricos mencionado.

Bochum 7-A se constituye con los 17 miembros del grupo B8 de la Tabla 43 cuya distancia resulta ser $\mathrm{d} \geq 4 \mathrm{kpc}$, todas ellas estrellas con tipos espectrales $\mathrm{B}$ de secuencia principal y gigantes 
y sólo una estrella con TE $=$ O9-9.5V. Entre las mismas se encuentran las tres estrellas del catálogo LS 1137, 1140 y 1146 que Moffat \& Vogt (1975) indicaron como miembros de la Asociación OB. Este grupo estelar tendría una distancia $\mathrm{d}=4.6 \pm 0.4 \mathrm{kpc}$ y un diámetro lineal $\mathrm{D}=36 \pm 3 \mathrm{pc}$. Si a él le sumamos la WR 12 ubicada a una distancia $\mathrm{d}=5 \mathrm{kpc}$, de la cual no se ha podido calcular su movimiento propio, siendo la misma una estrella evolucionada, en este grupo estelar tendríamos a la población más vieja de la Asociación OB denominada Bochum 7.

Bochum 7-B se constituye con los 10 miembros del grupo B4 de la Tabla 40, cuyos tipos espectrales indican que se trata de estrellas B tempranas de secuencia principal . La distancia del mismo sería $\mathrm{d}=4.3 \pm 0.6 \mathrm{kpc}$ y su diámetro lineal $\mathrm{D}=37 \pm 5$ pc. En esta región se observa una UCHIIR, las cuales se asocian generalmente con una estrella $\mathrm{O}$ que ha formado un "bowshock". Los vientos estelares apoyados por los "bowshocks" en las UCHIIRs explicarían las líneas de emisión observadas en esa zona en la banda A del MSX. Dicha geometría también explica su emisión IRAS y H $\alpha$ junto a la no detectabilidad de la estrella excitante del gas y polvo. Suponiendo que unas de las estrellas más tempranas de la muestra, como son LS 1131 y LS 1144, ambas con tipos espectrales O7.5V y ubicadas a una distancia $=4.6 \pm 0.9 \mathrm{kpc}$, a las cuales no fue posible calcularles sus movimientos propios, formaran parte del grupo estelar BO7-B, tendríamos en él a la población más jóven de la Asociación OB, Bochum 7.

Las edades aproximadas derivadas de los tipos espectrales de sus miembros junto a la distribución de los grupos y la posible asociación de Bo 7-B con una región UCHII, sugiere la existencia de formación estelar secuencial.

En la Figura 71 se muestran los dos grupos indicando con color rojo las estrellas miembro de Bochum 7-A y con color verde las estrellas miembro de Bochum 7-B. En color azul se indican las cuatro estrellas del catálogo LS que por sus distancias podrían pertenecer a alguno de estos grupos pero no hemos tenido la información necesaria para conocer sus respectivos movimientos propios.

En el grupo de cuatro estrellas mencionado en el párrafo anterior se está considerando a LS 1145 (WR12), LS 1131, LS 1144 y el sistema binario LS 1135. Este sistema binario con TE = O6.5V((f)) resulta ser el más temprano y por su distancia de $6.1 \pm 0.5 \mathrm{kpc}$, según el E(V - K) ó $6.7 \pm 1.3 \mathrm{kpc}$, según el E(B - V), podría considerarse miembro de Bo 7-B. Lamentablemente a LS 1135 tampoco fue posible calcularle su movimiento propio.

Si bien la distancia estimada tanto para Bo 7-A como para Bo 7-B no los ubica en la proyección del brazo de Perseo, vale la pena mencionar que a la distancia esperada se ubica el grupo B5 (10 miembros, $\mathrm{d}=8.6 \pm 0.5 \mathrm{kpc}$ y $\phi=194^{\circ}$ ). Sin embargo, contamos con sólo dos espectros de las estrellas de dicho cúmulo como para confirmar su existencia. 


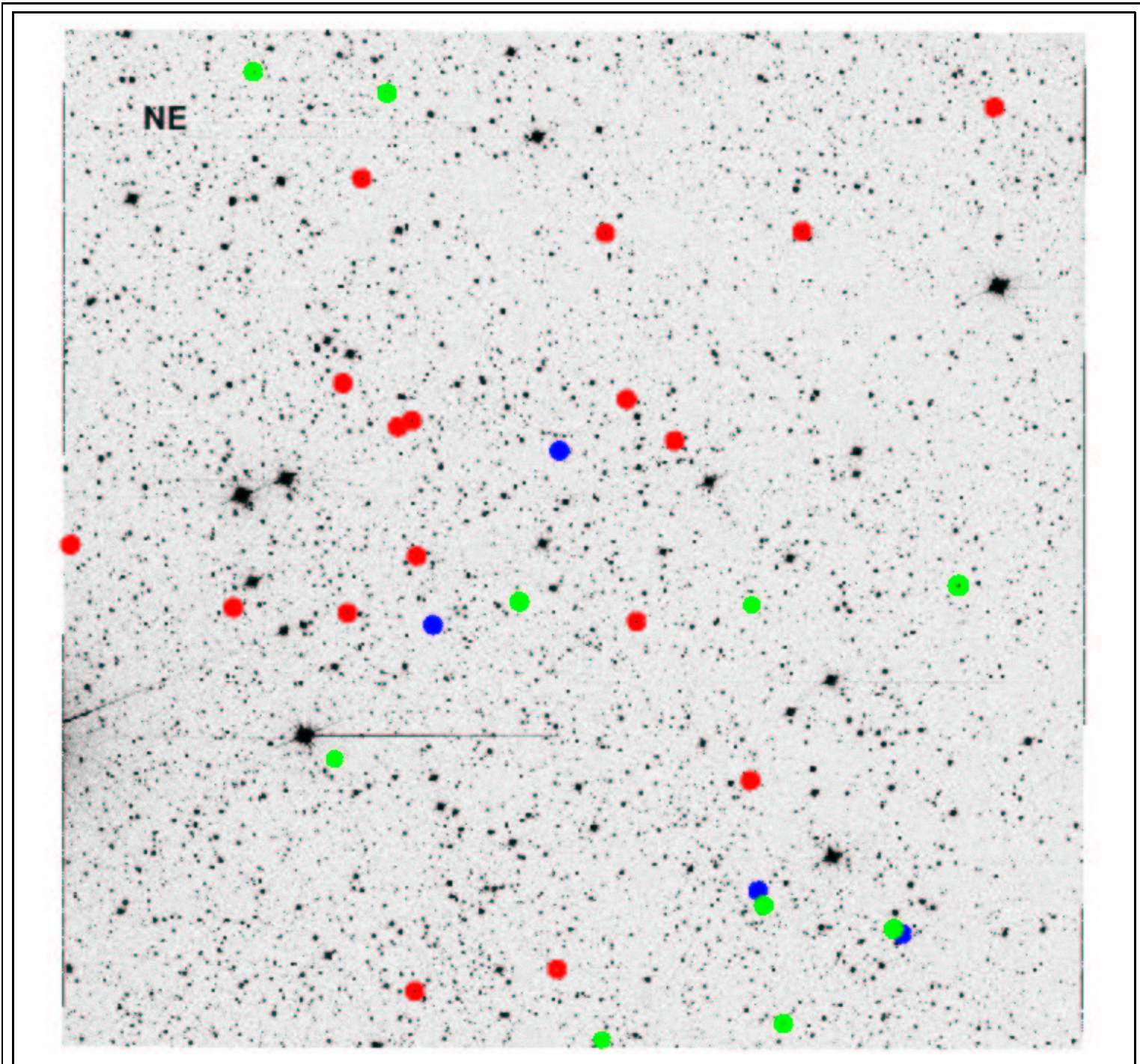

Figura 71: En la imagen fotométrica tomada con filtro $V$ se indican en color rojo los miembros de Bochum 7-A y en color verde los miembros de Bochum 7-B. En color azul se indican las cuatro estrellas del catálogo LS posibles miembros de alguno de estos grupos. 


\section{BIBLIOGRAFÍA}

- Alcala J.M., Terranegra L., Wichmann R., Chavarria-K C., Krautter J., Schmitt J.H.M.M., Moreno-Corral M.A., de Lara E. \& Wagner R.M., 1996, A\&AS, 119, 7.

- Alcala J.M., Chavarria-K C. \& Terranegra L, 1998, A\&A, 330, 1017.

- Arendt R.G., ApJS, 70, 181.

- Bertiau F.C. \& Grobben J., 1969, Ric. Astron. Sp. Vaticano 8, 1.

- Binney J. \& Tremaine S., 1987, Galactic Dynamics, Princeton Univ. Press. Princeton, New Jersey.

- Bolton C.T. \& Rogers G. L., 1978, ApJ, 222, 234.

- Bosch G., 1994, Práctica de la Especialidad, FCAGLP.

- Boulanger F. \& Perault M., 1988, ApJ, 330, 964.

- Bronfman L., Nyman L.A. \& May J., 1996, A\&ASS, 115, 81.

- Brown A., 2001, RevMexAA (Serie de Conferencias), 11, 89.

- Chanot A. \& Sivan J.P., 1983, A\&A, 121, 19.

- Churchwell E., 1990, A\&AR 2, 79.

- Clemens D. P., 1985, ApJ, 295, 422.

- Conti P. \& Alschuler W., 1971, ApJ, 170, 325.

- Conti P. \& Frost S., 1977, ApJ, 212, 728.

- Corti M., Niemela V. \& Morrell N., 2003, A\&A, 405, 571.

- Cutri R.M, Skrutskie M.F., Van Dyk S., et al., 2003, Univ. of Massachsetts an IR Processing and Analysis CEnter (IPAC), California Institute of Technology.

- Dame T.M., Dap Hartmann \& Thaddeus P., 2001, ApJ, 547, 792.

- de Bruijne J.H.J., 1999, MNRAS, 306, 381.

- de Zeeuw P.T., Hoogerwerf R., de Bruijne J.H.J., Brown A.G.A. \& Blaauw A., 1999, AJ, $\mathbf{1 1 7}, 354$.

- Draine B.T. \& Lee, 1984, ApJ, 285, 89.

- Draine B.T. \& Anderson N., 1985, ApJ, 292, 494. 
- Draine B.T., 1990, The interstellar Medium in Galaxies, ed. Thronson E Shull, pag. 483.

- Dubner G., Giacani E., Cappa de Nicolau C. \& Reynoso E., 1992, A\&AS, 96, 505.

- Duchene G., 1999, A\&A, 341, 547.

- Duchene G., Bouvier J. \& Simon T., 1999, Astron.Astrophys., 343, 831.

- Duke D., 1951, ApJ, 113, 100.

- Dwek E. \& Arendt G., 1992, ARA\&A, 30, 11.

- Englmaier P. \& Gerhard O, 1999, MNRAS, 304, 512.

- ESA, 1997, the Hipparcos and Tycho Catalogues, ESA SP - 1200.

- Ferriere K.M., 1995, ApJ, 441, 281.

- Ferriere K.M., 1998, ApJ, 497, 759.

- Ferriere K.M., 1998, ApJ, 503, 700.

- Fich M., Blitz L. \& Stark A., 1989, ApJ, 342, 272.

- Franco G.A.P., 1990, A\&A, 227, 499.

- Gammelgaard P., 1975, A\&A, 43, 85.

- García B., Malaroda S., Levato H., Morrell N. \& Grosso M., 1998, PASP, 110, 53.

- Garmany C.D., Conti P.S. \& Chiosi C., 1982, ApJ, 263, 777.

- Gaustad J.E., McCullough P.R., Rosing W. \& Van Buren D., 2001, PASP, 113, 1326.

- Ghez AM., Neugegauer G. \& Matthews K., 1993, AJ, 106, 2005.

- Gies D.R., Bagnuolo W.G. \& Penny L.R., 1997, ApJ, 479, 408.

- Glass I.S., Handbook of Infrared Astronomy, 1999, Cambridge University Press.

- Graham J.A., 1971, AJ, 76, 1079.

- Gum C.S., 1955, MNRAS, 67, 155.

- Herbig G.H., 1975, ApJ, 196, 129.

- Heyer M.H. \& Terebey S., 1998, ApJ, 502, 265.

- Hildebrand R.H., 1983, QJRAS, 24, 267. 
- Hog E., Fabricius C., Makarov V.V., et al., 2000, A\&A, 355, L27.

- Honma M. \& Sofue Y., 1996, PASJ, 48, L103.

- Honma M. \& Sofue Y., 1997, PASJ, 49, 539.

- Hoogerwerf R. \& Aguilar L.A., 1999, MNRAS., 306, 394.

- Humphreys R.M., 1978, ApJS, 38, 309.

- http://marc.sauvage.free.fr/index.html

- IRAS Explanatory Supplement, 1986, eds. C.A.Beichman, G.Neugebauer, H.J.Habing, P.E.Clegg, T.J.Chester, Government Printing Office, Washington, DC.

- Jaschek C. \& Jaschek M., 1990, The Classification of Stars, printed in Great Britain by the university Press, Cambridge.

- Journel A.G. \& Huijbrest Ch.J., 1981, Mining Geostatistics, Academic Press.

- Junkes N., Furst E. \& Reich W., 1992, A\&A, 261, 289.

- Kaltcheva N.T. \& Hilditch R.W., 2000, MNRAS, 312, 753.

- Keenan P.C. \& McNeil R.C., 1976, An Atlas of spectra of the cooler stars, Ohio State Univ. Press.

- Kerton C.R., Ballantyne D.R. \& Martin P.G., 1999, AJ, 117, 2485.

- Kohoutek L. \& Pauls R., 1995, A\&AS, 111, 493.

- Kohoutek L., 2001, A\&A, 378, 843

- Koornneef J., 1983, A\&A, 128, 84.

- Kroupa P., 1995a, MNRAS, 277, 1491.

- Kroupa P., 1995b, MNRAS, 277, 1507.

- Kroupa P., Petr M. \& McCaughrean MJ., 1999, NewAstron, 4, 495.

- Kroupa P., Aarseth S. \& Hurley J., 2001, MNRAS, 321, 699.

- Kurtz S., Churchwell E. \& Wood D.O.S., 1990, BAAS, 22, 1269.

- Lada C.J., Margulis M. \& Dearborn D., 1984, ApJ, 285, 141.

- Lamers H.J.G.L.M., Harzevoort J.M.A.G., Schijver H., Hoogerwerf R. \& Kudritzki R.P., 1997, A\&A, 325, L25. 
- Landolt \& Bornstein, 1982, New Series VI/2b A\&A, eds. K. Schaifers \& H. H. Voigt (Springer-Verlag Berlin. Heidelberg. New York).

- Landi J., Jaschek M. \& Jaschek C., 1977, Atlas de espectros estelares de red en mediana dispersión, Córdoba Obs.

- Landolt A.U., 1992, AJ, 104, 340.

- Leinert Ch., Zinnecker H., Weitzel N., Christou J., Ridgway ST., et al., 1993, A\&A, 278, 129.

- Lindblad B., 1922, ApJ, 55, 83.

- Linsley J., 1975, Phys. Rev. Lett., 34, 1530.

- Lundstrom I. \& Stenholm B., 1984, A\&AS, 58, 163.

- Marraco H. \& Muzzio J.C., 1980, PASP, 92, 700.

- McClure-Griffiths N., Dickey J. M., Gaensler B. M. \& Green A. J., 2004, ApJL, 607, 127.

- McKee C.F. \& Williams J.P., 1997, ApJ 476, 144.

- Mendez R.H., Forte J.C. \& Lopez R.H., 1986, Rev. Mex. AA, 13, 119.

- Merrill P.W., 1934, PASP, 46, 206.

- Mignard F., 2000, A\&A, 354, 522.

- Moffat A.F. \& Fitzgerald M.P., 1974, A\&AS, 18, 19.

- Moffat A.F. \& Vogt N., 1975, A\&AS, 20, 85.

- Monet D., Bird A., Canpian B., et al., 1998, The USNO-A2.0 Catalogue, Flagstaff Station 9USNOFS) and Universities Space Research Association (USRA) stationed at USNOFS.

- Morgan W.W., Keenan P.Ch. \& Kellman E., 1943, Chicago I11, The University of Chicago press.

- Morgan W.W., Abt H.A. \& Tapscott J.W., 1978, Revised MK spectral atlas for stars earlier than the sun, Yerkes and Kitt Peak National Observatory.

- Muzzio J.C., 1979, AJ, 84, 639.

- Nakano M., Wiramihardja S.D. \& Kogure T., 1995, PASJ, 47, 889.

- Niemela V., 1982, In Wolf-Rayet Stars: Observations, Physics, Evolution, Proc. IAU Sump. 99, 299, eds. C. de Loore $\&$ A.J.Willis, (Reidel-Dordrecht). 
- Olano C.A., 1982, A\&A, 112, 195.

- Patience J. \& Duchene G., 2001, In The Formation of Binary Stars, IAU, Symp. $N^{\circ}$ 200, ed. H. Zinecker, R. Mathieu, pp. 181-90. San Francisco; Astron. Soc. Pac.

- Pellerin A., Fullerton A.W., Robert C., Howk J.C., Hutchings J.B., Walborn N.R., Bianchi L., Crowther P.A \& Sonneborn G., 2002, ApJS, 143, 159.

- Penny L.R., Gies D.R., Hartkopf W.I., Mason B.D. \& Turner N.H., 1993, PASP, 105, 588.

- Pérault M., Boulanger F., Falgarone E. \& Puget J.L., 1987, Washington Star Formation in Galaxies. in NASA, pag. 97.

- Petr M., Coude Du Foresto V., Beckwith S.V.W., Richichi A. \& McCaughrean M.J., 1998, ApJ, 500, 825.

- Prosser CF., Stauffer JR., Hartmann L., Soderblom DR., Jones BF, et al., 1994, ApJ, 421, 517.

- Puget J.L., Léger A. \& Boulanger F., 1985, A\&A, 142, L19.

- Reed B.C., 2000, AJ, 119, 1855.

- Robin A.C., Reylé C., Derriére S. \& Picaud S., 2003, A\&A, 409, 523.

- Ruprecht J., 1966, IAU Trans. 12B. 350.

- Russeil D., 2003, A\&A, 397, 133.

- Ryter C., Puget J.L. \& Pérault M., 1987, A\&A, 186, 312.

- Sahu M.S., 1992, PhDT, 376.

- Sanders W.L., 1971, A\&A, 14, 226.

- Scally A., Clarke C. \& McCaughrean MJ., 1999, MNRAS, 306, 253.

- Schmidt-Kaler T., 1961, Z. Astrophys., 53, 1.

- Schmidt-Kaler, Th., 1982, In Landolt-Bornstein New Series, Group VI, Vol. 2b., eds. K. Schaifers and H. Voigt, (Springer - Verlag, Berlin).

- Schwering P.B.W., 1988, PhDT, 254, Leiden, The Netherlands.

- Simon M., Ghez AM., Leinert Ch., Cassar L., Chen WP., et al., 1995, ApJ. 443, 625.

- Simon M., Close LM. \& Beck TL., 1999, AJ, 117, 1375.

- Snow T.P., Zukowski D. \& Massey P., 2002, ApJ, 578, 877. 
- Stephenson C.B. \& Sanduleak N., 1971, 1, $n^{\circ}$ 1. Publications of the Warner and Swasey Observatory.

- Sung H, Bessell M.S. \& Lee S.W., 1998, AJ, 115, 734.

- Sung H., Bessell M., Park B. \& Kang H., 1999, JKAS, 32, 109.

- Telesco C.M. \& Harper D.A., 1980, ApJ, 235, 392.

- Testori J.C., Reich P., Bava J.A., Colomb F.R., Hurrel E.E., Larrarte J.J., Reich W. \& Sanz A.J., 2001, A\&A, 368, 1123.

- Urban S.E., Corbin T.E., Wycoff G.L. et al., 1998, AJ, 115, 1212.

- van der Hucht K.A., 1996, A New Orbital Solution for the WNL Binary System WR12, 33rd Liege Int. Astroph. Coll., eds. J-M. Vreux, A. Detal, D. Fraipont-Caro, E. Gosset $\mathscr{G}$ G. Rauw.

- van der Hucht K.A., 2001, New Astronomy Review 45, 135.

- Vasilevskis S., Klemola A. \& Preston G., 1958, AJ, 63, 387.

- Velghe A.G., 1957, ApJ, 126, 302.

- Verschueren W. \& David M., 1989, A\&A, 219, 105.

- Vogt N. \& Moffat A.F.J., 1972, A\&AS, 7, 133.

- Wainscoat R.J. \& Cowie L.L., 1992, AJ., 103, 332.

- Walborn N.R., 1980, ApJS, 44, 535.

- Walborn N. \& Fitzpatrick E., 1990, PASP, 102, 379.

- Walter F., Kerp J., Duric N., Brinks E. \& Klein U., 1998, ApJ, bf 502, L143.

- Wilking B.A., Blackwell J.H., Mundy L.G. \& Howe J.E., 1989, ApJ, 345, 257.

- Williams J.P. \& McKee C.F., 1997, ApJ, 476, 166.

- Wilson R.E., 1953, General Catalogue of Stellar Radial Velocities, Carnegie Institution of Washington Publication 601, Washington D.C.

- Wood D.O.S. \& Churchwell Ed., 1989a, ApJS, 69, 831.

- Wood D.O.S. \& Churchwell Ed., 1989b, ApJ, 340, 265.

- Wray J.D. \& Westerlund B.E., 1971, asmw.book, Atlas of the Southern Milky Way. 
- Wunderlich E., Wielebinsky R. \& Klein U., 1987, A\&AS, 69, 487.

- Yamaguchi R., Saito H., Mizuno N., Mine Y., et al., 1999, PASJ, 51, 791.

- Yamashita Y., Nariai K. \& Norimato Y., 1977, An Atlas of representative stellar spectra, Univ. of Tokyo Press.

- Zacharias N., Urban S.E., Zacharias M.I., et al., 2003, The Second US Naval Observatory CCD Astrograph Catalogue (UCAC2), AJ, 127, 3043. 
Tabla 44: Características de la configuración instrumental empleada para obtener el material de ambos Atlas (Walborn \& Fitzpatrick, 1990 y Corti \& Morrell)

\begin{tabular}{|l|l|}
\hline \hline $\begin{array}{l}\text { Walborn \& Fitzpatrick, 1990, } \\
\text { PASP 102, 379-411 }\end{array}$ & $\begin{array}{l}\text { Corti \& Morrell } \\
\text { http://lilen.fcaglp.unlp.edu.ar }\end{array}$ \\
\hline Telescopio de 1m de CTIO, Chile & Telescopio de 2.15m de CASLEO, Argentina \\
\hline Espectrógrafo Cassegrain & Espectrógrafo Reosc DS \\
\hline $\begin{array}{l}\text { Detector: contador de fotones Sheckman/Heathcote bidimensional, } \\
\text { (tubos de imágenes más CCD) }\end{array}$ & Detector CCD Tek $1024 \times 1024$ \\
\hline $\begin{array}{l}\text { Rango espectral cubierto: } \\
\delta \lambda=3950 \AA-4750 \AA\end{array}$ & $\begin{array}{l}\text { Rango espectral cubierto } \\
\delta \lambda=3700 \AA ~-~ 5000 \AA\end{array}$ \\
\hline Dispersión reciproca: $0.5 \AA$ pixel $^{-1}$ & Dispersión reciproca: $1.65 \AA$ pixel $^{-1}$ \\
\hline Relación S/N $=80$ & Relación S/N $=200$ \\
\hline Resolución: 3 px $=1.5 \AA$ & Resolución: 2 px $=3.4 \AA$ \\
\hline \hline
\end{tabular}

\section{APÉNDICE}

\subsection{Atlas CCD de estándares OB de clasificación espectral}

Los criterios de clasificación espectral empleados en el estudio de las estrellas tempranas, O y B de esta Tesis, se basaron principalmente en los descriptos en el Atlas de clasificación espectral de estrellas OB de Walborn \& Fitzpatrick (1990). Debido a que los espectros de las estrellas que analizamos fueron obtenidos en el CASLEO con una configuración instrumental diferente a la empleada en el Atlas de Walborn \& Fitzpatrick, confeccionamos nuestro propio Atlas CCD de estándares OB de clasificación espectral. Para ello obtuvimos los espectros de todas las estándares de clasificación espectral OB del Atlas de W \& F, con la misma configuración instrumental que la utilizada por nosotros en el CASLEO para obtener los espectros de las estrellas a clasificar. Nuestro Atlas CCD contiene estrellas estándares de clasificación espectral O y B observadas en el CASLEO con el espectrógrafo Reosc en su modo DS. En la la Tabla 44 se comparan las características de la configuración instrumental empleada para obtener el material de cada Atlas como también las características de los espectros obtenidos con las mismas, todos ellos correspondientes a estrellas con tipos espectrales de O3 a B8 y clase de luminosidad de I a V, también los hay Of, ON y OC. Es adecuado aclarar que nuestro Atlas aún está en proceso de elaboración, debido a que faltan obtener las imágenes espectrales de algunas estándares de clasificación espectral. Estas últimas no se han podido obtener aún por falta de tiempo de observación.

En la Figura 72 se compara el espectro de la estándar de clasificación espectral HD93146 (del TE O6.5V), obtenido con la configuración instrumental del CASLEO, con el espectro de la misma estrella obtenido en el CTIO (extraído del Atlas de Walborn \& Fitzpatrick, 1990). En el espec- 


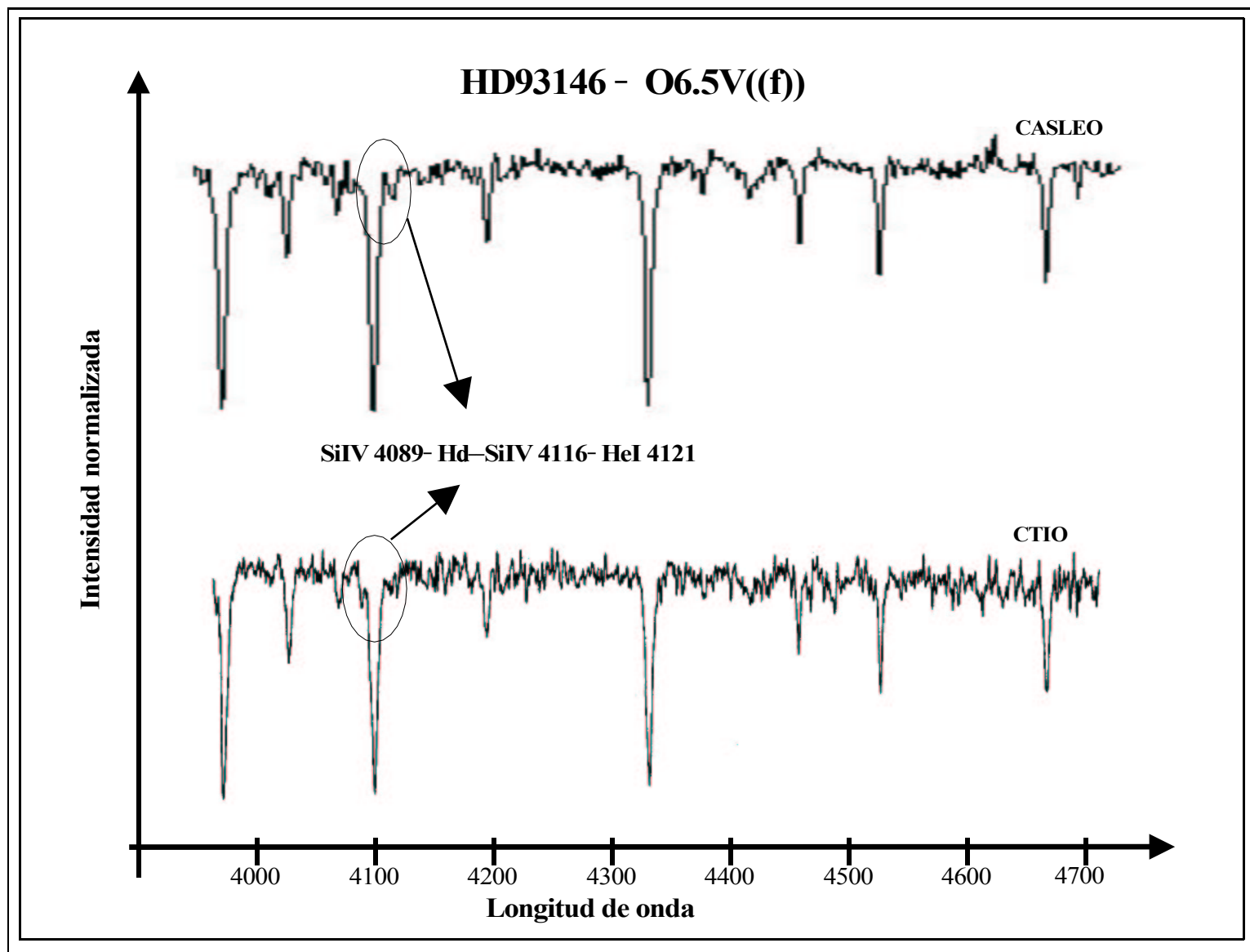

Figura 72: Comparación de dos espectros de HD93146 obtenidos con diferentes configuraciones instrumentales

tro obtenido en el CASLEO, se observa que las líneas de SiIV 4089 y H $\delta$ no llegan a resolverse, mientras que en aquel obtenido en el CTIO, ambas líneas se resuelven perfectamente. Esto es una consecuencia de la menor dispersión recíproca que posee la configuración instrumental del CASLEO empleada para la obtención del mismo, respecto de la empleada en el CTIO. Lo mismo sucede con el par de líneas SiIV 4116 y HeI 4121. Los perfiles débiles de SiIV 4116 y HeI 4121 cercanos a H $\delta$ que se ven en el tipo espectral $\mathrm{O} 6.5 \mathrm{~V}$, están más próximos al nivel del ruido en los espectros de este tipo obtenidos en el CTIO y ello hace más dificultosa la decisión de si se trata de un espectro de TE O6.5V u O6V. Esto último, en cambio, no sucede con los espectros obtenidos en el CASLEO ya que estos tienen mejor relación señal ruido que los obtenidos en el CTIO. En este caso el tipo espectral O6.5V tiene agregada la notación ((f)), lo cual indica que en el mismo se encuentra presente la débil emisión NIII $\lambda \lambda \lambda$ 4634-4640-4642.

En la Figura 73 también se observa que aquellas líneas que en un espectro obtenido en el CASLEO no llegan a resolverse, se resuelven claramente en el espectro de la misma estrella obtenido en el CTIO. En este caso tomamos como ejemplo a la supergigante luminosa HD105056 donde en 


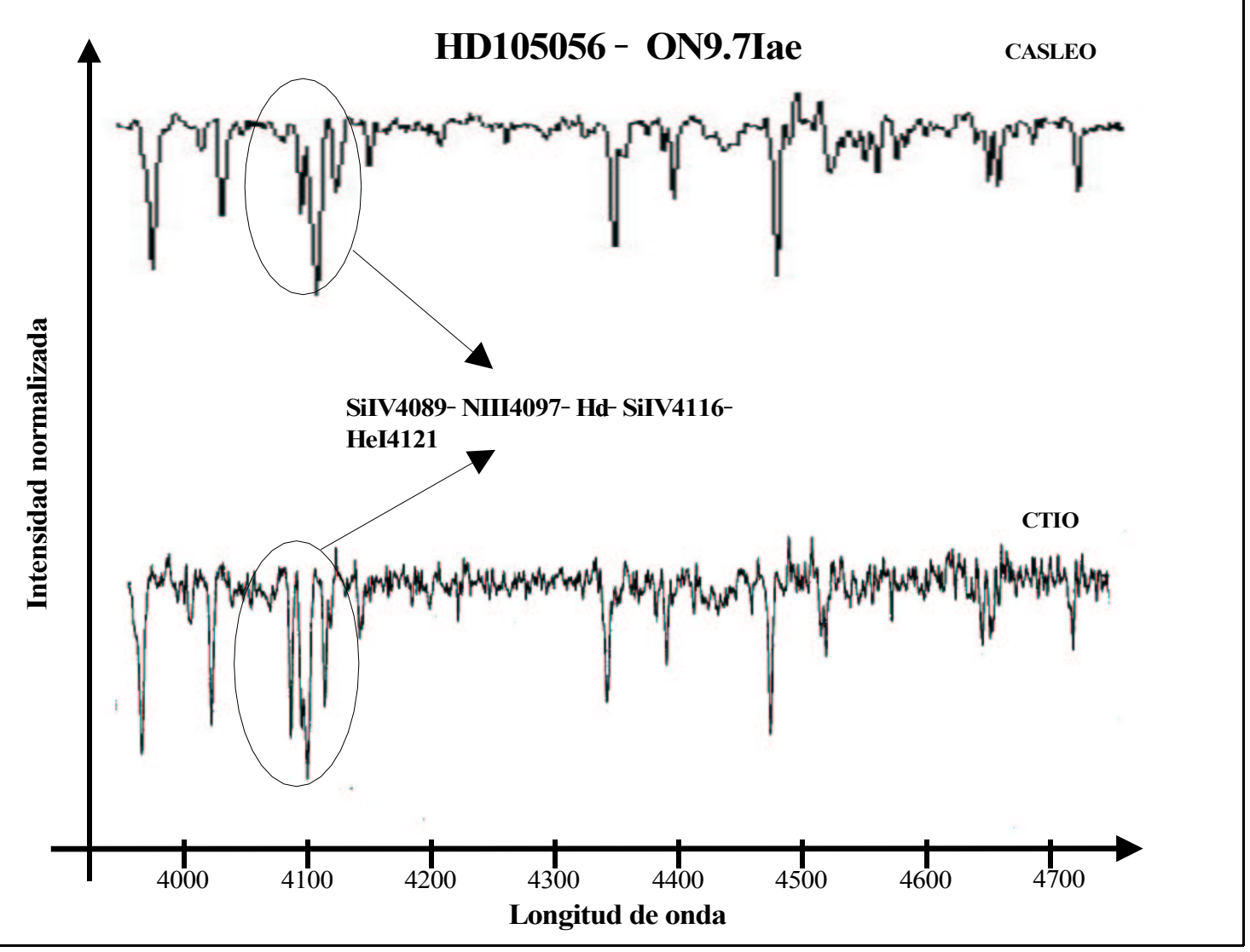

Figura 73: Comparación de dos espectros de HD105056 obtenidos con diferentes configuraciones instrumentales

los espectros del CASLEO los perfiles NIII 4097 y H $\delta$ no se resuelven bien. Lo mismo sucede con el par Si IV 4116 y HeI 4121. Para el tipo espectral ON9.7Iab que tiene esta estrella es importante poder distinguir en su espectro el perfil de NIII 4097 junto a los demas perfiles producidos por este mismo gas.

En la Figura 74 se muestran dos espectros de la misma estrella que en este caso es 22 Scorpio, donde también es posible ver que en el espectro obtenido con la configuración instrumental del CASLEO, las líneas HeI 4471 y MgII 4481 se observan muy pegadas mientras que en el espectro obtenido en el CTIO están bien resueltas. En el tipo espectral B2.5V que corresponde a esta estrella es importante la presencia del perfil MgII 4481 como así también cuál es la relación de intensidad que éste tiene con el perfil de HeI 4471.

La Figura 75 presenta los espectros de algunas estándares de clasificación espectral OB clasificadas como O o B tempranas con distintas clases de luminosidad según los criterios de Walborn \& Fitzpatrick (1990). Estos espectros fueron obtenidos con la configuración instrumental del 


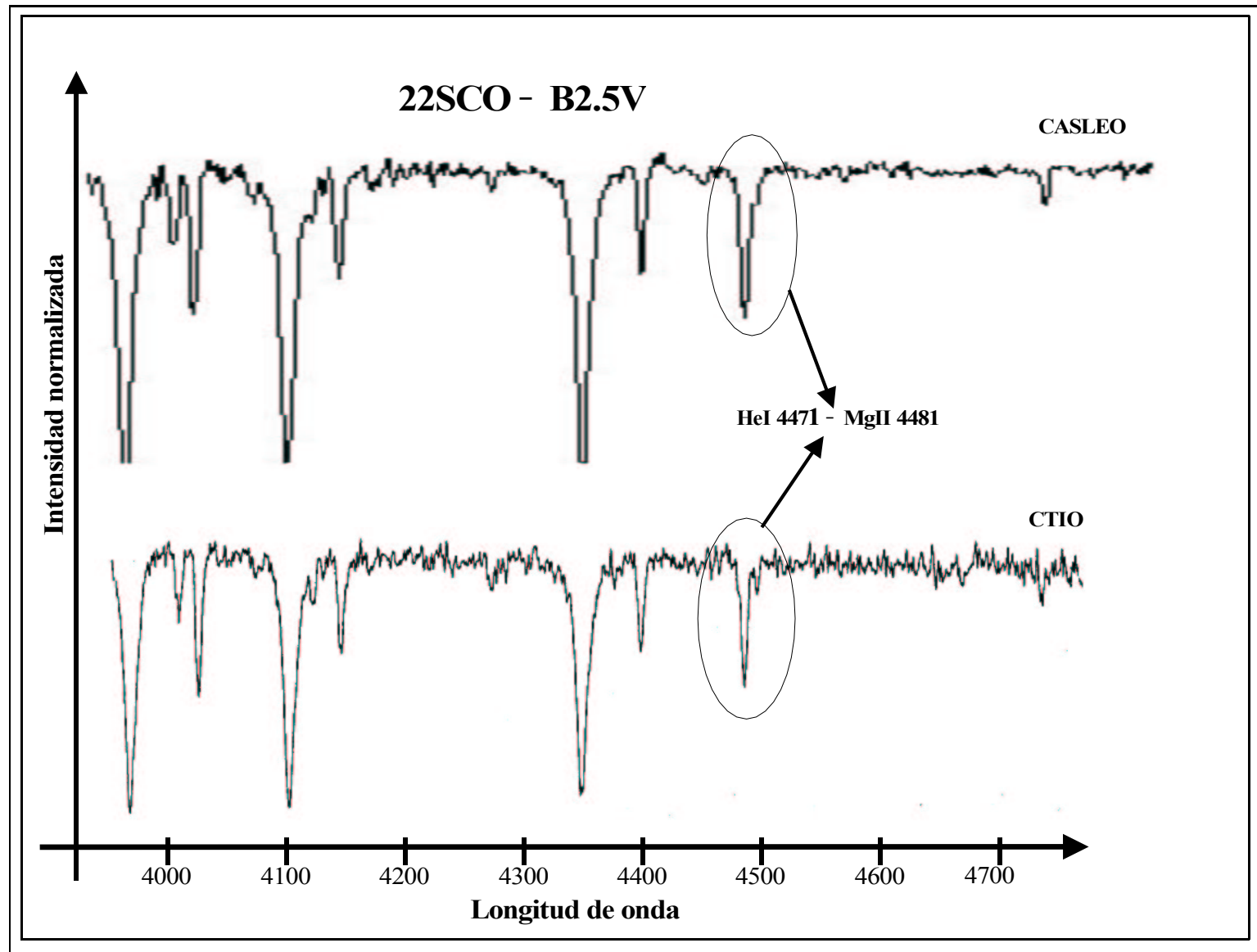

Figura 74: Comparación de dos espectros de 22SCO obtenidos con diferentes configuraciones instrumentales 


\section{Estándares de TE observadas en el azul- rojo con el fin de ampliar los criterios de clasificación espectral empleando también HeII 5411}

HD108639- B0.2III

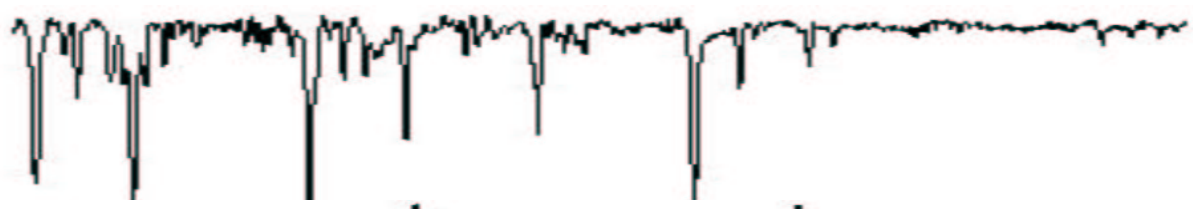

HD105056- ON9.71

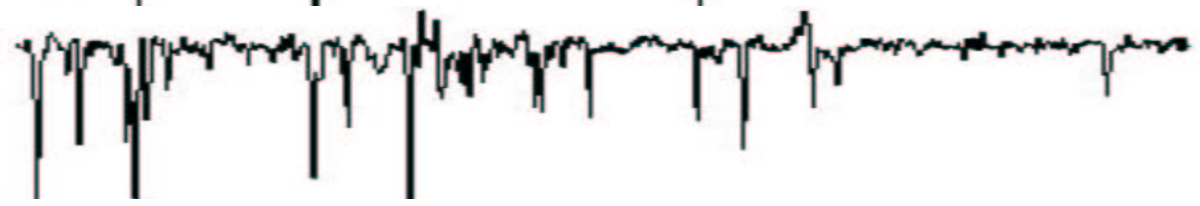

HD112244- O8.5Iab

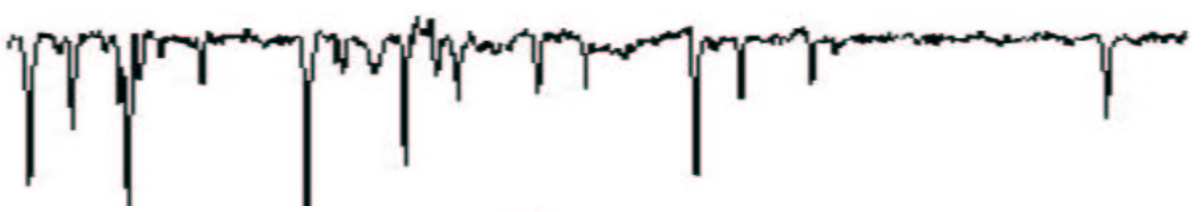

HD101190-O6V

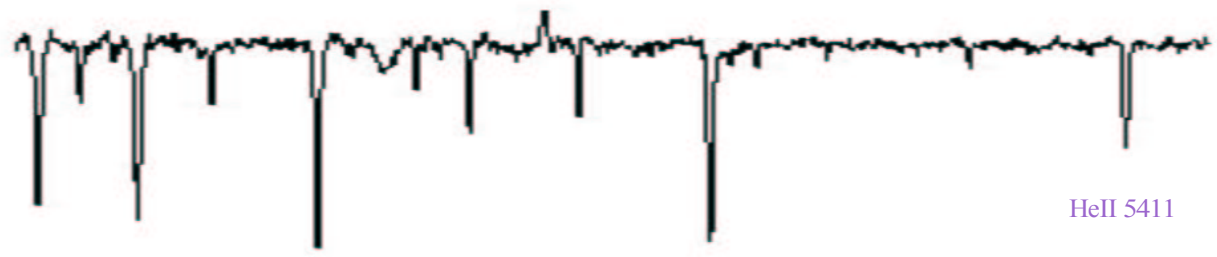

Figura 75: Espectros de estrellas estándares de clasificación espectral $O$ y $B$ con la presencia de la línea de HeII 5411

CASLEO en el rango espectral $\lambda \lambda$ 3940-5500, haciéndose presente en todos ellos el perfil de HeII 5411, se observa que el mismo posee diferentes intensidades según sea el tipo espectral de la estrella.

Los espectros también fueron empleados para testear si los criterios de clasificación establecidos por otros investigadores no contradicen el TE obtenido por Walborn \& Fitzpatrick en su Atlas. Nolan Walborn (1980) estudiando espectros estelares en la región amarillo - rojo, realiza una clasificación espectral en cuyo criterio emplea el perfil de HeII 5411, y los TEs que encuentra coinciden con aquellos de las estrellas del Atlas de Walborn \& Fitzpatrick (1990). El criterio de clasificación espectral de Kerton et al. (1999) del trabajo titulado "Classification of O stars in the yellow-green: the exciting star VES 735", cuyo criterio está basado en el cociente de los anchos equivalentes de HeI 4921 y HeII 5411, también coincide con lo que observamos.

En las Figuras 76, 77, 78, 79, 80, 81, 82, 83, 84, 85, 86, 87, 88 y 89, se presentan los espectros de las estándares de clasificación espectral OB que hemos obtenido con la misma configuración instrumental del CALEO empleada en esta Tesis para clasificar los espectros OB. Los turnos de 


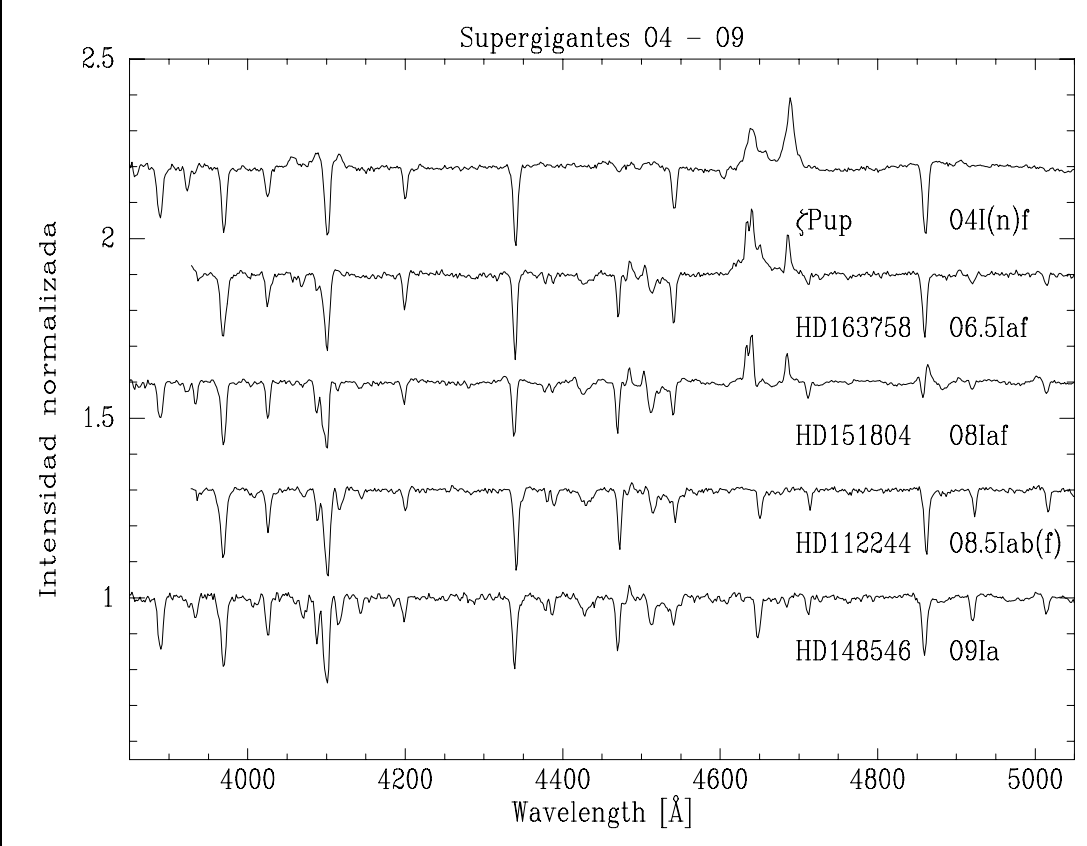

Figura 76: Espectros ópticos azules de las estándares de clasificación espectral $O$ y $B$ del Atlas de Walborn \& Fitzpatrick (1990), observadas con Reosc DS en el CASLEO. La intensidad de los espectros se indica en unidades arbitrarias. En esta Figura se presentan las supergigantes de 04 a $O 9$

observación a los que se ha asistido para ello, fueron los que se comentan en la sección 5.2.

\subsection{Resultados de estrellas en la visual a Bochum 7}

En esta subsección del Apéndice comentaremos los resultados obtenidos del estudio de estrellas con TEs A, F y G y clases de luminosidad V, IV, III y I observadas en diferentes turnos en el CASLEO, según se detalla en la sección5.2. Las Figuras 90, 91, 92, 93, 94, 95 y 96 muestran los espectros de las mismas. La Tabla 47 en sus sucesivas columnas contiene la identificación asignada a las estrellas según los criterios de la IAU, la Fecha Juliana de observación, datos espectrofométricos como magnitud visual, V, colores, (B - V) y (U - B) y tipo espectral, TE y en la última columna las referencias cruzadas obtenidas de la búsqueda realizada en INTERNET con el empleo del Aladin.

Aquí también comentamos los criterios de clasificación espectral, de estas 39 estrellas, las cuales pertenecen al grupo de las 102 seleccionadas previamente. Los criterios de clasificación espectral empleados fueron los de Jaschek \& Jaschek (1990). A continuación se presenta una breve descripción de los mismos. 


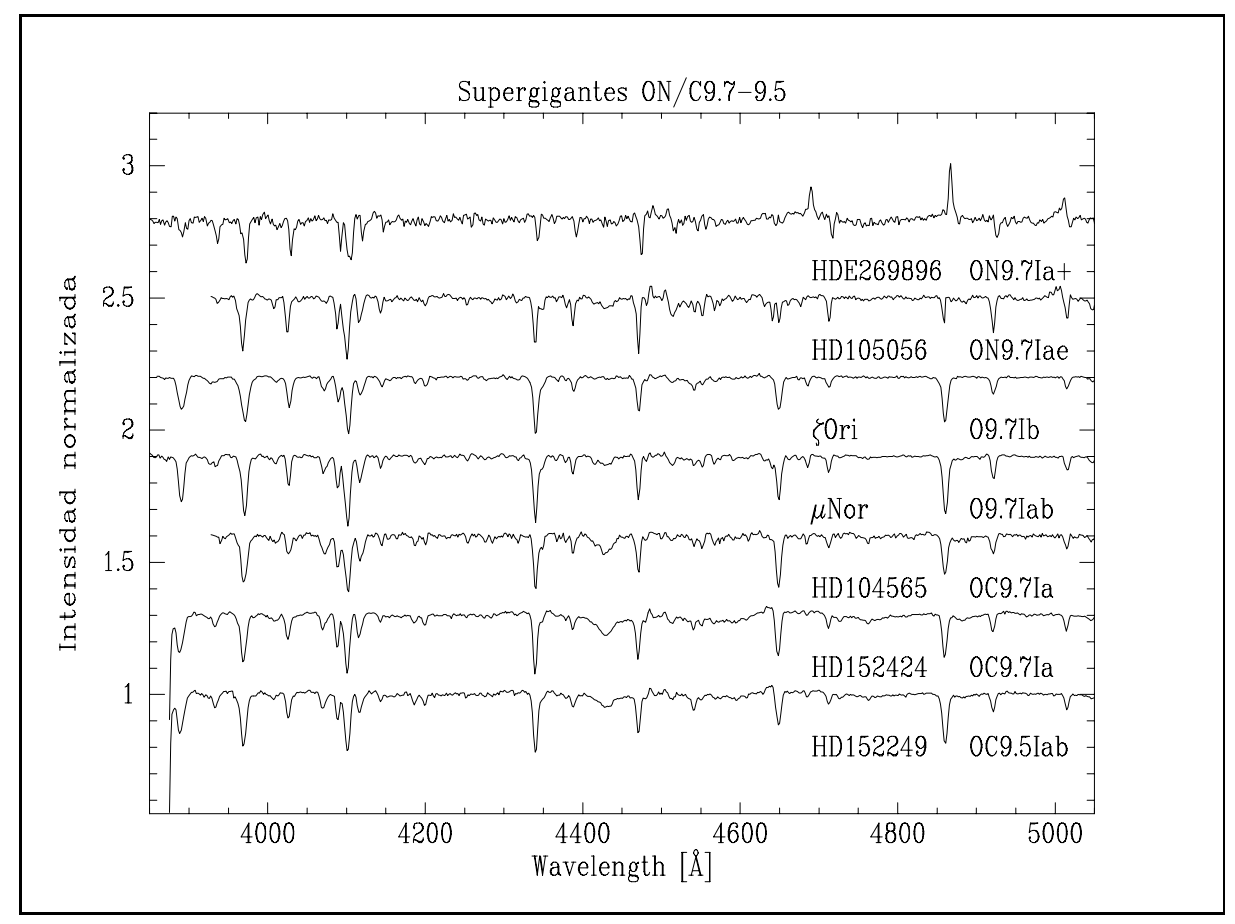

Figura 77: Idem Figura 76 para supergigantes 09.7 y 09.5 de carbono y nitrógeno.

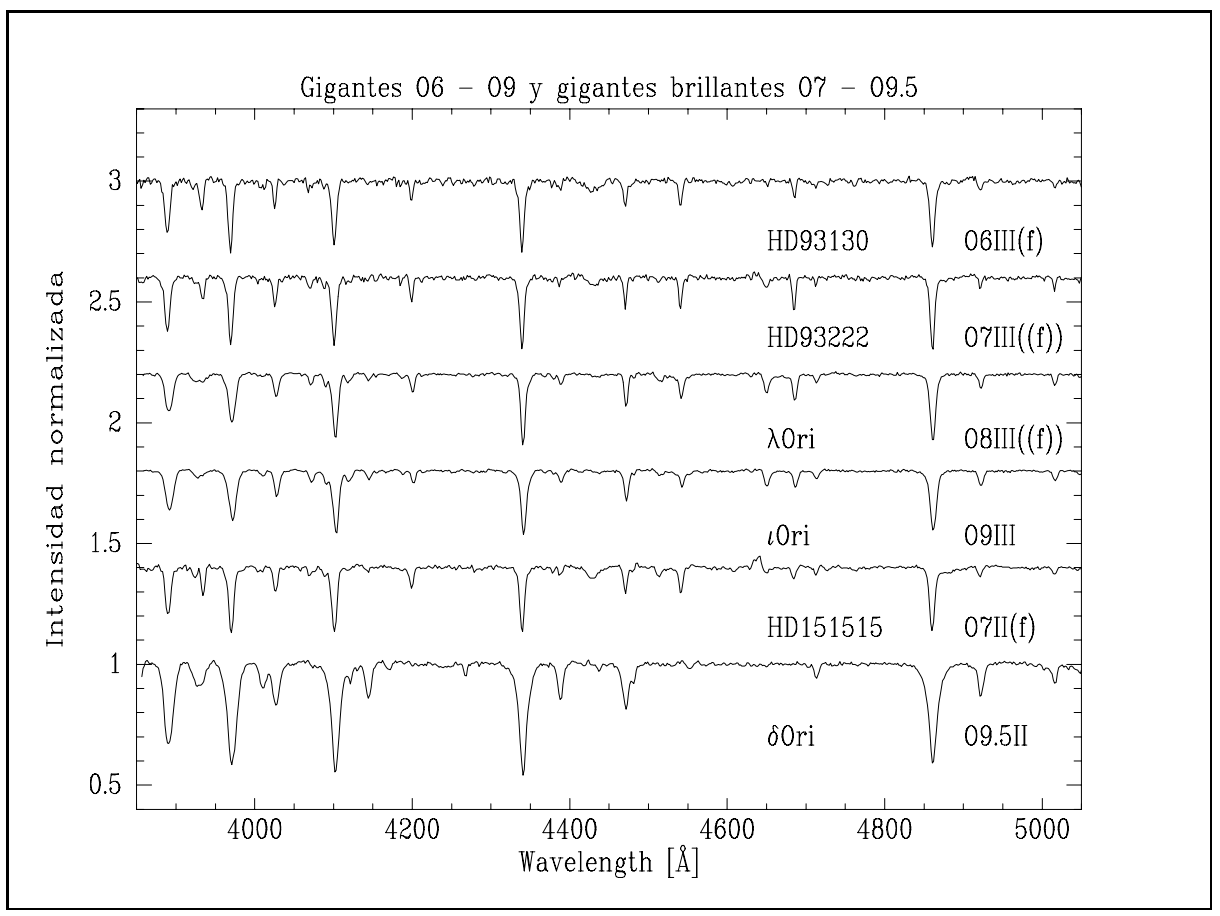

Figura 78: Idem Figura 76 para gigantes de 06 a 09 y gigantes brillantes de 07 a 09.5 


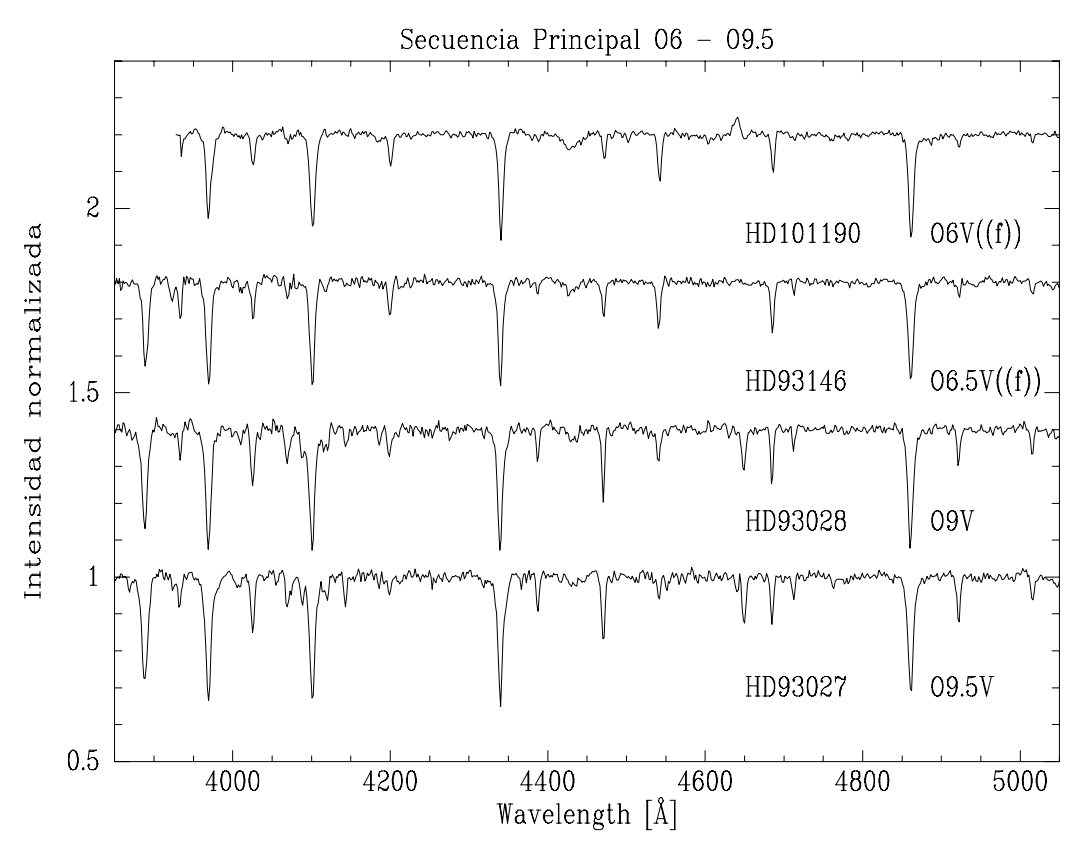

Figura 79: Idem Figura 76 para estrellas de secuencia principal con tipos espectrales de 06 a 09.5

\section{Estrellas de tipo espectral A}

De acuerdo al sistema de Harvard, una estrella con TE A es un objeto en el cual las intensas líneas de Balmer son acompañadas por muchas líneas metálicas. La intensidad de estas líneas metálicas se incrementa desde A0 a A9. Las estrellas tipo espectral A difieren de las estrellas tipo espectral B en que en las primeras no hay líneas de HeI. La diferencia entre las estrellas tipo espectral A y las estrellas tipo espectral F es algo sutil, en las últimas, las líneas metálicas son más numerosas e intensas.

El comportamiento de las líneas metálicas puede ser ilustrado por el de las líneas $\mathrm{H}(\lambda 3968)$ y K ( $\lambda 3933)$ del CaII. En las placas de $100 \AA \mathrm{mm}^{-1}$ estas líneas aparecen muy débiles para las estrellas A0. Ya que la línea $\mathrm{H}$ del CaII está próxima a la línea $\mathrm{H} \epsilon(\lambda 3970)$, únicamente se ven una línea débil $\mathrm{K}$ y una línea ensanchada formada por $\mathrm{H}+\mathrm{H} \epsilon$. En el TE A5, K es aproximadamente la mitad tan intensa como $\mathrm{H}+\mathrm{H} \epsilon$ y es en F0 donde las intensidades de ambas líneas se asimilan.

Las líneas de $\mathrm{H}$ tienen su máximo en el TE A2, decreciendo hacia los tipos espectrales siguientes; el CaII y los metales incrementan su intensidad hacia los tipos más tardíos. De este modo, las líneas de $\mathrm{H}$ y las de CaII, representando a los metales, pueden ser usadas para asignar los tipos 


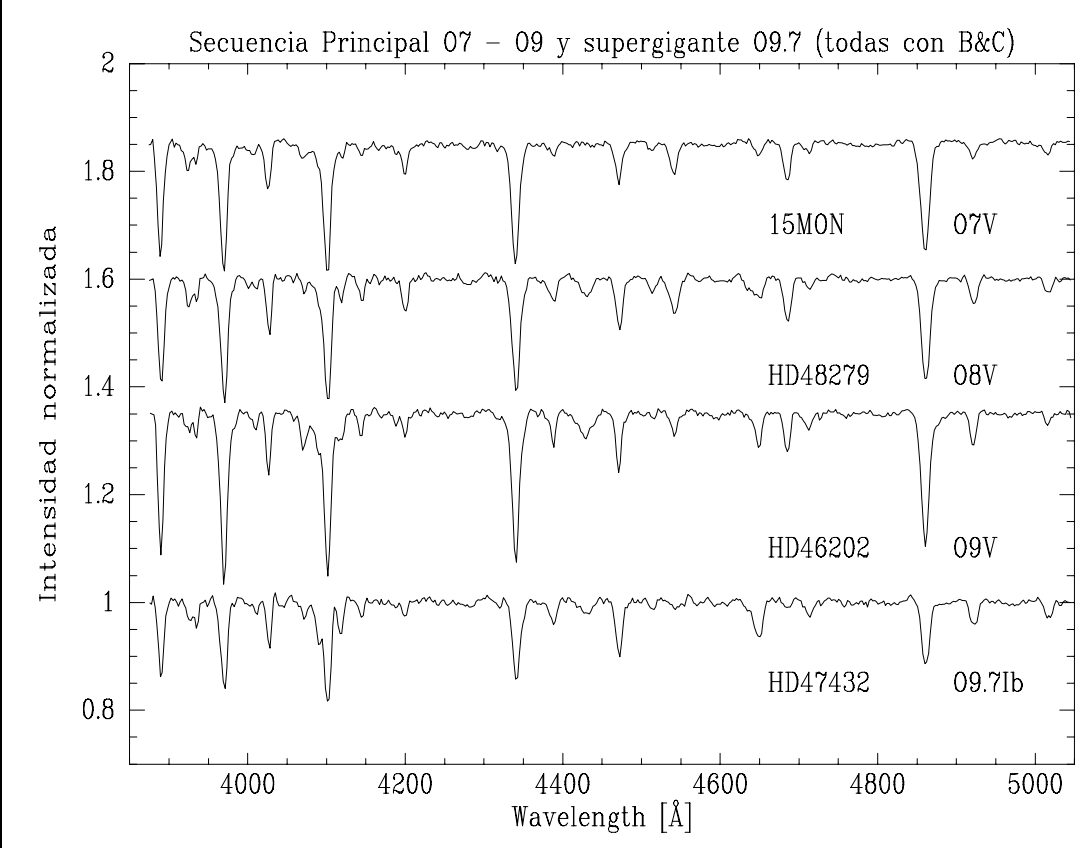

Figura 80: En esta Figura se presentan los espectros ópticos azules de las estándares de clasificación espectral $O$ y $B$ del Atlas de Walborn 8 Fitzpatrick (1990), observadas con Boller \& Chivens (BEC) en el CASLEO. La intensidad de los espectros se indica en unidades arbitrarias. Los espectros corresponden a estrellas de secuencia principal con tipos espectrales de 07 a O9 y un espectro de una supergigante O9.7

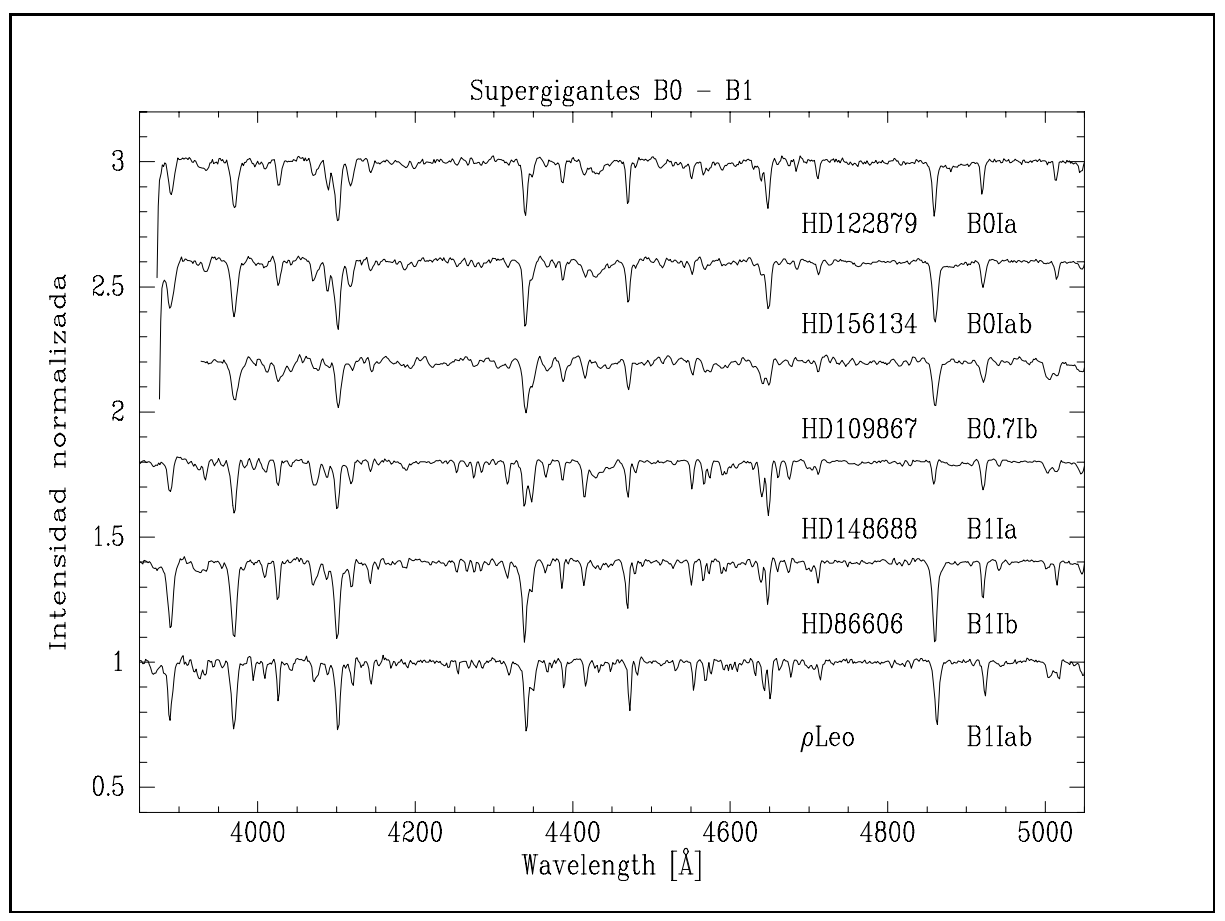

Figura 81: Idem Figura 76 para supergigantes con tipos espectrales de B0 a B1 


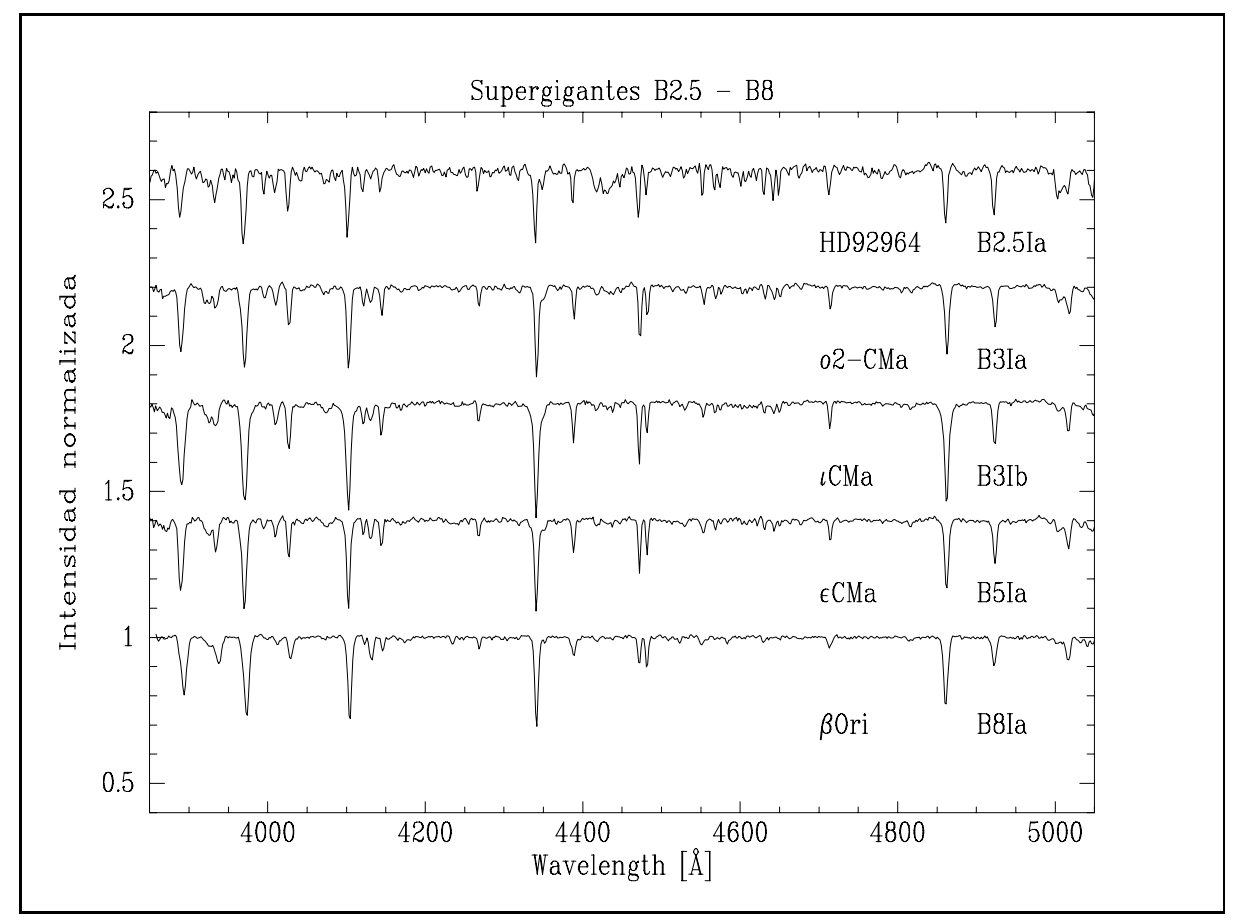

Figura 82: Idem Figura 76 para supergigantes con tipos espectrales de B2.5 a B8

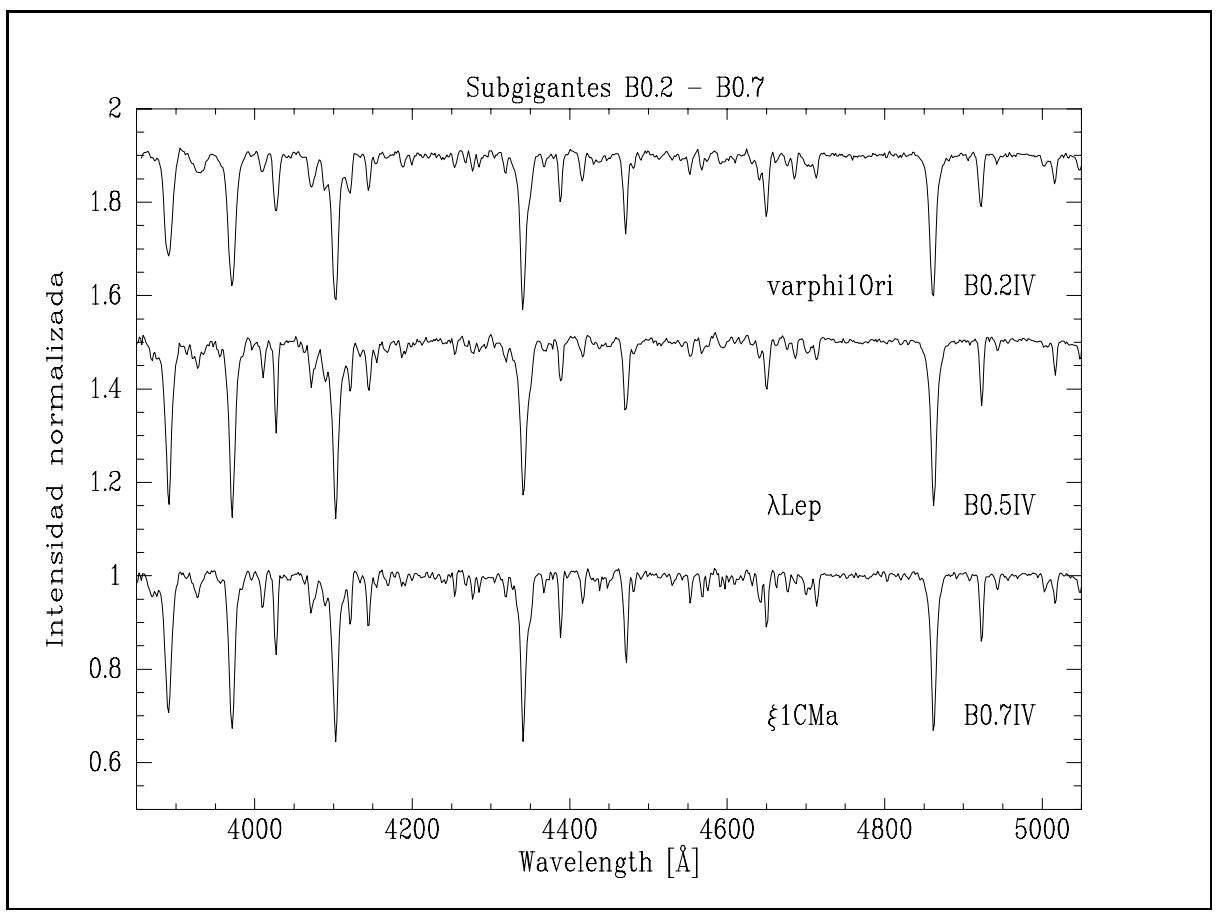

Figura 83: Idem Figura 76 para supergigantes con tipos espectrales de B0.2 a B0.7 


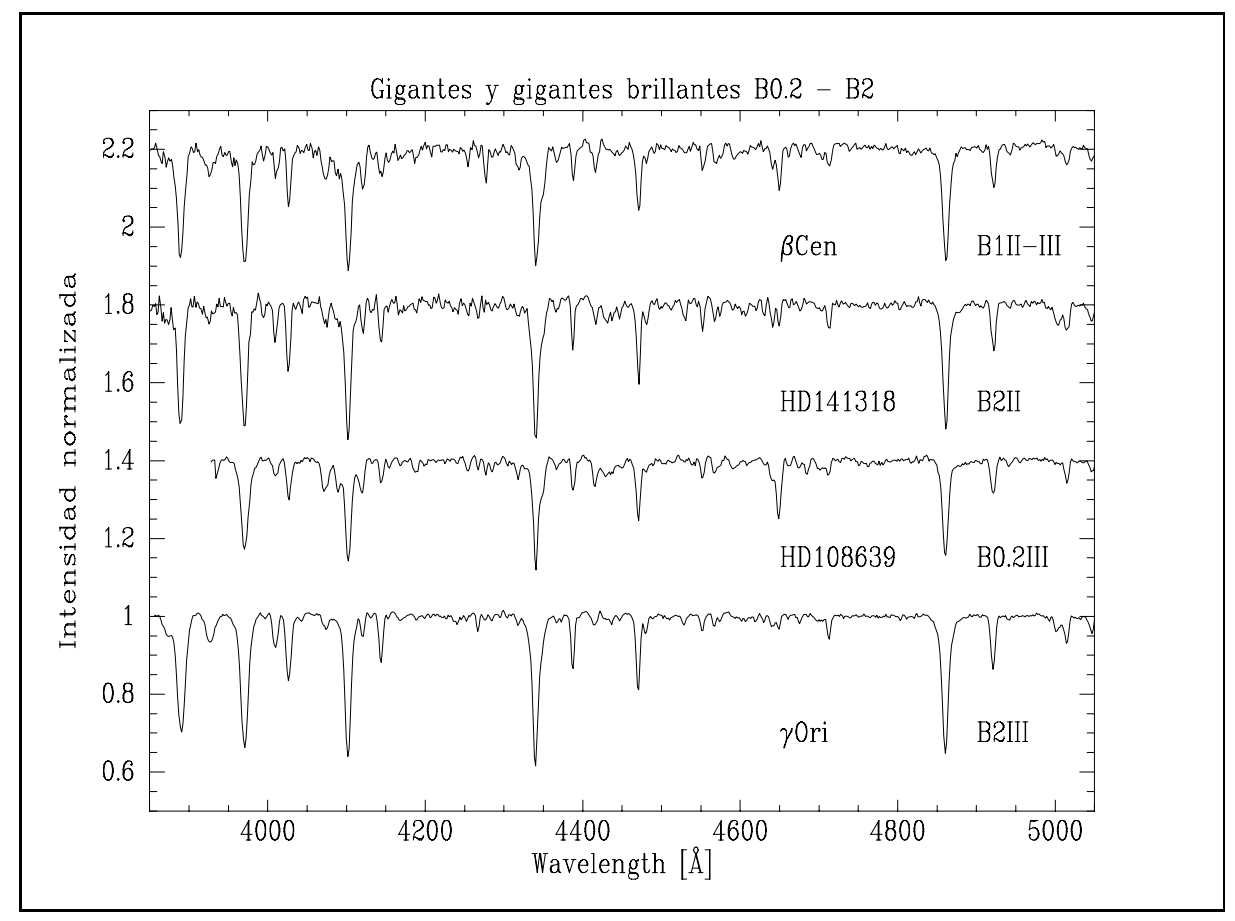

Figura 84: Idem Figura 76 para gigantes y gigantes brillantes de B0.2 a B2

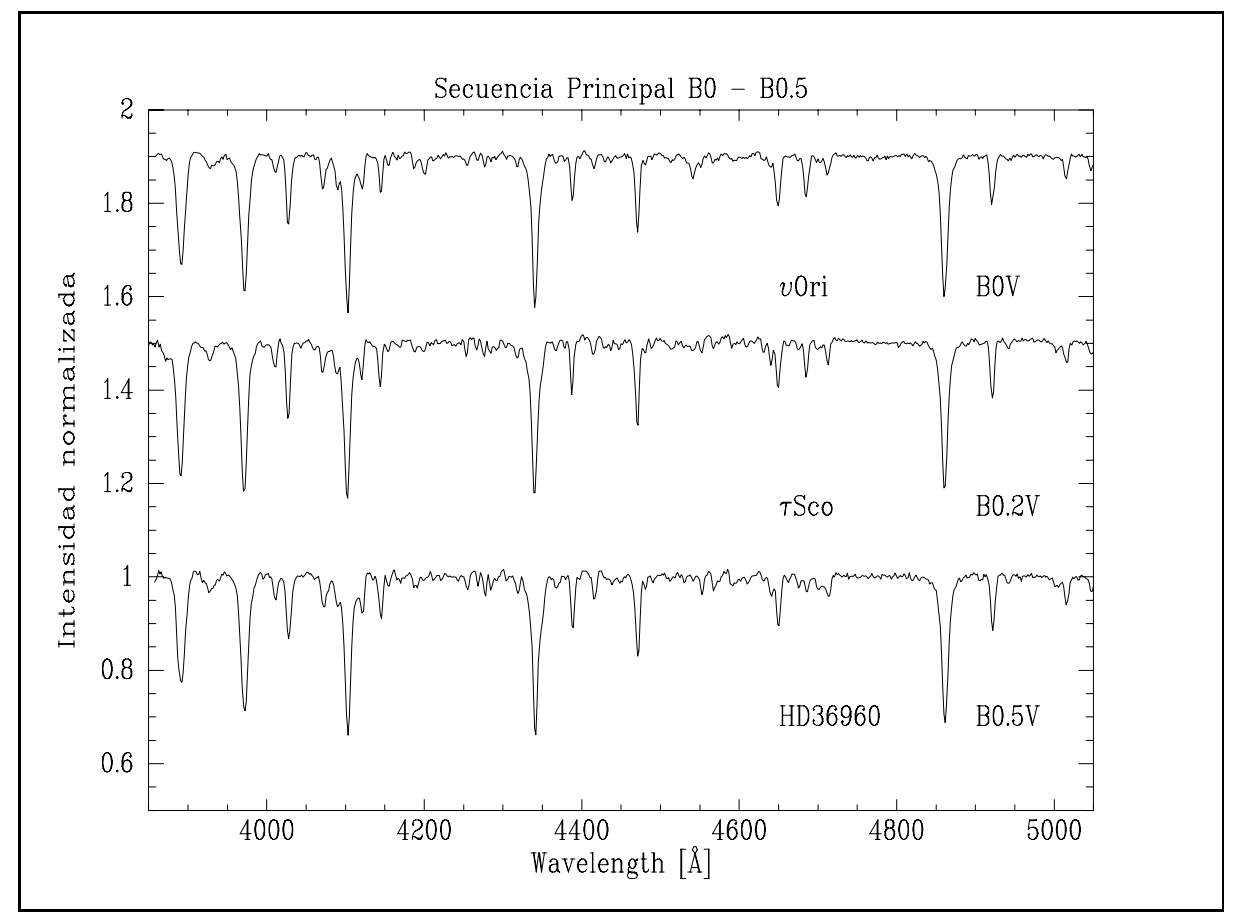

Figura 85: Idem Figura 76 para estrellas de secuencia principal con tipos espectrales de B0 a B 0.5 


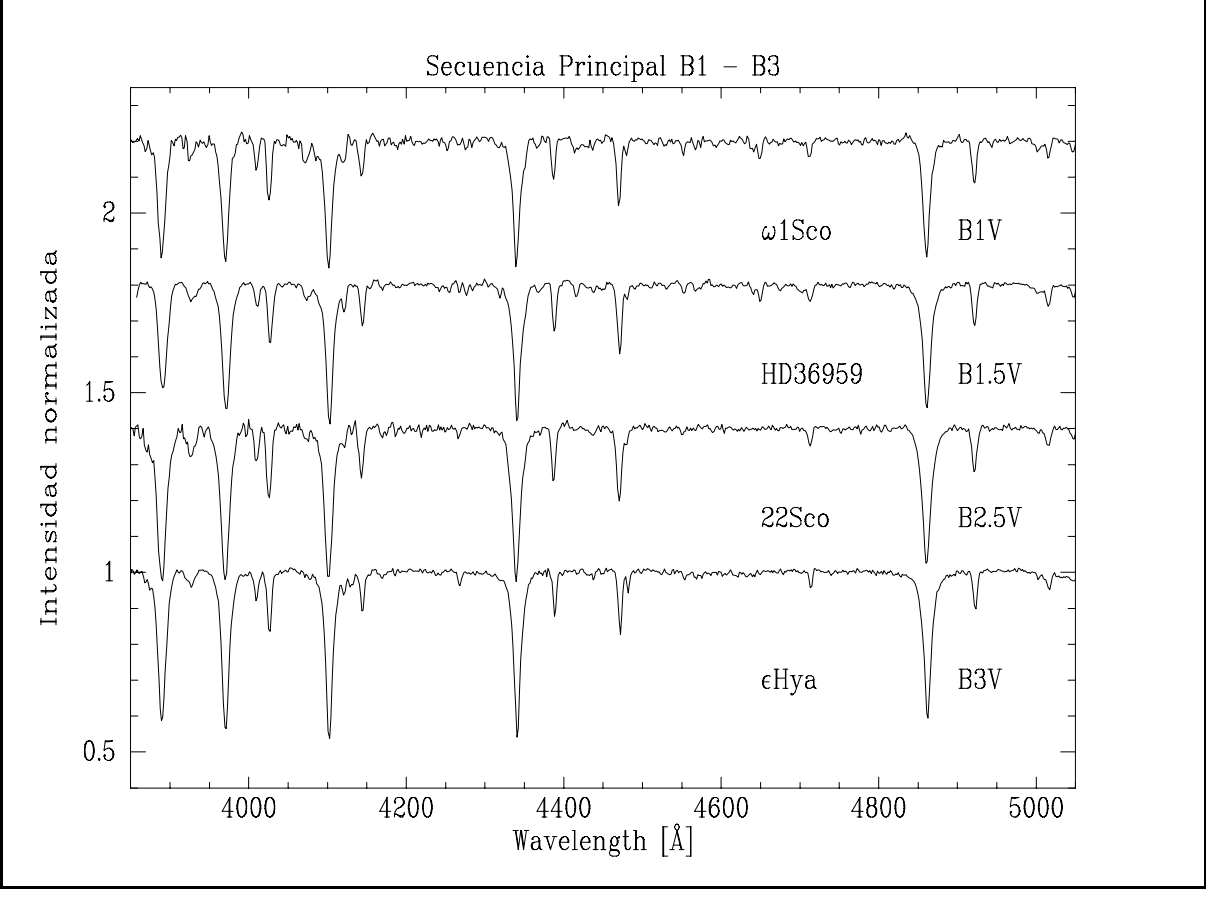

Figura 86: Idem Figura 76 para estrellas de secuencia principal con tipos espectrales de B1 a B3

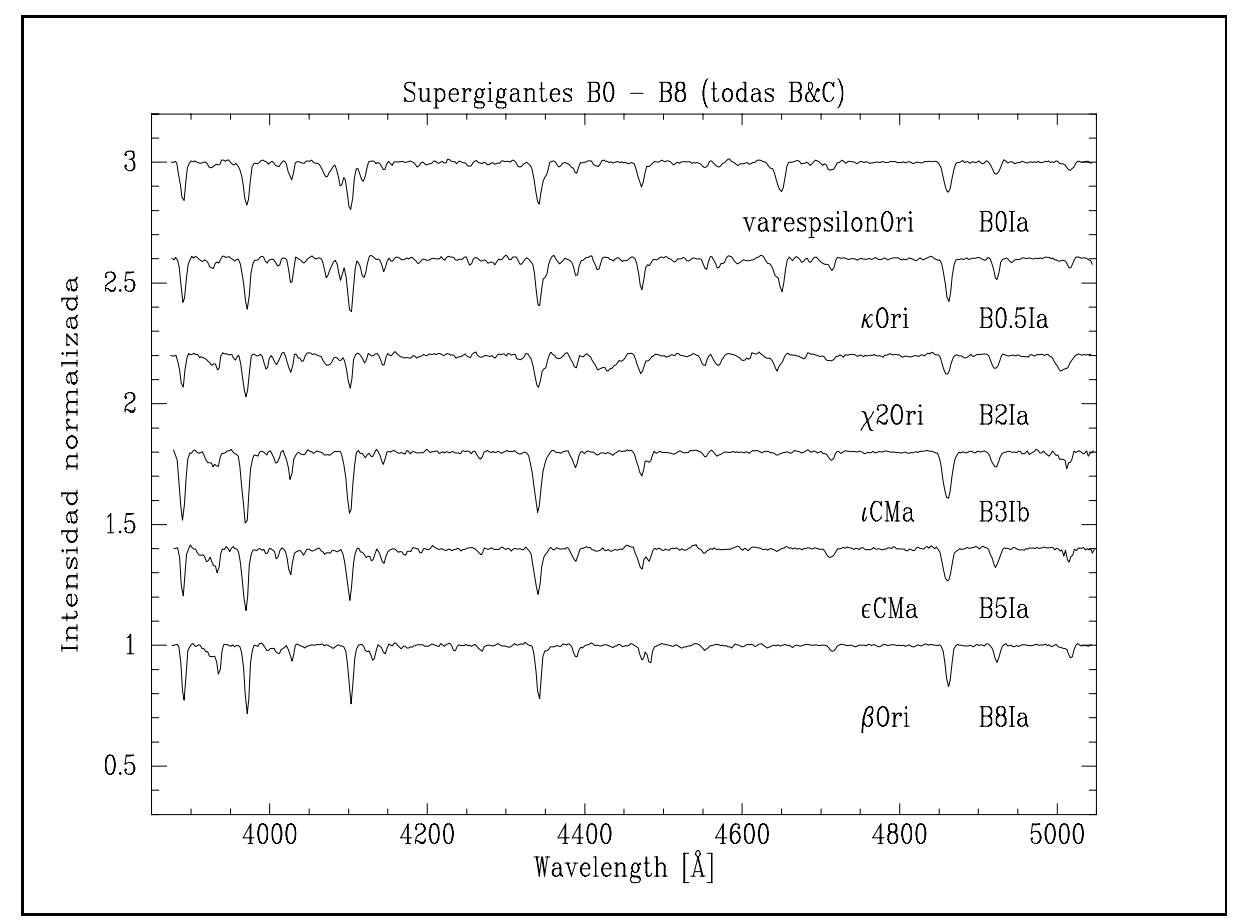

Figura 87: Idem 80. Los espectros corresponden a supergigantes de B0 a B8 


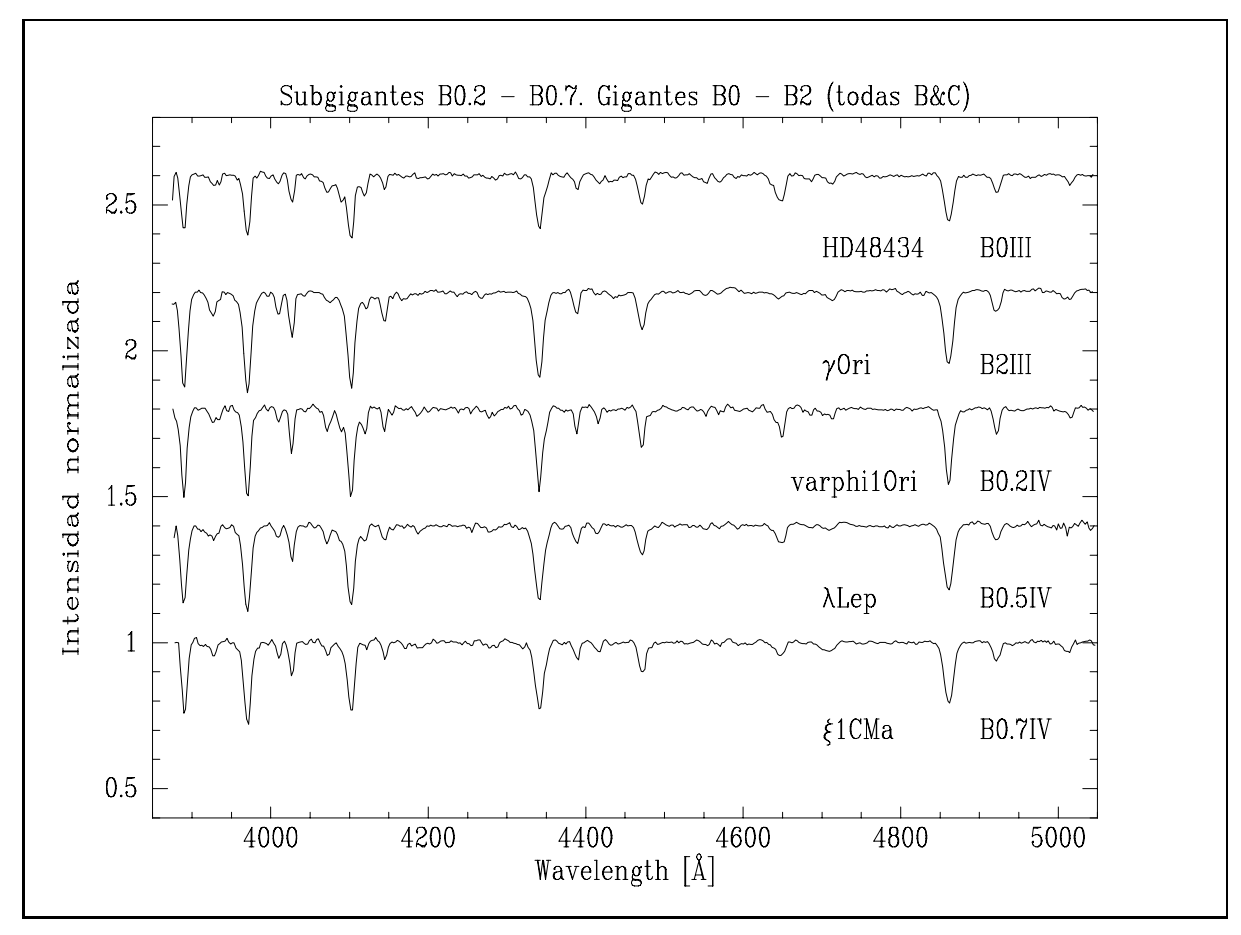

Figura 88: Idem 80. Los espectros corresponden a subgigantes de B0.2 a B0.7 y gigantes de BO $а$ B $B 2$

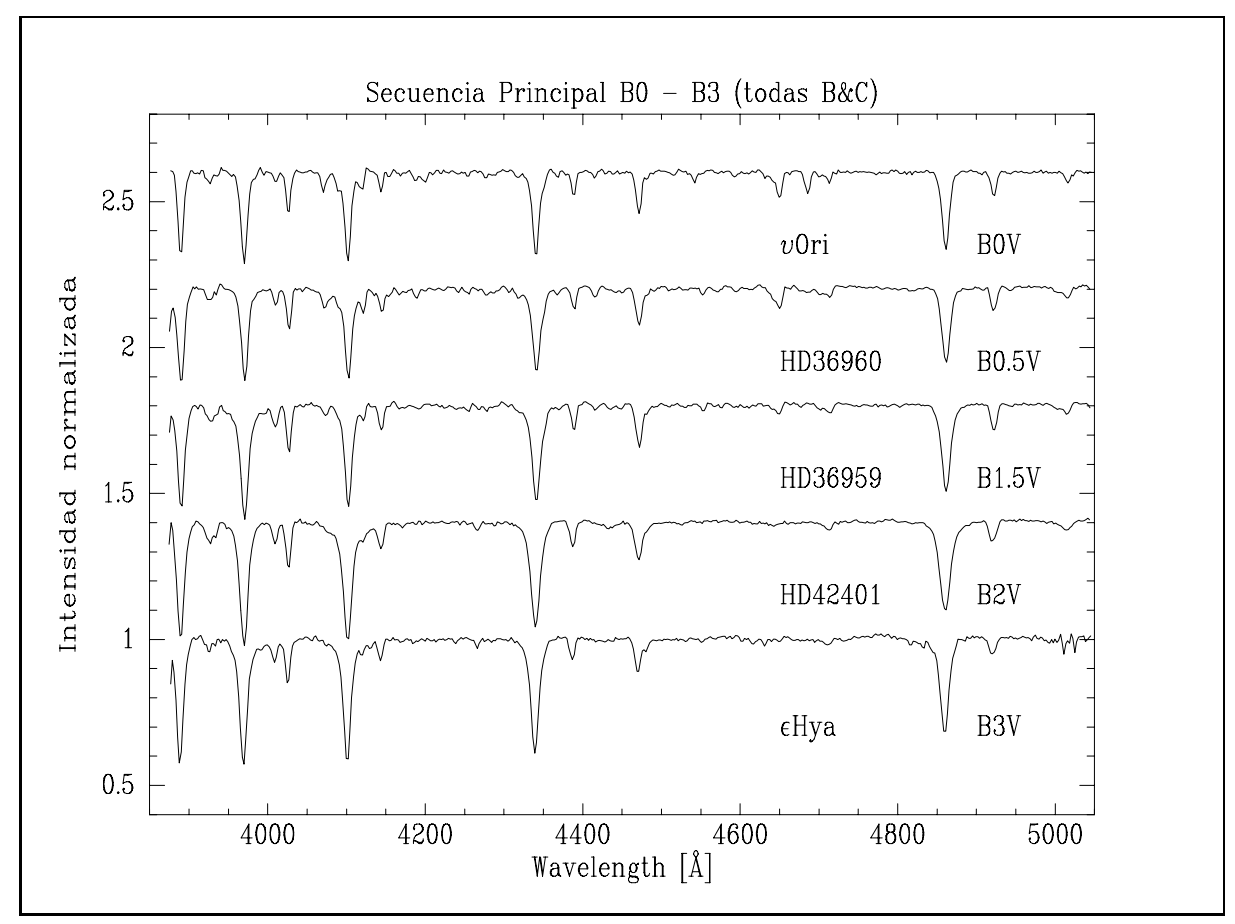

Figura 89: Idem 80. Los espectros corresponden a estrellas de secuencia principal de B0 a B3 
espectrales cuantitativamente.

Los principales elementos vistos en las estrellas TE A son las líneas de FeI y FeII, CrI y CrII y TiI y TiII, las cuales constituyen aproximadamente $2 / 3$ de todas las líneas. El número de líneas visibles crece rápidamente hacia las estrellas TE $\mathrm{F}$ y por esta razón todas las líneas se ven algo mezcladas. De este modo, resulta importante especificar el factor de placa. Una línea que a $2 \AA$ $\mathrm{mm}^{-1}$ está aislada de su vecina, a $20 \AA \mathrm{mm}^{-1}$ es una mezcla de varias líneas y a $100 \AA \mathrm{mm}^{-1}$ una mezcla de aún más líneas.

El sistema MK subdivide a las estrellas de tipo A en 10 subclases de tipos espectrales, ya que las mismas pueden ser clasificadas por luminosidad. Razones entre las intensidades de las líneas del mismo elemento neutro e ionizado o este cociente entre elementos similares, son usados exclusivamente como indicadores de luminosidad. Debido a que las líneas de hidrógeno aún son, por lejos, las líneas más intensas del espectro, es tentador usar sus perfiles para criterios de clasificación en luminosidad. Aunque es cierto, en general (en el sentido de que las supergigantes tienen sus alas menos marcadas que las enanas), uno debe recordar que las estrellas enanas con baja velocidad de rotación también producen líneas de hidrógeno con perfiles delgados.

Los criterios de luminosidad en las estrellas de tipo espectral A son: Morgan, Abt y Tapscott (1978), $125 \AA \mathrm{mm}^{-1}$ : A0 los perfiles de las líneas de hidrógeno; A2 (FeI,II) $\lambda 4383-85 /(\mathrm{MgII}) \lambda 4481$; A5 (FeII,TiII) $\lambda 4471 /$ (MgII) $\lambda 4481$. La mezcla en estas últimas es más intensa a más alta luminosidad.

Yamashita, Nariai y Norimato (1977), $73 \AA \mathrm{mm}^{-1}$ : A2-A3-A5 (FeII, TiII) $\lambda 4417 /(\mathrm{MgII}) \lambda 4481$ más grande a luminosidad más alta; A7-F0 (SrII) $\lambda 4215 /(\mathrm{CaI}) \lambda 4226$ más grande a luminosidad más alta.

Landi, Jaschek y Jaschek (1977), $42 \AA \mathrm{mm}^{-1}$ : A0-A2 intensificación de FeII $\lambda 4173-78, \lambda 4233$ a alta luminosidad; A3 FeII $\lambda 4416 / \mathrm{MgII} \lambda 4481$ más grande a alta luminosidad; A5-7 FeII $\lambda 4351 / \mathrm{MgII}$ $\lambda 4481$ más grande a alta luminosidad; A7-F0 SrII $\lambda 4215 / \mathrm{CaI} \lambda 4226$ más grande a alta luminosidad.

\section{Estrellas de tipo espectral $\mathbf{F}$}

De acuerdo al sistema de clasificación de Harvard una estrella tipo espectral F está caracterizada por las intensas líneas de $\mathrm{CaII}(\mathrm{K}$ y H) , las cuales se tornan más intensas que las líneas de hidrógeno de la serie de Balmer. Ambos perfiles son acompañados por una multitud de líneas metálicas débiles. En el TE F0, como se mencionó previamente, la intensidad de la línea K del CaII coincide con la intensidad de la línea formada por la mezcla de $\mathrm{H}$ y $\mathrm{H} \epsilon$, es decir $\mathrm{I}(\mathrm{K})=\mathrm{I}(\mathrm{H}+\mathrm{H} \epsilon)$; en 
el TE G0, I(K) 》 I(H). En $100 \AA \mathrm{mm}^{-1}$ las líneas de Balmer en las estrellas de TE F, no son tan intensas como si lo son en los TE A. Otro perfil que aparece en esta dispersión es la banda G (cerca de $\lambda 4300$ ), la cual se origina debido a la molécula $\mathrm{CH}$; este perfil aparece en F3 y se intensifica hacia los subtipos más tardíos. El mismo está constituido por la cabeza de una banda molecular y tiende a disolverse cuando se observa con placas cuyos factores son más bajos. Además de las líneas intensas existe un gran número de líneas débiles.

El tipo espectral se obtiene de las razones de intensidad involucrando perfiles de intensidad media, en su mayor parte de los elementos neutros. Es necesario prestar atención a dos factores. El primero es que debido al gran número de líneas que se presentan en las imágenes espectrales de estas estrellas, cualquier perfil es una mezcla de varias líneas, excepto en factores de placa muy pequeños. El segundo está muy relacionado con el primero y es que todos los criterios dependen del factor de placa con el que se esté trabajando y por lo tanto no pueden ser aplicados a diferentes factores de placa sin tomar las debidas precauciones. Considerar por ejemplo la banda G del CH. Esta banda se ve bien como tal a $240 \AA \mathrm{mm}^{-1}$ en aproximadamente F3 y a $100 \AA$ $\mathrm{mm}^{-1}$ en aproximadamente F5, considerando que a $20 \AA \mathrm{mm}^{-1}$ ésta se disuelve en líneas separadas.

El sistema de Yerkes usa las razones de líneas dadas en la Tabla 45, las cuales crecen hacia subtipos espectrales $\mathrm{F}$ más tardíos. Los mismos criterios son usados a $73 \AA \mathrm{mm}^{-1}$ (Yamashita, Nariai \& Norimato, 1977); a $40 \AA \mathrm{mm}^{-1}$ (Landi, Jaschek \& Jaschek, 1977) debe agregarsele (CaI) $\lambda 4226 /(\mathrm{MgII}) \lambda 4481$. La banda $\mathrm{G}$ como se mencionó antes se torna visible en aproximadamente F5 en las enanas y sólamente en G0 en las supergigantes.

Además de los tipos espectrales, también son observados los tipos de luminosidad. Las razones de las líneas usadas en el sistema de Yerkes son resumidas en la Tabla 46. Las mismas adquieren mayor valor para estrellas con mayor luminosidad. En la Tabla 46 se observa que en tres criterios de luminosidad se emplea la línea SrII, la cual tiene un efecto luminoso positivo pronunciado (es decir, el perfil se torna más intenso hacia luminosidades más altas). A los criterios de la tabla se le agregan algunos otros como ser: razones de las líneas de FeI y también FeII, CrII o Ti II. A 73 $\AA \mathrm{mm}^{-1}$ Yamashita et al., (1977) usan por ejemplo las razones (FeII) $\lambda 4179 /(\mathrm{FeI}) \lambda 4144,(\mathrm{SrII})$ $\lambda 4216 /(\mathrm{CaI}) \lambda 4226$ y (BaII) $\lambda 4554 /(\mathrm{MgII}) \lambda 4481$, las cuales muestran un efecto luminoso positivo.

Las líneas de Balmer varian levemente con la luminosidad, mientras que las líneas de CaII muestran un efecto de luminosidad positivo. Sin embargo ambos perfiles no son completamente útiles para la clasificación porque ellos son muy intensos. También el salto de Balmer pierde su utilidad con el progresivo debilitamiento de las líneas de Balmer y la progresiva intensidad de las líneas metálicas superimpuestas. 
Tabla 45: Criterios de clasificación espectral para las estrellas de tipo F. Los cocientes de líneas crecen para subtipos espectrales $\mathrm{F}$ más tardíos.

\begin{tabular}{ll}
\hline \hline$\frac{\lambda 4045 \mathrm{FeI}}{\lambda 4101 \mathrm{H} \delta}$ & $\frac{\lambda \lambda 4030-34 \mathrm{MnI}}{\lambda \lambda 4128-32 \mathrm{SiII}}$ \\
$\frac{\lambda 44226 \mathrm{CaI}}{\lambda 4340 \mathrm{H} \gamma}$ & $\frac{\lambda 4300 \mathrm{CH}}{\lambda 4385 \mathrm{FeI}}$ \\
\hline \hline
\end{tabular}

Tabla 46: Criterios de luminosidad para las estrellas de tipo espectral F. Los cocientes de líneas crecen para estrellas más luminosas.

\begin{tabular}{ll}
\hline \hline$\frac{\lambda 4444 \mathrm{TiII}}{\lambda 4481 \mathrm{MgII}}$ & $\frac{\lambda 4071 \mathrm{FeI}}{\lambda 4077 \mathrm{SrII}}$ \\
$\frac{\lambda 4077 \mathrm{SrII}}{\lambda 4045 \mathrm{FeI}}$ & $\frac{\lambda 4077 \mathrm{SrII}}{\lambda 4100 \mathrm{HI}}$ \\
\hline
\end{tabular}

\section{Estrellas de tipo espectral G}

Estas estrellas se carazterizan por tener líneas de $\mathrm{H}$ débiles, las cuales se tornan comparables en intensidad a las líneas de algunos metales. Las líneas metálicas se incrementan en intensidad y número hacia las subdivisiones espectrales más tardías y las bandas moleculares de $\mathrm{CH}$ y $\mathrm{CN}$ se tornan perfiles claramente visibles.

Los tipos espectrales quedan determinados por la comparación de las líneas de hidrógeno y las metálicas, como ser FeI $\lambda 4144$ y $\mathrm{H} \delta$; ellas son aproximadamente igual de intensas en el TE G8 cuando se trabaja en $80 \AA \mathrm{mm}^{-1}$. En lugar de estos pares de líneas, también deben usarse (FeI) $\lambda 4045 /(\mathrm{H} \delta) \lambda 4101$ o (FeI) $\lambda 4384 /(\mathrm{H} \gamma) \lambda 4340$ y $\lambda 4921 /(\mathrm{H} \beta) \lambda 4861$. Para los tipos mas tardíos que G5 la línea de CaI $\lambda 4226$ se torna sensible a la temperatura y puede ser usada para la determinación del tipo espectral mediante la relación (CaI) $\lambda 4226 /(\mathrm{H} \delta) \lambda 4101$.

En caso de sospechar la presencia de alguna composición anómala, la razón hidrógeno-metal debe reemplazarse por (CrI) $\lambda 4254 /(\mathrm{FeI}) \lambda 4250$ y (CrI) $\lambda 4274 /$ (FeI) $\lambda 4271$ (Keenan \& McNeil, 1976). Si por ejemplo, la estrella tiene líneas metálicas débiles la razón entre líneas de H y metálicas darán para la estrella un tipo espectral más temprano, solamente la razón de dos pefiles metálicos pueden proporcionar el TE correcto. Para estrellas débiles en metales esto puede proporcionar un corrimiento de varias decenas del tipo espectral.

Los efectos de luminosidad en las estrellas tipo G son claramente visibles, a baja dispersión, en las bandas de CN. Lindblad (1922) usó la banda a $\lambda 4180$ y midió la depresión producida por ésta sobre el pseudo-continuo; tipicamente la diferencia entre gigantes y enanas es del orden del 10-20\%. A más altas dispersiones, la banda CN es menos útil debido a que tiende a disolverse. 
Por esta razón, en el sistema de Yerkes, Keenan \& McNeil (1976) usan exclusivamente las razones de líneas, aunque en realidad seria más correcto decir la razón de perfiles. Por ejemplo, la línea Sr a $\lambda 4215$ está mezclada con Fe, entonces deberiamos hablar del perfil (SrII,Fe) $\lambda 4216$. El perfil es sensitivo en luminosidad si se considera la razón ( $\mathrm{SrII}, \mathrm{Fe}) \lambda 4216 /(\mathrm{CaI}) \lambda 4226$. Similarmente pueden ser usados (SrII) $\lambda 4077 /(\mathrm{FeI}) \lambda 4063$ y $\lambda 4071$. Para supergigantes deben usarse (YII,Fe) $\lambda 4376 /$ (FeI) $\lambda 4383$ o la mezcla $\lambda \lambda 4172+78 / \mathrm{H} \delta$. Otros criterios son (YII) $\lambda 3983 /(\mathrm{FeI}) \lambda 4005$, (SrII) $\lambda 4077 /(\mathrm{H} \delta) \lambda 4101$ у (SrII) $\lambda 4216 /(\mathrm{FeI}) \lambda 4144$.

Tabla 47: Datos espectrofotométricos de las 39 estrellas con TEs A, F, G y clases de luminosidad V, IV, III y I observadas en la visual a la región de Bochum 7

\begin{tabular}{|c|c|c|c|c|c|c|}
\hline \hline ID & $\begin{array}{c}\text { Fecha Juliana } \\
(2450000+)\end{array}$ & V & B-V & U-B & TE & Otras ID \\
\hline CBN84521.2-455454 & 1557.687 & 08.6 & -0.27 & -0.23 & F5-7V & CD-454502, CPD-452987 \\
CBN84514.0-455906 & 1557.741 & 10.6 & 0.48 & -0.05 & F7I-V & CD-454499, CPD-452982 \\
CBN84332.4-455419 & 1557.830 & 11.0 & 0.48 & -0.04 & F5-7V & CD-454452, CPD-452904 \\
CBN84433.4-460540 & 1556.817 & 11.2 & 0.14 & -0.17 & A0-2V & CPD-452493 \\
CBN84435.8-460935 & 1555.706 & 11.5 & 0.16 & -0.05 & A2V & CPD-452947 \\
CBN84524.1-454713 & 1556.681 & 11.5 & 0.34 & -0.02 & F0V & CPD-452989 \\
CBN84423.8-455509 & 1555.854 & 11.9 & 0.51 & -0.03 & F5-7V & CPD-452937 \\
CBN84331.6-460219 & 1556.782 & 12.0 & 0.49 & -0.03 & F7I-V & CPD-452905 \\
CBN84501.2-460641 & 1558.767 & 12.2 & 0.36 & -0.03 & A5-7III & \\
CBN84435.2-461058 & 1928.722 & 12.2 & 0.45 & -0.06 & F5-9V & \\
CBN84548.7-460047 & 1946.625 & 12.2 & 0.20 & -0.13 & A2V & \\
CBN84332.3-454526 & 1946.840 & 12.3 & 0.41 & -0.02 & A2V & \\
CBN84455.8-461004 & 1926.756 & 12.3 & 0.20 & -0.03 & A0-2V & CPD-452967 \\
CBN84511.4-460737 & 1945.660 & 12.4 & 0.40 & -0.06 & F5-7V & \\
CBN84320.5-460730 & 1560.764 & 12.4 & 0.46 & -0.07 & F5V & \\
CBN84434.2-455213 & 1559.730 & 12.5 & 0.23 & -0.30 & A0-2V & \\
CBN84340.9-454703 & 1946.866 & 12.5 & 0.50 & -0.03 & F5V & \\
CBN84417.3-454637 & 1559.714 & 12.6 & 0.56 & -0.02 & F0III-IV & \\
CBN84314.7-455637 & 1561.727 & 12.7 & 0.39 & -0.02 & F7I-V & \\
CBN84454.9-460809 & 1561.786 & 12.7 & 0.39 & -0.03 & F7I-V & \\
CBN84453.4-460824 & 1561.786 & 12.7 & 0.42 & -0.06 & F5V & \\
CBN84521.8-461002 & 1944.710 & 12.7 & 0.18 & -0.20 & A2V & \\
\hline
\end{tabular}

continua 
Tabla 47: (continuación)

\begin{tabular}{|c|c|c|c|c|c|c|}
\hline ID & $\begin{array}{c}\text { Fecha Juliana } \\
(2450000+)\end{array}$ & $\overline{\mathrm{V}}$ & $\mathrm{B}-\mathrm{V}$ & U-B & $\mathrm{TE}$ & Otras ID \\
\hline CBN84519.6-455510 & 1926.808 & 12.8 & 0.26 & -0.09 & $\mathrm{~A} 0-2 \mathrm{~V}$ & \\
\hline CBN84446.0-455404 & 1559.756 & 12.9 & 0.28 & -0.22 & $\mathrm{~A} 2 \mathrm{~V}$ & \\
\hline CBN84328.4-460218 & 1559.832 & 12.9 & 0.41 & -0.04 & F5-9V & \\
\hline CBN84320.8-460213 & 1559.832 & 12.9 & 0.40 & -0.03 & $\mathrm{~A} 2 \mathrm{~V}$ & \\
\hline CBN84431.8-455813 & 1558.811 & 13.0 & 0.26 & -0.26 & $\mathrm{~A} 0-2 \mathrm{~V}$ & \\
\hline CBN84419.1-455906 & 1559.809 & 13.0 & 0.26 & -0.08 & $\mathrm{~A} 2 \mathrm{~V}$ & \\
\hline CBN84334.5-455819 & 1559.858 & 13.1 & 0.52 & -0.01 & F5-7V & \\
\hline CBN84416.0-454734 & 1559.695 & 13.3 & 0.48 & -0.04 & $\mathrm{~A} 0 \mathrm{~V}$ & \\
\hline CBN84522.4-455421 & 1561.833 & 13.5 & 0.60 & -0.03 & G3I-V & \\
\hline CBN84434.4-461059 & 1928.722 & 13.5 & 0.55 & -0.13 & F3V & \\
\hline CBN84526.8-460622 & 1561.802 & 13.7 & 0.36 & -0.06 & F5V & \\
\hline CBN84447.4-454540 & 1558.847 & 13.8 & 0.49 & -0.06 & $\mathrm{~A} 0-2 \mathrm{~V}$ & \\
\hline CBN84352.5-460751 & 1561.757 & 14.2 & 0.66 & -0.01 & F7I & \\
\hline CBN84417.0-455416 & 1561.678 & 14.2 & 0.39 & -0.01 & $\mathrm{~A} 0 \mathrm{~V}$ & \\
\hline CBN84341.2-460235 & 1561.739 & 14.4 & 0.74 & -0.06 & G0III & \\
\hline CBN84503.2-455127 & 1559.781 & 14.5 & 0.65 & -0.06 & F5V & \\
\hline CBN84434.4-455835 & 1558.811 & 14.8 & 0.50 & -0.11 & F5V & \\
\hline
\end{tabular}

\subsection{Sistema Binario: LS 1135}

El trabajo efectuado con el sistema binario LS 1135 ha sido publicado en la revista internacional

"Astronomy \& Astrophysics" en abril del año 2003. El título del mismo ha sido: "LS 1135: and OType Spectroscopic Binary in the galactic OB association Bochum 7"y sus autores: Mariela Corti, Virpi Niemela \& Nidia Morrell. A continuación se presenta la versión en castellano del mismo.

\section{Resumen}

De las velocidades radiales obtenidas de las observaciones espectroscópicas hechas en el Observatorio Internacional de Cerro Tololo (CTIO) en Chile y el Complejo Astronómico El Leoncito (CASLEO) en Argentina, nosotros hemos descubierto que LS 1135 es un sistema binario a un espectro de tipo espectral $\mathrm{O}$ con un período orbital de 2.7532 días. Presentamos un análisis de los 


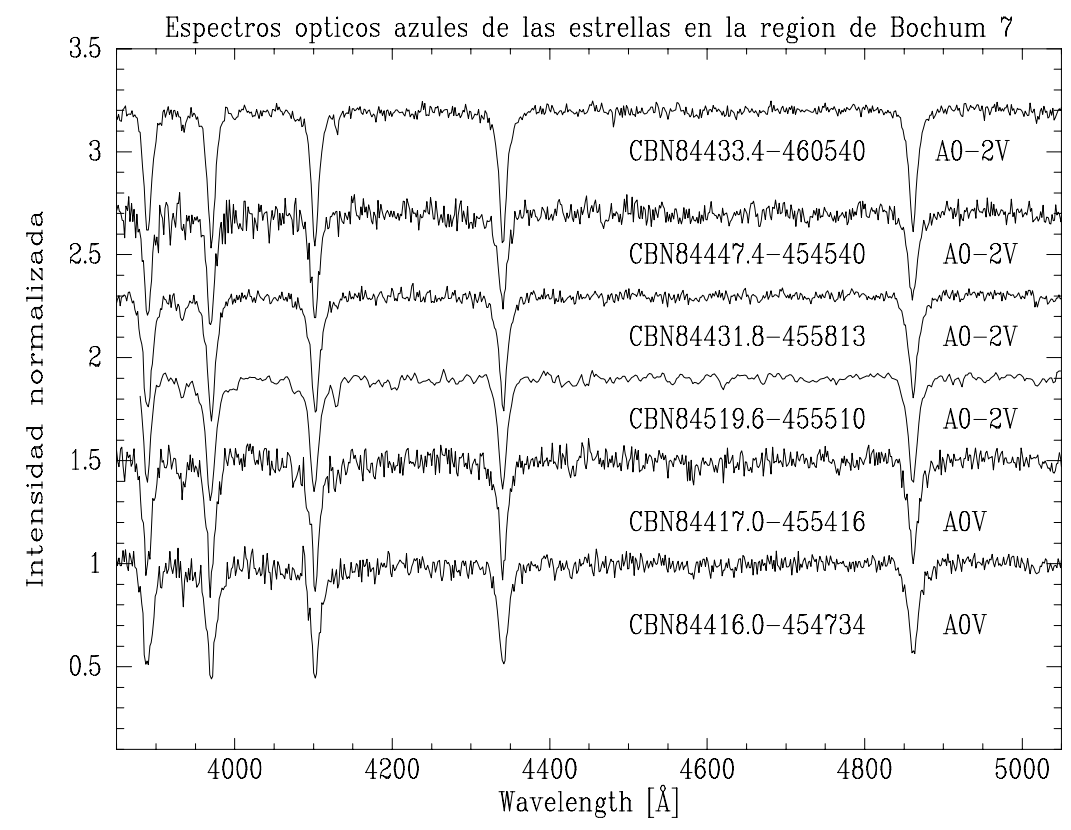

Figura 90: Espectros ópticos azules de las estrellas con tipos espectrales A0-2V y AOV. Todas ellas observadas en el CASLEO en los turnos que se describen en la sección 5.2

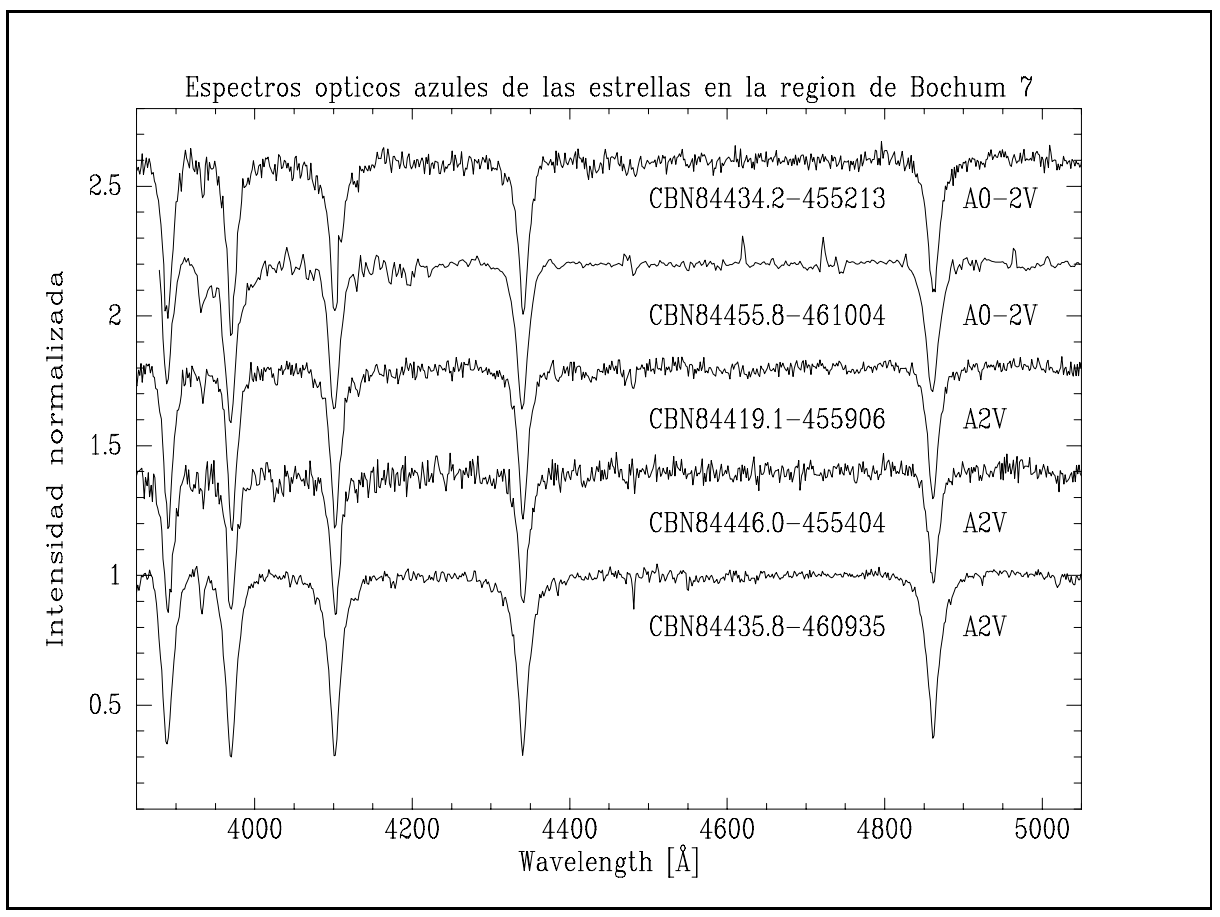

Figura 91: Espectros ópticos azules de las estrellas con tipos espectrales A0-2V y A2V. Todas ellas observadas en el CASLEO en los turnos que se describen en la sección 5.2 


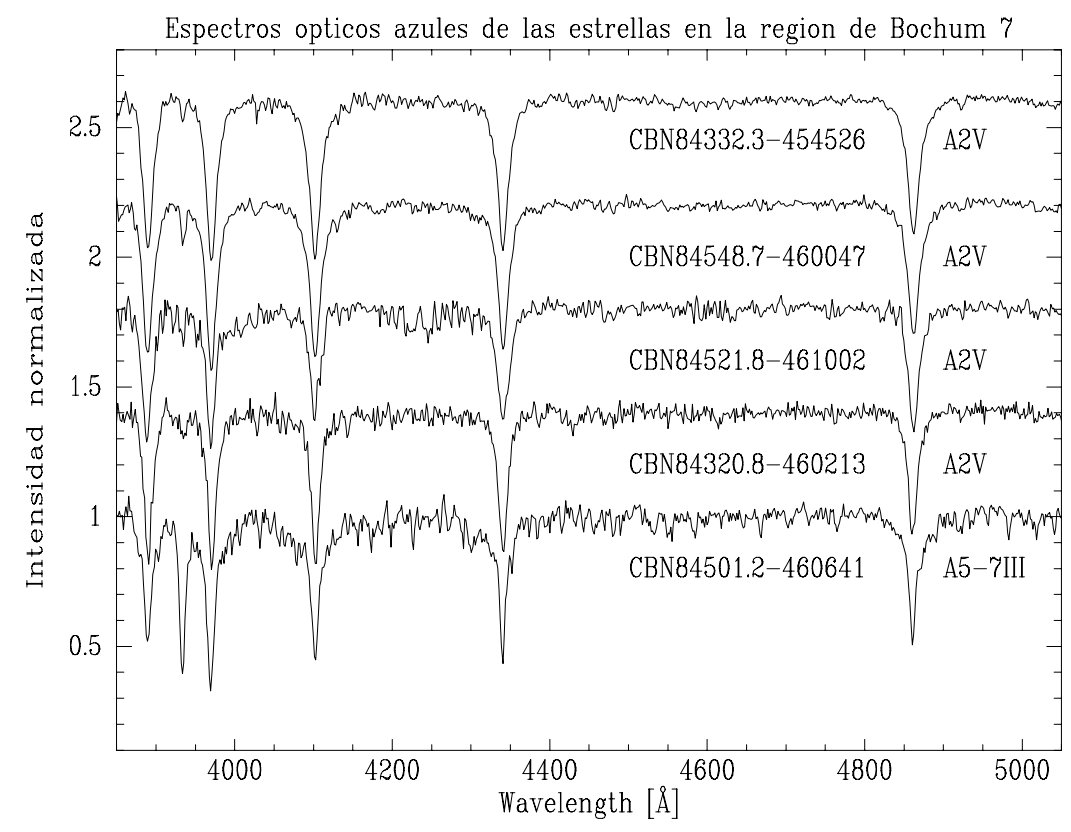

Figura 92: Espectros ópticos azules de las estrellas con tipos espectrales A2V y A5-7III. Todas ellas observadas en el CASLEO en los turnos que se describen en la sección 5.2

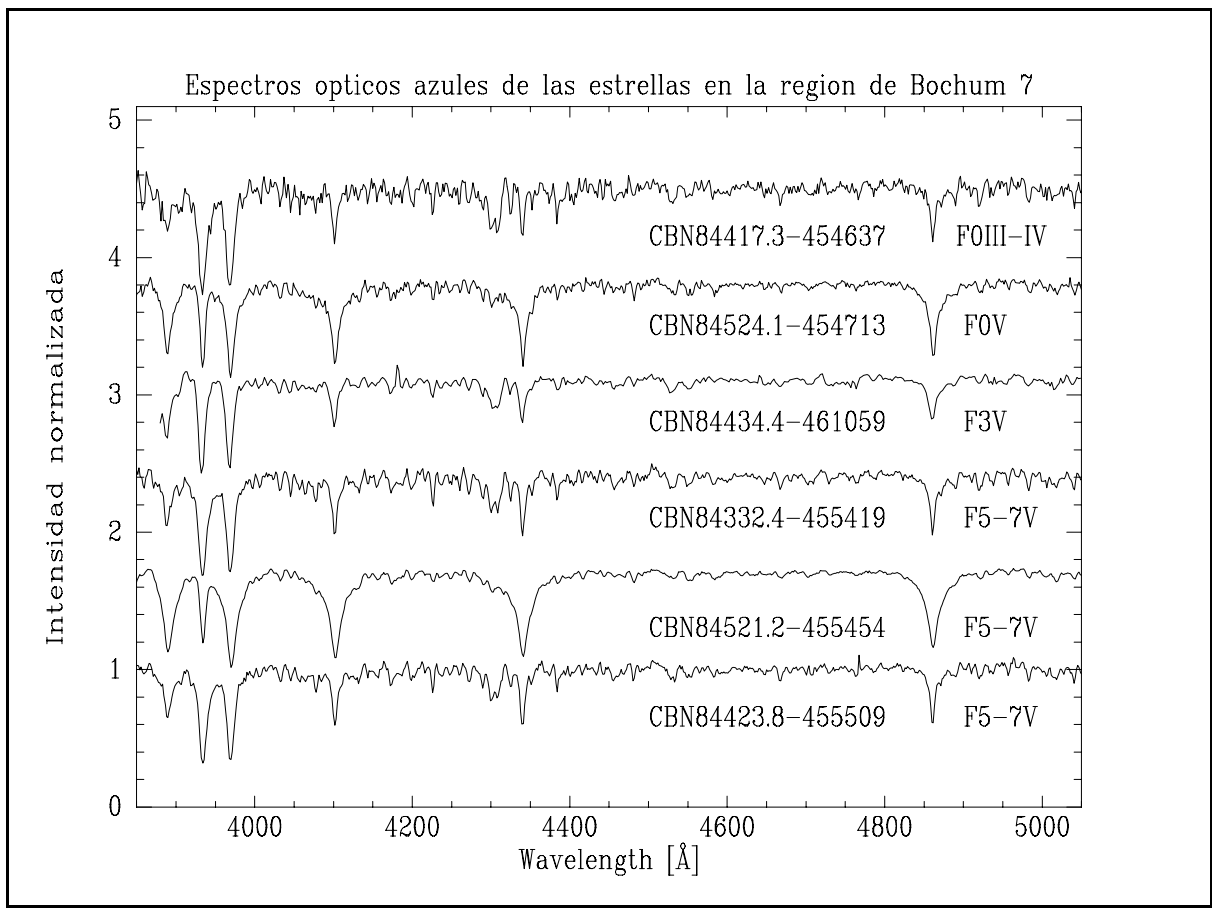

Figura 93: Espectros ópticos azules de las estrellas con tipos espectrales F0III-IV, F0V, F3V y F5-7V. Todas ellas observadas en el CASLEO en los turnos que se describen en la sección 5.2 


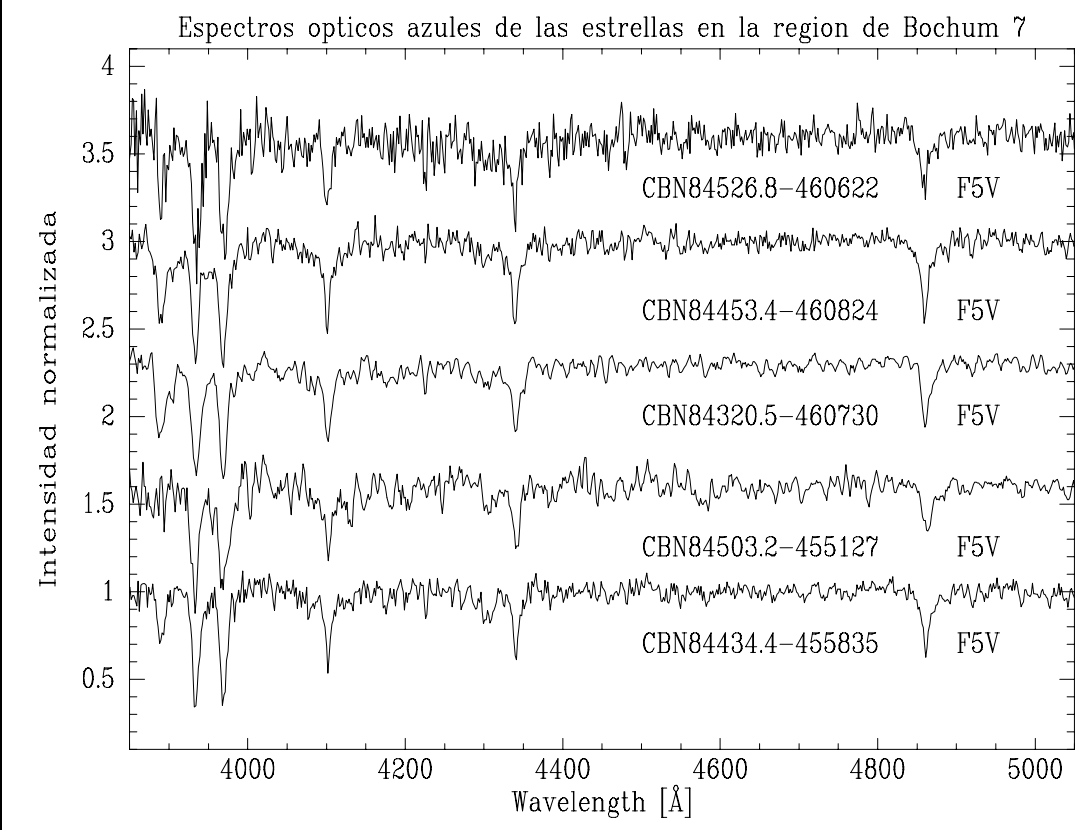

Figura 94: Espectros ópticos azules de las estrellas con tipos espectrales F5V. Todas ellas observadas en el CASLEO en los turnos que se describen en la sección 5.2

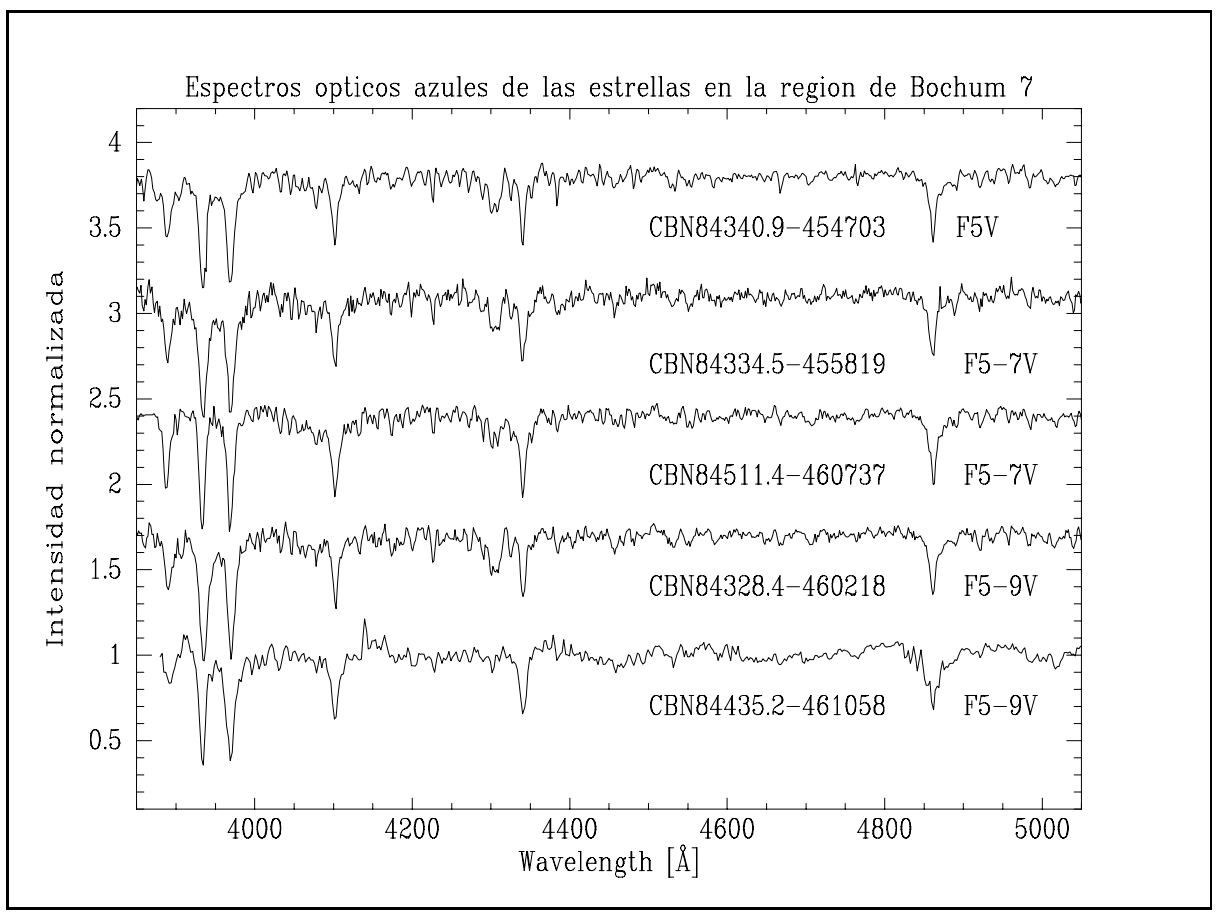

Figura 95: Espectros ópticos azules de las estrellas con tipos espectrales F5V, F5-7V y F5-9V. Todas ellas observadas en el CASLEO en los turnos que se describen en la sección 5.2 


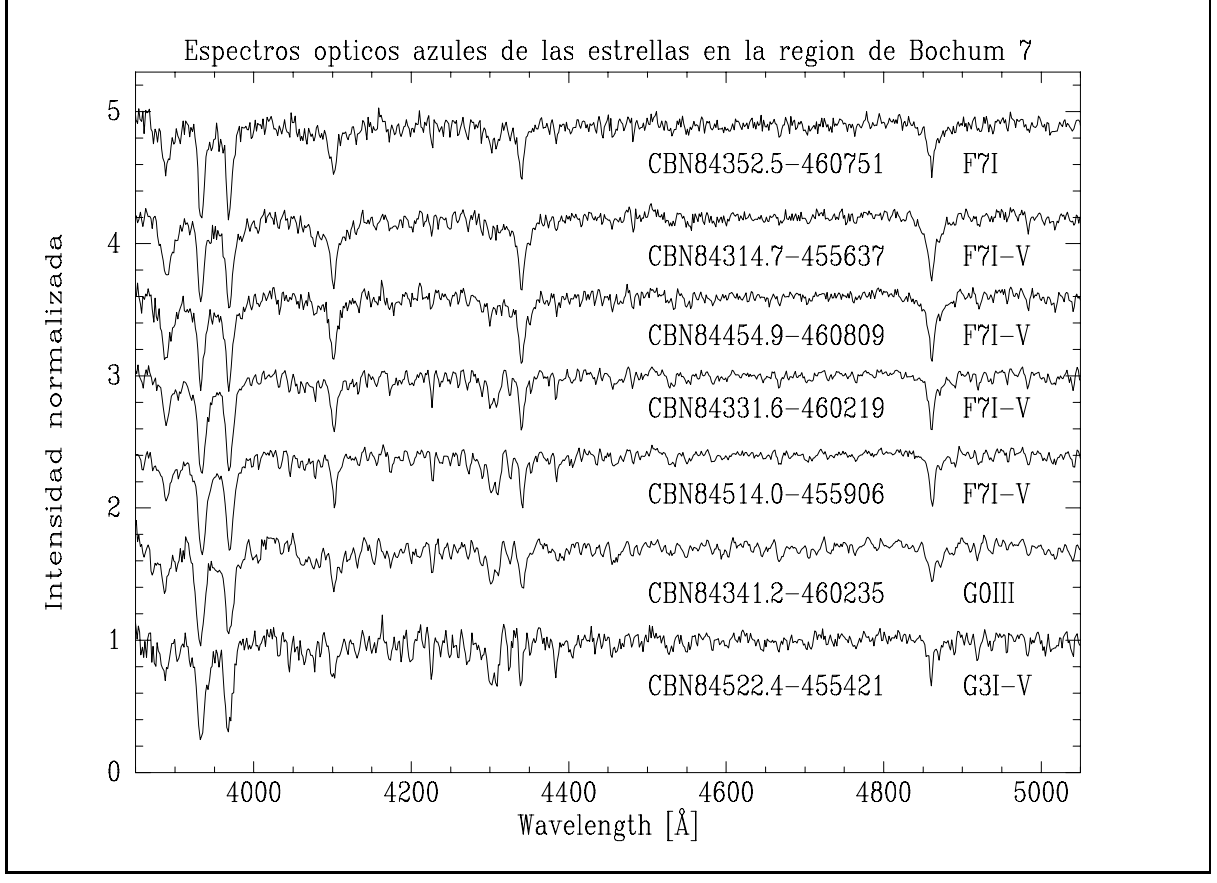

Figura 96: Espectros ópticos azules de las estrellas con tipos espectrales F7I, F7I-V, G0III y G3I-V. Todas ellas observadas en el CASLEO en los turnos que se describen en la sección 5.2

elementos orbitales de este sistema basado en las velocidades radiales de las líneas de absorción del He. Clasificamos al espectro de LS 1135 como O6.5V((f)). Presentamos también la clasificación espectral y velocidades radiales de las otras siete estrellas OB en la región de Bochum 7 en la cual se encuentra LS 1135. Nuestros datos indican que este grupo estelar tendría una distancia de $5.0 \mathrm{kpc}$.

\section{Introducción}

En el Catálogo de Luminous Stars in The Southern Milky Way (LS) (Stephenson \& Sanduleak), a la estrella LS $1135\left(\alpha_{2000}=8^{h} 43^{m} 46^{s}\right.$ y $\left.\delta_{2000}=-46^{\circ} 07^{\prime} 14^{\prime \prime}\right)$ le fue asignado un tipo espectral OB y una magnitud fotográfica $\mathrm{m}_{p g}=11.2$. De la fotometría fotoeléctrica, Moffat \& Vogt (1975) propusieron que LS 1135 junto con la estrella Wolf-Rayet LS 1145 y otras 7 estrellas OB presentadas en el catálogo LS, forman una asociación $\mathrm{OB}$ con coordenadas galácticas $1=265^{\circ} .20 ; \mathrm{b}=$ $-2^{\circ}$.1. Ellos llamaron Bochum 7 (Bo 7) a este grupo estelar.

Recientemente, Sung et al. (1999) analizando fotometría CCD UBVI de la región de Bo 7 han sugerido que Bo 7 es parte de la gran asociación OB Vela OB3.

En este paper presentamos datos espectroscópicos de LS 1135, los cuales muestran que esta estrella es un sistema binario cerrado. También presentamos tipos espectrales y velocidades radiales 
Tabla 48: Configuración instrumental usada

\begin{tabular}{|cllllcccc|}
\hline Nr. & Observ. & Epoca(s) & Telesc. & Espectróg. & $\begin{array}{c}\text { Disp.recip. } \\
\left(\AA \mathrm{mm}^{-1}\right)\end{array}$ & $\begin{array}{c}\Delta \lambda \\
(\AA)\end{array}$ & S/N \\
\hline I & CASLEO & $03 / 97-05 / 99$ & $2.1-\mathrm{m}$ & B\&C & 115 & $3800-5000$ & $120-200$ \\
II & CTIO & $02 / 82-03 / 85$ & $1-\mathrm{m}$ & CITS & 45 & $3700-4900$ & $30-60$ \\
III & CASLEO & $02 / 97-02 / 98$ & $2.1-\mathrm{m}$ & REOSC & 7 & $3700-6000$ & $20-50$ \\
\hline
\end{tabular}

para las otras 7 estrellas OB incluidas por Moffat \& Vogt (1975) en Bo 7, denominadas LS 1131, $1132,1137,1140,1144,1146$ y 1147.

El paper está organizado de la siguiente manera: en la Sección 2 describimos las observaciones. En la Sección 3 discutimos los resultados y presentamos velocidades radiales y clasificación espectral para estrellas en Bo 7 y los parámetros orbitales para LS 1135. En la Sección 4 resumimos nuestros resultados principales.

\section{Observaciones}

El material observacional consistió de 21 espectros fotográficos y 29 espectros CCD digitales de LS 1135. Obtuvimos también 13 espectros fotográficos y digitales de las otras estrellas propuestas por Moffat \& Vogt (1975) como miembros de Bo 7. Las configuraciones instrumentales usadas están detalladas en la Tabla 48.

\subsection{Espectros fotográficos}

Todos los espectros fotográficos fueron obtenidos por VSN entre Febrero 1982 y Marzo 1985, en el CTIO, Chile. Estos espectros fueron procurados con el Carnegie Image Tube Spectrograph (CITS) adosado al telescopio reflector Yale de 1 metro de diámetro. Todas las exposiciones fueron hechas sobre emulsión Kodak III a-J y ampliadas a 1mm. Como fuente de comparación se usó la lámpara de He-Ar.

Los espectros fotográficos fueron medidos por VSN con un osciloscopio microdensitómetro (GRANT) en el Instituto de Astronomía y Física del Espacio, Buenos Aires, Argentina. Esto último se realizó con el propósito de determinar las velocidades radiales. Nosotros también digitalizamos algunos espectros fotográficos con el instrumento GRANT en el Observatorio Astronómico de La Plata, Argentina.

\subsection{Espectros digitales}


Las imágenes espectrales digitales de LS 1135 fueron obtenidas entre Febrero de 1997 y 1999 , con los espectrógrafos REOSC Cassegrain echelle y Boller \& Chivens (B\&C), adosados ellos al telescopio de 2.15m del Complejo Astronómico El Leoncito (CASLEO) en San Juan, Argentina.

Con el espectrógrafo B \& C y el detector CCD PM $512 \times 512$ px con pixeles de $20 \mu \mathrm{m}$, se obtuvieron 15 espectros de LS 1135. Con el dispersor cruzado usamos una red de $400 \mathrm{l} \times \mathrm{mm}^{-1} \mathrm{y}$ empleamos un ancho de ranura que varió entre $250 \mu$ y $300 \mu$. En Febrero de 1998 se obtuvieron 10 espectros échelle de LS 1135 bineando al CCD por un factor 2.

Las imágenes de arcos de comparación observadas con el telescopio en la misma posición que la empleada para obtener las imágenes estelares, antes y después de cada exposición de ellas fueron He-Ar (o Th-Ar con el espectrógrafo REOSC). Cada noche se obtuvieron también los bias, flat-field y los espectros de las estrellas estándares de flujo y de velocidad radial.

Las velocidades radiales medidas en todos los espectros se obtuvieron con errores típicos de aproximadamente $20 \mathrm{~km} \mathrm{~s}^{-1}$ (error estándar del promedio) para las configuraciones instrumentales I y II y $15 \mathrm{~km} \mathrm{~s}^{-1}$ para la configuración instrumental III. Las velocidades radiales heliocéntricas de las líneas de absorción interestelar, que se han medido en los espectros de alta dispersión échelle de LS 1135, con sus respectivos errores estándares fueron: CaII $\mathrm{K} \lambda 3933 \AA=25 \pm 5 \mathrm{~km} \mathrm{~s}^{-1}$, CaII $\mathrm{H} \lambda 3968 \AA=24 \pm 4 \mathrm{~km} \mathrm{~s}^{-1}$, NaI $\lambda 5890 \AA=25 \pm 4 \mathrm{~km} \mathrm{~s}^{-1}$ y NaI $\lambda 5896 \AA=27 \pm 4 \mathrm{~km} \mathrm{~s}^{-1}$. En nuestros espectros sólo fue observada una componente de cada línea interestelar.

\section{Resultados y discusión}

\subsection{Tipos espectrales y velocidades radiales de las estrellas en la región de Bo 7}

Nuestros espectros fotográficos de las estrellas propuestas como miembros de Bo 7 por Moffat \& Vogt (1975) las confirman, a primera vista, como estrellas OB, debido a que sus espectros muestran líneas de absorción de $\mathrm{H}$ y de He. Inicialmente, se determinaron aproximaciones de los tipos espectrales debido a estimaciones visuales hechas en los espectros fotográficos a la relación de intensidad de las líneas de absorción. Luego, comparando los espectros digitalizados y los digitales con los espectros digitales del atlas de estrellas OB (Walborn \& Fitzpatrick, 1990). Las clasificaciones espectrales están indicadas en la Figura 97 describiendo los espectros de las estrellas observadas en la región de Bo 7.

Para la determinación de las velocidades radiales, medimos todas las líneas de absorción visibles en los espectros. Se encontró que la velocidad radial de LS 1135 variaba de una noche a la siguiente

Estudio de una Asociación $O B$ distante en la Vía Láctea $208 \quad$ Mariela A. Corti 


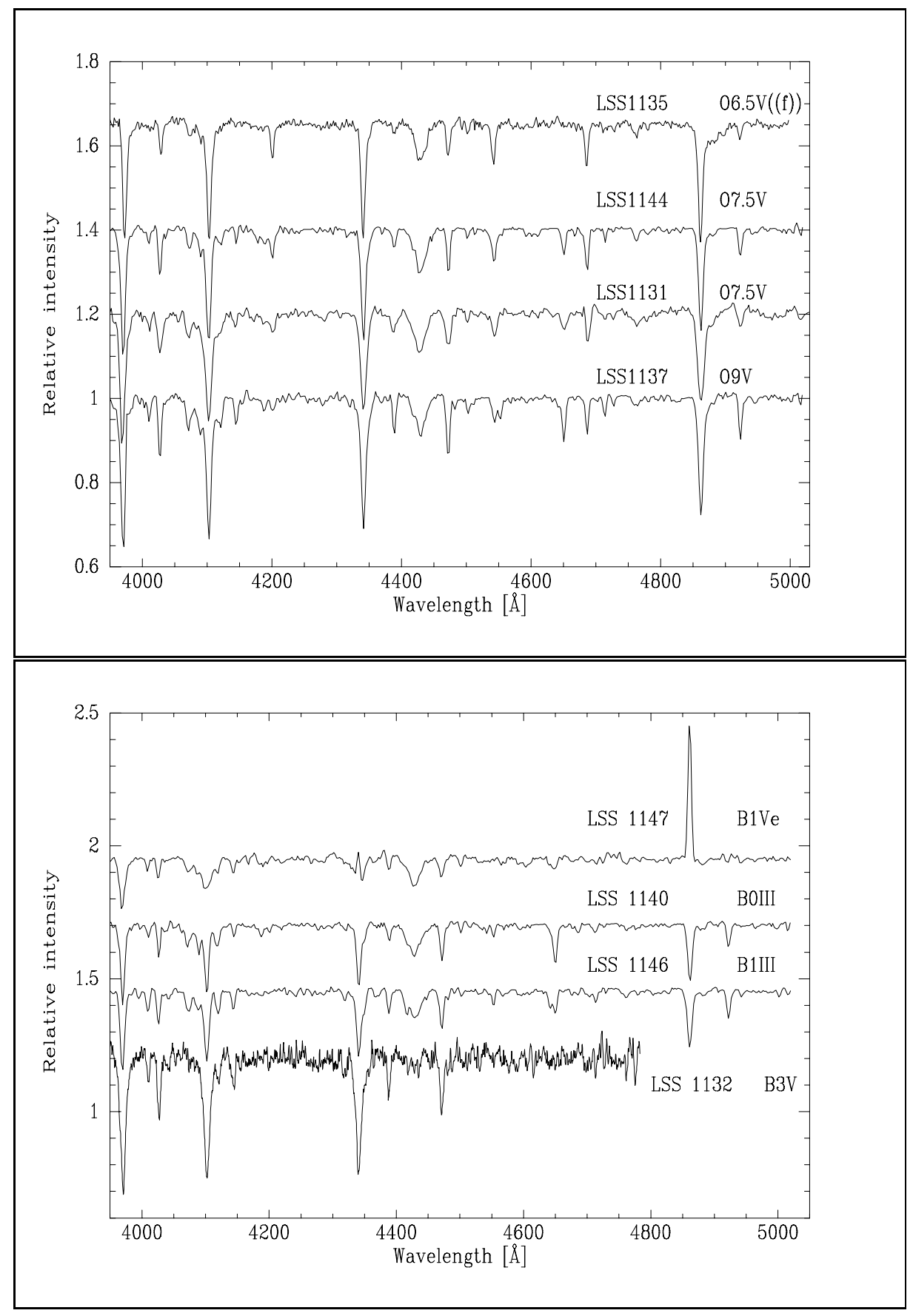

Figura 97: Espectros ópticos azules de las estrellas en la región de Bochum 7 
Tabla 49: Velocidades Radiales Heliocéntricas de estrellas en la región de Bochum 7

\begin{tabular}{|c|c|c|c|c|c|c|c|c|c|}
\hline \multirow{2}{*}{$\begin{array}{l}\text { ID } \\
\text { LS }\end{array}$} & \multirow{2}{*}{$\begin{array}{c}\text { HJD } \\
2400000+\end{array}$} & \multicolumn{3}{|c|}{ Veloc. Radial Helic. } & \multirow{2}{*}{$\begin{array}{l}\text { ID } \\
\text { LS }\end{array}$} & \multirow{2}{*}{$\begin{array}{c}\text { HJD } \\
2400000+\end{array}$} & \multicolumn{3}{|c|}{ Veloc. Radial Helic. } \\
\hline & & $\mathrm{CI}$ & $\operatorname{VR}\left(\mathrm{km} \mathrm{s}^{-1}\right)$ & $\mathrm{n}$ & & & $\mathrm{CI}$ & $\operatorname{VR}\left(\mathrm{km} \mathrm{s}^{-1}\right)$ & $\mathrm{n}$ \\
\hline 1131 & 45510.47 & II & +64 & 6 & 1144 & 45013.69 & II & +74 & 11 \\
\hline 1131 & 45511.47 & II & +90 & 9 & 1144 & 45017.62 & II & +78 & 7 \\
\hline 1131 & 51204.85 & $\mathrm{I}$ & +44 & 5 & 1144 & 45071.50 & II & +65 & 8 \\
\hline \multirow[t]{2}{*}{1131} & 51219.58 & I & +61 & 6 & 1144 & 45126.51 & II & +57 & 8 \\
\hline & & & & & 1144 & 51203.79 & I & +64 & 11 \\
\hline 1132 & 45017.66 & II & +03 & 11 & 1144 & 51221.83 & I & +78 & 12 \\
\hline 1137 & 45017.68 & II & +56 & 10 & 1146 & 45509.48 & II & +49 & 4 \\
\hline 1137 & 51202.81 & I & +64 & 10 & 1146 & 45512.47 & II & +33 & 8 \\
\hline \multirow[t]{2}{*}{1137} & 51204.83 & I & +55 & 10 & 1146 & 50868.66 & I & +48 & 11 \\
\hline & & & & & 1146 & 51203.73 & $\mathrm{I}$ & +26 & 8 \\
\hline 1140 & 45013.71 & II & +73 & 10 & 1146 & 51220.84 & $\mathrm{I}$ & +64 & 8 \\
\hline 1140 & 45017.65 & II & +40 & 6 & & & & & \\
\hline 1140 & 51203.77 & $\mathrm{I}$ & +54 & 10 & 1147 & 45017.72 & II & +41 & 2 \\
\hline \multirow[t]{2}{*}{1140} & 51219.83 & I & +58 & 8 & 1147 & 45071.61 & II & +55 & 2 \\
\hline & & & & & 1147 & 50868.64 & $\mathrm{I}$ & +67 & 6 \\
\hline
\end{tabular}

HJD = Heliocentric Julian Date están en días.

Nr. CI hace referencia a la configuración instrumental mostrada en la Tabla 48

$\mathrm{n}$ indica el número de líneas incluidas en cada valor medio de velocidad

y por esta razón incluimos a la estrella en nuestro programa de estudio de binarias espectroscópicas de tipo espectral O. Los resultados para LS 1135 se presentan separadamente más abajo. Las velocidades radiales para las estrellas en la región de Bo 7 están en la Tabla49.

\subsection{El espectro de LS 1135}

La Figura 98 es uno de los espectros digitales de más alta relación señal ruido de LS 1135 obtenido en el CASLEO con las configuración instrumental I. Este espectro muestra las líneas de absorción de HeII, HeI e H características del tipo espectral temprano O. De hecho, algunos de nuestros espectros muestran emisión débil de NiII $\lambda \lambda 4634-40 \AA$ La banda interestelar difusa (DIB) $\lambda 4428 \AA$ y otras absorciones interestelares también están presentes en el espectro de LS 1135 . 
Para la clasificación espectral de LS 1135 en nuestros espectros de resolución intermedia, realizamos una comparación de los mismos con los espectros del Atlas Digital de estrellas OB publicado por Walborn \& Fitzpatrick (1990) en la región espectral azul del óptico. Esta comparación muestra un tipo espectral O6.5((f)). En nuestros espectros de más alta resolución, también usamos la razón de HeI $\lambda 5875$ a HeII $\lambda 5411$, como es descripto por Walborn (1980) para la clasificación de espectros de tipo $\mathrm{O}$ en la región espectral óptica amarillo-rojo. En la región espectral azul de nuestros espectros de alta resolución, usamos la razón de anchos equivalentes de la clasificación espectral cuantitativa para estrellas tipo O de Conti \& Alschuler (1971) y Conti \& Frost (1977). Todos estos confirman para LS 1135 el tipo espectral O6.5V((f)).

Como binaria de tipo espectral O de corto período, LS 1135 aparece como una candidata potencial para mostrarnos los efectos de colisión de vientos estelares. Por esta razón investigamos los efectos de Struve-Sahade (S-S), lo cual es producido por colisión de vientos estelares de acuerdo al modelo propuesto por Gies et al. (1997). Examinando a nuestros espectros en detalle, comparamos cuidadosamente una cuadratura con otra en orden a detectar diferencias sistemáticas en la relación de intensidad de las líneas de He observadas en las fases próximas y opuestas. En nuestros datos no detectamos ningún cambio espectral más allá de los errores; por lo tanto el efecto S-S no parece estar presente en este sistema binario.

La contribución de la componente secundaria a las líneas espectrales de LS 1135 no es evidente en nuestros espectros, excepto quizas en las líneas de Hidrógeno de Balmer cuyas variaciones de velocidad radial aparecen de algún modo con amplitud más baja que aquella de las líneas de He, cuando está en fase con el período binario (ver más abajo). Por lo tanto debemos suponer que la magnitud absoluta visual de la componente secundaria es al menos dos magnitudes más débil que la estrella O6.5((f)), la cual correspondería a un tipo espectral B temprano.

\subsection{La órbita de velocidad radial de LS 1135}

La Tabla 50 lista las observaciones y velocidades radiales heliocéntricas medias obtenidas promediando en los espectros de LS 1135 las líneas de HeI $\lambda 4471, \lambda 5875$ y HeII $\lambda 4199, \lambda 4541$ y $\lambda 4685$. El número después de las velocidades medias de las líneas de absorción indica cuántas líneas fueron incluidas en cada promedio.

Como es evidente de la Tabla 50, las velocidades radiales de las líneas de absorción en el espectro de LS 1135 muestran grandes variaciones de una noche a otra pero las velocidades radiales obtenidas durante la misma noche no muestran diferencias apreciables, implicando un período del

sistema binario de unos pocos días. A las velocidades radiales de la Tabla 50 se aplicó un algoritmo de búsqueda de períodos (Marraco \& Muzzio, 1980). 


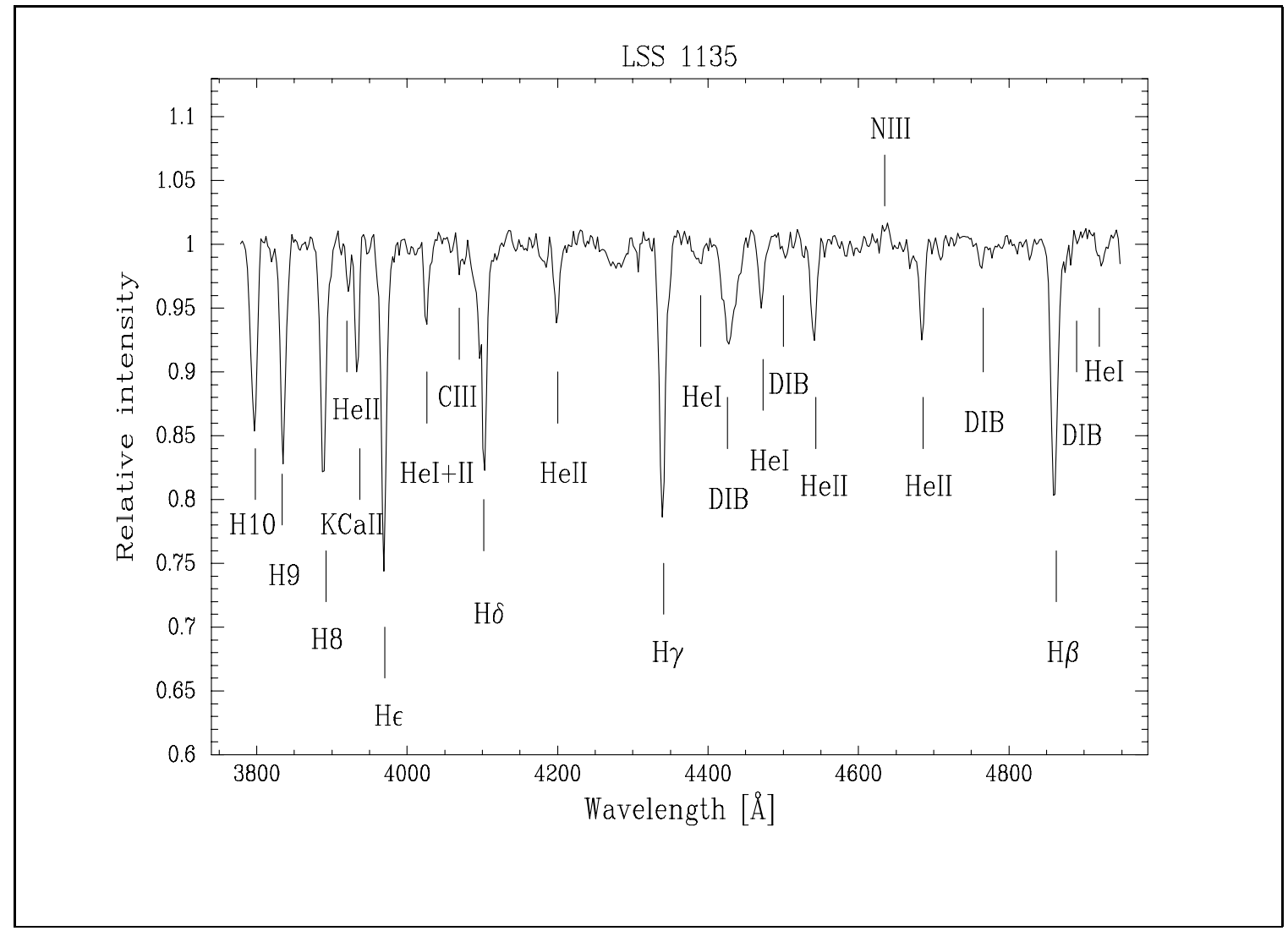

Figura 98: Espectro rectificado continuo de LS 1135 obtenido en el CASLEO en abril de 1997 con la configuración instrumental III. Son identificados los principales perfiles espectrales. 


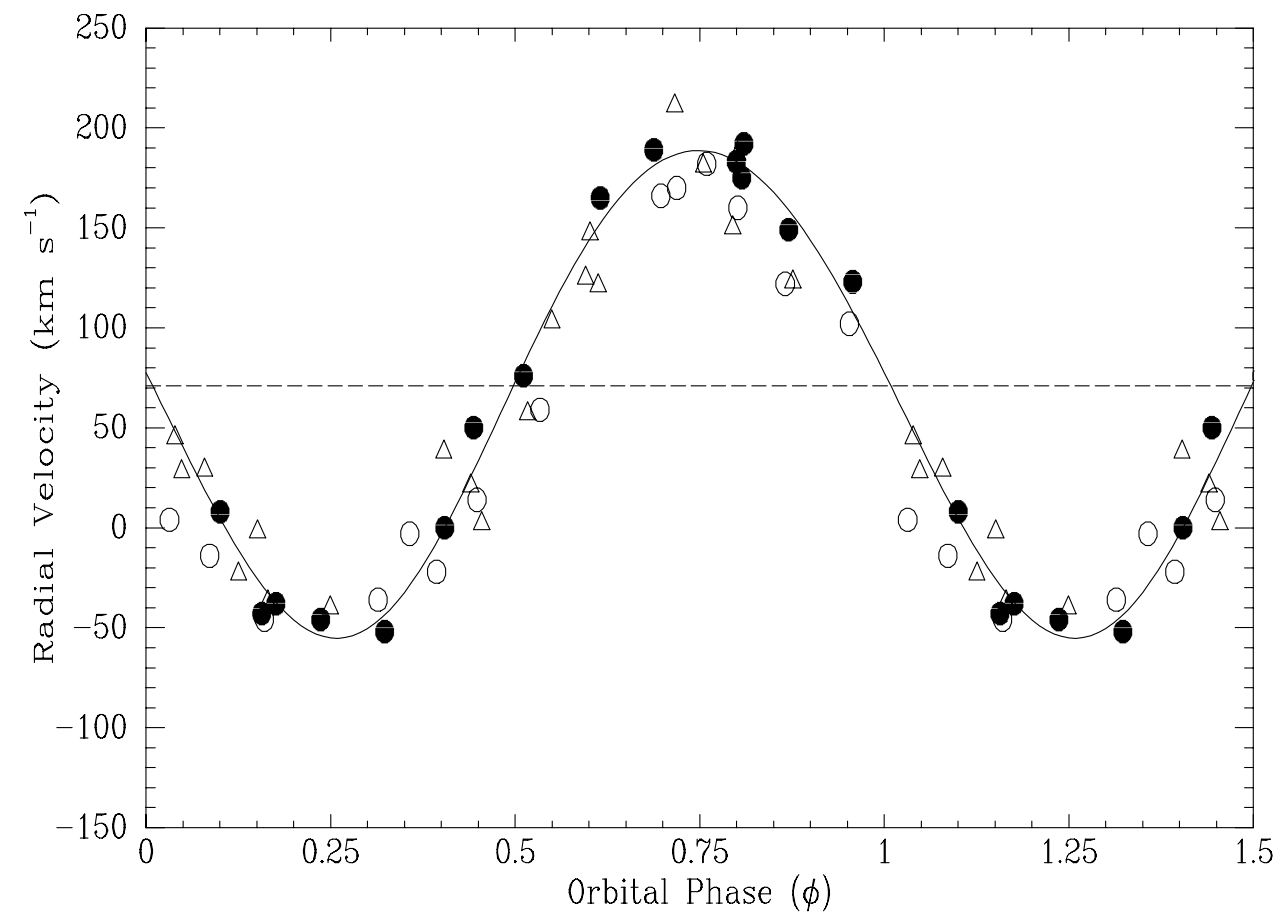

Figura 99: Velocidades radiales de LS 1135 de la Tabla 50 con un período de 2.7532 días. Los círculos llenos representan las velocidades radiales medidas en espectros obtenidos con la configuración instrumental III y los triángulos y círculos vacíos aquellos obtenidos con las configuraciones isntrumentales I y II, respectivamente. La curva continua representa la solución orbital de la Tabla 51

El mejor período encontrado fue $\mathrm{P}=2.75320 \pm 0.00001$ días y no estuvieron presentes períodos alias con probabilidades similares. Este período fue entrado como un valor inicial al cálculo de elementos orbitales de LS 1135. Estos fueron calculados con una versión mejorada del programa inicialmente publicado por Bertiau \& Grobben (1969). En la determinación de los elementos orbitales asignamos mayor peso a los espectros obtenidos con la configuración instrumental III que a los obtenidos con las otras configuraciones instrumentales. Los elementos orbitales están listados en la Tabla51. Los errores citados en esa Tabla son aquellos calculados por el programa mencionado previamente. Las variaciones de velocidad radial y la órbita de LS 1135 están ilustradas en la Figura 99. 
Tabla 50: Observaciones de LS 1135

\begin{tabular}{|c|c|c|c|c|c|c|c|}
\hline \multirow{2}{*}{$\begin{array}{c}\text { HJD } \\
2400000+\end{array}$} & \multicolumn{3}{|c|}{ V.R.Heliocént. } & \multirow{2}{*}{$\begin{array}{c}\text { HJD } \\
2400000+\end{array}$} & \multicolumn{3}{|c|}{ V.R.Heliocént. } \\
\hline & $\mathrm{CI}$ & $\mathrm{He}$ & $\mathrm{n}$ & & $\mathrm{CI}$ & $\mathrm{He}$ & $\mathrm{n}$ \\
\hline 45508.463 & II & 211 & 4 & 50537.590 & $\mathrm{I}$ & -3 & 4 \\
\hline 45509.464 & II & 29 & 3 & 50538.586 & I & 170 & 4 \\
\hline 45510.456 & II & 21 & 4 & 50540.596 & I & 14 & 4 \\
\hline 45511.453 & II & 187 & 4 & 50541.567 & $\mathrm{I}$ & 160 & 4 \\
\hline 45512.452 & II & -37 & 3 & 50542.553 & I & -46 & 4 \\
\hline 45769.686 & II & 125 & 4 & 50841.659 & III & 183 & 4 \\
\hline 45769.703 & II & 147 & 3 & 50842.646 & III & -43 & 5 \\
\hline 45773.689 & II & 28 & 4 & 50843.620 & III & 76 & 5 \\
\hline \multirow[t]{2}{*}{45775.634} & II & 181 & 4 & 50844.608 & III & 149 & 5 \\
\hline & & & & 50845.620 & III & -46 & 4 \\
\hline \multirow[t]{2}{*}{45842.494} & II & 45 & 4 & 50846.661 & III & 165 & 4 \\
\hline & & & & 50847.601 & III & 123 & 3 \\
\hline 46132.582 & II & 38 & 4 & 50848.609 & III & -52 & 3 \\
\hline 46132.724 & II & 2 & 2 & 50849.612 & III & 189 & 4 \\
\hline 46133.661 & II & 150 & 4 & 50851.584 & III & 0 & 5 \\
\hline 46134.569 & II & -23 & 4 & & & & \\
\hline 46134.639 & II & -2 & 4 & 50854.700 & $\mathrm{I}$ & 59 & 4 \\
\hline 46135.647 & II & 57 & 4 & 50855.608 & $\mathrm{I}$ & 122 & 4 \\
\hline 46135.739 & II & 103 & 4 & 50858.601 & $\mathrm{I}$ & 102 & 4 \\
\hline 46136.639 & II & 123 & 4 & 50859.600 & I & -36 & 3 \\
\hline 46137.664 & II & -40 & 4 & 50860.652 & $\mathrm{I}$ & 166 & 5 \\
\hline 46138.663 & II & 121 & 3 & 50861.721 & $\mathrm{I}$ & -14 & 4 \\
\hline \multirow[t]{2}{*}{46139.773} & II & 17 & 3 & & & & \\
\hline & & & & 50963.442 & $\mathrm{I}$ & 4 & 4 \\
\hline 50494.777 & III & 175 & 4 & 50964.436 & $\mathrm{I}$ & -22 & 4 \\
\hline 50495.794 & III & -38 & 4 & 50965.447 & I & 182 & 4 \\
\hline 50506.597 & III & 8 & 4 & & & & \\
\hline 50507.542 & III & 50 & 5 & & & & \\
\hline 50508.549 & III & 192 & 5 & & & & \\
\hline
\end{tabular}

HJD = Heliocentric Julian Date (en días). CI configuración instrumental (Tabla 48) n: número de líneas incluidas en cada valor medio de velocidad 
Tabla 51: Elementos de la órbita circular de LS 1135

\begin{tabular}{|c|c|c|}
\hline \multicolumn{3}{|l|}{ elemento } \\
\hline$a \sin i\left[\mathrm{R}_{\odot}\right]$ & 6.6 & $\pm \quad 0.11$ \\
\hline$K\left[\mathrm{~km} \mathrm{~s}^{-1}\right]$ & 122 & $\pm \quad 2$ \\
\hline$V_{o}\left[\mathrm{~km} \mathrm{~s}^{-1}\right]$ & 71 & \pm 1 \\
\hline $\mathrm{F}(\mathrm{M})\left[\mathrm{M}_{\odot}\right]$ & 0.52 & $\pm \quad 0.03$ \\
\hline$T_{o}[\mathrm{HJD}]$ & 2450508.38 & $\pm \quad 0.01$ \\
\hline$P$ [days $]$ & 2.75320 & $\pm 1 \mathrm{E}^{-5}$ \\
\hline$\sigma\left[\mathrm{km} \mathrm{s}^{-1}\right]$ & 9 & \\
\hline
\end{tabular}

\subsection{Distancia}

En la Tabla 52 listamos los datos para las estrellas en la región de Bo 7. Las sucesivas columnas en esta tabla indican: el número en el catálogo LS (Stephenson \& Sanduleak, 1971); nuestra estimación del tipo espectral; valores V y B-V de Moffat \& Vogt (1975); E(B - V) calculado de los colores intrínsecos correspondientes a los tipos espectrales; los módulos de distancia espectrofotométrica determinados adoptando las magnitudes absolutas correspondientes a los tipos espectrales, de acuerdo a la calibración de Schmidt-Kaler (1982); velocidad radial estelar (en $\mathrm{km} \mathrm{s}^{-1}$ ) referida al LSR.

Los módulos de distancia media para las estrellas en Bo 7 (excluyendo el objeto de campo LS 1132 y la estrella con líneas de emisión LS 1147) es 13.5, el cual corresponde a la distancia de $5.0 \mathrm{kpc}$. Este valor está en buen acuerdo con la distancia encontrada por Sung et al. (1999) de la fotometría CCD. Nosotros también notamos que la distancia fotométrica de LS $1145=$ WR 12 citada por van der Hucht (2001) es $5 \mathrm{kpc}$, confirmando que esta estrella pertenece al grupo estelar de Bo 7. Las velocidades radiales medias (LSR) de los miembros del cúmulo están entre 55 y 40 $\mathrm{km} \mathrm{s}^{-1}$ (excluyendo a LS 1146, nota en la Tabla 32) implicando una distancia cinemática entre 5.0 y $6.0 \mathrm{kpc}$ en el modelo de rotación galáctica circular. Así Bo 7 parece estar ubicado en el extremo del brazo espiral de Perseo en nuestra galaxia (Figura 5 en Russeil, 2003).

\section{Conclusiones}

Un estudio de velocidad radial de líneas espectrales de LS 1135, un miembro de la asociación galáctica $\mathrm{OB}$ Bo 7, muestra que esta es una binaria de tipo espectral $\mathrm{O}$ a un espectro, la cual Estudio de una Asociación $O B$ distante en la Vía Láctea $215 \quad$ Mariela A. Corti 
Tabla 52: Datos de las estrellas en la Region de Bo 7

\begin{tabular}{|llccccc|}
\hline LS & Tipo Esp. & $\mathrm{V}^{a}$ & ${\mathrm{~B}-\mathrm{V}^{a}}^{\mathrm{E}}(\mathrm{B}-\mathrm{V})$ & $\mathrm{V}_{0}-\mathrm{M}_{v}$ & $\begin{array}{c}\mathrm{VR} \\
(\mathrm{LSR})\end{array}$ \\
\hline 1131 & O7.5V & 10.80 & 0.51 & 0.83 & 13.33 & +50 \\
$1132^{b}$ & B3V & 10.05 & 0.37 & 0.54 & 9.88 & -13 \\
1135 & O6.5V((f)) & 10.88 & 0.40 & 0.73 & 13.95 & +55 \\
1137 & O9V & 11.38 & 0.49 & 0.80 & 13.40 & +42 \\
1140 & B0III & 11.65 & 0.76 & 1.05 & 13.49 & +40 \\
1144 & O7.5V & 11.27 & 0.64 & 0.96 & 13.39 & +53 \\
$1145^{c}$ & WN8 & 10.78 & 0.56 & & & var. \\
$1146^{d}$ & B1III & 11.57 & 0.50 & 0.82 & 13.43 & +26 \\
$1147^{e}$ & B1Ve & 11.53 & 0.58 & 0.78 & 13.11 & +54 \\
\hline
\end{tabular}

$a$ de Moffat \& Vogt (1975)

$b$ estrella de campo, ver también Lundstrom \& Stenholm (1984)

$c$ WR 12 cf (van der Hucht, 2001). Binaria espectroscópica (Niemela, 1982).

$d$ Anchos de las líneas variables. Sistema binario a líneas dobles no resuelto?

e Líneas $\mathrm{H}$ Balmer, $\mathrm{H} \beta$ y $\mathrm{H} \gamma$ muestran emisión central, see Fig.97

clasificamos como $\mathrm{O} 6.5 \mathrm{~V}((\mathrm{f}))$. Para esta binaria encontramos un período orbital de 2.75320 días. El valor de la semi-amplitud (K) de las variaciones de velocidad radial de las líneas de He es 122 $\mathrm{km} \mathrm{s}^{-1}$ y la función de masa $(\mathrm{F}(\mathrm{M}))$ del sistema binario es $0.52 \mathrm{M}_{\odot}$. La componente secundaria no es detectada en nuetros espectros, lo cual indica que esta sería al menos 2 magnitudes más débil, correspondiendo a una estrella de tipo espectral B temprano.

Nosotros también observamos otras siete estrellas OB en la región de Bo 7, para lo cual presentamos los tipos espectrales y velocidades radiales. De estos datos obtuvimos para Bo 7 una distancia espectroscópica y cinemática de aproximadamente $5.0 \mathrm{kpc}$ y concluimos que la estrella Wolf-Rayet LS $1145=$ WR 12 también es miembro de esta asociación. 